\author{
UNIVERSIDADE DE BRASÍLIA \\ FACULDADE DE TECNOLOGIA \\ DEPARTAMENTO DE ENGENHARIA CIVIL
}

\title{
AVALIAÇÃO DE AMEAÇA POR ESCORREGAMENTOS DE ENCOSTAS NA REGIÃO LESTE DE CUBA
}

\author{
ANNETTE LLERA COTARELO \\ ORIENTADOR: HERNÁN EDUARDO MARTÍNEZ \\ CARVAJAL, PhD.
}

DISSERTAÇÃO DE MESTRADO EM GEOTECNIA BRASÍLIA / DF: SETEMBRO DE 2015 


\section{UNIVERSIDADE DE BRASÍLIA \\ FACULDADE DE TECNOLOGIA \\ DEPARTAMENTO DE ENGENHARIA CIVIL}

\section{AVALIAÇÃO DE AMEAÇA POR ESCORREGAMENTOS DE ENCOSTTAS NA REGIÃO LESTE DE CUBA}

\section{ANNETTE LLERA COTARELO}

DISSERTAÇÃO DE MESTRADO SUBMETIDA AO DEPARTAMENTO DE ENGENHARIA CIVIL DA UNIVERSIDADE DE BRASÍLIA COMO PARTE DOS REQUISITOS NECESSÁRIOS PARA A OBTENÇÃO DO GRAU DE MESTRE.

APROVADA POR:

HERNÁN EDUARDO MARTÍNEZ CARVAJAL, PhD., UNB (ORIENTADOR)

JUAN FELIX RODRIGUEZ REBOLLEDO, PhD., UNB (EXAMINADOR INTERNO)

PAULO RUIZ CUBILLO, PhD., LANAMME /UCR (EXAMINADOR EXTERNO)

DATA: BRASÍLIA/DF, 17 de Setembro de 2015. 


\section{FICHA CATALOGRÁFICA}

COTARELO, ANNETTE LLERA

Avaliação de Ameaça por Escorregamentos de Encostas na Região Leste de Cuba [Distrito Federal] 2015

xiii, 169 p., 297 mm (ENC/FT/UnB, Mestre, Geotecnia, 2015)

Dissertação de Mestrado - Universidade de Brasília. Faculdade de Tecnologia. Departamento de Engenharia Civil.

1. Fluxo de Detritos

2.Análise de ameaça

3. Sistemas de Alerta

4.Estabilidade de encostas

I. ENC/FT/UnB

II. Título (série)

\section{REFERÊNCIA BIBLIOGRÁFICA}

COTARELO, A.L. (2015). Avaliação de Ameaça por Escorregamentos de Encostas na Região Leste de Cuba. Dissertação de Mestrado, Publicação G.TD - 107/15, Departamento de Engenharia Civil, Universidade de Brasília, Brasília, DF, 169 p.

\section{CESSÃO DE DIREITOS}

NOME DO AUTOR: Annette Llera Cotarelo

TíTULO DA DISSERTAÇÃO DE MESTRADO: Avaliação de Ameaça por Escorregamentos de Encostas na Região Leste de Cuba.

GRAU / ANO: Mestre / 2015.

É concedida à Universidade de Brasília a permissão para reproduzir cópias desta tese de doutorado e para emprestar ou vender tais cópias somente para propósitos acadêmicos e científicos. $\mathrm{O}$ autor reserva outros direitos de publicação e nenhuma parte desta tese de doutorado pode ser reproduzida sem a autorização por escrito do autor.

\footnotetext{
Annette Llera Cotarelo

Línea 359 apto. 8 / G y H

CP-10400 Vedado. Habana. Cuba
} 


\section{RESUMO}

No presente estudo, foi aplicado em uma região tropical e montanhosa de Cuba, uma metodologia baseada em um modelo de previsão da iniciação de fluxo de detritos (Papa et al., 2011), com base na solução analítica da equação de Richards válida na hipótese de uma infiltração vertical (Iverson, 2000). Este modelo é baseado em um sistema capaz de alertar a ocorrência de fluxos de detritos através das simulações de estabilidade feitas previamente, para qualquer combinação possível de ocorrência de precipitações em termos de intensidade e duração das chuvas que podem gerar ou não fluxos de detritos na região analisada. Estas simulações levam em consideração uma precipitação antecedente cujos efeitos são calculados pela hipótese de condições de estado estacionário (Montgomery e Dietrich, 1994).

Com esta metodologia podem ser identificados um conjunto de limiares críticos de precipitações, cada um deles correspondente ao nível fixo de ameaça de fluxo de detritos, que podem ser analisados em termos de porcentagem de células das encostas com probabilidade de falha ou em volumes aproximados de solo espalhado pela ocorrência de fluxo de detritos. Esta metodologia de simulação é extremamente simplificada, exigindo um curto período de tempo utilizado no processamento computacional e um conjunto limitado de insumos básicos. 


\begin{abstract}
In the current study, a methodology is applied for the calculations of hazard based on the prediction of the start of debris flows (Papa et al. 2011) on a mountainous and tropical region in the West of Cuba.

The methodology is based on the analytic solution of the Richards' equation, valid for a case of vertical infiltration (Iverson, 2000). This is a tool able to alert about the initiation of debris flows through simulations previously performed in slope stability. These simulations are conducted for any possible combination of occurrence of rainfalls- in terms of intensity and duration of the precipitations- that can or cannot generate debris flows in the region of study.

With this methodology, it is possible to identify with anticipation a series of critical thresholds of rainfall, each corresponding to a fixed level of hazard of occurrence of debris flow. These thresholds can be analyzed in terms of percentage of cells with probabilities of braking or in approximate volume of soil displaced by the occurrence of debris flow. The methodology of simulation is greatly simplified, requiring a short period of time utilized in the computational process and a limited set of basic inputs.
\end{abstract}




\section{ÍNDICE}

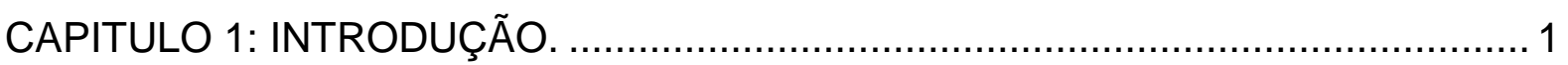

1.1. DEFINIÇÃO DO PROBLEMA. .......................................................... 1

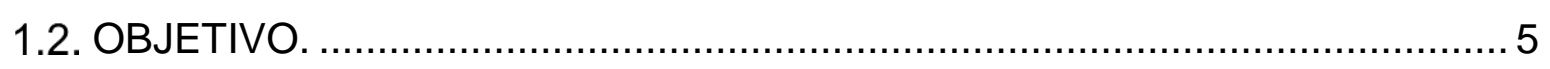

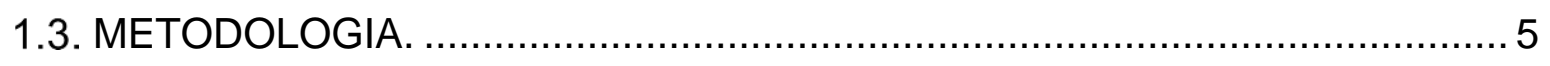

1.3.1. ESCOLHA DA ÁREA DE TRABALHO .......................................... 5

1.3.2. APLICAÇÃO DA METODOLOGIA PARA O CÁLCULO DA AMEAÇA. ..... 6

1.3.2.1. METODOLOGIA DE CÁLCULO .................................................. 6

1.3.2.2. CALIBRAÇÃO DO MODELO ...................................................... 7

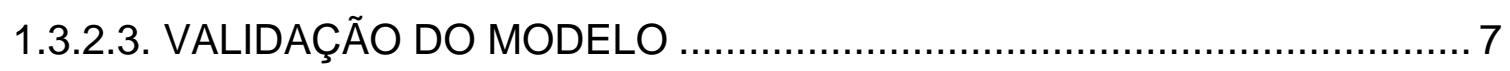

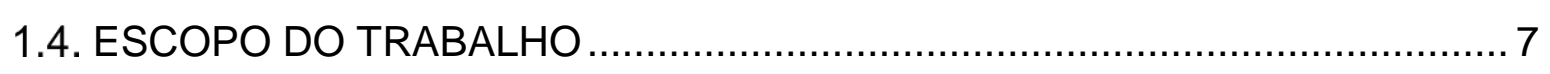

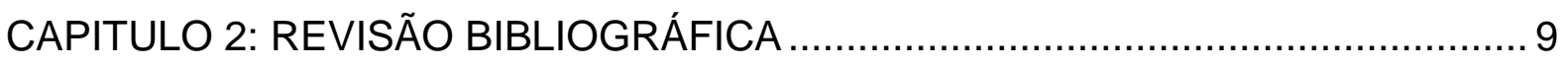

2.1. CONCEITOS E CRITÉRIOS FUNDAMENTAIS SOBRE RISCO..................9

2.2. MOVIMENTOS DE MASSA. CLASSIFICAÇÃO. .................................... 12

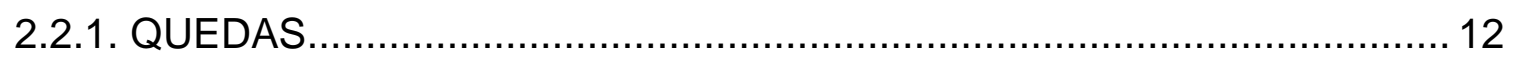

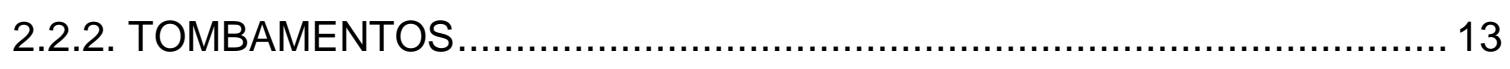

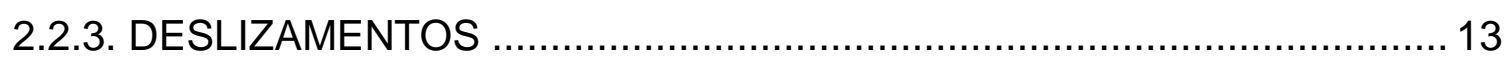

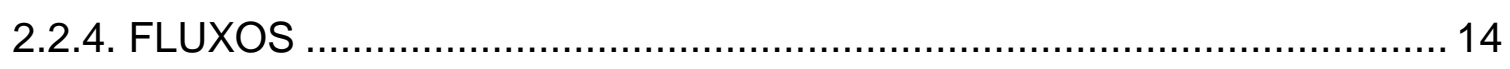

2.2.4.1. FLUXO EM ROCHA ............................................................. 14

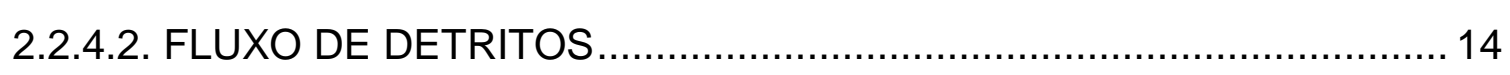

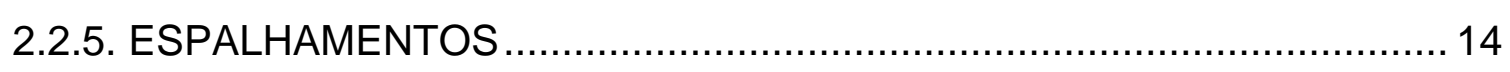

2.3. MÉTODOS DE ESTIMATIVA DE SUSCETIBILIDADE DO TERRENO NA FORMAÇÃO DE DESLIZAMENTOS. ................................................. 15

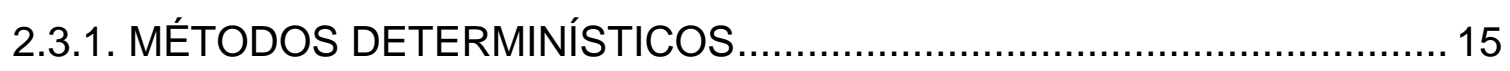

2.3.2. MÉTODOS HEURÍSTICOS .......................................................... 15

2.3.3. MÉTODOS PROBABILÍSTICOS ....................................................... 16

2.3.4. MÉTODOS GEOMORFOLÓGICOS .................................................. 16

2.3.5. MODELO DE BASE FÍSICA (TALUDE INFINITO) ............................ 17

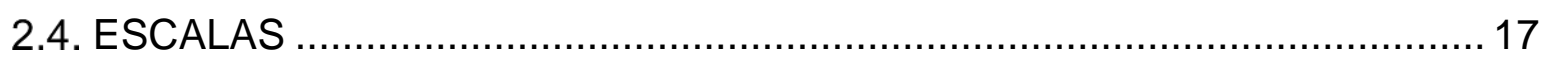

2.5. O MAPEAMENTO DE SUSCETIBILIDADE E AMEAÇA ........................... 18

CAPITULO 3: CARATERÍSTICAS GERAIS DA ÁREA DE ESTUDO .....................23

3.1. LOCALIZAÇÃO GEOGRÁFICA E CARATERÍSTICAS FÍSICAS DA ÁREA DE

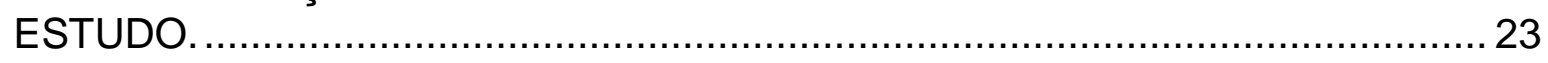

3.2. FORMAÇÃO DO RELEVO AO SUDESTE DE CUBA............................. 24 
3.3. CARATERÍSTICAS GEOLÓGICAS DA REGIÃO......................................... 26

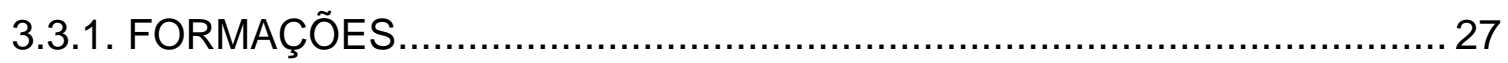

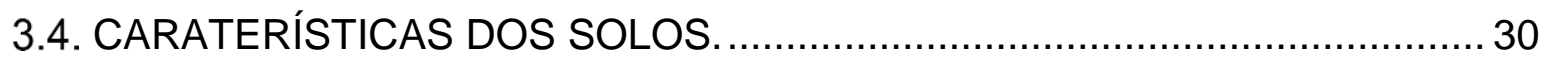

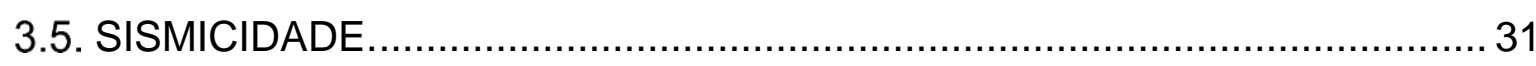

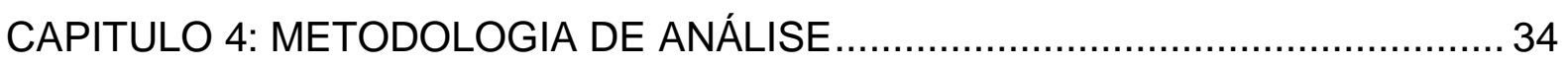

4.1. INTRODUÇÃO

4.2. MODELO DE PREVISÃO DE INICIAÇÃO DE FLUXO DE DETRITOS .......... 35

4.3. DADOS REQUERIDOS PARA IMPLEMENTAR O MODELO ..................... 41

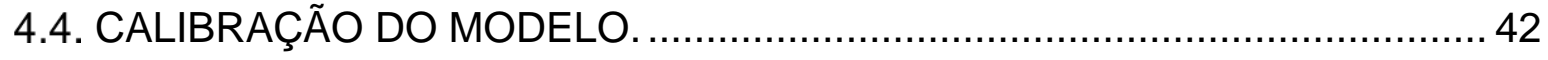

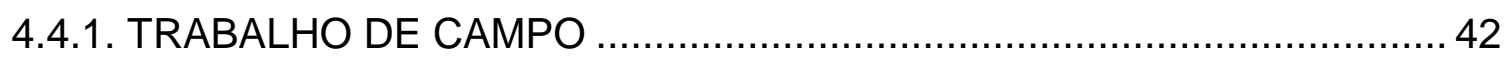

4.4.2. PROCESSAMENTO DAS IMAGENS DE VOOS AÉREOS .................... 50

4.4.3. PROCESSAMENTO DAS VARIÁVEIS ESTÁTICAS ............................. 53

4.4.3.1. DEFINIÇÃO DOS PARÂMETROS DOS SOLOS DA REGIÃO..............57

4.4.4. DETERMINAÇÃO DO PARÂMETRO DE CALIBRAÇÃO $\left(\mathrm{D}_{0}\right) \ldots \ldots \ldots \ldots \ldots . . . . . . .61$

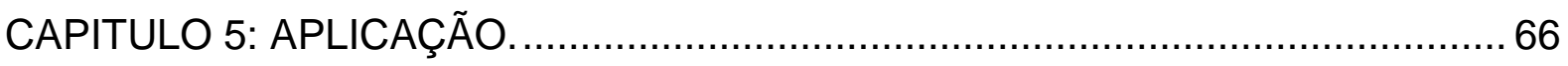

5.1. IDENTIFICAÇÃO DE CÉLULAS PROVAVELMENTE INSTÁVEIS................66

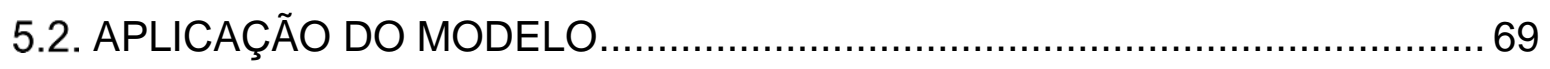

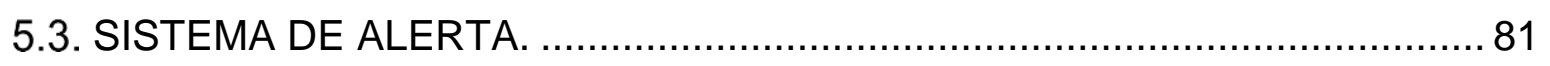

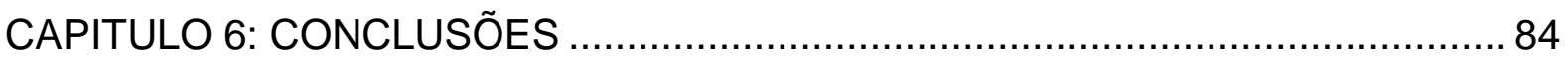

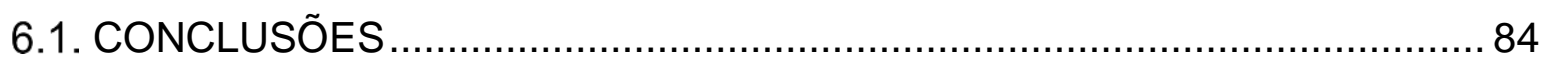

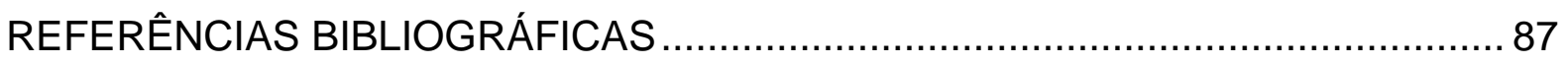

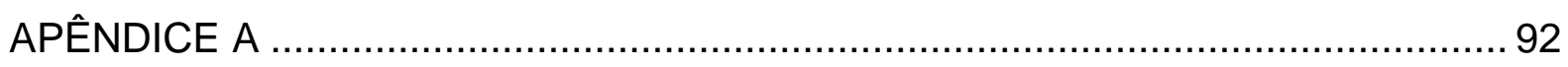

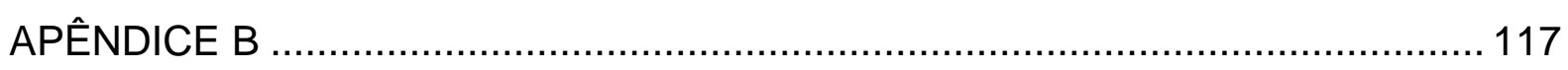

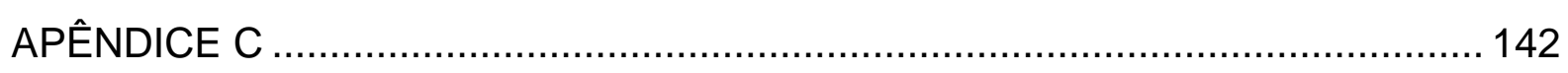




\section{ÍNDICE DE TABELAS}

Tabela

Página

Tabela 3.1 - Registro histórico dos sismos mais fortes registrados pelo Centro

Nacional de Investigações Sismológicas de Cuba, CENAIS. ........................... 32

Tabela 4.1 - Variáveis dinâmicas e estáticas (modificado - Papa et al., 2011) ........ 39

Tabela 4.2 - Estações do percurso de campo ..................................................... 46

Tabela 4.3- Parâmetros do solo, adotados para os distritos homogêneos................ 61

Tabela 4.4 - Intensidades de precipitações extremas durante a passagem de furacões, Atlas Nacional de Cuba, modificado Kochiachivili (1989). 63

Tabela 4.5 - Valores da média e do desvio padrão do FS para os diferentes valores de $D_{0}$ na calibração do modelo. 65 


\section{ÍNDICE DE FIGURAS}

Figura

Página

Figura 1.1- Mapa de relevo de Cuba, (modificado - Castellanos, 2008) e os eventos de deslizamentos de terra mais importantes nos últimos 50 anos, (modificado Castellanos \& Van Westen, 2005).

Figura 1.2 - Mapa de rico por deslizamento, (modificado - Castellanos \& Van

Westen, 2007)

Figura 2.1 - Tipos de movimentos de massa. a) Quedas b) Tombamentos c)

deslizamento d) Fluxo e) Espalhamento. (Suarez,1998)

Figura 3.1 - Localizações, Santiago de Cuba. Modificado,

http://www.bedinCuba.com

Figura 3.2 - Formações do Caribe e Cuba. http://www.redciencia.cu 25

Figura 3.3 - Localizações das áreas de estudo. 26

Figura 3.4 - Mapa Geológico da área de estudo (Escala: 1:100 000 IGP, 2008). 27

Figura 3.5 - Presença de rocha vulcânica basálticas na região da "Gran Piedra"

pertencente à formação "El Cobre". Trabalho de campo, dezembro 2014. 28

Figura 3.6 - Imagem onde são observadas as elevações formadas pelo Grupo "EI

Cobre", na região da "Gran Piedra", na direção sul.

Figura 3.7 - Presença de rocha calcária na linha costeira, na região da "Gran

Piedra", pertencente à formação "Jaimanita". Trabalho de campo, dezembro 2014.

Figura 3.8 - Mapa de Epicentros de Terremotos com Magnitude $M>3.0$ Richter no período 1968 - 1999. (Chuy et al., 2001) Atlas de Ameaças Naturais do Guamá.

Figura 3.9 - Desprendimentos de rochas produzidos pelo sismo de "Pilón" no dia 19 de fevereiro de 1976. Chuy et al.(2001) Atlas de Ameaças Naturais do Guamá.

Figura 4.1 - Esquema do modelo de estabilidade de taludes (Papa et al., 2011) 36

Figura 4.2 - Área da "Gran Piedra”. Google Maps, 2014.

Figura 4.3 - Estações do percurso de campo na região da "Gran Piedra". Sistema de coordenadas plana-retangulares Cuba-Sul. Projeção cónica de Lambert. $\quad 43$

Figura 4.4 - Estações do percurso de campo na região da "Sierra Maestra". 44

Figura 4.5 - Granitos meteorizado, na, estação 93 do percurso de campo Fig. 4.345 
Figura 4.6 - Deslizamento de terra na estação 129 do percurso de campo Fig. 4.345

Figura 4.7 - Deslizamento planar em lutita na estação 105 do percurso de campo

Fig. 4.4

Figura 4.8 - Esquemas de trabalho para a obtenção de escorregamento em imagens aéreas.

Figura 4.9 - Localização das imagens aéreas.

Figura 4.10 - Inventário de deslizamentos de terra, obtidos das imagens aéreas 52

Figura 4.11 - Inventário de deslizamento na região da "Gran Piedra". 53

Figura 4.12 - Mapa de declividade da região da "Gran Piedra".

Figura 4.13 - Mapa de acumulação de fluxo (A) dividido (b) na região da "Gran Piedra".

Figura 4.14 - Mapa geológico da região "Gran Piedra".

Figura 4.15 - Permeabilidades saturadas típicas em solos residuais, modificado de Schnaid et al. (2004); Coutinho e Silva (2006) citado por Viana da Fonseca (2009) com a inclusão de solos residuais do Brasil e solos residuais de granito do Porto.

Figura 4.16 - Distritos homogéneos da área de estudo com o inventário de deslizamentos.

Figura 4.17 - Relação entre a difusividade hidráulica do solo e o conteúdo da água.

(Modificado, van Genuchten,1980)

Figura 4.18 - Gráfica do evento do furacão "Flora".

Figura 4.19 - Distribuições de chuva máximas anuais em 24h para uma probabilidade de ocorrência de $2 \%$.

Figura 5.1 - Susceptibilidades aos escorregamentos em função da espessura do solo e da declividade (modificado de Aristizabal et al. 2013)

Figura 5.2 - Metodologia para obter células provavelmente instáveis, aplicada ao modelo de Papa et al. (2011) (modificado de Aristizabal et al. 2013)

Figura 5.3 - Inventário de escorregamentos produzidos pelo furação "Flora", tomado do Atlas de ameaças da província de Guamá, Reyes et al. (2001).

Figura 5.4 - Comportamento das ladeiras durante a simulação do furação "Flora" em "Sierra Maestra" para uma I $=72 \mathrm{~mm} / \mathrm{h}$ em $1 \mathrm{~h}$.

Figura 5.5 - Comportamento das ladeiras durante a simulação do furação "Flora" em "Sierra Maestra" para uma I=66 mm/h em $1.5 \mathrm{~h}$. 
Figura 5.6 - Comportamento das ladeiras durante a simulação do furação "Flora" em "Sierra Maestra" para uma I=55mm $/ \mathrm{h}$ em 2.5h. 75

Figura 5.7 - Comportamento das ladeiras durante a simulação do furação "Flora" em "Sierra Maestra" para uma I=48mm/h em $5 \mathrm{~h} . \quad 76$

Figura 5.8 - Comportamento das ladeiras durante a simulação do furação "Flora" em "Sierra Maestra" para uma I=37mm $/ \mathrm{h}$ em 12h. 77

Figura 5.9 - Comportamento das ladeiras durante a simulação do furação "Flora" em "Sierra Maestra" para uma I=28.5mm/h em 24h. 78

Figura 5.10 - Curva de Intensidade, Duração do furação "Flora".

Figura 5.11 - Mapa de curvas de nível da região "Sierra Maestra". 80

Figura 5.12 - Gráfica de curvas IDF para a região da Gran Piedra, com períodos de retorno $T$ de 2, 5, 10, 25, 50, 100 e 500 anos. 82

Figura 5.13 - Gráficas do comportamento da PR na região da "Gran Piedra para as diferentes probabilidades de chuva. 


\section{LISTA DE ABREVIATURAS E SÍMBOLOS}

ANMM $\quad$ Acima do Nível Médio do Mar

CENAIS Centro Nacional de Investigações Sismológicas

DEM Digital Elevation Model

DPA Divisão Político Administrativa

EMNDC Estado Mayor Nacional de la Defensa Civil

FORTRAN Formula Translating System

FOSM First Order Second Moment

FS $\quad$ Fator de Segurança

IAEG International Association for Engineering Geology and the Environment

ICGC Instituto Cubano de Geodesia e Cartografia

IDF Intensidade Duração e Frequência

ISSMGE International Society of Soil Mechanics and Geotechnical Engineering

MDE Modelo Digital de Elevação

METI Ministry of Economy Trade and Industry

NASA National Aeronautics and Space Administration"

PR porcentagem de células com probabilidade de ruptura

SIG Sistema de Informação Geográfica

SRTM Shuttle Radar Topography Mission

SHIA Simulación Hidrológica Abierta

ABNT Associação Brasileira de Normas Técnicas,
A
Área da bacia drenada
b Largura do elemento da encosta
Co Mudança no conteúdo volumétrico da água
d Profundidade até o lençol freático
Do Difusividade máxima característica 
Elementos em risco

$\mathrm{H}$

Ameaça natural

$I_{z}$

Taxa de infiltração na superfície do solo

$\left(I_{z}\right.$ estacionário

Taxa de infiltração na superfície do solo em condições estacionária

$\mathrm{K}_{\mathrm{x}}$

Condutividade hidráulica na direção paralela ao talude

$\mathrm{K}_{\mathrm{z}}$

Condutividade hidráulica em relação à direção normal da encosta

Rs

Risco específico

$\mathrm{R}_{\mathrm{t}}$

Risco total

$\mathrm{R}\left(\mathrm{T}^{*}\right) \quad$ Termo utilizado no cálculo da carga hidráulica total

$\mathrm{T}$

Duração do evento de chuva

$\mathrm{T}^{*}$

Termo utilizado no cálculo da carga hidráulica total

V

Vulnerabilidade

$\mathrm{X}$

Coordenadas paralelas a inclinação do talude

z

Coordenadas normal a inclinação do talude

Z

Profundidade do solo

$Z_{\min }$

Espessura mínima do solo

$Z_{\max }$

Espessura máxima do solo

$\mathrm{Z}_{\mathrm{T}}$

Profundidade da camada impermeável

$\alpha$

Declividade do talude

$\alpha_{0}$

Declividade máxima

$\varphi$

Angulo de atrito interno

C

Coesão do solo

$\gamma_{\mathrm{s}}$

Peso específico do solo

$\gamma w$

Peso específico da água

$\Psi(Z, 0) \quad$ Carga hidráulica no início do evento pluviométrico intenso

$\Psi(\mathrm{Z}, \mathrm{t}) \quad$ Carga hidráulica total 


\section{Capitulo 1: Introdução.}

\subsection{Definição do Problema.}

Os movimentos de massa são fenômenos naturais complexos que, apesar de serem parte da evolução da superfície terrestre, constituem uma ameaça com sérias consequências econômicas e sociais para muitos países (Brabb \& Harrod, 1989).

Em Cuba, os eventos de escorregamento são relacionados com frequência com a ocorrência de furacões, eles causam danos consideráveis nas áreas montanhosas, (Fig.1.1), que conformam ao redor de $25 \%$ do país. (Castellanos \& van Westen, 2007).

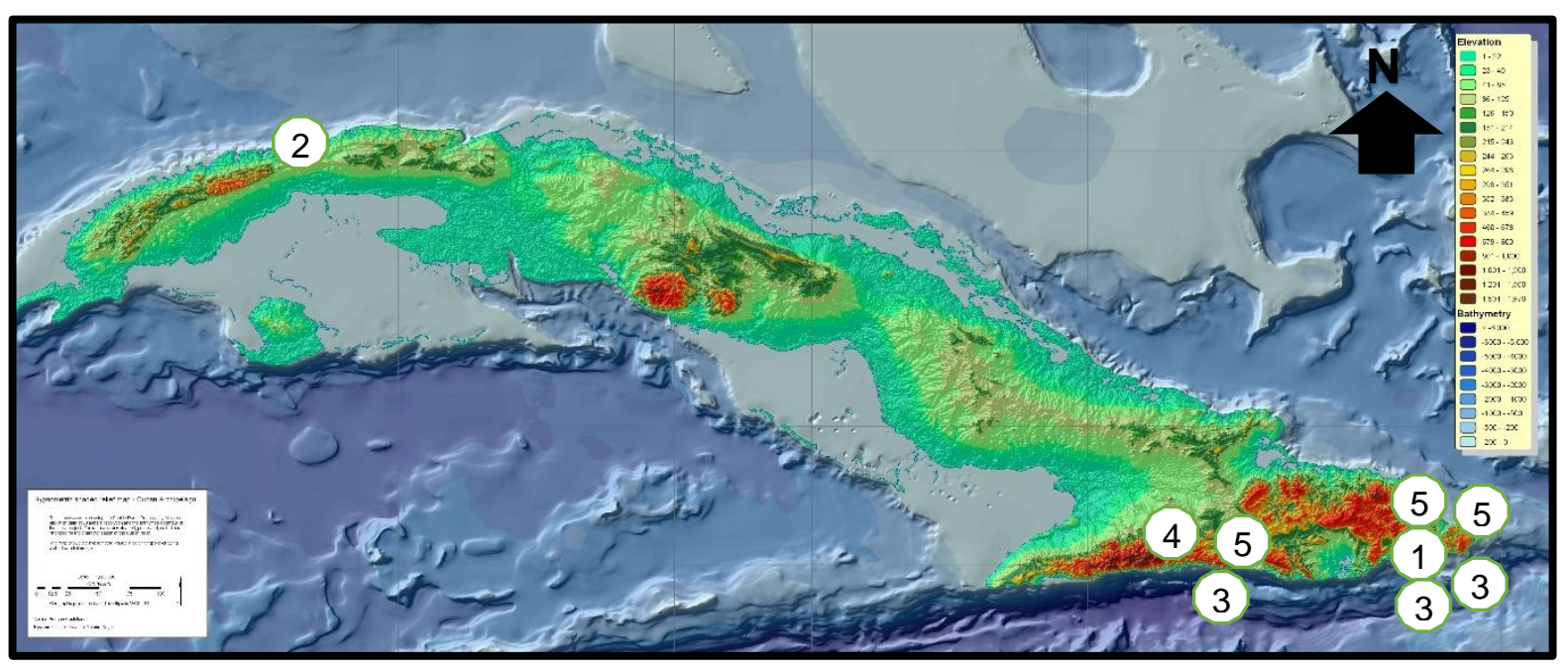

Figura 1.1- Mapa de relevo de Cuba, (modificado - Castellanos, 2008) e os eventos de deslizamentos de terra mais importantes nos últimos 50 anos, (modificado Castellanos \& Van Westen, 2005).

A Fig. 1.1 mostra os principais deslizamentos de terra ocorridos nos últimos 50 anos, (Castellanos \& Van Westen, 2005). O número $1 \mathrm{em}$ Fig. 1.1 representa o maior deslizamento de terra que se conhece, ocorrido depois de 3 dias de intensas chuva $(1.100 \mathrm{~mm})$ durante a passagem do furacão Flora no ano 1963. O número 2 em Fig. 1.1 é um deslizamento de terra ativo desde o ano 1918, com movimentos conhecidos de $19 \mathrm{~cm}$ em 99 horas no ano 1979 e $32.5 \mathrm{~cm}$ em 51 horas no ano 1985, os dois movimentos aconteceram depois da ocorrência de intensas chuvas. O número 3 em Fig. 1.1 representa grandes desprendimentos de terras localizados na linha costeira. O número 4 em Fig. 1.1 representa um deslizamento de $350 \mathrm{~m}$ de comprimento por 100 de largura ocorrido no ano 1977, produzido após de uma intensa seca seguida 
de intensas chuvas. Se conhece que o deslizamento é reativo, já que tem atividade reportada nos anos 1951 e 1960 e o número 5 em Fig. 1.1 representa instabilidades de encostas em cortes de talude realizados durante as construções de estradas ou por atividades mineiras.

Existe uma variada gama de conceitos para o termo "risco" proposta na literatura. Entre estas definições, destaca-se Varnes (1984), que estabelece a definição de risco conforme a Eq. 1.1:

$R_{t}=(E) \cdot\left(R_{S}\right)=(E) \cdot(H \cdot V)$

Onde: $\mathbf{R}_{\mathbf{t}}$ representa o risco total, referente à expetativa de perda de vidas humanas, de pessoas afetadas, de danos a propriedades ou interrupção de atividades econômicas em virtude de um fenômeno natural particular; E corresponde aos elementos em risco, concernentes à população, propriedades, atividades econômicas sob risco em determinada área; Rs refere-se ao risco específico, exprimindo o grau de expetativa de perdas em razão de um fenômeno natural em particular e sendo expresso pelo produto entre a ameaça natural e a vulnerabilidade; $\mathbf{H}$ é a ameaça natural, relacionado à probabilidade de ocorrência de um fenômeno potencialmente danoso, em um período de tempo específico e em determinada área; $\mathbf{V}$ relaciona-se à vulnerabilidade, referente ao grau de perda de um dado elemento ou um conjunto de elementos em risco, resultante da ocorrência de um fenômeno natural que apresenta uma dada magnitude.

De acordo com o "Estado Mayor Nacional de la Defensa Civil" (EMNDC, 2002), citado por Castellanos \& Van Westen (2005) 45 mil habitantes em Cuba encontramse ameaçados por deslizamentos de terra. Para reduzir as perdas por deslizamentos e devido ao pouco conhecimento sobre este tipo de eventos em Cuba, a defesa civil nacional começou no ano 2004 uma avaliação nacional de risco por escorregamentos de terra, (Castellanos \& Van Westen, 2007). O resultado é um mapa de risco apresentado na Fig. 1.2, onde são obtidas as percentagens das áreas por município com índice de risco por deslizamento de terra maior do que zero e os valores médios do índice de risco do deslizamento de terra por município, delimitando as seguintes regiões com os maiores valores de risco: 
1. O sistema montanhoso "Sierra Maestra" (zona 1 em Fig. 1.2) é a área maior em Cuba com altos valores de risco de escorregamentos de terra. Apresenta taludes bem acentuados e a presença de rochas sedimentares e vulcânicas altamente suscetíveis a estes eventos. Os valores dos indicadores de vulnerabilidade são baixos, quando comparados com outras áreas, e aumentam nas proximidades da cidade de Santiago de Cuba, devido ao aumento da densidade de população e às atividades económicas. A região também contém muitos deslizamentos de terras pré-históricos, que são principalmente deslizamentos rotacionais com grandes volumes (Iturralde \&Vinent, 1991).

2. A região "Nipe-Cristal-Baracoa" (zona 2 em Fig. 1.2) é um grande complexo geológico e tectónico, formado por rochas ofiolito e metamórficas com processos de intemperismo. Esta região tem os maiores valores de risco na "Sierra de Nipe" e "Sierra Cristal", causados por altos valores de ameaça e de vulnerabilidade. As fortes inclinações em serpentinito ou peridotito e as quantidades elevadas de precipitações, são as responsáveis pelos altos valores de índice de ameaça. Enquanto os altos valores econômicos, devido à indústria mineira de níquel e à presença de áreas ambientais protegidas, fazem desta região mais vulnerável. Os deslizamentos de terra nesta região devem-se à atividade mineira e às práticas erradas de uso da terra e associam-se com a presença ativa de ravinas e voçorocas.

3. O sistema montanhoso "Guaniguanico" (zona 3 em Fig. 1.2), no Oeste de Cuba, também tem uma área considerável com altos valores de risco de deslizamentos, mas mostram um padrão espacial mais disperso em comparação com as duas regiões apresentadas anteriormente.

4. A pesar da "Ciudad de la Habana" (zona 4 em Fig. 1.2) não encontrar-se em uma região montanhosa, contém uma série de áreas com valores de alto risco de deslizamentos de terra. Isto é principalmente devido à combinação de valores moderados de ameaça, com valores muito altos de vulnerabilidade, causados pela alta densidade de população e a concentração das atividades económicas.

5. A região do "Macizo Guamhuaya" (área 5 em Fig. 1.2) tem também algumas áreas com valores de índice de alto risco, pois encontram-se perto de uma grande barragem, "Hanabanilla". Os altos valores aqui apresentados são devidos à presença de rochas metamórficas intemperizadas e às fortes declividades. 


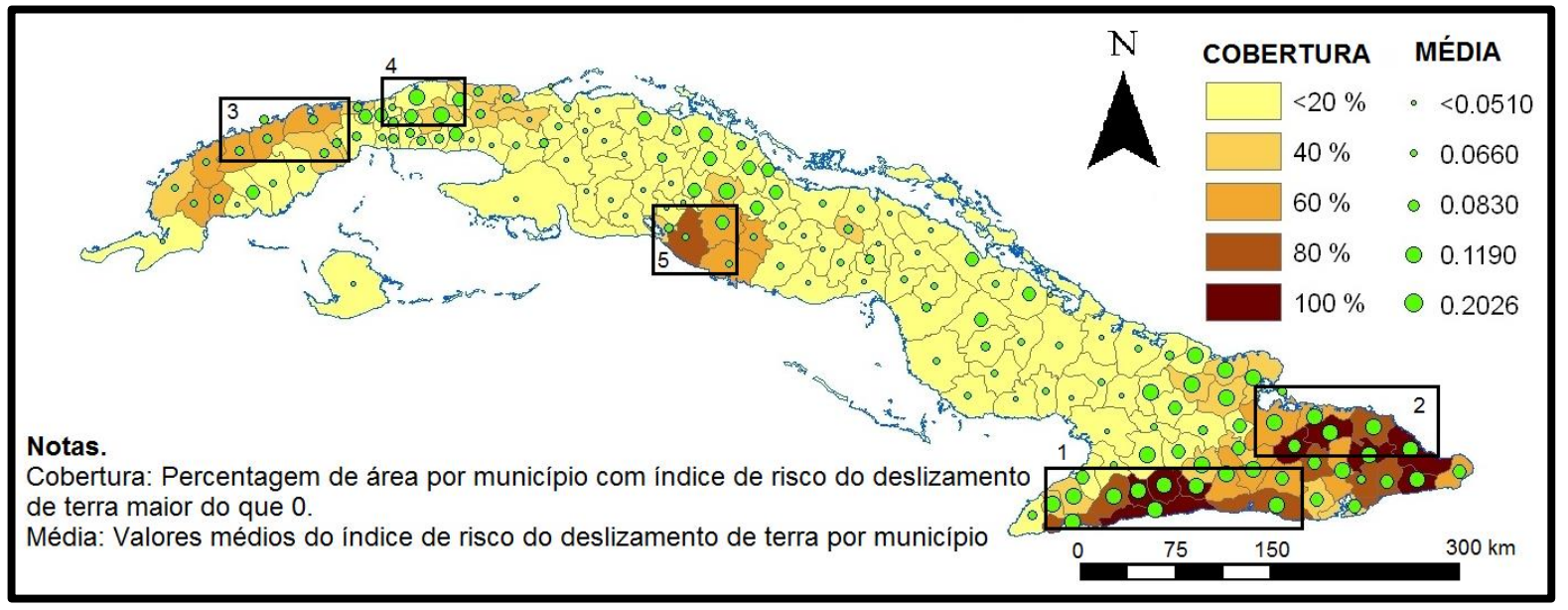

Figura 1.2 - Mapa de rico por deslizamento, (modificado - Castellanos \& Van Westen, 2007)

Os deslizamentos de terras geram um número crescente de catástrofes em todo o mundo, devido às alterações climáticas e ao aumento da densidade da população nas zonas montanhosas, pelo que a pesquisa relacionada com a redução do risco quanto a esta questão deve ser incrementada.

Dentre as medidas relacionadas com a gestão da ameaça do desastre, os sistemas de alerta rápida são ações principais, contribuindo de forma eficaz para evitar a perda de vidas humanas e reduzir o impacto econômico e material sobre as populações vulneráveis afetadas por esses eventos. Por essa razão, são necessárias ferramentas rápidas, através das quais seja possível monitorar uma ameaça ou evento e tomar medidas sobre seus possíveis efeitos.

As principais metodologias usadas na atualidade na avaliação das ameaças por escorregamentos são as análises multicritério (Castellanos \& Van Westen, 2007), modelos de base física (Papa et al., 2011, 2013), metodologias baseadas no uso de inteligência artificial e redes neuronais artificias (Martinez, 2006) e lógica difusa ou "fuzzy logic" (Garcia, 2004).

Papa et al. (2011) propõe um trabalho para desenvolver um sistema capaz de fornecer alertas de eventos de fluxo de detritos, em áreas onde os dados históricos não estão disponíveis, bem como no caso de mudanças ambientais e do clima, usando curvas de limiares de precipitações críticas derivadas de simulações matemáticas e numéricas, em vez da derivação clássica de dados empíricos de 
chuva. Estas curvas podem ser utilizadas para a avaliação em tempo real dos possíveis eventos de fluxo de detritos sobre a base de chuvas observadas e previstas.

Bregoli et al. (2015) propõe um sistema capaz de avaliar a susceptibilidade de fluxo de detritos em escala regional. Aqui são introduzidos dois modelos físicos que simulam o início de fluxos de detritos mediante escorregamentos rasos: o primeiro, baseado no fluxo de água subterrânea lateral e o outro no fluxo de águas subterrâneas vertical, para finalmente serem comparados com um modelo estatístico, baseado em uma regressão logística.

\subsection{Objetivo.}

O objetivo principal desta pesquisa é calibrar o modelo proposto por Papa et al. (2011) baseado no estudo feito por Iverson et al. (2000), nas regiões montanhosas do leste de Cuba e avaliar o desempenho do mesmo aplicando a metodologia após a calibração. Com esta metodologia, é possível obter valores de ameaça relacionada à probabilidade de ocorrência de escorregamentos em um tempo determinado e na área analisada.

\subsection{Metodologia.}

A calibração e a validação do modelo proposto por Papa et al. (2011) serão feitas comparando os resultados obtidos com inventários de deslizamentos reais da região.

A área de trabalho foi escolhida a partir dos resultados da carta de risco por escorregamentos, obtida no estudo realizado por Castellanos \& Van Westen (2008), Fig. 1.2, a partir de uma análise semi-quantitativa com avaliação espacial multi-critério a escala regional 1:1'000.000 em Cuba.

Seguidamente se presentam os passos e a etapas principais que compõem esta pesquisa.

\subsubsection{Escolha da área de trabalho.}

A carta de risco por escorregamentos, elaborada por Castellanos \& Van Westen (2007) foi obtida a partir de uma analise semi-quantitativa, com 10 mapas indicadores e usando técnicas de avaliação espacial multicritérios, num Sistema de Informação 
Geográfica (SIG). Os indicadores padronizados foram pesados e combinados para obter o mapa de índice de risco por escorregamentos na escala 1:1'000.000. Este método permite a incorporação da opinião de especialistas e o uso da tomada de decisões em grupo, dando lugar a resultados confiáveis (Castellanos \& Van Westen, 2008).

Depois de analisar as cinco áreas expostas na Fig. 1.2, foi escolhida a zona 1 em Fig.1.2, representada pelo Sistema Montanhoso "Sierra Maestra", a topografia da região, o tipo de solo e a queda de intensas chuvas anuais fazem desta uma área suscetível à ocorrência deste tipo de eventos.

\subsubsection{Aplicação da metodologia para o cálculo da ameaça.}

A metodologia de cálculo proposta por Papa et al. (2011) é a responsável pela avaliação da ameaça, tem como objetivo principal fornecer a matriz representativa da área de estudo com os valores associados à probabilidade de ruptura dos taludes, em relação a certo período de tempo e mediante a aplicação da ação de uma precipitação que atua como agente deflagrador. A abordagem conferida a Papa et al. (2011) é sustentada em um modelo de simulação bem simplificado, demandando um curto período de tempo despendido ao processamento computacional e a um conjunto limitado de insumos básicos. Este conjunto de características é uma das principais razões de que o referido modelo seja usado para o desenvolvimento desta dissertação.

Segundo os autores, foi usado um modelo matemático pautado na técnica conhecida como "análise baseado no talude infinito", conforme o trabalho de Iverson (2000), que simula a possível deflagração de escorregamentos em um elemento genérico da bacia em estudo.

\subsubsection{Metodologia de cálculo}

O software utilizado para a implementação do modelo é o programa Excel 2013 e contempla sua integração com uma plataforma SIG, neste caso ArcGIS 10.1 oferecendo a possibilidade da extensão das análises a um contexto com características espaciais. 


\subsubsection{Calibração do modelo}

A calibração foi feita usando como referência um inventario de deslizamentos na área de estudo, resultado da identificação visual durante um trabalho de campo realizado em dezembro de 2014 , e da interpretação de fotografias de voos aéreos, tomadas no ano 1957.

\subsubsection{Validação do modelo}

Uma vez calibrado o modelo, foi feita uma análise em outra região com características similares, onde se tem um inventario de escorregamento produzido por um evento de chuva em particular.

\subsection{Escopo do trabalho}

Este trabalho está dividido basicamente em três partes: a Revisão Bibliográfica, o Processo de Modelagem que abrange a calibração e a validação, e os Resultados. Para sua apresentação, será organizado a em seis capítulos.

\section{Capitulo 1: Introdução}

No primeiro capítulo, apresentam-se a definição do problema, os objetivos do trabalho e a metodologia a ser usada nesta pesquisa

\section{Capitulo 2: Revisão Bibliográfica}

No segundo capítulo, tratam-se os principais tipos de movimentos de massa, os métodos para a avaliação de ameaça na formação de deslizamento de terra, os diferentes tipos de escala usados e são apresentados diferentes trabalhos realizados sobre este assunto em Cuba, no Brasil e no mundo.

\section{Capitulo 3: Características gerais da área de estudo}

No terceiro capitulo, são apresentadas as características físicas, geológicas e do solo da área de estudo.

\section{Capitulo 4: Metodologia}

No quarto capitulo, explica-se a metodologia de previsão de fluxo de detritos desenvolvida por Papa et al. (2011), além da obtenção e o processamento dos dados 
de entrada para aplicação do modelo. São apresentadas as informações obtidas no trabalho de campo e os resultados da calibração.

\section{Capitulo 5: Resultados}

No quinto capitulo, são apresentados os resultados da validação do modelo, incluindo durante o processo de validação um procedimento que permite minimizar os cálculos.

\section{Capitulo 6: Conclusões}

No sexto capítulo, são resumidas as conclusões gerais de cada uma das etapas da dissertação e se propõem sugestões para investigações futuras. 


\section{Capitulo 2: Revisão Bibliográfica}

\subsection{Conceitos e critérios fundamentais sobre risco.}

Conforme a norma brasileira ISSO 31000 (ABNT, 2009), são definidos os seguintes conceitos relacionados com o risco.

Risco: Efeito da incerteza sobre os objetivos.

Efeito: É um desvio do que se espera, seja positivo, negativo ou ambos.

Objetivos: Eles podem ter aspetos diferentes, por exemplo financeiros, saúde e segurança, e as metas ambientais, e podem ser aplicados em diferentes níveis (estratégico, em toda a organização, em projetos, produtos e processos). Muitas vezes, o risco é caracterizado pela referência aos acontecimentos potenciais e suas consequências, ou a uma combinação dos mesmos. Frequentemente, o risco é expresso em termos de uma combinação das consequências de um acontecimento incluindo alterações nas circunstâncias e na probabilidade de que aconteça.

Incerteza: É o estado, mesmo que parcial, de deficiência de informação relacionada com a compreensão ou com o conhecimento de um acontecimento, sua consequência ou probabilidade.

Gestão de risco: São atividades coordenadas para dirigir e controlar uma organização no que diz respeito ao risco.

Atitude face ao risco: $O$ foco da organização para avaliar e fazer finalmente, manter, adotar ou afastar-se do risco.

Consequência: Resultado de um evento que afeta os objetivos.

Um evento pode causar uma série de consequências. Uma consequência pode ser certa ou não e pode ter efeitos positivos ou negativos sobre os objetivos. As consequências podem ser expressas qualitativa ou quantitativamente.

Probabilidade: É a oportunidade para que algo aconteça. 
Na terminologia da gestão de risco, a palavra "probabilidade" é utilizada para se referir à oportunidade de algo acontecer, seja ou não definido, medido ou determinado objetiva ou subjetivamente, qualitativa ou quantitativamente, e descrito utilizando termos gerais ou matemáticos como a probabilidade numérica ou a frequência num determinado período de tempo.

Análise do risco: Processo para perceber a natureza do risco e determinar o nível de risco.

A análise do risco fornece as bases para a avaliação do risco e as decisões sobre o seu tratamento. A análise do risco inclui a estimativa do risco.

Nível de risco: Magnitude do risco, expresso em termos da combinação de consequências e suas probabilidades.

Avaliação do risco: Processo de comparação dos resultados da análise do risco com os critérios do risco, para determinar se o risco, sua magnitude ou ambos são aceitáveis ou toleráveis. A avaliação do risco ajuda na decisão acerca do seu tratamento.

Tratamento do risco: Processo para modificar o risco. Isso pode envolver evitar o risco ao decidir não iniciar ou prosseguir a atividade que o causou; tirar ou aumentar o risco a fim de perseguir una oportunidade; retirar a fonte do risco; alterar a probabilidade; alterar as consequências; ou compartilhar o risco com uma ou várias das partes incluindo o financiamento do risco.

O tratamento do risco está dado pela seleção de uma ou mais opções para modificá-los, e pela aplicação dessas opções. A seleção da opção mais adequada para o tratamento de riscos é equilibrar os custos e esforços de aplicação face os benefícios derivados. As decisões também podem levar em conta riscos que possam justificar um tratamento de risco não justificado por razões económicas.

Conforme Fell et al., (2005), foi desenvolvido pelo Comitê Técnico em Gerenciamento e Avaliação de Riscos da "International Society of Soil Mechanics and Geotechnical Engineering" (ISSMGE), um glossário de termos referentes à avaliação de risco, com o objetivo de promover uma uniformidade quanto ao emprego destes 
termos pela comunidade internacional. Fell et al., (2008) ressaltam que estas definições devem ser usadas para todo zoneamento, registros e documentos de planejamento de uso do solo, sendo recomendando que os conceitos estejam vinculados a estes materiais, na tentativa de evitar interpretações erradas. Os principais termos presentes no documento citado, bem como as suas respetivas definições, encontram-se explicitados abaixo.

Deslizamento: Movimento de uma massa de rocha, detritos ou solo ao longo de uma encosta.

Deslizamento ativo: Um deslizamento que está se movimentado atualmente, podendo ser pela primeira vez ou por uma reativação.

Deslizamento reativado: Um deslizamento que se apresenta novamente como ativo, após permanecer um período sem atividade.

Inventário de deslizamentos: Um inventário de localização, classificação, volume, atividade, data de ocorrência e outras características dos deslizamentos em uma área.

Susceptibilidade de deslizamentos: Uma avaliação quantitativa ou qualitativa da classificação, volume ou área, e distribuição espacial de deslizamentos que existem ou podem ocorrer potencialmente em uma área. Uma descrição da velocidade e da intensidade dos deslizamentos reais ou potenciais também pode ser incluída na susceptibilidade.

Ameaça: Refere-se a uma condição com o potencial para causar uma consequência indesejável. Na descrição da ameaça de deslizamento devem ser considerados a localização, volume ou área, classificação e velocidade dos deslizamentos potenciais, juntamente com a probabilidade de sua ocorrência dentro de um dado período de tempo.

Elementos em risco: População, edifícios, obras de engenharia, atividades econômicas, serviços de utilidades públicas e outras infraestruturas em áreas potencialmente afetadas por ameaça de deslizamentos. 
Vulnerabilidade: Grau de perda de um determinado elemento ou conjunto de elementos dentro de uma área afetada por deslizamentos. É expressa em uma escala que varia de 0 (representando ausência de perda) a 1 (representando perda total). Conforme Li et al., (2010) deve ser feita a análise da interação entre uma dada intensidade de deslizamento e os correspondentes elementos afetados para se obter a estimativa da vulnerabilidade.

Zoneamento: Divisão da terra em áreas ou domínios homogêneos, juntamente com a sua classificação mediante o grau de susceptibilidade, ameaça ou risco decorrente de deslizamento atual ou potencial, ou a aplicação de certos regulamentos relacionados com a ameaça.

\subsection{Movimentos de Massa. Classificação.}

Os processos geotectônicos ativos das encostas geralmente se correspondem com os movimentos dos materiais que compõem o talude da rocha, um solo natural ou preenchido. Estes movimentos geralmente ocorrem ao longo de superfícies de ruptura, por queda livre, deslizamentos, erosão ou fluxos.

Para a classificação dos movimentos de massa, é apresentado o sistema originalmente proposto por Varnes (1978), que define os principais tipos de sistema de movimento.

\subsubsection{Quedas}

É o movimento de uma massa de qualquer tamanho, como blocos isolados, que emerge a partir de uma encosta ao longo de uma superfície, em que ocorre muito, pouco ou nenhum deslocamento de corte e desce principalmente por queda livre, aos saltos ou por rolamento (Fig. 2.1a).

O movimento é muito rápido e geralmente ocorrem em encostas íngremes ou verticais, em áreas costeiras ou em encostas de estradas e margens rochosas de rios ou córregos. 
(a)

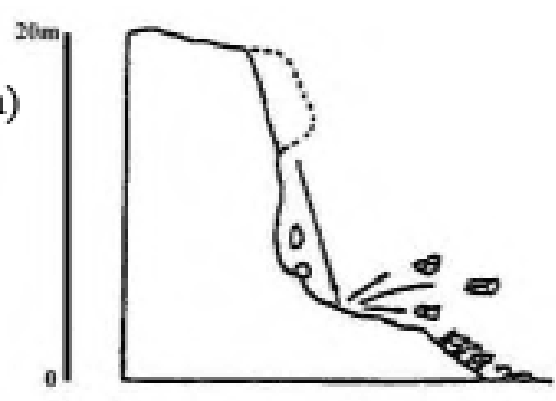

(c)

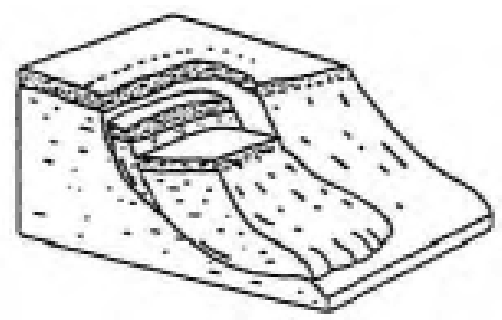

(e) (b)

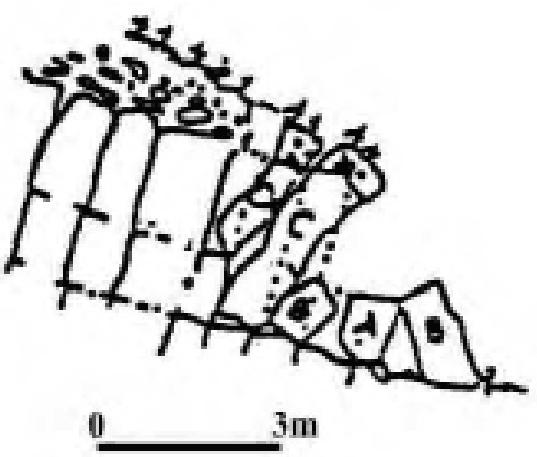

(d)

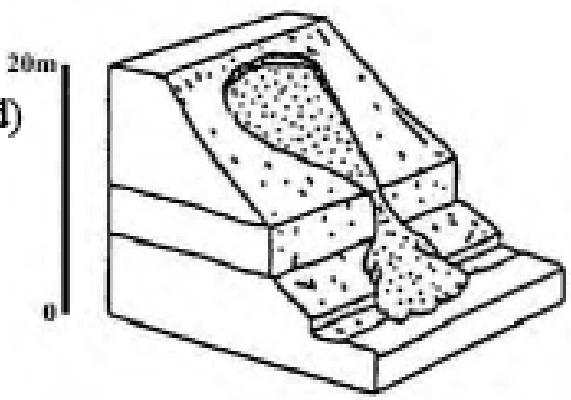

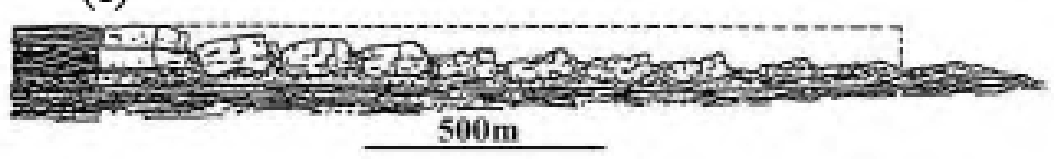

Figura 2.1 - Tipos de movimentos de massa. a) Quedas b) Tombamentos c) deslizamento d) Fluxo e) Espalhamento. (Suarez Díaz,1998)

\subsubsection{Tombamentos}

Este tipo de movimento é uma rotação para a frente de uma ou mais unidades do material com o centro de rotação abaixo do centro de gravidade da unidade, e geralmente ocorrem em formações rochosas. As forças que os produzem são geradas por unidades adjacentes, água em fendas ou bordas, expansões e terremotos (Fig. 2.1b).

\subsubsection{Deslizamentos}

É um movimento descendente de uma massa de solo ou rocha que ocorre, predominantemente, ao longo de uma superfície de ruptura ou numa zona fina de intensa deformação e corte. O movimento pode ser progressivo, ele não é iniciado em simultâneo ao longo da superfície da falha. Na classificação de Varnes (1978), os deslizamentos de terra são determinados seguindo a forma da superfície da falha em translação e rotação. A principal diferença entre a rotação e translação é 
essencialmente sobre a aplicabilidade ou não dos vários sistemas de estabilização. Um movimento de rotação tenta auto estabilizar-se, enquanto um outro de translação pode prosseguir indefinidamente ao longo da encosta para abaixo (Fig. 2.1c).

\subsubsection{Fluxos}

Em um fluxo existem movimentos relativos das partículas ou pequenos blocos dentro de uma massa em movimento ou deslizando sobre uma superfície de falha. Os fluxos podem ser lentos ou rápidos, e secos ou molhados, de rocha, de solo ou de resíduos (Fig. 2.1d). A ocorrência de fluxo é geralmente relacionada com a saturação dos materiais interiores. Alguns solos absorvem água muito facilmente quando alterados, fraturados ou rachados por um deslizamento inicial, e esta saturação leva à formação de um fluxo.

\subsubsection{Fluxo em rocha}

Os movimentos de fluxo compreendem deformações rochosas, distribuídas ao longo de muitas fraturas, grandes e pequenas. A distribuição de velocidade pode simular líquidos viscosos. Este tipo de movimento ocorre com frequência em regiões tropicais com altas montanhas e pouca vegetação.

\subsubsection{Fluxo de Detritos}

Normalmente, um fluxo de rochas acaba num fluxo de resíduos. Os materiais são moídos através do mesmo processo de fluxo e é possível ver uma diferença significativa de tamanho entre a cabeça e o pé do movimento.

A circulação de fluxos de detritos pode ser ativada pela chuva, devido à perda de resistência, à diminuição da sucção do material que se satura, ou ao desenvolvimento de forças que causa o movimento das águas subterrâneas, (Collins e Znidarcic, 1997).

\subsubsection{Espalhamentos}

Nos espalhamentos laterais, o modo dominante de movimento é a extensão lateral acomodada por fraturas de cisalhamento e de tensão. O mecanismo de falha pode incluir não só os elementos de rotação e translação, mas também de fluxo. Em geral, os movimentos são complexos e difíceis de caracterizar. A falha é geralmente progressiva, começa em uma área local e expande-se. O movimento é geralmente extremamente lento (Fig. 2.1e). 


\subsection{Métodos de estimativa de suscetibilidade do terreno na formação de}

deslizamentos.

Existem várias abordagens para avaliar o grau de suscetibilidade do solo aquando os deslizamentos de terra, na maior parte com base na identificação de fatores que influenciam o aparecimento de rupturas. Esses fatores combinam-se para definir os diferentes graus de susceptibilidade, expressando os resultados de forma cartográfica através da criação de mapas de susceptibilidade.

Existem quatro métodos principais utilizados na avaliação e mapeamento de suscetibilidade da terra para produzir rupturas de encosta: métodos determinísticos, heurísticos, probabilísticos e geomorfológicos.

\subsubsection{Métodos determinísticos}

Os métodos determinísticos utilizam análises e modelos de estabilidade mecânica, com base física para a determinação do fator de segurança de uma encosta, o que é uma grande vantagem sobre outros métodos. Os dados de entrada são derivados a partir de testes de laboratório e são utilizados para determinar o fator de segurança da encosta, são muito fiáveis e precisos quando se tem dados válidos dos parâmetros do solo. Não só permitem a análise da susceptibilidade à ruptura, mas também a extensão e a frequência do fenômeno. Existe uma grande variedade de métodos determinísticos disponíveis para análise de estabilidade, desde a análise de talude infinito em seu caso mais simples, até modelos tridimensionais complexos (Graham, 1984).

\subsubsection{Métodos heurísticos}

Os métodos heurísticos são baseados no conhecimento dos fatores que causam instabilidade de encostas, sabendo categorizar e pesá-los de acordo com a influência esperada sobre a geração de deslizamentos de terra. Eles são conhecidos como métodos indiretos, os resultados podem ser extrapolados para áreas sem deslizamento com uma combinação de fatores semelhantes. Um método deste tipo é a análise qualitativa, baseada na combinação de mapas de fatores. Cada um desses fatores forma um mapa que será combinado com outros para obter o mapa final de zoneamento de instabilidade. A desvantagem deste método bastante popularizado reside na ponderação exata dos vários fatores, uma vez que muitas vezes é baseado no conhecimento insuficiente do domínio dos fatores importantes para definir a 
estabilidade. Estes métodos permitem a regionalização ou estudo a nível regional e são adequados para aplicações por especialistas.

A análise heurística introduz um grau de subjetividade que torna impossível comparar documentos produzidos por diferentes autores.

\subsubsection{Métodos probabilísticos}

Conforme Assis et al (2012), os métodos probabilísticos podem ser considerados como aqueles que possibilitam a avaliação da distribuição de probabilidade de uma variável considerada como dependente, em função do conhecimento das distribuições estatísticas das variáveis independentes que determinam esta primeira variável. A avaliação da distribuição estatística de uma função de desempenho, é geralmente realizada mediante uma análise numérica probabilística (Suchomel \& Mašin, 2009).

Montoya \& Assis (2010) destacam que, na análise de confiabilidade, a utilização de técnicas com esta natureza estatística possibilita que a incerteza possa ser tratada de uma maneira mais rigorosa nos procedimentos e processos de projeto geotécnico.

Reis (2010) destaca que é necessário um conjunto de dados consistente, envolvendo os solos constituintes da região em estudo para o uso das análises probabilísticas em problemas de estabilidade de taludes, onde estas informações devem ser provenientes de ensaios de laboratórios e trabalhos de campo. Ainda conforme o autor, a representatividade destas análises estará fortemente relacionada ao montante de incertezas inerentes ao problema que se encontram envolvidas na solução empregada.

\subsubsection{Métodos geomorfológicos}

São baseados em mapeamento geomorfológico, a partir do qual o autor identifica e localiza deslizamentos de terra e processos associados a eles diretamente no campo. Com observações, o especialista elabora critérios para determinar áreas potencialmente instáveis e prepara o mapa de suscetibilidade e/ ou ameaça final. O desenvolvimento destes mapas requer do conhecimento da morfologia e tipologia de movimento. 
A principal vantagem são a validade, a análise detalhada e o mapa resultante, no caso de ser feito por um bom especialista. A desvantagem destes métodos é o alto grau de subjetividade, dependendo da experiência do autor.

\subsubsection{Modelo de base física (talude infinito)}

Nas encostas cobertas dos solos tropicais, a superfície potencial de falha é normalmente encontrada no contato entre o solo residual relativamente permeável e o solo subjacente relativamente impermeável. Se o solo residual tem espessura limitada em comparação com o comprimento da ladeira, pode assumir-se na análise a hipótese de estabilidade do talude infinito.

O termo talude infinito representa uma ladeira uniforme que se pode considerar representativo no seu conjunto, onde as propriedades do solo e a poropressão da água, em qualquer distância sob a superfície do solo, podem ser consideradas constantes (Graham, 1984).

A análise unidimensional da estabilidade de talude infinito é a abordagem mais comum utilizada entre os modelos de ruptura do talude. Ela baseia-se numa geometria simples de escorregamentos de terra, que assume uma superfície plana de deslizamento sobre uma inclinação plana infinitamente estendida.

A análise pressupõe que a superfície de deslizamento é paralela à superfície do solo e que coincide com a camada impermeável.

O solo é sujeito a duas influências opostas: a componente do peso do solo, que atua como um corte ao longo do plano potencial da falha e paralelo à inclinação do talude e a resistência ao cisalhamento do solo. A relação entre estas duas componentes é expressa como o fator de segurança FS.

Geralmente, quanto maior for a pressão da água nos poros, menor será a resistência ao atrito e a resistência ao corte; um aumento do conteúdo de água no solo, também aumenta o peso aparente do solo.

\subsection{Escalas}

$\mathrm{Na}$ elaboração de mapas de risco, deve ser avaliada a influência de uma série de fatores que afetará a probabilidade de ocorrência de deslizamentos de terra. Quanto mais detalhado for o mapa, mais fatores deverão ser estudados. A escala de análise é um dos primeiros itens a serem considerados em um projeto, pois dela 
dependerá a metodologia utilizada, os fatores ou dados considerados, a unidade de terra, etc. Em geral, existem três escalas (IAEG, 1976) para o zoneamento de susceptibilidade a escorregamento:

- Escala regional $(<1: 100.000)$

- Escala média (1:25.000 a 1:50.000)

- Grande escala (1:5.000 a 1:10.000)

- Escala detalhada (> 1:5.000), que pode ser adicionada às três anteriores (Luzi,1995).

$\mathrm{Na}$ escala regional, os mapas são usados para identificar áreas com problemas de escorregamento de uma forma genérica, e são utilizados por organizações que trabalham com o planejamento regional. São utilizados métodos semi-quantitativos como a sobreposição de mapas, e as unidades do terreno são baseadas em características morfológicas obtidas a partir de imagens estereográficas em pequena escala (1:60 000-1:50000) (Rengers et al., 1992)

A escala média é usada para estudos de planejamento e engenharia interlocal. São utilizados também diferentes métodos analíticos, principalmente estatísticos, bem como modelos digitais de elevação detalhada, outros mapas temáticos e imagens estereográficas em escalas de 1: 15000 até 1: 25000 (Rengers et al., 1992). Os métodos de análise de sensibilidade estatísticos são adequados para esta escala (Mulder, 1991; Dhakal et al., 2000).

Mapas de grande escala são criados para estudar problemas locais de instabilidade, para planejar projetos de infraestrutura e edifícios industriais (Luzi, 1995). Os métodos de análise utilizados são métodos quantitativos, incluindo modelos estatísticos multivariados e modelos numéricos de estabilidade. Esta escala requer informações de mapeamento de muito boa qualidade, bem como imagens estereográficas de 1: 5000 até 1: 10.000) (Rengers et al., 1992).

\subsection{O mapeamento de suscetibilidade e ameaça.}

Foram realizados em Cuba vários trabalhos relacionados com a implementação da cartografia digital na avaliação de suscetibilidade, ameaça e riscos geológicos. 
Castellanos, (2003) executa o mapeamento e a avaliação das ameaças a deslizamentos de terra em duas áreas do leste de Cuba. Neste trabalho, foi realizado um levantamento geomorfológico semi-detalhado, criando um mapa de unidades de terra com um extenso banco de dados associado. Foram interpretados mediante fotos mais de 50 deslizamentos de terra ou uma parte deles e foi criado um banco de dados associado, onde são divulgados esses deslizamentos. Para fazer um modelo de avaliação de ameaça, foi criado um modelo heurístico e foram usadas técnicas de suporte de decisão espacial, atribuindo peso a cada tipo de variável para obter um Mapa de Ameaça de Deslizamentos de Terra. Em Castellanos, (2008) trabalhou na avaliação nacional de riscos de deslizamento de terra, uma pesquisa importante a partir da qual foi obtido o mapa do índice de risco nacional de deslizamento de terra. Este trabalho explica o procedimento realizado para a Avaliação Nacional de 110.860 $\mathrm{km}^{2}$, abrangendo o arquipélago cubano com uma resolução espacial de $90 \mathrm{~m}$. Foi projetado e implementado um modelo de avaliação semi-quantitativo de risco de deslizamento de terra com 11 indicadores, que utilizam técnicas de multi-critérios num Sistema de Informação Geográfica. Cada indicador foi processado, analisado e padronizado de acordo com o modelo. Os resultados permitem projetar um plano de mitigação de risco adequado de deslizamentos de terra em todo o país.

Del Puerto \& Ulloa (2003) realizaram o mapeamento da distribuição espacial das ameaças naturais e a classificação da bacia de Santiago de Cuba a partir da predominância dos tipos de ameaça que podem vir a ocorrer em determinados setores da região. A pesquisa é apoiada pelo desenvolvimento e interpretação de mapas morfométricos, resultando no mapa tipológico de ameaças e de regionalização, mas estes não foram validados com nenhum mapa de inventários de fenómenos da área em questão.

Castellanos \& van Westen (2005) mostra os resultados de um processamento de dados do "Shuttle Radar Topography Mission" SRTM para o arquipélago cubano, a análise para produzir mapas derivados do Modelo Digital de Elevação (MDE) e a avaliação da ameaça geomorfométrica de deslizamento de terra. A análise e o processamento são feitos utilizando técnicas GIS e software de teledetecção. $O$ mapeamento de susceptibilidade do Arquipélago de Cuba é feito usando mapas derivados do DEM, como são o ângulo da inclinação e relevo interno (dissecação 
vertical) que mostram as áreas onde existe maior possibilidade de ocorrência de deslizamentos de terra quando os fatores morfométricos têm valores mais altos. No entanto, o processo de pesagem de cada fator analisado não é feito considerando a distribuição areal dos movimentos de massa, mas referia-se apenas à coincidência com as cadeias de montanhas do país e são obtidos pelos intervalos que poderiam causar, em maior ou menor medida, quebras nas encostas, segundo o critério do autor.

Febles \& Rodríguez (2005) apresentam um mapa de perigo para deslizamentos de terra de Cuba na escala 1: 250 000, que definem as áreas mais propensas a este fenômeno em todo o país, usando como determinantes a declividade do relevo topográfico, a composição das rochas e/ ou do solo, as condições tectônicas, o efeito antrópico (densidade populacional e densidade de auto-estradas e estradas) e as precipitações.

Vega (2005) faz uma aplicação de GIS na obtenção de um mapa de erosão de Cuba na escala 1: 250 000, através da análise de vários fatores, como a precipitação e o escoamento superficial, o relevo e as propriedades do solo, direção do fluxo e o fluxo acumulativo.

Aguller (2008) faz uma avaliação da ameaça por fenômenos de desprendimentos de rochas na estrada "La Plata - Punta Babujal" ao Sul de Santiago de Cuba, Município Guamá, prevendo futuros estudos de risco e a aplicação de medidas de prevenção de estes fenômenos na área.

Outras pesquisas relacionadas com a avaliação da ameaça são desenvolvidas no Brasil e no mundo.

Segundo Iverson (2000), a ocorrência de escorregamentos em resposta a precipitação envolve processos físicos que operam em escalas de tempo diferentes. As relações entre estes prazos guia o desenvolvimento de um modelo matemático que utiliza formas reduzidas da equação de Richards para avaliar os efeitos da infiltração das precipitações na ocorrência de deslizamentos, o tempo e a profundidade. O uso conjunto dos dados topográficos, a intensidade de precipitação, a duração, o critério de falha de talude infinito e a segunda lei de Newton prediz o momento, a profundidade e a aceleração da chuva que ativa os deslizamentos de terra. 
Azevedo (2011) aplica uma metodologia para o cálculo da ameaça para gerar curvas de probabilidade de ruptura em função da precipitação acumulada. Esta metodologia se concentrou em obter e examinar informações pertinentes que fornecessem a análise e o consequente entendimento da relação entre chuvas e escorregamentos no município do Rio de Janeiro, na procura de um método que possibilitasse averiguar a possível interação entre as séries históricas de chuvas ocorridas na região de estudo e os registros de acidentes geotécnicos deflagrados por precipitações.

Conforme Azevedo et al. (2013), são aplicados métodos probabilísticos na análise espacial da susceptibilidade de ocorrência de deslizamentos rasos na área da Vila Varjão no Distrito Federal, Brasil. Os métodos probabilísticos são associados a uma plataforma baseada em sistemas de informação geográfica SIG, com a finalidade de analisar e determinar a probabilidade de ruptura por escorregamento planar. Foram aplicados o Método FOSM e o Método das Estimativas Pontuais à área mencionada. Como principais resultados, além da elaboração das cartas relacionadas à probabilidade de ruptura e ao índice de confiabilidade, a possibilidade de tecer considerações acerca dos valores indicados pelos métodos utilizados, permitindo realizar a verificação da distribuição da susceptibilidade de escorregamentos rasos por toda a área de estudo. Considerou-se uma função de desempenho que fornece valores de fator de segurança (FS), tratado como variável dependente, tomando-se como base um modelo de talude infinito para solos homogêneos, considerado em termos de uma análise de tensões efetivas (Biondi et al. 2000).

Aristizábal (2014) propôs um modelo conceitual e físico, denominado SHIA_Landslide, para a previsão de escorregamentos rasos detonados por chuvas em ambientes tropicais montanhosos e em terrenos complexos, suportados por aspetos geológicos e hidrológicos que ocorrem em escala de bacia. A abordagem oferece uma nova perspectiva para a análise desta categoria de problemas em escala de bacias hidrográficas, empregando este completo e abrangente modelo, que envolve o conceito de tanque hidrológico, incluindo o armazenamento de água no solo de forma acoplada a uma análise geotécnica de estabilidade de taludes infinitos em condições saturadas. A implementação do algoritmo foi realizada na linguagem 
FORTRAN, com a aplicação a um caso real em uma região andina da Colômbia, como forma de testar a sua capacidade preditiva.

O módulo hidrológico utilizado no modelo baseia-se em uma metodologia desenvolvida por Vélez (2001), denominada "Simulación Hidrológica Abierta" (SHIA), formado por uma componente de balanço hídrico, responsável por simular os processos hidrológicos dominantes na bacia, e um elemento de direcionamento, capaz de retratar o fluxo de água através da rede de rios.

A pesquisa de Papa et al. $(2011,2013)$ é baseada no trabalho de Iverson (2000), cujo foco principal se concentrou na criação de um sistema capaz de prover alertas acerca da ocorrência de fluxos de detritos em regiões desprovidas de uma base de dados histórica, ou no caso de situações em que mudanças climáticas e ambientais acarretam este tipo de evento. São usadas curvas de limiares críticos de precipitações derivadas de simulações matemáticas e numéricas, utilizando a análises de estabilidade de talude infinito, onde a instabilidade é regida pelo aumento da pressão da água subterrânea nos poros do solo devida as precipitações. O efeito da infiltração da chuva na ocorrência de escorregamentos é modelado através de uma forma reduzida da equação de Richards. A metodologia foi implementada e testada em uma bacia da costa de Amalfi no Sul da Itália.

Bregoli et al. (2015) utiliza dois modelos físicos simulando a iniciação de fluxo de detritos como consequência de deslizamentos superficiais: um baseado no fluxo lateral das águas subterrâneas e um outro baseado no fluxo vertical das águas subterrâneas.

A metodologia é aplicada em uma bacia dos Pirineos espanhóis. Os resultados são comparados como um modelo estatístico, baseado em regressão logística. Finalmente, o modelo baseado em fluxo vertical, tem um rendimento melhor de18\% quando comparado com o modelo baseado em fluxo lateral. Além disso, o rendimento do modelo baseado em fluxo vertical encontra-se similar a regressão logística, que tem um índice de qualidade médio de $70 \%$. 


\section{Capitulo 3: Caraterísticas Gerais da área de estudo}

\subsection{Localização geográfica e caraterísticas físicas da área de estudo.}

A província de Santiago de Cuba situa-se na porção leste da República de Cuba (Fig. 3.1), faz fronteira ao Leste com a província de Guantánamo; ao Oeste, com a província Granma; ao Norte, com a província de Holguín e ao Sul, com o Mar do Caribe. Possui uma extensão territorial de 6156,44 km² e uma população de 1047 181 habitantes, para uma densidade de população de 170,1 hab/ km² (Anuário Estatístico, 2009). De acordo com a Divisão Político Administrativa (DPA) atual, possui 9 municípios.

As zonas de estudo encontram-se localizadas no Grande Parque Nacional "Sierra Maestra", especificamente numa parte do sistema montanhoso "Sierra Maestra", ao Oeste da província Santiago de Cuba e na região da "Gran Piedra", área mais ao leste do parque.

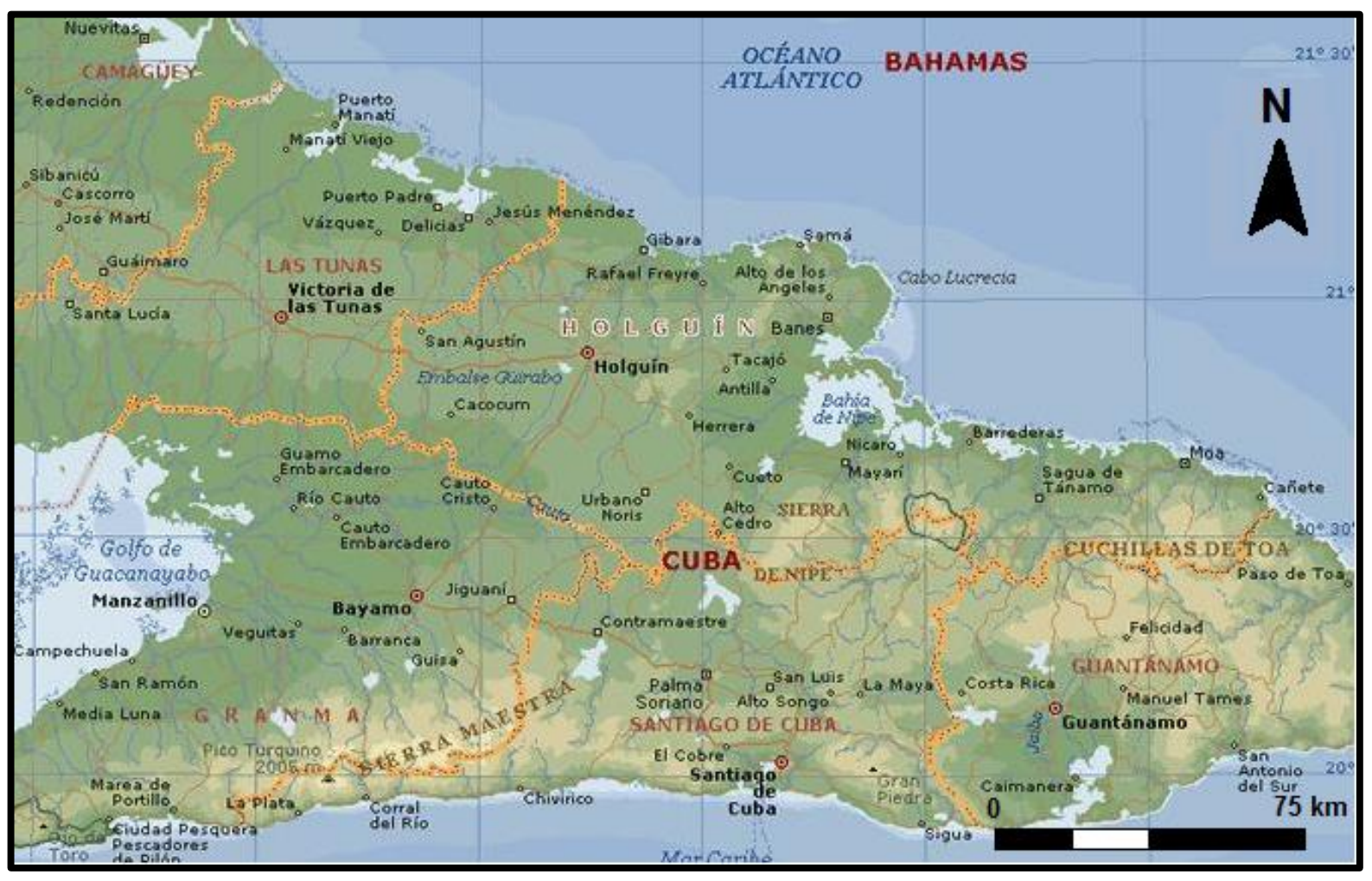

Figura 3.1 - Localizações, Santiago de Cuba. Modificado, http://www.bedinCuba.com 
A rede fluvial é caraterizada pelo pouco desenvolvimento, na qual tem um papel importante o regime de chuvas, observando escassos rios com caráter intermitente, que desaparecem em períodos de seca.

A zona é pouco povoada, com pequenos assentamentos que se concentram na linha costeira, existindo nas áreas montanhosas povoamentos menores.

\subsection{Clima no Parque Nacional "Sierra Maestra"”}

O clima da região é tropical cálido e representa uma das zonas com maiores acumulados de precipitações anuais em todo o país. As precipitações medias anuais variam entre $1200 \mathrm{~mm}$ e $1400 \mathrm{~mm}$. No período de chuva de Maio até Outubro acontecem 80 a $100 \%$ dos totais de precipitação anual sendo nos meses de Setembro e Outubro os de maior ocorrência de chuvas.

\subsection{Formação do relevo ao Sudeste de Cuba}

A megamorfoestrutura geodinâmica principal da região é representada pela Fossa de Bartlett, que herdou parcialmente a antiga zona de expansão da bacia do Caribe, constituindo, em parte, uma nova formação morfoestructural (Fig. 3.2).

Segundo (Hernandez, 1989) no Cretáceo Inferior, formou-se o arco insular vulcânico das Antilhas Maiores (Fig. 3.2 B), que incluiu Cuba. Mais tarde, no Cretáceo Superior (Fig. 3.2 C), durante o processo de abertura da depressão de Yucatán, este arco deslocou-se para o Norte e, aparentemente, por obducção, encontrou-se com o extremo sul da Placa Norte-americana (Jain, 1979; Shein et al, 1978). Ao mesmo tempo, a abertura do limite norte da Placa do Caribe, representada pela Fossa profunda de Bartlett, formou a megamorfoestrutura da cordilheira insular "CaimánSierra Maestra", separadas do arquipélago Cubano pela parte oriental da depressão Yucatán. No Eoceno (Fig. 3.2 D), este arco vulcânico se deslocou para a margem sul da Microplaca Cubana. A partir desta fase, começou a formação da fossa profunda, que se desenvolveu como uma morfoestrutura de distensão, o que determinou a fratura do arco insular "Caimán-Sierra Maestra", inicialmente anexado (Fig. 3.2 E e Fig. 3.2 F). 
O desenvolvimento posterior da tectogênese e da morfogênese, levou à desmembração e à crescente complexidade do relevo.

Nas morfoestruturas, ao leste de Cuba, na etapa atual, destacam-se cinco grandes unidades morfoestruturais, uma delas é o sistema montanhoso "Sierra Maestra" (1500-2000 m), articulado contrastantemente pelo sul com a jovem Fossa profunda de Bartlett (5000-7000 m) (Formell et al., 1984 citado por Hernandez, 1989).

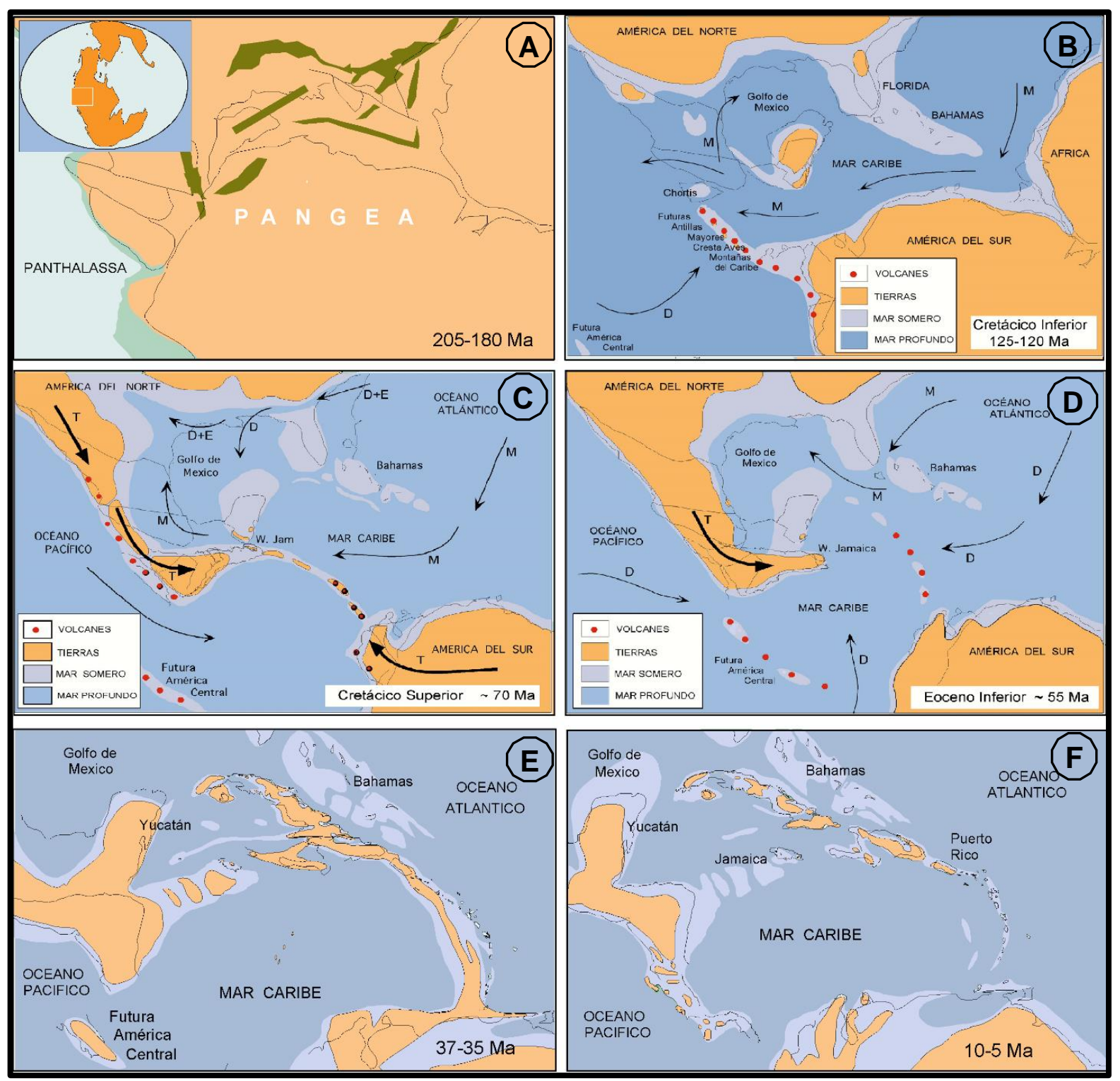

Figura 3.2 - Evolução Tectônica do Caribe e Cuba. http://www.redciencia.cu

Dentro do macrobloco do sistema montanhoso da "Sierra Maestra" (Fig. 3.3), destacam-se: 
- A "Sierra Maestra", no oeste e no leste com montanhas baixas (300-500 m) e (700$1000 \mathrm{~m})$ e no centro de montanhas médias (1200-2000 m)

- O maciço de montanhas baixas da "Gran Piedra" (800-1200 m)

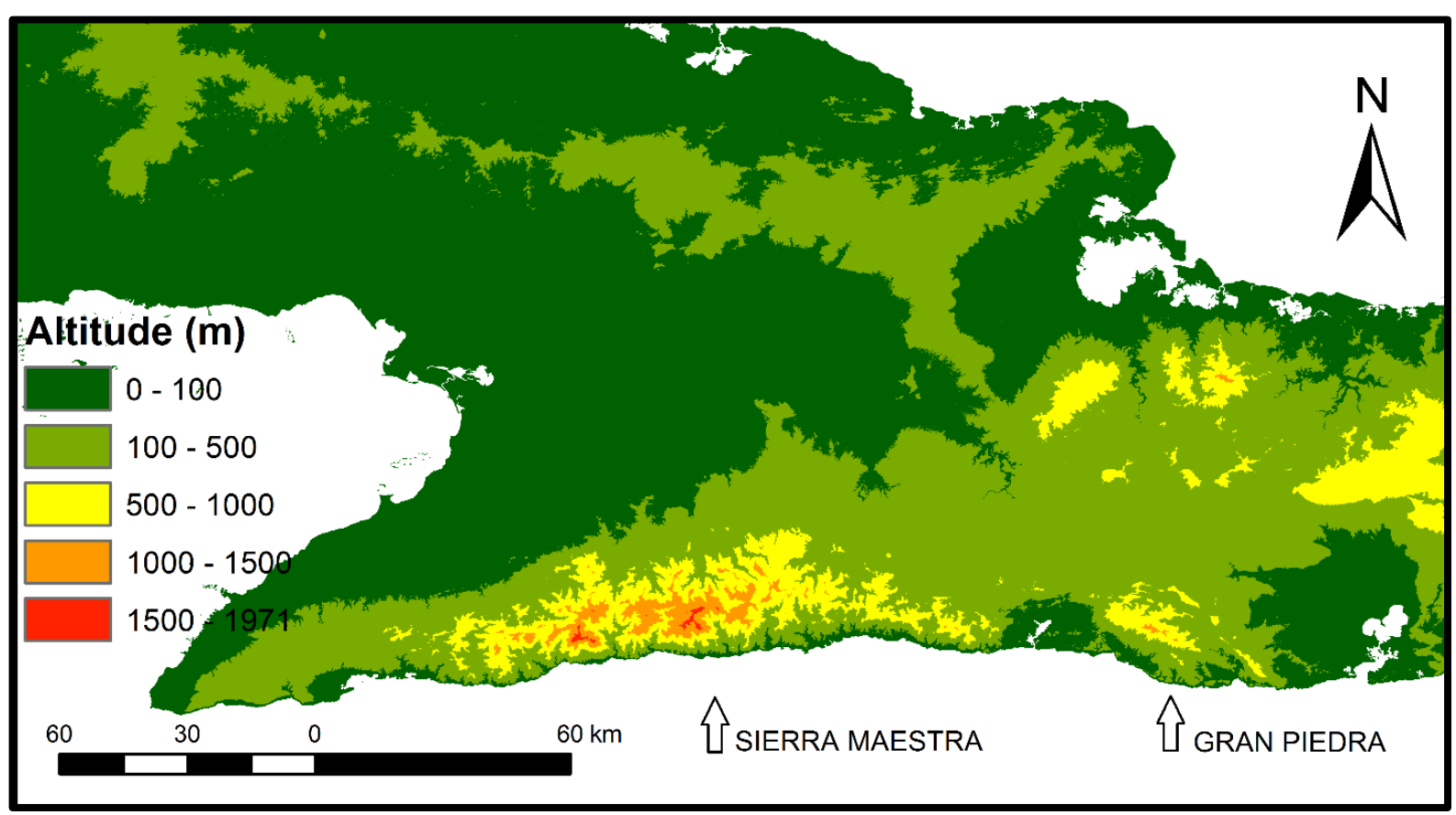

Figura 3.3 - Localizações das áreas de estudo.

O grande poder do relevo montanhoso, juntamente com os processos tropicais, condiciona sua intensa modelagem exogenêtica. A poderosa denudação transporta uma grande quantidade de material solto pelas encostas, formando cones diluviais. Neste território, manifestam-se ativamente os processos gravitacionais.

Um outro fator determinante na formação do relevo tropical são os furacões, que geram fortes processos erosivos, gravitacionais, levando à lavagem intensa das encostas e ao deslocamento de material de diferentes granulometrias.

Assim, a morfoescultura antiga e recente destaca-se por uma alta energia dos processos exógenos, formando o relevo com traços típicos da morfogênese tropical.

\subsection{Caraterísticas geológicas da região.}

O sistema montanhoso "Sierra Maestra" é caracterizado por uma estrutura geológica muito complexa, devido ao desenvolvimento de diferentes complexos litológicos de rochas, extensa manifestação de vulcanismo e magmatismo intrusivo, 
bem como inúmeras luxações de ruptura (Kuzovkov, 1977). No corte estratigráfico da região (Fig. 3.4), destacam-se as subdivisões a seguir.

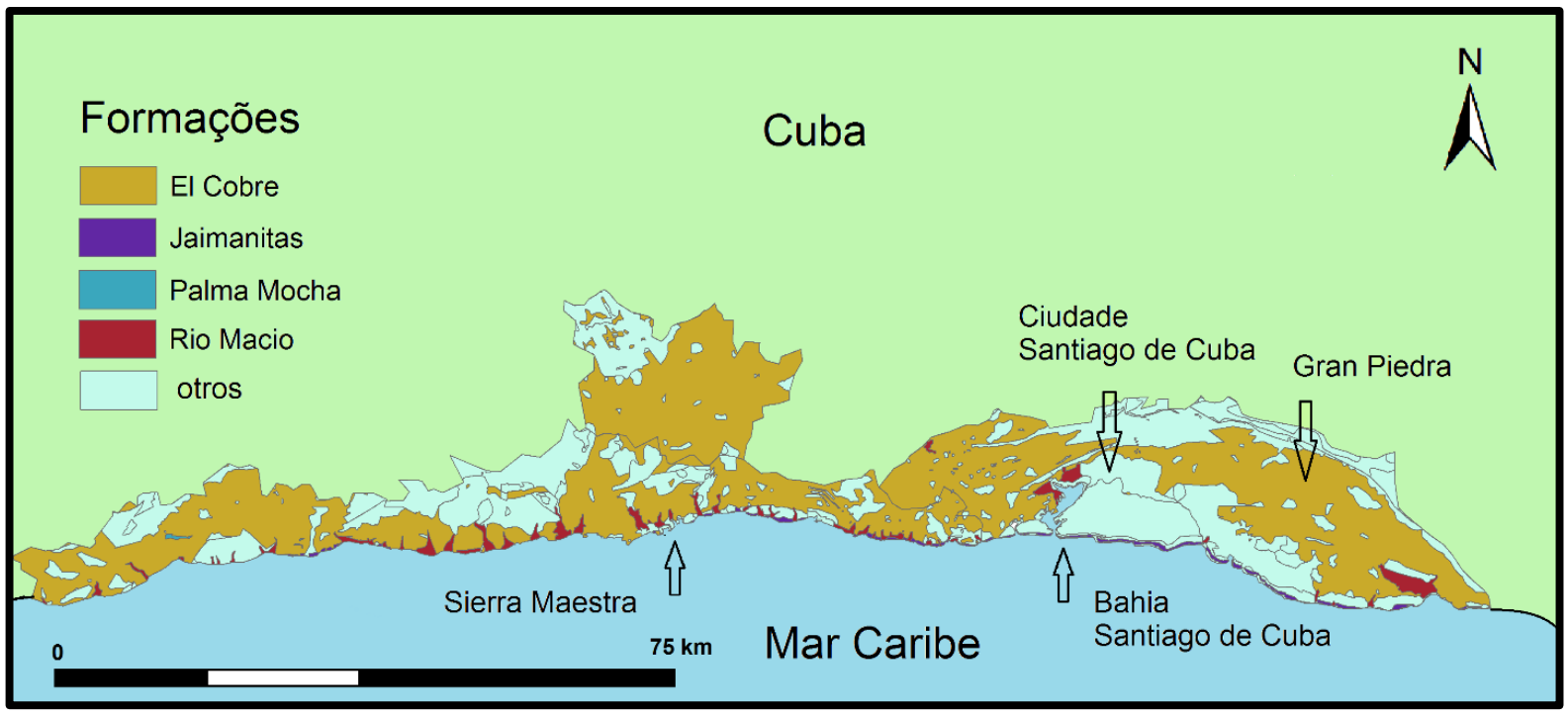

Figura 3.4 - Mapa Geológico da área de estudo (Escala: 1:100 000 IGP, 2008).

\subsection{Formações}

- Sistema Cretáceo. Grupo Palma Mocha. Rochas terrígenas clásticas e vulcanógênicas, em menor quantidade, aparecem calcários e intercalações de argilitos. Os tufos e aglomerados desta unidade são de composição básica. $\mathrm{Na}$ parte baixa, predominam os tufos e aglomerados; na parte média, os aglomerados e na parte alta, predominam os calcários sobre os arenitos tuffaceous e os tufos; em todo o corte tem intercalações de argilitos.

- Sistema Paleogeno. Grupo "El Cobre", idade Paleoceno-Eoceno Médio (parte baixa). Ocupa a maior parte da área e é formado pelas sequências efusivas do arco vulcânico do Paleogeno; representado por poderosas sequências vulcanogenas-sedimentares, com predominância de tufos de composição andesítico-basáltica (Fig. 3.5). De modo subordinado, aparecem arenitos e calcários tufaceous, bem como mantos de andesito e andesito-basálticos. Em menor grau, encontram-se dacitas, riolitas, riodacitas e seus derivados efusivos (Fig. 3.6). 


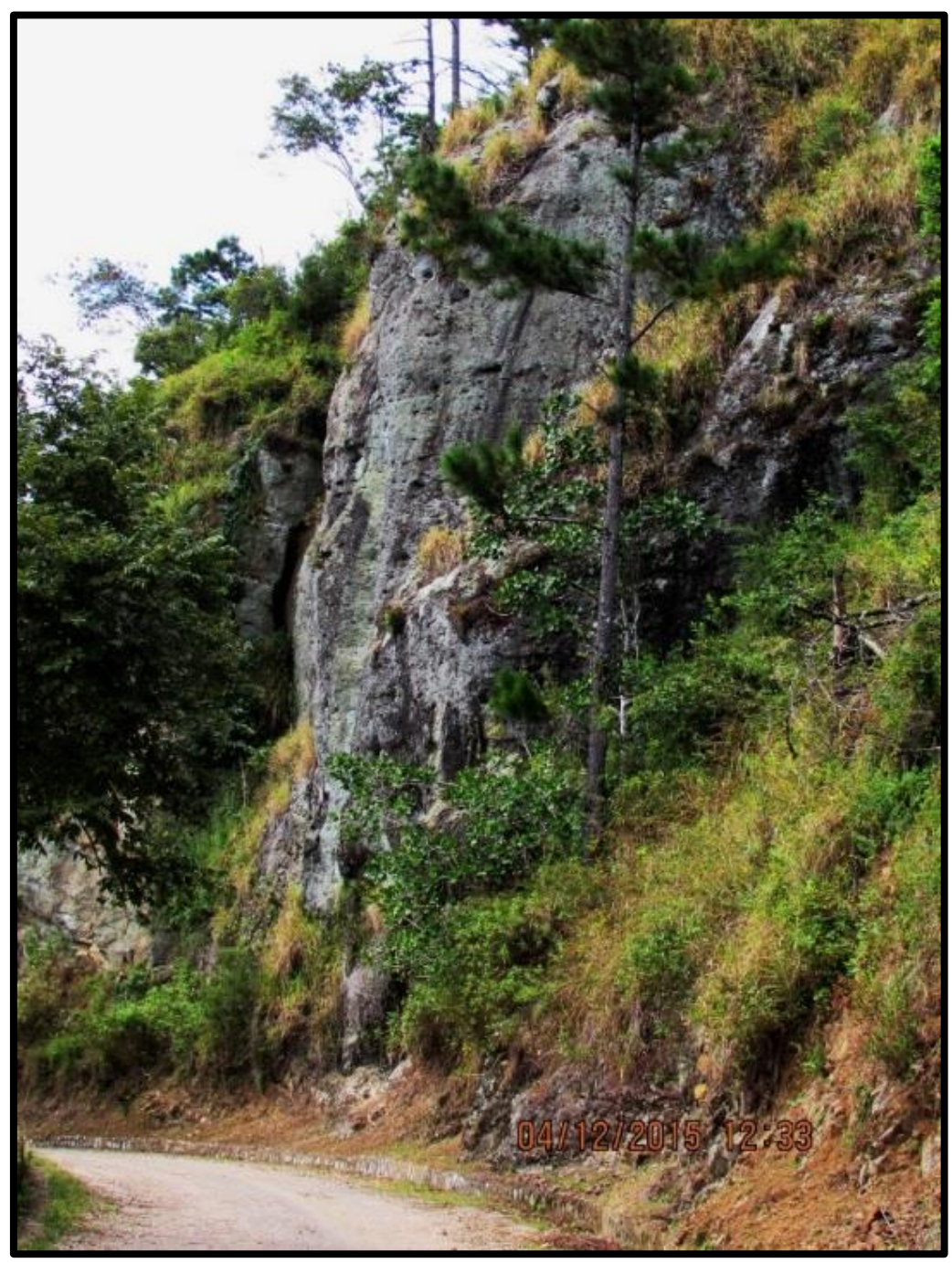

Figura 3.5 - Presença de rocha vulcânica basálticas na região da "Gran Piedra" pertencente à formação "El Cobre”. Trabalho de campo, dezembro 2014.

- Sistema Quaternário. Formação Jaimanitas, idade Pleistoceno Superior. Calcário biodetríticos masivos, geralmente carsificados, com presença de fósseis, contendo principalmente conchas bem preservadas e corais de espécies já existentes. Os sacos cársicos são preenchidos por uma fina mistura carbonatoargilosa ferruginosa cor de tijolo. Passam para calcarenitas massivas ou finamente estratificadas e, por vezes, contêm intercalações de margas (Fig. 3.7).

- Formação Río Macío. A formação estende-se no leito e nas beiras dos rios e nas bocas dos mesmos, em diferentes áreas do território da ilha. Esta formação consiste em blocos, pedregulhos, areias e argilas, derivadas da erosão do rio e regional; a estratificação é geralmente cruzada e lenticular, típica dos terraços e do transporte fluvial. 


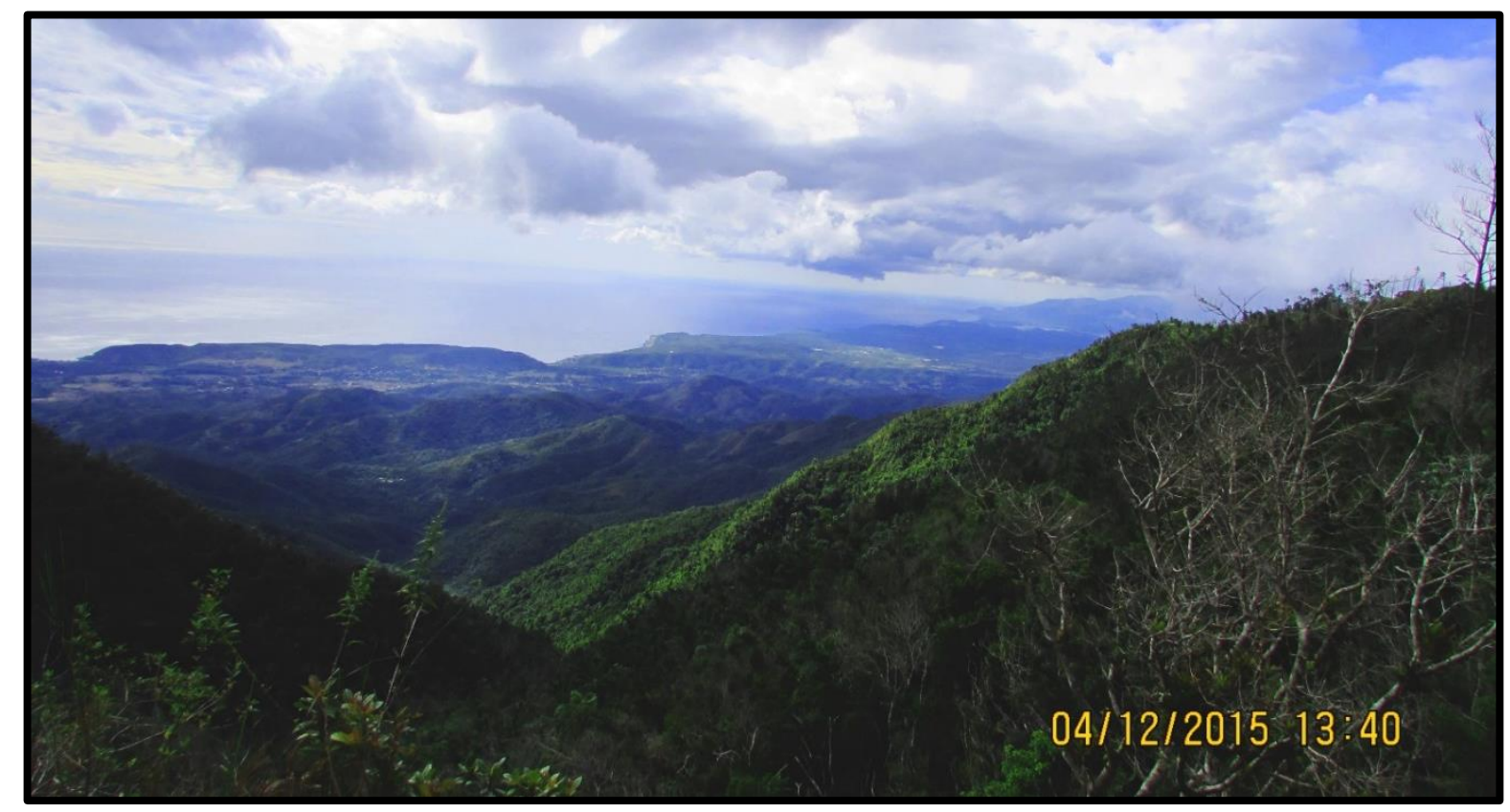

Figura 3.6 - Imagem onde são observadas as elevações formadas pelo Grupo "El Cobre", na região da "Gran Piedra", na direção sul.

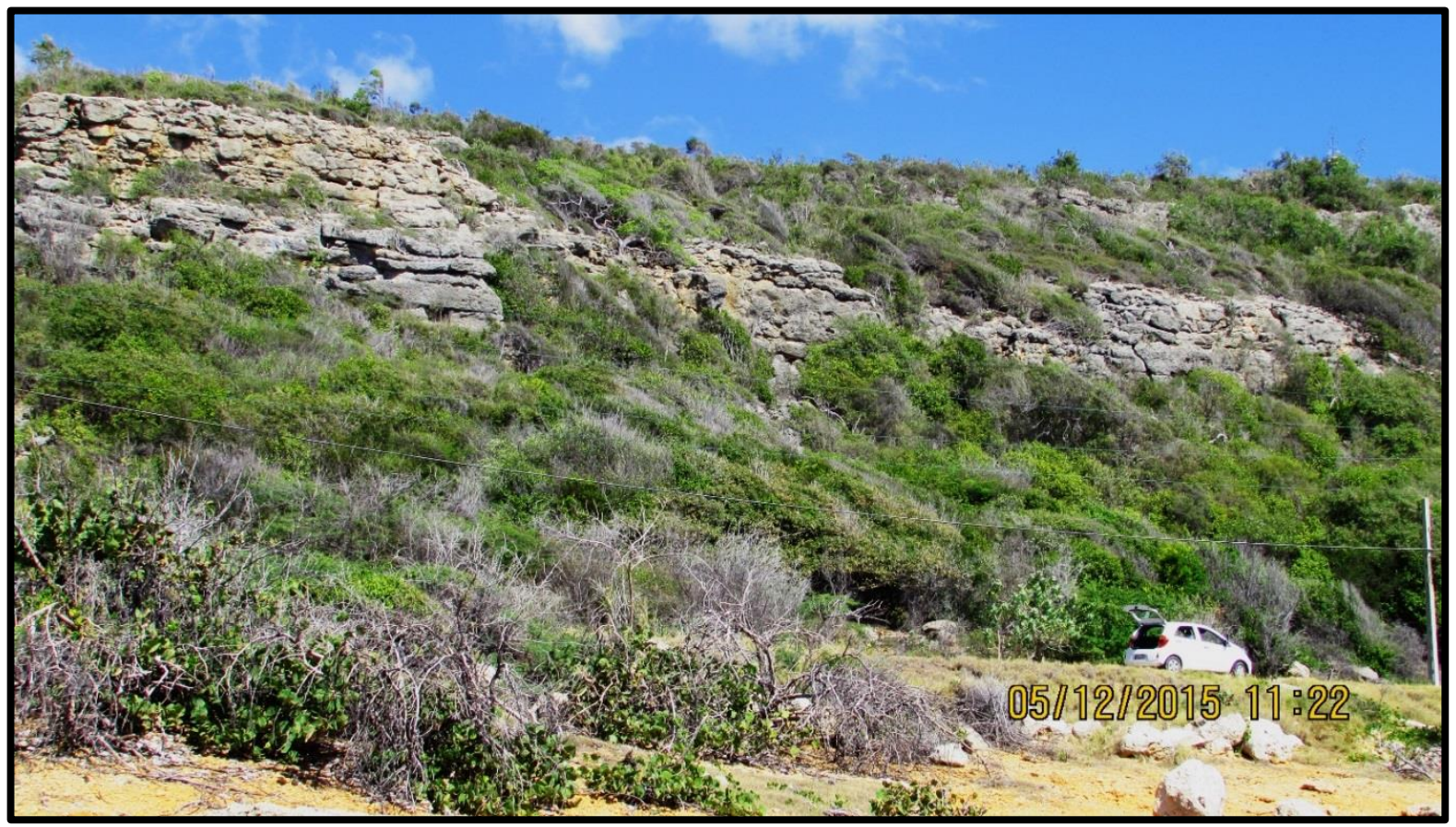

Figura 3.7 - Presença de rocha calcária na linha costeira, na região da "Gran Piedra", pertencente à formação “Jaimanita”. Trabalho de campo, dezembro 2014. 


\subsection{Caraterísticas dos solos.}

Segundo um informe sobre estudos de ameaça, vulnerabilidade e risco aos deslizamentos de terra na província Santiago de Cuba, realizado pelo Centro Nacional de Investigações Sismológicas, (Villalón et al., 2012), no território da província de Santiago de Cuba, a área montanhosa ocupa $66,51 \%$, enquanto as planícies abrangem apenas $33,49 \%$.

Os tipos de solos existentes nestas zonas montanhosas podem ser classificados em:

- Marrom sem carbonato. Eles são a variedade mais abundantes, espalhados em grande parte da Cordilheira da "Sierra Maestra".

- Fersialítico vermelho acastanhado ferromagnesial. Este tipo de solo não está presente com a mesma extensão que o anterior, mas frequentemente aparecem ligados a eles.

- Ferralíticos vermelhos e amarelos lixiviados. Eles ocupam a parte superior da Cordilheira da "Sierra Maestra", sua extensão territorial pode ser classificada em baixa a média.

- Roxo ferrítico. Este solo encontra-se esporadicamente nas zonas mais altas da Cordilheira da "Sierra Maestra".

- Pouco desenvolvido ou esquelético. São solos que carecem de horizontes pedológicos, não possuem camadas de solos, apresentam abundantes pedras, cascalho e afloramentos rochosos. Em quase todos os munícipios da província estão presentes em proporção média, eles são produto da ação erosiva e má gestão do homem durante sua exploração.

Os solos de tipo roxo ferralítico, os ferralíticos vermelhos e os ferralíticos amarelos lixiviados são os mais susceptíveis aos rastreamentos, devido ao tipo de textura que possuem, composta por grande teor de areias, barro, bolhas de ferro e baixo nível de argila. No caso dos roxo ferrítico e dos ferralíticos vermelhos, a composição de sua textura é barro, argila e um nível de areia.

Nos solos de tipo fersialítico, marrom sem carbonato e marrom com carbonato, a composição de sua textura é argila e barro, com predominância de argila. Por isso, 
eles oferecem uma maior resistência ao impacto das chuvas e ao arrasto causado pelo escoamento superficial a causa das chuvas.

Estes tipos de solos nas montanhas são mais frágeis, uma vez que aparecem fatores limitantes como a textura, inclinação e a erosão, que os tornam vulneráveis à ação das chuvas, gerando deslizamentos dos solos para as áreas mais baixas, causando danos.

\subsection{Sismicidade.}

Esta área é caracterizada por uma grande atividade sísmica (Fig. 3.8) como consequência de sua proximidade à estrutura geológica Bartlett - Cayman, fronteira entre as placas do Caribe e a América do Norte, onde têm sido reportados 28 sismos fortes, deles 20 na província Santiago de Cuba (Tab. 3.1) (Chuy, 1999).

Esta estrutura sismogeradora é capaz de produzir terremotos de até 8,0 graus de magnitude Richter (Chuy \& Despaine, 2001), Atlas de Ameaças Naturais do Município Guamá).

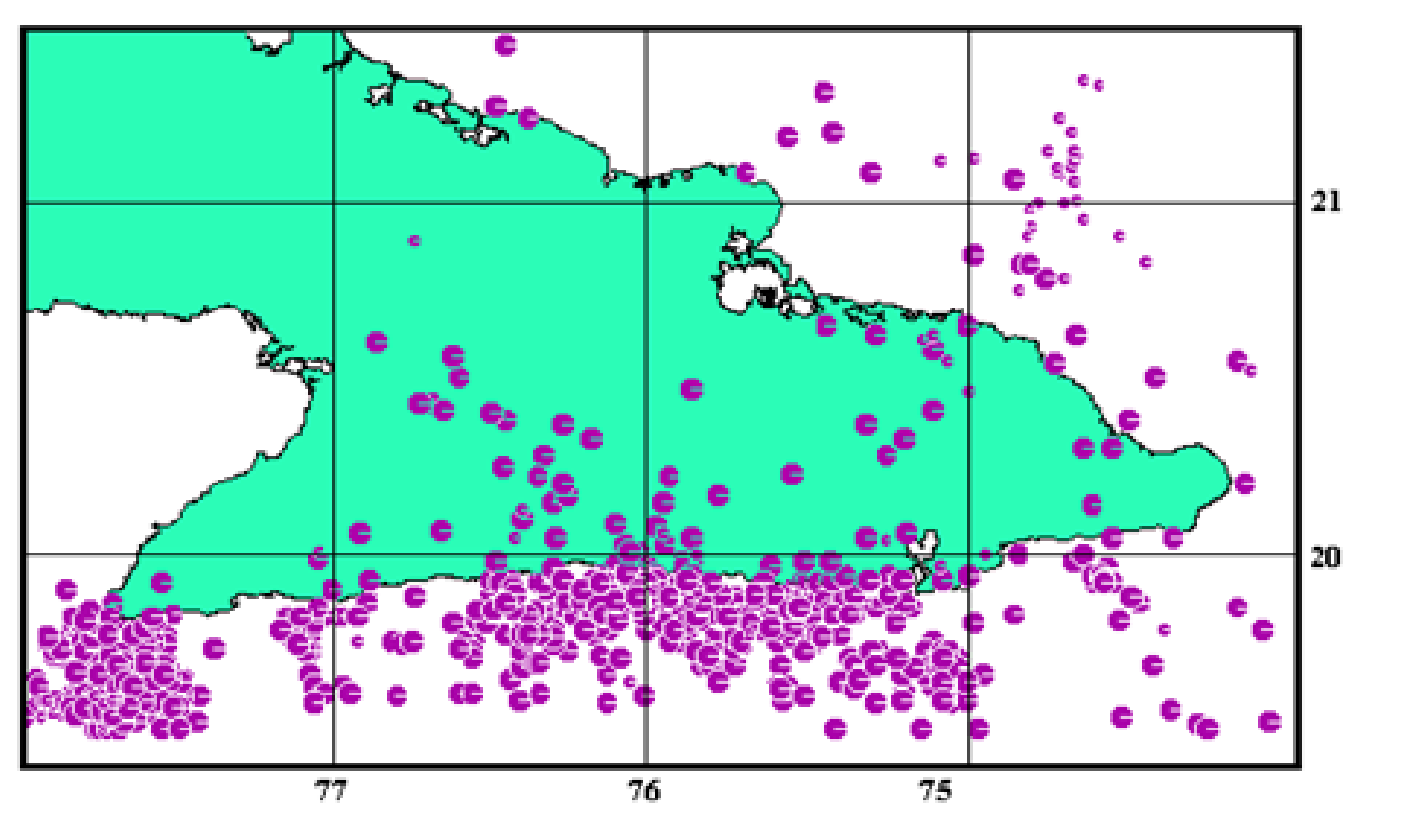

Figura 3.8 - Mapa de Epicentros de Terremotos com Magnitude $M>3.0$ Richter no período 1968 - 1999. (Chuy \& Despaigne, 2001) Atlas de Ameaças Naturais do Guamá. 
Tabela 3.1 - Registro histórico dos sismos mais fortes registrados pelo Centro Nacional de Investigações Sismológicas de Cuba, CENAIS.

\begin{tabular}{|c|c|c|c|c|c|c|}
\hline Ano & $\begin{array}{l}\text { Latitude } \\
\mathrm{N}\end{array}$ & $\begin{array}{c}\text { Longitude } \\
\text { W }\end{array}$ & \begin{tabular}{|c} 
Magnitude \\
Ms
\end{tabular} & \begin{tabular}{|c}
$\begin{array}{c}\text { Profundidade } \\
(\mathrm{km})\end{array}$ \\
\end{tabular} & $\begin{array}{c}\text { Intensidade } \\
\text { (MSK) }\end{array}$ & Localidade \\
\hline $18 / 10 / 1551$ & 20.4 & 76.6 & 5.8 & 15 & 8 & Bayamo \\
\hline$\_/ 8 / 1578$ & 19.9 & 76 & 6.8 & 30 & 8 & $\begin{array}{l}\text { Santiago } \\
\text { de Cuba }\end{array}$ \\
\hline I/1580 & 19.9 & 76 & 5.8 & 30 & 7 & $\begin{array}{l}\text { Santiago } \\
\text { de Cuba }\end{array}$ \\
\hline _/10/1624 & 20.4 & 76 & 5.2 & 15 & 7 & Bayamo \\
\hline $11 / 2 / 1675$ & 19.9 & 76 & 5.8 & 30 & 7 & $\begin{array}{l}\text { Santiago } \\
\text { de Cuba }\end{array}$ \\
\hline $11 / 2 / 1678$ & 19.9 & 76 & 6.8 & 30 & 8 & $\begin{array}{l}\text { Santiago } \\
\text { de Cuba }\end{array}$ \\
\hline I_/1682 & 19.9 & 76 & 5.8 & 30 & 7 & $\begin{array}{l}\text { Santiago } \\
\text { de Cuba }\end{array}$ \\
\hline _/10/1752 & 19.9 & 76 & 5.8 & 30 & 7 & $\begin{array}{l}\text { Santiago } \\
\text { de Cuba }\end{array}$ \\
\hline $11 / 7 / 1760$ & 19.9 & 76 & 6.8 & 30 & 8 & $\begin{array}{l}\text { Santiago } \\
\text { de Cuba }\end{array}$ \\
\hline 12/6/1766 & 19.8 & 76.1 & 7.6 & 35 & 9 & $\begin{array}{l}\text { Santiago } \\
\text { de Cuba }\end{array}$ \\
\hline $11 / 2 / 1775$ & 19.9 & 76 & 5.8 & 30 & 7 & $\begin{array}{l}\text { Santiago } \\
\text { de Cuba }\end{array}$ \\
\hline $18 / 9 / 1826$ & 19.9 & 76 & 5.8 & 30 & 7 & $\begin{array}{l}\text { Santiago } \\
\text { de Cuba }\end{array}$ \\
\hline 7/7/1842 & 19.9 & 76 & 6 & 30 & 7 & $\begin{array}{l}\text { Santiago } \\
\text { de Cuba }\end{array}$ \\
\hline 20/8/1852 & 19.77 & 75.35 & 7.3 & 30 & 9 & $\begin{array}{l}\text { Santiago } \\
\text { de Cuba }\end{array}$ \\
\hline $26 / 11 / 1852$ & 19.5 & 76.25 & 7 & 35 & 8 & $\begin{array}{l}\text { Santiago } \\
\text { de Cuba }\end{array}$ \\
\hline $28 / 1 / 1858$ & 19.9 & 76 & 6.5 & 30 & 7 & $\begin{array}{l}\text { Santiago } \\
\text { de Cuba }\end{array}$ \\
\hline 23/1/1880 & 22.7 & 83 & 6 & 15 & 8 & $\begin{array}{c}\text { San } \\
\text { Cristóbal }\end{array}$ \\
\hline 22/9/1903 & 19.9 & 76 & 5.7 & 30 & 7 & $\begin{array}{l}\text { Santiago } \\
\text { de Cuba }\end{array}$ \\
\hline 22/6/1906 & 19.65 & 76.25 & 6.2 & 30 & 7 & $\begin{array}{l}\text { Santiago } \\
\text { de Cuba }\end{array}$ \\
\hline 28/2/1914 & 21.22 & 76.17 & 6.2 & 32 & 7 & Gibara \\
\hline $25 / 12 / 1914$ & 19.45 & 76.3 & 6.7 & 30 & 7 & $\begin{array}{l}\text { Santiago } \\
\text { de Cuba }\end{array}$ \\
\hline
\end{tabular}




\begin{tabular}{|c|c|c|c|c|c|c|}
\hline Ano & $\begin{array}{c}\text { Latitude } \\
\mathrm{N}\end{array}$ & $\begin{array}{c}\text { Longitude } \\
\text { W }\end{array}$ & $\begin{array}{c}\text { Magnitude } \\
\text { Ms }\end{array}$ & $\begin{array}{c}\text { Profundidade } \\
(\mathrm{km})\end{array}$ & $\begin{array}{c}\text { Intensidade } \\
(\mathrm{MSK})\end{array}$ & Localidade \\
\hline $3 / 8 / 1926$ & 20.3 & 77.1 & 5.4 & 15 & 7 & Manzanillo \\
\hline $17 / 1 / 1930$ & 19.9 & 76 & 5.8 & 25 & 7 & $\begin{array}{c}\text { Santiago } \\
\text { de Cuba }\end{array}$ \\
\hline $3 / 2 / 1932$ & 19.8 & 75.8 & 6.75 & - & 8 & $\begin{array}{c}\text { Santiago } \\
\text { de Cuba }\end{array}$ \\
\hline $15 / 8 / 1939$ & 22.5 & 79.25 & 5.6 & - & 7 & $\begin{array}{c}\text { Remedios- } \\
\text { Caibarien }\end{array}$ \\
\hline $7 / 8 / 1947$ & 19.9 & 75.3 & 6.75 & 50 & 7 & $\begin{array}{c}\text { Santiago } \\
\text { de Cuba }\end{array}$ \\
\hline $19 / 2 / 1976$ & 19.87 & 76.87 & 5.7 & 15 & 8 & Pilon \\
\hline $25 / 5 / 1992$ & 19.62 & 77.7 & 7 & 30 & 7 & Cabo cruz \\
\hline
\end{tabular}

Desde o ano 1514, que foi inaugurada a província Santiago de Cuba, até o ano 1999, dos 961 sismos perceptíveis no país, 537 foram perceptíveis na província de Santiago de Cuba (Chuy, 1999).

Segundo Villalón et al. (2012), são poucos os registros de deslizamentos de terra relacionados com a ocorrência de sismos. Este é o caso dos sismos ocorridos no dia 20 de agosto de 1852 na Serra da "Gran Piedra" (Chuy, 1999), um outro em 1947 na "Loma del Cake" (Zapata, 1995), cidade de Santiago de Cuba e o terremoto de Pilón de 19 de fevereiro de 1976 na "Sierra Maestra" (Reyes \& Seisdedos, 2001) (Fig. 3.9).

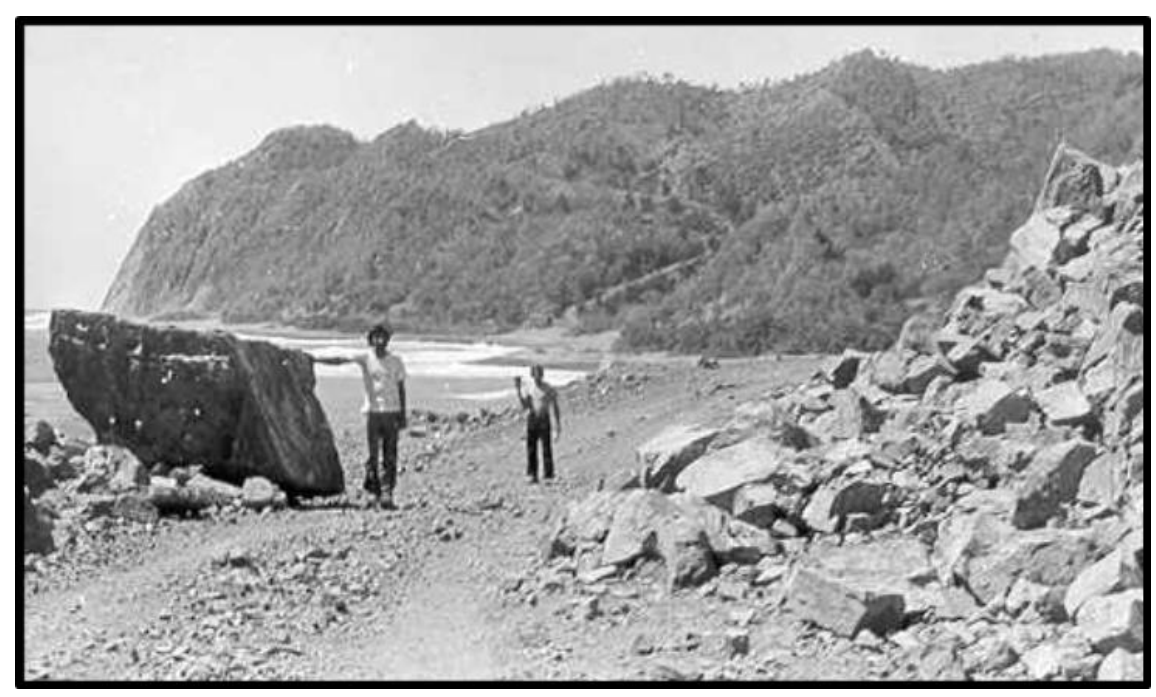

Figura 3.9 - Desprendimentos de rochas produzidos pelo sismo de "Pilón" no dia 19 de fevereiro de 1976. Chuy \& Despaigne, (2001) Atlas de Ameaças Naturais do Guamá. 


\section{Capitulo 4: Metodologia de Análise}

\subsection{Introdução}

A ocorrência de eventos de fluxo de detritos em áreas vulneráveis poderá causar um risco elevado de caráter natural. Em algumas áreas, as condições morfológicas, climáticas e geológicas que conduzem à formação de fluxos de detritos são bastante generalizadas e, nestes casos, as reduções de risco através de soluções de engenharia podem tornar-se caras ou, em alguns casos, as características topográficas da área de estudo fazem impossível a sua execução. Por estas razões, em alguns casos, para reduzir o risco, é necessária a aplicação de contramedidas não-estruturais, tais como alertas por avaliações de risco em tempo real (Papa et al., 2011, 2013).

A abordagem mais comum na literatura para avaliar a ameaça de fluxo de detritos em tempo real é baseada no uso de limiares de precipitação derivadas empiricamente a partir de observações de eventos passados (Wieczorek \& Glade, 2005). González Diez et al., (2005) sugere que a quantidade de chuva infiltrada necessária para o fluxo de detritos varia de uma encosta para outra. Sendo assim, o estabelecimento dos limiares de precipitação em grandes áreas depende mais da homogeneidade das encostas do que das chuvas. Outra desvantagem dos limiares empiricamente derivados é não preverem como é que as ameaças por fluxos de detritos podem mudar com as alterações climáticas.

Segundo Papa et al. (2011), para superar essas limitações, é preciso usar sistemas de alerta de fluxos de detritos através de modelos que refletem o fenômeno físico. Esses sistemas devem oferecer uma ligação entre a chuva e as possíveis ameaças por fluxos de detritos e devem ser baseados em regras simples, a fim de serem os suficientemente rápidos para tornar possíveis aplicações em tempo real. Os modelos teóricos de chuva que causam fluxos de detritos são baseados na análise de estabilidade de talude infinito em que a instabilidade do terreno é regido pelo aumento de pressão das águas subterrâneas, devido às precipitações. Estes modelos são geralmente aplicados em cada célula da área, onde o fator de segurança é calculado. A aplicação destes modelos requer de uma caracterização espacial precisa 
de distribuição das propriedades do solo, o que não está disponível em muitas aplicações práticas.

No ano 2000, Iverson propôs um modelo simplificado representando as condições transitórias de fluxo de água subterrânea.

Comparações de marcas observadas em áreas de formação de fluxo de detritos (Godt et al, 2008) mostram que a contribuição dos efeitos transitórios de chuva infiltrada na pressão dos poros e os efeitos resultantes sobre a estabilidade de taludes, melhora a eficácia de mapas de risco de deslizamentos rasos na região.

O trabalho apresentado por Papa et al. (2011) fundamenta-se na simulação de um grande número de casos que cobrem todo o leque de variáveis ligadas à precipitação, (intensidade e duração). Tendo em conta as várias possibilidades de combinação entre elas, são obtidos resultados para cada combinação possível de intensidade e duração da chuva.

A base de dados resultante é feita para obter curvas de limiares de chuva. Ao operar em tempo real, se a precipitação observada e esperada ultrapassa um determinado limiar, é possível calcular a probabilidade de ocorrência de fluxos de detritos. Esta capacidade no uso do modelo vai ser explicitada mais detalhadamente adiante

\subsection{Modelo de previsão de iniciação de fluxo de detritos}

O foco principal deste modelo proposto por Papa et al. (2011) é baseado na criação de um sistema capaz de alertar acerca da ocorrência de fluxos de detritos através da simulação de precipitações que podem atuar como agente deflagrador, resultados diferentes são obtidos dependendo das chuvas.

O modelo avalia a possível instabilidade do terreno de forma extremamente rápida, usando poucas características do solo. Isso faz com que a metodologia de simulação selecionada pelos autores seja extremamente simplificada, exigindo um curto período de tempo utilizado no processamento computacional e um conjunto limitado de insumos básicos.

Esse conjunto de recursos é uma das principais razões pelas que esse modelo será usado no desenvolvimento desta pesquisa. 
A ativação de fluxos de detritos pode ser simulada em uma bacia genérica através de uma análise de estabilidade de taludes infinita para se obter o fator de segurança $(\mathbf{F S})$ para qualquer profundidade do solo $(\mathbf{Z})$, a qualquer momento $(\mathbf{t})$. $O$ cálculo do FS é dado pela Eq. 4.1. (Iverson, 2000; Taylor, 1948) citados por Papa et al. (2011).

A Fig. 4.1 mostra de forma simplificada a hipótese de talude infinito, onde $\mathbf{Z}$ é a profundidade até a linha de falha medido verticalmente, $\mathbf{d}$ é a profundidade até $\mathrm{o}$ lençol freático medido verticalmente, $\alpha$ é a declividade do talude, e o sistema de coordenadas representado por $\mathbf{z} \mathbf{z}$, onde as coordenadas $\mathbf{x}$ são paralelas a inclinação do talude e as coordenadas $\mathbf{z}$ na direção normal a este.

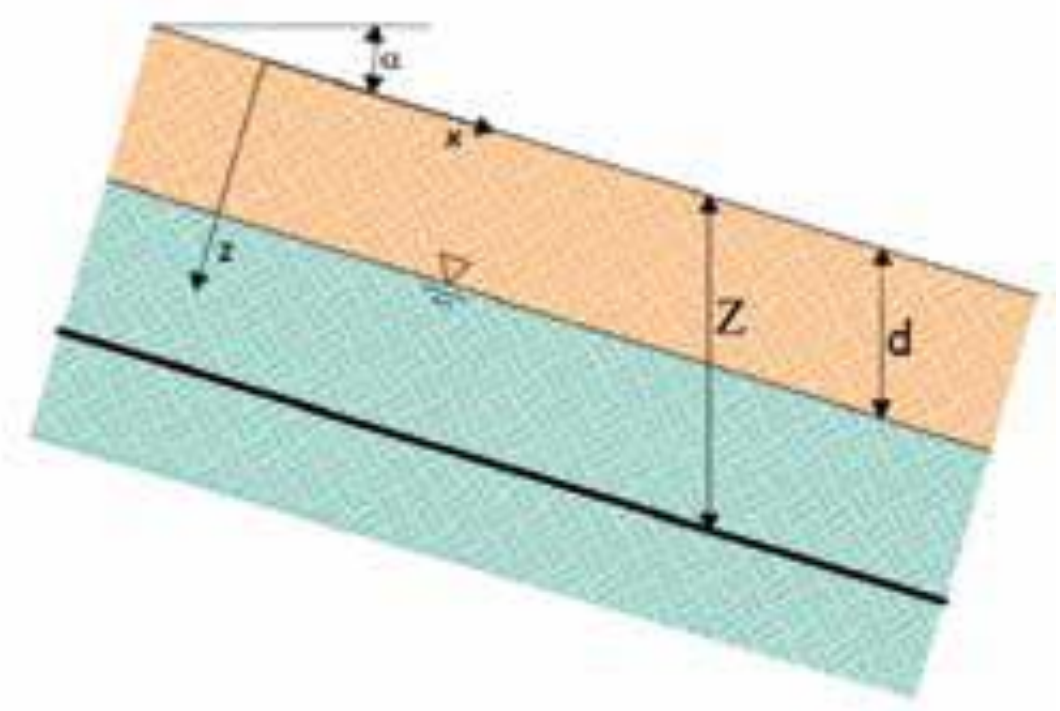

Figura 4.1 - Esquema do modelo de estabilidade de taludes (Papa et al., 2011)

$$
\mathrm{FS}(\mathrm{Z}, \mathrm{t})=\frac{\tan \varphi}{\tan \alpha}+\frac{\mathrm{c}-\psi(\mathrm{Z}, \mathrm{t}) \cdot \gamma_{\mathrm{w}} \cdot \tan \varphi}{\gamma_{\mathrm{s}} \cdot \mathrm{Z} \cdot \sin \alpha \cdot \cos \alpha}
$$

Na equação 4.1, $\alpha$ é a inclinação do talude, c refere-se à coesão do solo, $\mathbf{Z}$ é a coordenada vertical orientada positivamente para baixo, $\varphi$ relaciona-se com o ângulo de atrito interno, $\gamma_{s}$ é o peso específico do solo, $\gamma_{w}$ corresponde ao peso específico da água e é igual a $9,8 \mathrm{kN} / \mathrm{m}^{3}$, e $\boldsymbol{\Psi}(\mathbf{Z}, \mathbf{t})$ é carga hidráulica total, sendo esta dependente da profundidade e do tempo. Quando alcançado o valor crítico do FS (neste caso $F S=1$ ), o solo na profundidade $\mathbf{Z}$ é considerado instável.

Papa et al. (2011) citam trabalhos em que houve a observação de muitos episódios de escorregamentos detonados pela ação de um longo período de precipitação com baixa intensidade, seguido por um curto limite de tempo com 
intensas chuvas. Tomando-se este fato como referência, a determinação da carga hidráulica total $\boldsymbol{\Psi}(\mathbf{Z}, \mathbf{t})$, considerada como desencadeadora do processo, é realizada pela sobreposição dos efeitos da chuva com menor intensidade, considerada como antecedente, e o evento pluviométrico mais concentrado, de forma que a condição inicial empregada para o cálculo da carga hidráulica total final, devido ao evento intenso de chuva, é aquela resultante da precipitação antecedente.

Considerando o estabelecimento do estado estacionário e assumindo que a direção do fluxo subterrâneo seja paralela ao talude, caso a precipitação antecedente tenha intensidade suficientemente baixa e de longa duração, aplica-se a Eq. 4.2 para a obtenção da carga hidráulica concernente à água subterrânea:

$$
\psi(Z, 0)=(Z-d) \cdot(\cos \alpha)^{2}
$$

Onde $\mathbf{d}$ refere-se à profundidade do lençol freático, medida na direção de $\mathbf{Z ~ e}$ em condições estacionárias. A Eq. 4.3 de conservação de massa em relação à água subterrânea, conforme Montgomery \& Dietrich (1994) citado por Papa et al. (2011), fornece:

$$
\mathrm{Z}_{\mathrm{T}}-\mathrm{d}=\frac{\left(\mathrm{I}_{\mathrm{z}}\right)_{\text {estacionáio }}}{\mathrm{K}_{\mathrm{x}}} \cdot \frac{\mathrm{A}}{\mathrm{b} \cdot \sin \alpha \cdot \cos \alpha}
$$

Na expressão acima, $\mathbf{Z}_{\mathrm{T}}$ é a profundidade da camada impermeável, $\left(\mathbf{I}_{\mathbf{Z}}\right)_{\text {estacionário }}$ é a taxa de infiltração na superfície do solo em condições estacionárias e na direção normal ao talude, que pode ser considerada como a chuva antecedente; $\mathbf{K}_{\mathbf{x}}$ corresponde à condutividade hidráulica na direção paralela ao talude; $\mathbf{A}$ é a bacia drenada, área geografia que faz a drenagem da água das precipitações até o ponto analisado, e b relaciona-se com a largura do elemento da encosta ao longo da direção tangente ao contorno topográfico local.

Papa et al. (2011) optaram por adotar o enfoque oferecido por Iverson, (2000), que propõe uma resolução analítica da equação de Richards voltada para o cálculo da carga hidráulica, resultante do período curto de precipitação.

Tomando-se as hipóteses de infiltração vertical, as condições iniciais de umidade, bem como as condições de contorno definidas por um fluxo vertical 
subterrâneo nulo para grandes profundidades abaixo do nível freático e a entrada de água na superfície do solo regida pela lei de Darcy, a Eq. 4.4 traz a solução indicada:

$\psi(Z, T)=\psi(Z, 0)+Z \cdot \frac{I_{z}}{K_{z}} \cdot\left[R\left(T^{*}\right)\right]$

Em que $\boldsymbol{\Psi}(\mathbf{Z}, \mathbf{0})$ corresponde à carga hidráulica no início do evento pluviométrico intenso; l z é a taxa de infiltração na superfície do solo, em uma direção normal ao talude, relacionando-se com a intensidade da precipitação que deflagra os eventos de corridas de detritos; $\mathbf{K}_{\mathbf{z}}$ refere-se a condutividade hidráulica em relação à direção normal da encosta e a parcela $\mathbf{R}\left(\mathbf{T}^{\star}\right)$ é expressa pela Eq. 4.5 da seguinte forma:

$$
R\left(T^{*}\right)=\sqrt{\frac{T^{*}}{\pi}} \exp \left(\frac{-1}{T^{*}}\right)-\operatorname{erfc}\left(\frac{1}{\sqrt{T^{*}}}\right)
$$

Onde erfc representa a função de erro complementar, assim definida na Eq. 4.6:

$$
\operatorname{erfc}(x)=\frac{2}{\sqrt{\pi}} \int_{x}^{\infty} e^{-t^{2}} d t
$$

O termo $\mathrm{T}^{*}$ é dado pela Eq. 4.7:

$$
\mathrm{T}^{*}=\frac{\mathrm{T}}{\left[\frac{\mathrm{Z}^{2}}{4 \cdot \mathrm{D}_{0}(\cos \alpha)^{2}}\right]}
$$

Em que $\mathbf{T}$ se relaciona com a duração do evento de chuva e $\boldsymbol{D}_{0}$ é a difusividade máxima característica, que governa a transmissão da carga hidráulica quando o solo está próximo da saturação, com a possibilidade de assumir valores positivos, dependendo da proximidade em relação à saturação completa. Apoiando-se nesta fundamentação, Papa et al. (2011) utilizaram a razão $\mathbf{D}_{0} / \mathbf{K}_{\mathbf{z}}$ como parâmetro de calibração.

Papa et al. (2011) realizaram, ainda, uma divisão das variáveis de entrada em duas classes principais, categorizando-as em estáticas e dinâmicas. Na Tab. 4.1, encontram-se relacionada à listagem das variáveis, sua classe e as unidades em que devem ser incorporadas ao sistema de risco. Promoveu-se a implementação do modelo matemático descrito anteriormente, no sentido de avaliar possíveis instabilidades presentes em elementos de uma determinada bacia com certas características e sujeitos a uma dada chuva. 
Tabela 4.1 - Variáveis dinâmicas e estáticas (modificado - Papa et al., 2011).

\begin{tabular}{|c|c|c|c|c|}
\hline Classificação & No & Variável & Unidade & Descrição \\
\hline \multirow{3}{*}{ Dinâmica } & 1 & T & hora & Duração do evento de chuva \\
\hline & 2 & $I_{z}$ & $\mathrm{~mm} / \mathrm{h}$ & $\begin{array}{l}\text { Taxa de infiltração da chuva na } \\
\text { superfície do terreno, na direção } \\
\text { normal do talude }\end{array}$ \\
\hline & 3 & $\left(I_{z}\right)$ estacionário & $\mathrm{mm} / \mathrm{mês}$ & $\begin{array}{l}\text { Taxa de infiltração da chuva } \\
\text { antecedente na superfície do } \\
\text { terreno, na direção normal do talude }\end{array}$ \\
\hline \multirow{9}{*}{ Estática } & 4 & $A / b$ & $\mathrm{~m}$ & $\begin{array}{l}\text { Razão entre a bacia drenada e a } \\
\text { largura do elemento do talude ao } \\
\text { longo da direção tangente ao } \\
\text { contorno topográfico local }\end{array}$ \\
\hline & 5 & $Z_{T}$ & $\mathrm{~m}$ & $\begin{array}{l}\text { Profundidade total disponível do } \\
\text { solo - profundidade da camada } \\
\text { rígida impermeável }\end{array}$ \\
\hline & 6 & $\gamma_{\mathbf{s}}$ & $\mathrm{kN} / \mathrm{m}^{3}$ & Peso volumétrico do solo \\
\hline & 7 & $\varphi$ & $\begin{array}{c}\text { Graus } \\
(\stackrel{\circ}{*})\end{array}$ & Ângulo de atrito interno \\
\hline & 8 & c & $\mathrm{kPa}$ & Coesão do solo \\
\hline & 9 & $\alpha$ & 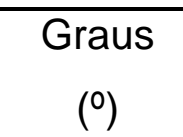 & Declividade do talude \\
\hline & 10 & $\mathrm{~K}_{\mathrm{x}}$ & $\mathrm{mm} / \mathrm{s}$ & $\begin{array}{l}\text { Condutividade hidráulica na direção } \\
\text { paralela ao talude }\end{array}$ \\
\hline & 11 & $\mathrm{~K}_{\mathrm{z}}$ & $\mathrm{mm} / \mathrm{s}$ & $\begin{array}{l}\text { Condutividade hidráulica na direção } \\
\text { na direção normal ao talude }\end{array}$ \\
\hline & 12 & $D_{0}$ & $\mathrm{~m}^{2} / \mathrm{s}$ & $\begin{array}{l}\text { Difusividade máxima característica } \\
\text { que governa a transmissão da carga } \\
\text { hidráulica quando o solo está } \\
\text { próximo da saturação }\end{array}$ \\
\hline
\end{tabular}


A proposta original montada por Papa et al. (2011) contempla apenas uma quantidade determinada de elementos computacionais, que devem ser incorporados ao modelo e que sejam capazes de representar o comportamento completo da bacia analisada. Segundo os autores, torna-se impraticável a análise de estabilidade para todas as células que compõem a bacia, em virtude do tempo dispensado pelo modelo e da necessidade de informações detalhadas sobre as propriedades dos materiais envolvidos.

A organização para os dados de entrada é caracterizada, então, em uma matriz de variáveis estáticas que representam a bacia analisada. O procedimento para a estruturação desta matriz corresponde à divisão da bacia em distritos, homogêneos do ponto de vista dos atributos geomorfológicos, possuindo, portanto, os mesmos valores para o conjunto de variáveis do solo: $\mathbf{Z}_{\mathbf{T}}, \gamma_{\mathbf{s}}, \boldsymbol{\varphi}, \mathbf{c}, \mathbf{K}_{\mathbf{x}}$ e $\mathbf{K}_{\mathbf{z}}$. A difusividade máxima característica $D_{0}$ tem a possibilidade de assumir um valor positivo dependendo da proximidade em relação à saturação completa, de forma que, baseando-se nesta consideração, $\mathbf{D}_{\mathbf{0}} / \mathbf{K}_{\mathbf{z}}$ pode ser usado como um parâmetro de calibração.

As variáveis topográficas $\boldsymbol{\alpha}$ e $\mathbf{A} / \mathbf{b}$ são derivadas para cada célula pertencente à região estudada a partir da aplicação ao modelo numérico de terreno, de ferramentas incorporadas ao SIG, sendo que seus valores são atribuídos a cada distrito obedecendo à distribuição dos valores da bacia real.

Papa et al. (2011) definem também que a quantidade $\mathbf{n}$ de elementos a serem aplicados às análises pode ser estabelecida como um parâmetro de entrada, atuando diretamente tanto no tempo de processamento quanto na representatividade da matriz de entrada.

Para as variáveis de entrada dinâmicas $\mathbf{T}, \mathbf{l} \mathbf{z}$ e lz estacionário, deve-se estabelecer os limites inferior e superior do intervalo de valores possíveis, assim como a quantidade total de valores para uma dada variável específica, $\mathbf{m}_{\mathbf{i}}$, com $\mathbf{i}$ assumindo os valores 1,2 e 3 .

Procede-se a simulação para cada linha da matriz de input estática, que representa um distrito homogêneo, em conjunto com cada combinação para as 
variáveis de entradas dinâmicas, de forma que o número total de simulações executadas $(\mathbf{N})$ pode ser representado por:

$$
\mathrm{N}=\mathrm{n} \cdot \prod_{\mathrm{i}=1}^{3} \mathrm{~m}_{\mathrm{i}}
$$

A saída de dados fornecida a cada simulação, corresponde ao número de elementos instáveis e ao volume correspondente de detritos. A partir dos dados gerados, por interpolação simples, é possível estabelecer, em relação a cada valor

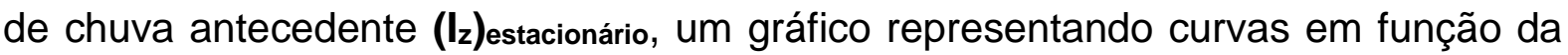
intensidade e duração das chuvas que reproduzem um valor fixo de percentagem de células instáveis ou um valor fixo de volume total de detritos.

\subsection{Dados requeridos para implementar o modelo}

Para a implementação da metodologia proposta por Papa et al. (2011) na área de estudo, foi usado o programa Excel 2013, acoplado com ArcGIS 10.1 e os dados de entrada requeridos são citados de seguida:

- Matriz representativa da área de estudo, trazendo as informações dos distritos homogêneos sob a forma de numeração sequenciada, onde cada número se refere a um conjunto de valores de variáveis estáticas que definem cada distrito homogêneo.

- Grade de declividade dos taludes a para todas as células da bacia analisada (em graus), derivada a partir do modelo numérico de terreno.

- Grade numérica portando os valores para a relação $\mathbf{A} / \mathbf{b}$. O procedimento para atingir esta matriz é composto incialmente pela geração da grade de fluxo acumulado, representada por $\mathbf{A}$. Esta pode ser obtida através dos recursos específicos voltados para processos hidrológicos, que se encontram disponíveis em sistemas de informação geográfica. Uma vez definida esta matriz, ao dividi-la pela dimensão do pixel utilizado b, esta operação irá fornecer o dado em questão.

- Valores das variáveis estáticas para cada distrito homogêneo do ponto de vista das características do solo: $\mathbf{Z}_{\mathbf{T}}, \gamma_{\mathbf{s}}, \boldsymbol{\varphi}, \mathbf{c}, \mathbf{K}_{\mathbf{x}}, \mathbf{K}_{\mathbf{z}}, \mathbf{D}_{\mathbf{0}}$.

- Matriz representativa da área de estudo trazendo as informações da $\mathbf{I}_{\mathbf{z}}$, taxa de infiltração na superfície do solo, representativa do evento de precipitações de corta duração e de grande intensidade.

- Valores das variáveis dinâmicas $\mathbf{T}$ e $\mathbf{I}_{\mathbf{z}}$ estacionário. 


\subsection{Calibração do modelo.}

A calibração do modelo foi feita na área da "Gran Piedra", Fig. 4.2. Para isso é preciso ter um inventário de escorregamentos. Para efeitos desta pesquisa, foi realizado um trabalho de campo e um processamento de imagens de voos aéreos.

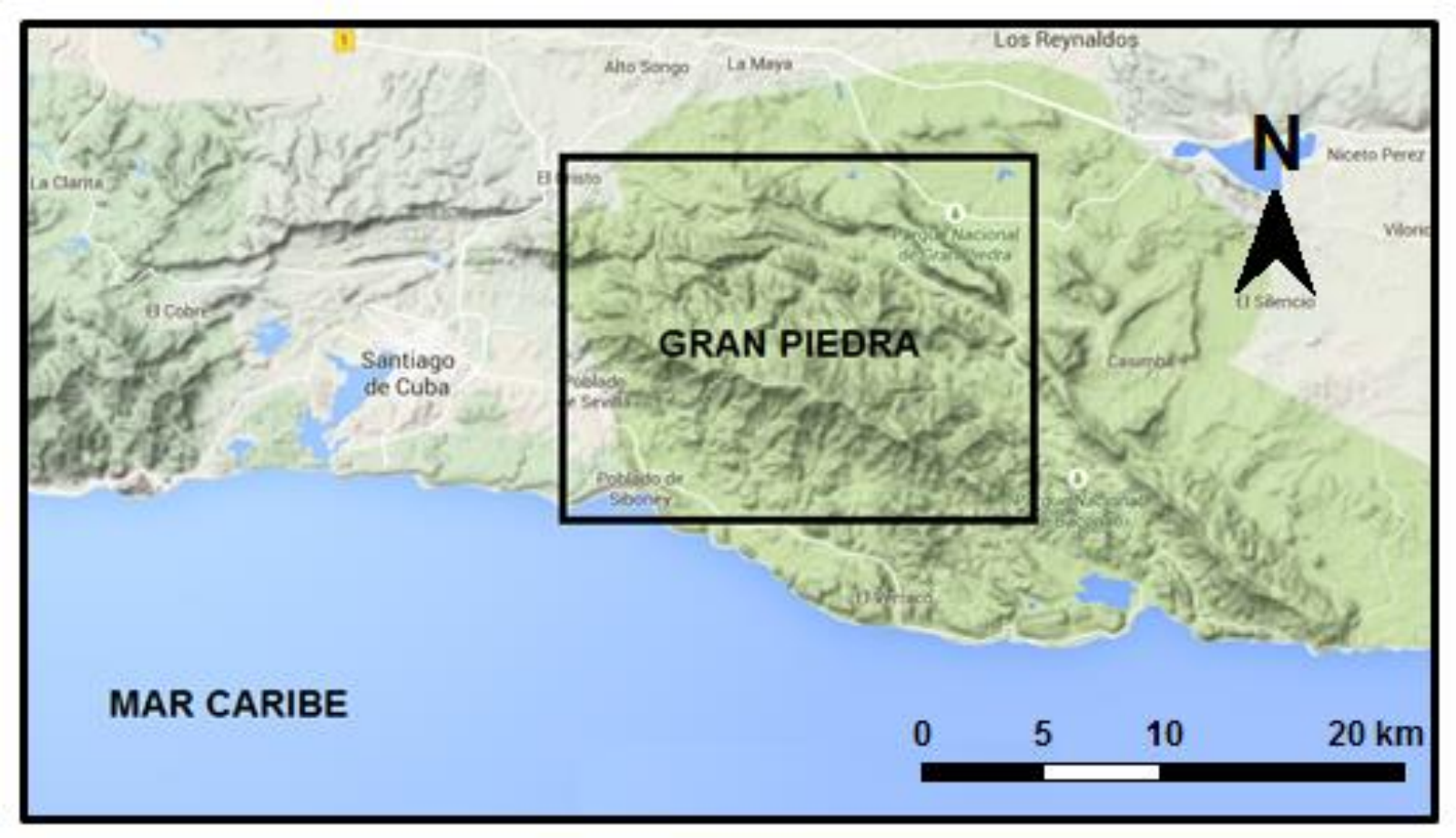

Figura 4.2 - Área da "Gran Piedra". Google Maps, 2014.

\subsubsection{Trabalho de Campo}

Foi realizado um trabalho de campo em dezembro do 2014, com o objetivo de elaborar um inventário de deslizamentos na área de estudo e identificar, caso fosse possível, os tipos de solos e rochas presentes na região. Na Fig. 4.3 e Fig. 4.4 é possível observar o percurso e nas Fig. 4.5, Fig. 4.6 e Fig. 4.7, uma amostra dos solos e escorregamentos encontrados.

O percurso envolveu um total de 60 estações (Tab. 4.2) em 14 delas com presença de escorregamento de terra. As imagens da Tab. 4.2 aparecem no Apêndice A. 


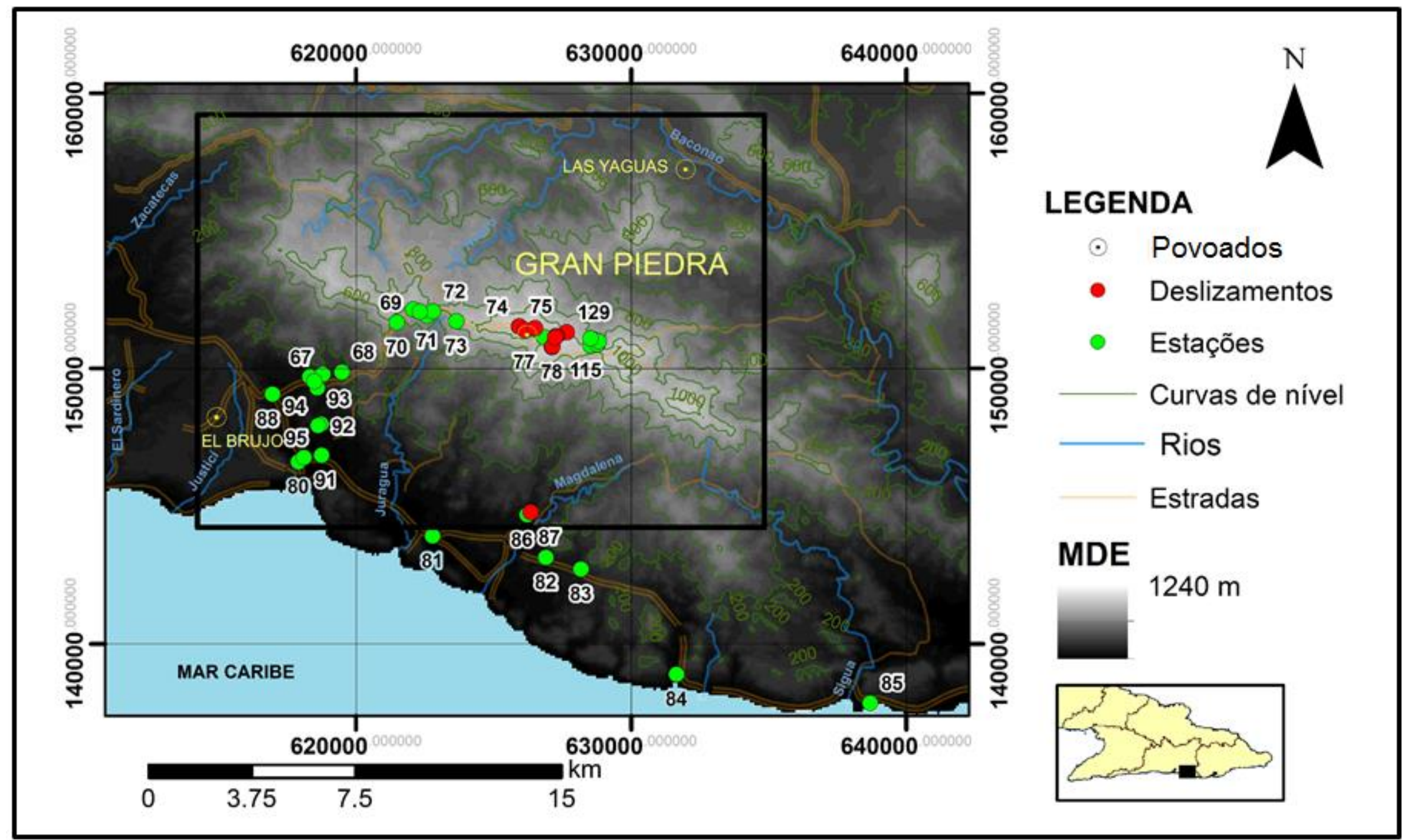

Figura 4.3 - Estações do percurso de campo na região da "Gran Piedra". Sistema de coordenadas plana-retangulares Cuba-Sul. Projeção cónica de Lambert. 


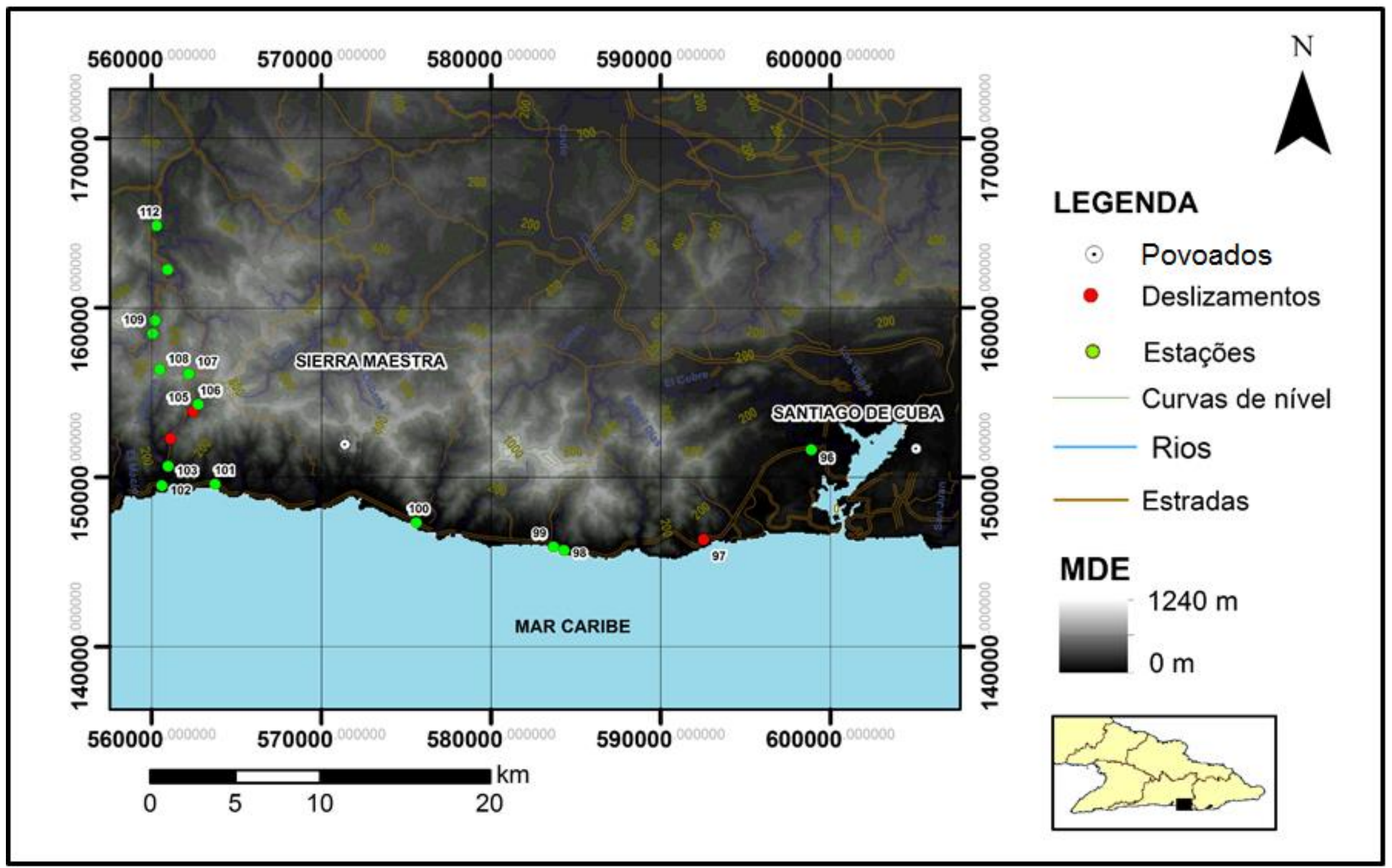

Figura 4.4 - Estações do percurso de campo na região da "Sierra Maestra". 


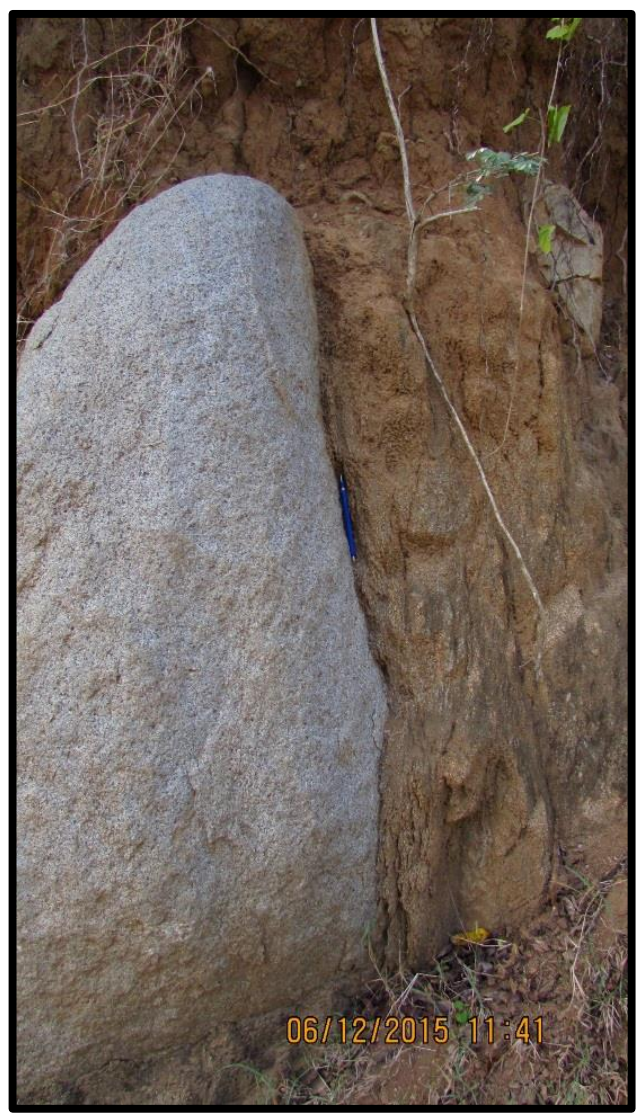

Figura 4.5 - Granitos meteorizado, na estação 93 do percurso de campo apresentado na Fig. 4.3

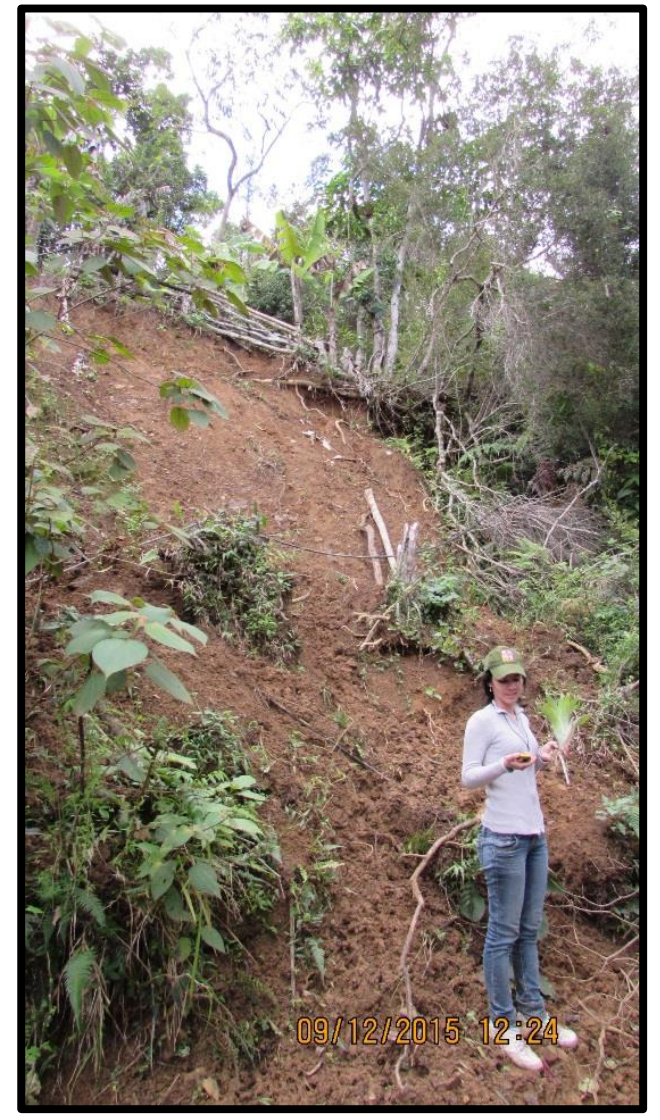

Figura 4.6 - Deslizamento de terra na estação 129 do percurso de campo apresentado na Fig. 4.3

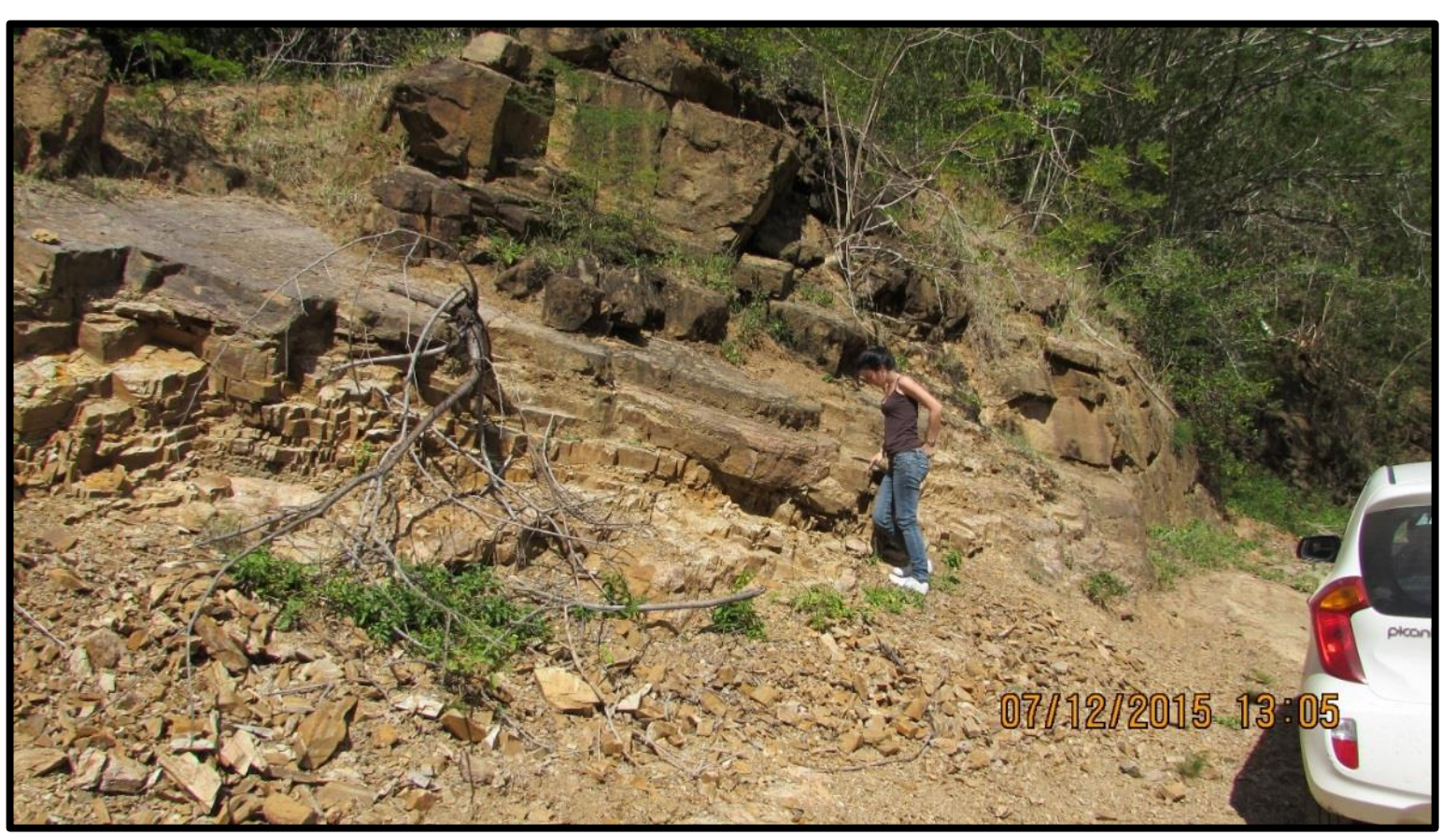

Figura 4.7 - Deslizamento planar em lutita na estação 105 do percurso de campo apresentado na Fig. 4.4 
Tabela 4.2 - Estações do percurso de campo

\begin{tabular}{|c|c|c|c|c|c|}
\hline \multirow{2}{*}{ Estação } & \multicolumn{2}{|c|}{ UTM/NAD27 } & \multirow{2}{*}{$\begin{array}{c}\mathrm{Z}(\mathrm{m}) \\
\text { ANMM }\end{array}$} & \multirow{2}{*}{ Descrição } & \multirow{2}{*}{ Apêndice A } \\
\hline & Leste & Norte & & & \\
\hline 66 & 426467 & 2210943 & 64 & $\begin{array}{l}\text { Presença de granito meteorizado em taludes, na estrada da "Gran } \\
\text { Piedra" }\end{array}$ & Fotografia_001 \\
\hline 67 & 426931 & 2211024 & 120 & Montanhas da "Gran Piedra", fotografia tomada na direção E & Fotografia_002 \\
\hline 68 & 427623 & 2211089 & 160 & Identificação de desgarres no topo das montanhas & Fotografia_003 \\
\hline 69 & 430236 & 2213349 & 711 & Deformações na via, fotografia tomada na direção SW & Fotografia_004 \\
\hline 70 & 429641 & 2212877 & 521 & Presença de juntas em rochas, fotografia tomada na direção NE & Fotografia_005 \\
\hline 70 & 429641 & 2212877 & 521 & Presença de coluviões & Fotografia_006 \\
\hline 71 & 430742 & 2213108 & 785 & Ponto de controle, & - \\
\hline 72 & 430957 & 2213262 & 822 & Geomorfologia da região da "Gran Piedra" & Fotografia_007 \\
\hline 73 & 431801 & 2212895 & 957 & Estrada "Gran Piedra" vista desde acima & Fotografia_008 \\
\hline 74 & 434083 & 2212683 & 1131 & Deslizamento, fotografia tomada na direção W & Fotografia_009 \\
\hline 75 & 434093 & 2212680 & 1104 & Deslizamento, fotografia tomada na direção NW & Fotografia_010 \\
\hline 76 & 434290 & 2212551 & 1110 & Deslizamento, fotografia tomada na direção NW & Fotografia_011 \\
\hline 77 & 434981 & 2212278 & 1103 & Radar e estação meteorológica "Gran Piedra" & Fotografia_012 \\
\hline 78 & 435268 & 2211921 & 1117 & Deslizamento na estrada & Fotografia_013 \\
\hline
\end{tabular}




\begin{tabular}{|c|c|c|c|c|c|}
\hline \multirow{2}{*}{ Estação } & \multicolumn{2}{|c|}{ UTM/NAD27 } & \multirow{2}{*}{$\begin{array}{l}Z(m) \\
\text { ANMM }\end{array}$} & \multirow{2}{*}{ Descrição } & \multirow{2}{*}{ Apêndice A } \\
\hline & Leste & Norte & & & \\
\hline 79 & 435280 & 2211951 & 1102 & Deslizamento na estrada, fotografia tomada na direção N & Fotografia_014 \\
\hline 80 & 426011 & 2207855 & 13 & Deslizamento, fotografia tomada na direção SW & Fotografia_015 \\
\hline 81 & 430846 & 2205104 & 25 & Cordilheira, fotografia tomada na direção N & Fotografia_016 \\
\hline 82 & 434952 & 2204285 & 93 & Relevo, fotografia tomada na direção $\mathrm{N}$ & Fotografia_017 \\
\hline 83 & 436224 & 2203846 & 112 & Erosão, fotografia tomada na direção $\mathrm{N}$ & Fotografia_018 \\
\hline 84 & 439654 & 2199989 & 8 & Ponto de controle & - \\
\hline 85 & 446682 & 2198860 & 31 & $\begin{array}{l}\text { Talude em rocha calcária na estrada, fotografia tomada na direção } \\
\text { NW }\end{array}$ & Fotografia_019 \\
\hline 86 & 434321 & 2205887 & 67 & Ponto de controle & - \\
\hline 87 & 434301 & 2205837 & 71 & Presença de capa vegetal acima de capa de deslizamento antigo & Fotografia_020 \\
\hline 88 & 434430 & 2205935 & 67 & Presença de coluviões & Fotografia_021 \\
\hline 89 & 434654 & 2206048 & 96 & Casa, fotografia tomada na direção $\mathrm{N}$ & Fotografia_022 \\
\hline 90 & 425099 & 2210325 & 39 & Ponto de controle & - \\
\hline 91 & 426206 & 2208006 & 16 & Ponto de controle & - \\
\hline 92 & 426843 & 2209217 & 28 & Rio "Seco" & Fotografia_023 \\
\hline 93 & 426727 & 2210531 & 73 & $\begin{array}{l}\text { Intemperismo esferoidal do granito, queda de bloques, fotografia } \\
\text { tomada na direção N }\end{array}$ & Fotografia_024 \\
\hline
\end{tabular}




\begin{tabular}{|c|c|c|c|c|c|}
\hline \multirow{2}{*}{ Estação } & \multicolumn{2}{|c|}{ UTM/NAD27 } & \multirow{2}{*}{$\begin{array}{l}Z(m) \\
\text { ANMM }\end{array}$} & \multirow{2}{*}{ Descrição } & \multirow{2}{*}{ Apêndice A } \\
\hline & Leste & Norte & & & \\
\hline 94 & 426620 & 2210763 & 100 & $\begin{array}{l}\text { Interseção com a estrada da "Gran Piedra", fotografia tomada na } \\
\text { direção E }\end{array}$ & Fotografia_025 \\
\hline 95 & 426744 & 2209161 & 29 & Trajetória do rio, fotografia tomada na direção NE & Fotografia_026 \\
\hline 96 & 407036 & 2213093 & 21 & Montanhas da "Sierra Maestra", fotografia tomada na direção W & Fotografia_027 \\
\hline 97 & 400624 & 2207853 & 18 & Solo residual e rocha fraturada & Fotografia_028 \\
\hline 98 & 392407 & 2207300 & 15 & $\begin{array}{l}\text { Talude, meteorização esferoidal perfeita, fotografia tomada na } \\
\text { direção W }\end{array}$ & Fotografia_029 \\
\hline 99 & 391783 & 2207515 & 21 & Coluviões & Fotografia_030 \\
\hline 100 & 383728 & 2209028 & 11 & Montanha da "Sierra Maestra", fotografia tomada na direção NW & Fotografia_031 \\
\hline 101 & 371902 & 2211435 & 18 & Ponto de controle & - \\
\hline 102 & 368764 & 2211388 & 20 & Entrada ao Rio "Seco" & - \\
\hline 103 & 369152 & 2212532 & 62 & Vale do Rio "Seco" & Fotografia_032 \\
\hline 104 & 369297 & 2214159 & 136 & Deslizamento & Fotografia_033 \\
\hline 105 & 370640 & 2215753 & 255 & lutita em deslizamentos planar, fotografia tomada na direção N & Fotografia_034 \\
\hline 106 & 370954 & 2216167 & 264 & Planícies por sobrepastoreo & Fotografia_035 \\
\hline 107 & 370415 & 2217968 & 617 & Geomorfologia da "Sierra Maestra" & Fotografia_036 \\
\hline 108 & 368714 & 2218241 & 650 & Deslizamento & Fotografia_037 \\
\hline
\end{tabular}




\begin{tabular}{|c|c|c|c|c|c|}
\hline \multirow{2}{*}{ Estação } & \multicolumn{2}{|c|}{ UTM/NAD27 } & \multirow{2}{*}{$\begin{array}{c}Z(m) \\
\text { ANMM }\end{array}$} & \multirow{2}{*}{ Descrição } & \multirow{2}{*}{ Apêndice A } \\
\hline & Leste & Norte & & & \\
\hline 109 & 368329 & 2220364 & 357 & Casa, fotografia tomada na direção NW & Fotografia_038 \\
\hline 110 & 368466 & 2221134 & 333 & Lutitas na "Sierra Maestra" & Fotografia_039 \\
\hline 111 & 369234 & 2224129 & 235 & Bloques de rochas no rio "Contramaestre" & Fotografia_040 \\
\hline 112 & 368611 & 2226732 & 309 & Estrada na "Sierra Maestra" & Fotografia_041 \\
\hline 114 & 434737 & 2212645 & 1117 & Deslizamento em rocha na "Gran Piedra" & Fotografia_042 \\
\hline 115 & 436500 & 2211966 & 996 & Panorâmica planície praia "Daiquiri" & Fotografia_043 \\
\hline 117 & 436713 & 2212009 & 942 & Ponto de controle & - \\
\hline 118 & 436753 & 2212124 & 941 & Montanhas, fotografia tomada na direção $\mathrm{N}$ & Fotografia_044 \\
\hline 119 & 436760 & 2212115 & 908 & Montanhas, fotografia tomada na direção $\mathrm{E}$ & Fotografia_045 \\
\hline 120 & 436498 & 2212233 & 830 & Rio "Plantón" & Fotografia_046 \\
\hline 129 & 435740 & 2212476 & 1001 & Deslizamento, fotografia tomada na direção W & Fotografia_047 \\
\hline 130 & 435419 & 2212334 & 1053 & Deslizamento em granito, fotografia tomada na direção $E$ & Fotografia_048 \\
\hline 131 & 435394 & 2212333 & 1060 & Deslizamento em granito & Fotografia_049 \\
\hline 132 & 435371 & 2212285 & 1074 & Deslizamento em granito & Fotografia_050 \\
\hline
\end{tabular}




\subsubsection{Processamento das imagens de voos aéreos}

As fotografias utilizadas foram fornecidas pelo "Instituto Cubano de Geodesia e Cartografia" (ICGC), e pertencem a um voo americano realizado em Cuba entre os anos 1956 e 1957. Tem uma escala aproximada de 1: 50.000, cada imagem tem dimensões de $24 \times 24 \mathrm{~cm}$ e uma resolução de 1270 pixels / polegada.

No processamento das imagens aéreas, foram utilizadas um total de 25 fotos. A análise das imagens foi realizada com um estereoscópio de espelho e georeferenciadas no Google Earth para finalmente, unificar os resultados dos deslizamentos de todas as imagens, em um único inventário no software ArcGIS 10.1. (Fig. 4.8). As imagens aéreas citadas, se encontram localizadas na Fig. $4.9 \mathrm{e}$ aparecem no Apêndice B. Na identificação dos escorregamentos, foram seguidos uma série de critérios, incluindo mudanças na vegetação, mudanças na paisagem e a presença de cicatrizes de deslizamentos de terra.

O processamento do modelo digital de elevação MDE a ser empregue neste trabalho, vai ser explicitado no próximo subitem. Ele está conformado por células de $30 \times 30 \mathrm{~m}$ e, uma vez georeferenciados os deslizamentos de terra nesse modelo, passou-se a contabilizar a quantidade de células da área de estudo, que são marcadas com deslizamentos por este inventário (Fig. 4.10). De um total de 227296 células contendo a região, tem 228 células pertencentes ao inventário de deslizamento de terra.

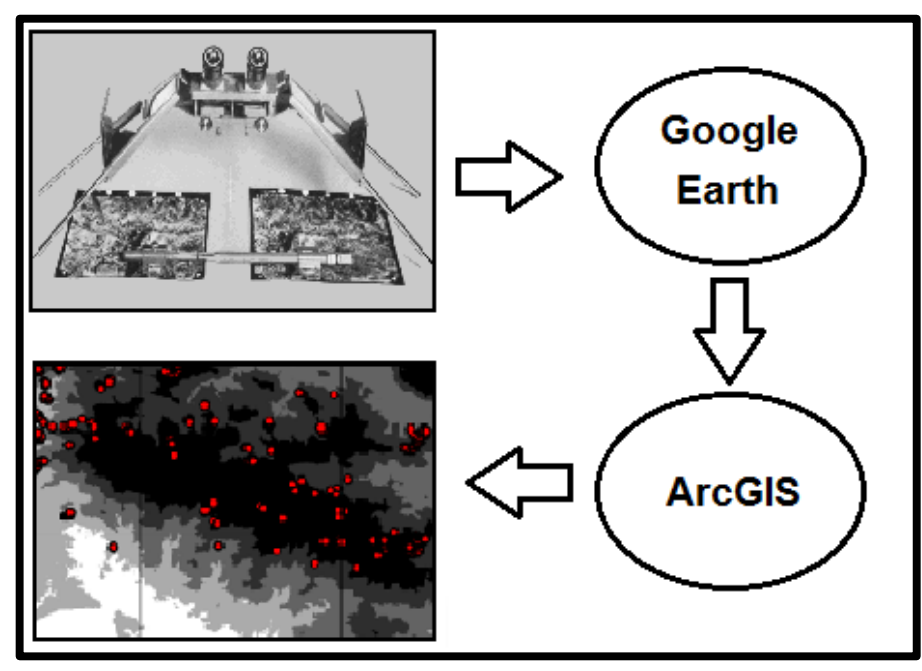

Figura 4.8 - Esquemas de trabalho para a obtenção de escorregamento em imagens aéreas. 


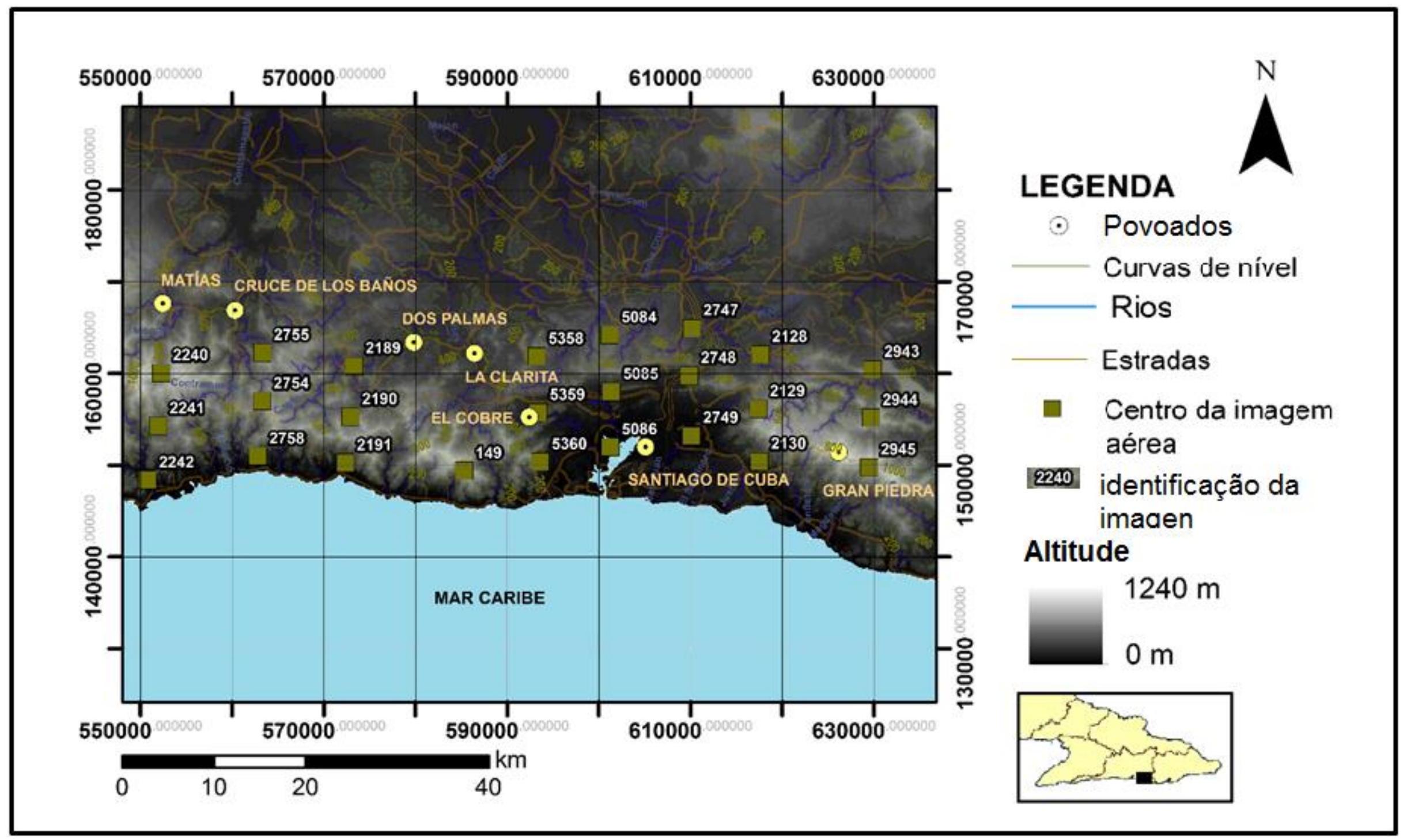

Figura 4.9 - Localização das imagens aéreas. 


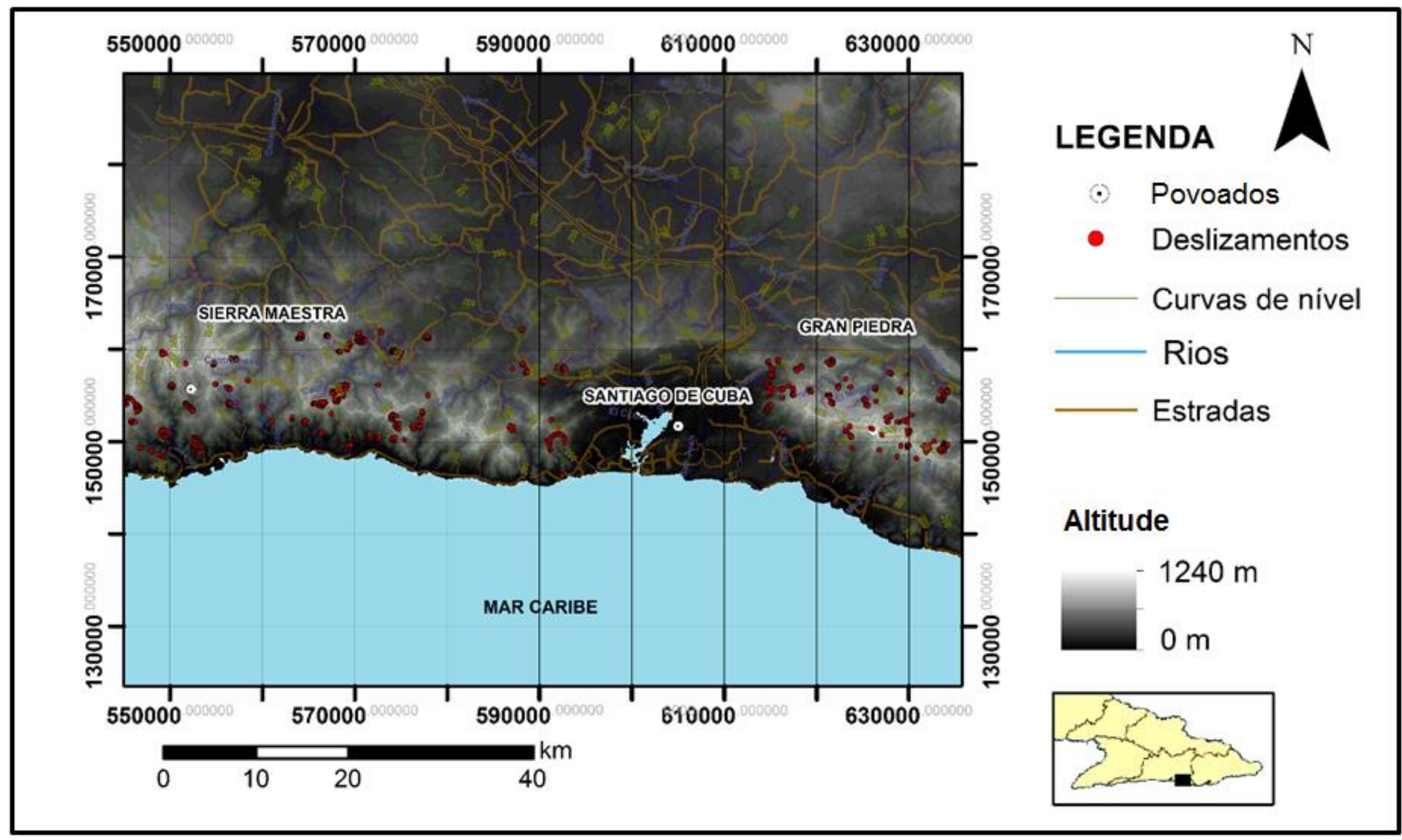

Figura 4.10 - Inventário de deslizamentos de terra, obtidos das imagens aéreas 
De acordo com estudos realizados por Guzzetti et al. (2006), citado por Bregoli et al. (2015) que analisaram grupos de deslizamentos de terra em diferentes intervalos de tempo e a suscetibilidade nesses intervalos, os autores concluem que um único inventário de deslizamento de terra multi-temporal fornece melhores resultados.

Portanto, na Fig. 4.11, decidiu-se unificar em um só registro, todos os inventários de deslizamentos de terra produto do inventario de escorregamentos obtido no percurso de campo e do processamento das imagens de voos aéreos, sem ter em conta a origem ou a época em que ocorreram.

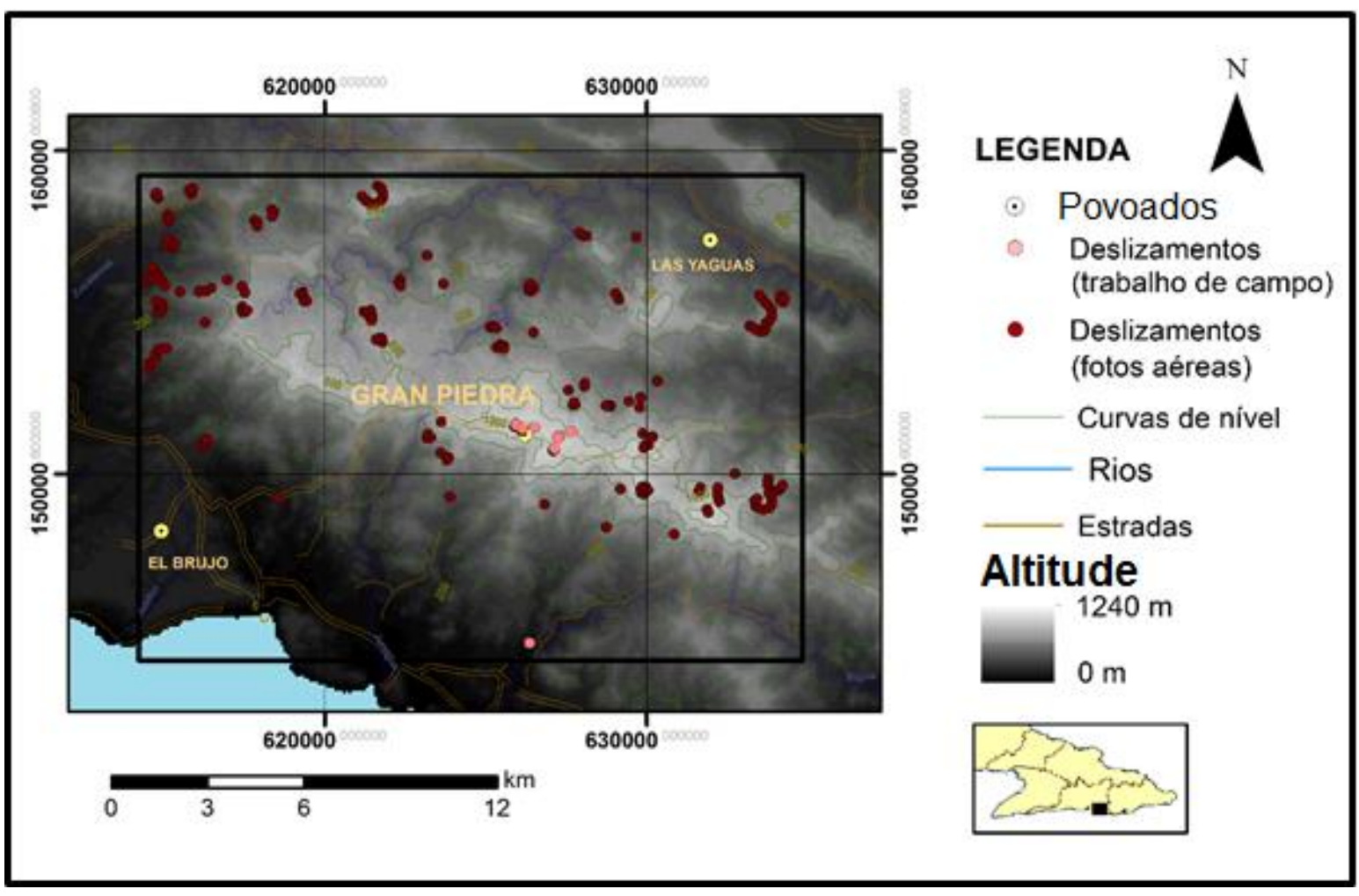

Figura 4.11 - Inventário de deslizamento na região da "Gran Piedra".

\subsubsection{Processamento das variáveis estáticas}

O modelo digital de elevação MDE é o principal elemento necessário quando são utilizados modelos com abordagem física.

No que diz respeito à avaliação de susceptibilidade, muitos autores têm discutido sobre o peso da resolução do MDE a usar. Bregoli et al. (2015) citam os seguintes autores: Montgomery e Foufoula-Georgiou (1993) recomendam uma resolução inferior a $30 \times 30$ m; Tarolli e Tarboton (2006) sugerem uma resolução 
inferior a $10 \times 10 \mathrm{~m}$; Dai e Lee (2002) utilizam resoluções $20 \times 20 \mathrm{~m}$ em desenvolvimentos de deslizamentos de terra em Hong Kong; Borga et ai. (1998), e Frattini Crosta (2003), e Carrara et ai. (2008) usaram tamanho de células de $10 \times 10 \mathrm{~m}$ em avaliações de escorregamentos e fluxos de detritos no Norte da Itália; Borga et al. (2002), utilizam células $5 \times 5 \mathrm{~m}$ para escorregamentos superficiais; Vanacker et al (2003) usou uma DEM com uma resolução de $5 \times 5 \mathrm{~m}$ para avaliar a estabilidade de taludes nos Andes do Equador; e Bregoli et al. (2015) emprega uma resolução de 5 x $5 \mathrm{~m}$ para avaliar a susceptibilidade de fluxos de detritos em uma escala regional.

No caso de estudo desta pesquisa é usado um MDE que está disponível no site da NASA (https://earthdata.nasa.gov/), com células $30 \times 30 \mathrm{~m}$. Este modelo, "Advanced Spaceborne Thermal Emission and Reflection Radiometer" (ASTER) na versão 2, é produzido pelo "Ministry of Economy Trade and Industry" (METI) e a "National Aeronautics and Space Administration" (NASA).

Não foi possível localizar um MDE com uma resolução espacial melhor que a usada neste trabalho. No site da NASA estão disponíveis MDE com tamanhos de célula de 90 × 90m até $30 \times 30 \mathrm{~m}$.

Durante o processamento desta informação, é preciso eliminar as áreas que não fornecem dados sobre a obtenção do FS, e tal é o caso das células que possuem valores "no data" e negativos.

Quando o MDE está pronto, é possível obter o mapa de declividade e o mapa de acumulação de fluxo. Na (Fig. 4.12) é representado o mapa de declividade para a região da "Gran Piedra" e na (Fig. 4.13) aparece o mapa de acumulação de fluxo para a mesma região da "Gran Piedra".

Para obter o mapa de acumulação de fluxo, é necessário ter processado previamente o mapa da direção do fluxo.

O processamento destes dados deve ser realizado em um Sistema de Informação Geográfica, GIS por sus siglas em inglês, neste caso, foi utilizado o software ArcGIS 10.1. 


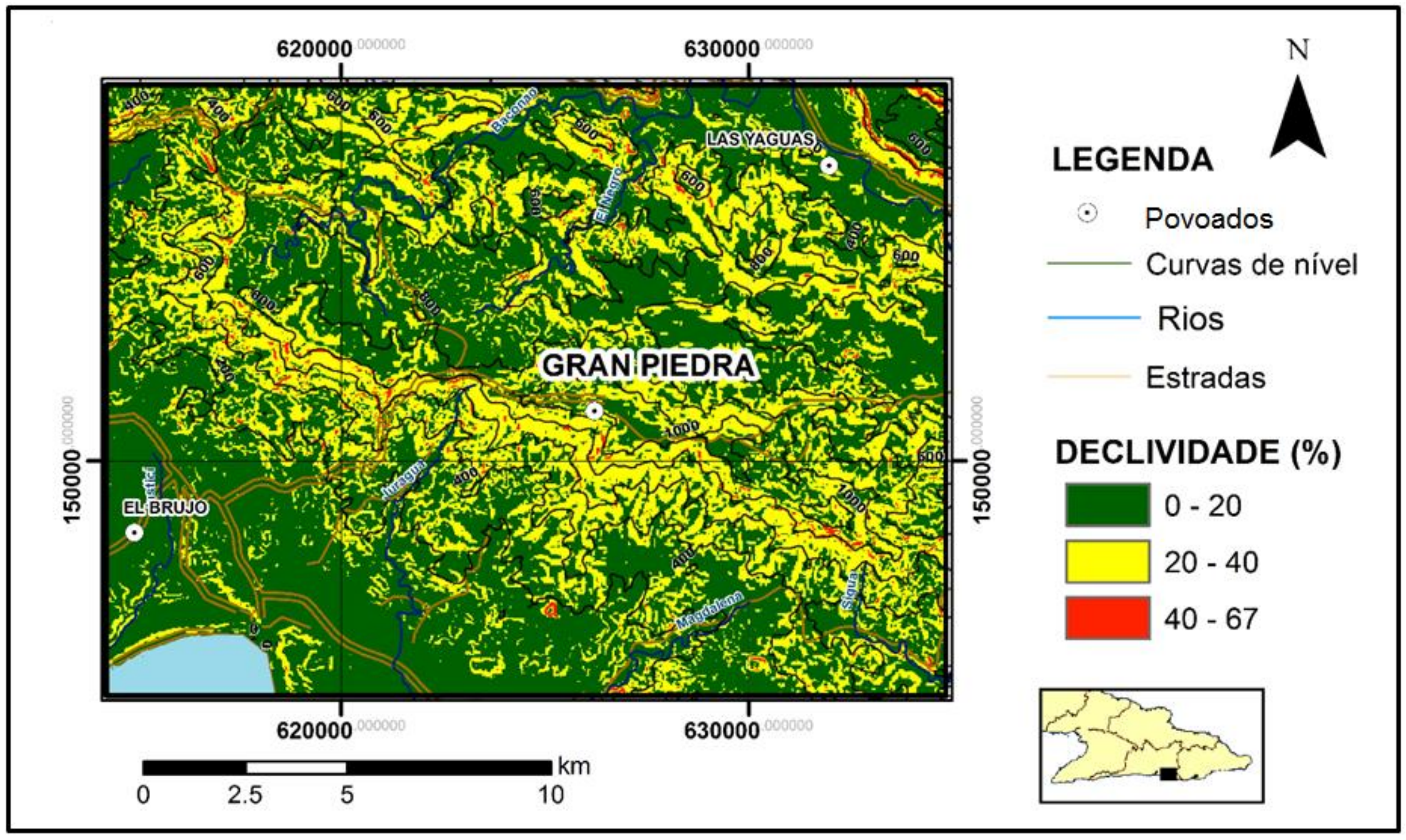

Figura 4.12 - Mapa de declividade da região da "Gran Piedra". 


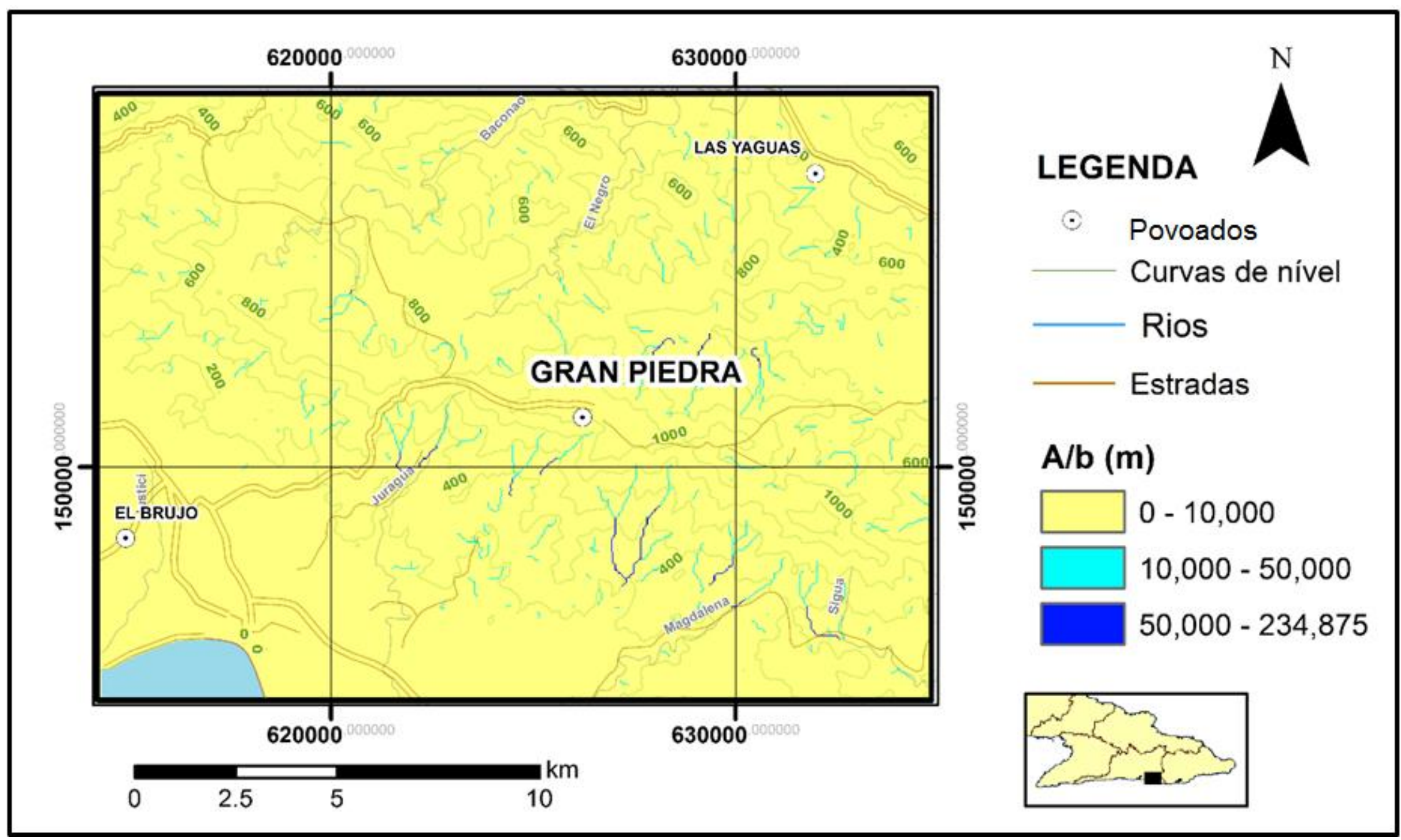

Figura 4.13 - Mapa de acumulação de fluxo (A) dividido (b) na região da "Gran Piedra". 


\subsubsection{Definição dos parâmetros dos solos da região.}

Os parâmetros do solo, necessários para a obtenção de FS, são: a coesão c', o ângulo de atrito interno $\boldsymbol{\varphi}$, o peso específico do solo $\gamma_{\mathbf{s}}$, a condutividade hidráulica $\mathbf{k}$ e a difusividade hidráulica característica $\mathbf{D}_{0}$.

Uma análise de sensibilidade realizada por Borga et al. (2002), sugere que a gama de influência dos parâmetros, considerando um conjunto adequado de variação é quando, por exemplo, um aumento de $25 \%$ da declividade produz uma diminuição de cerca de $25 \%$ do FS, enquanto que uma diminuição de $25 \%$ na declividade gera um aumento de mais de $25 \%$. Esta alta sensibilidade só pode ser melhorada, aumentando a resolução de MDE.

A declividade é obtida a partir de MDE, enquanto as informações de parâmetros do solo: a coesão 'c', o ângulo de atrito interno $\boldsymbol{\varphi}$, o peso específico do solo $\gamma_{\mathbf{s}}$, a condutividade hidráulica $\mathbf{k}$ e a difusividade hidráulica característica $\mathbf{D}_{\mathbf{0}}$ as vezes não estão disponíveis.

Uma análise de estabilidade de taludes em grande escala é marcada por uma variabilidade espacial nos parâmetros. Estes valores podem variar fortemente dentro de uma pequena área. De acordo com Bregoli et al. (2015), podem ser ajustados apenas os valores das propriedades físicas e mecânicas do solo nessa região, bem como valores diferentes para cada região homogénea.

É importante ressaltar que o procedimento correto, ao distinguir regiões com os mesmos parâmetros físicos e mecânicos, deve ser feito com base na utilização de mapas de solo. $\mathrm{Na}$ atualidade, esses mapas estão disponíveis localmente e é pouco comum encontrá-los numa escala regional (Papa et al., 2012). A forma mais ordinária de achar parâmetros de solo é extrapolá-los dos mapas geológicos e dos mapas de cobertura de solo. As regiões homogêneas podem ser reclassificadas como áreas do território com a mesma formação geológica ou a mesma entidade de cobertura do solo.

Para definir corretamente as propriedades de uma região homogénea, é necessário realizar testes de laboratório. Nestes ensaios se podem obter $\gamma_{\mathbf{s}}, \boldsymbol{\varphi}, \mathbf{c}^{\prime}, \mathbf{K}_{\mathbf{x}}$ e $K_{\mathbf{z}}$, no entanto, quando o território é muito grande, os testes laboratoriais não são mais viáveis, e começa a prevalecer o critério dos especialistas, na tarefa de definir 
os valores dos parâmetros do solo para regiões homogêneas de um território. Esta tarefa é muito delicada e deve ser realizada por geólogos ou engenheiros geotécnicos familiarizados com as características geomorfológicas e geológicas da área de estudo Bregoli et al (2015).

No presente estudo, não foi possível ter um mapa do solo ou um mapa de cobertura de solo; para a obtenção dos parâmetros, contou-se apenas com o mapa geológico, por isso, a fim de avaliar as propriedades de solo, foi decidido operar como se segue.

O mapa geológico tem uma escala de 1: 100.000, desenvolvido em 2008 pelo "Instituto de Geologia e Paleontologia" de Cuba. Fig. 4.14.

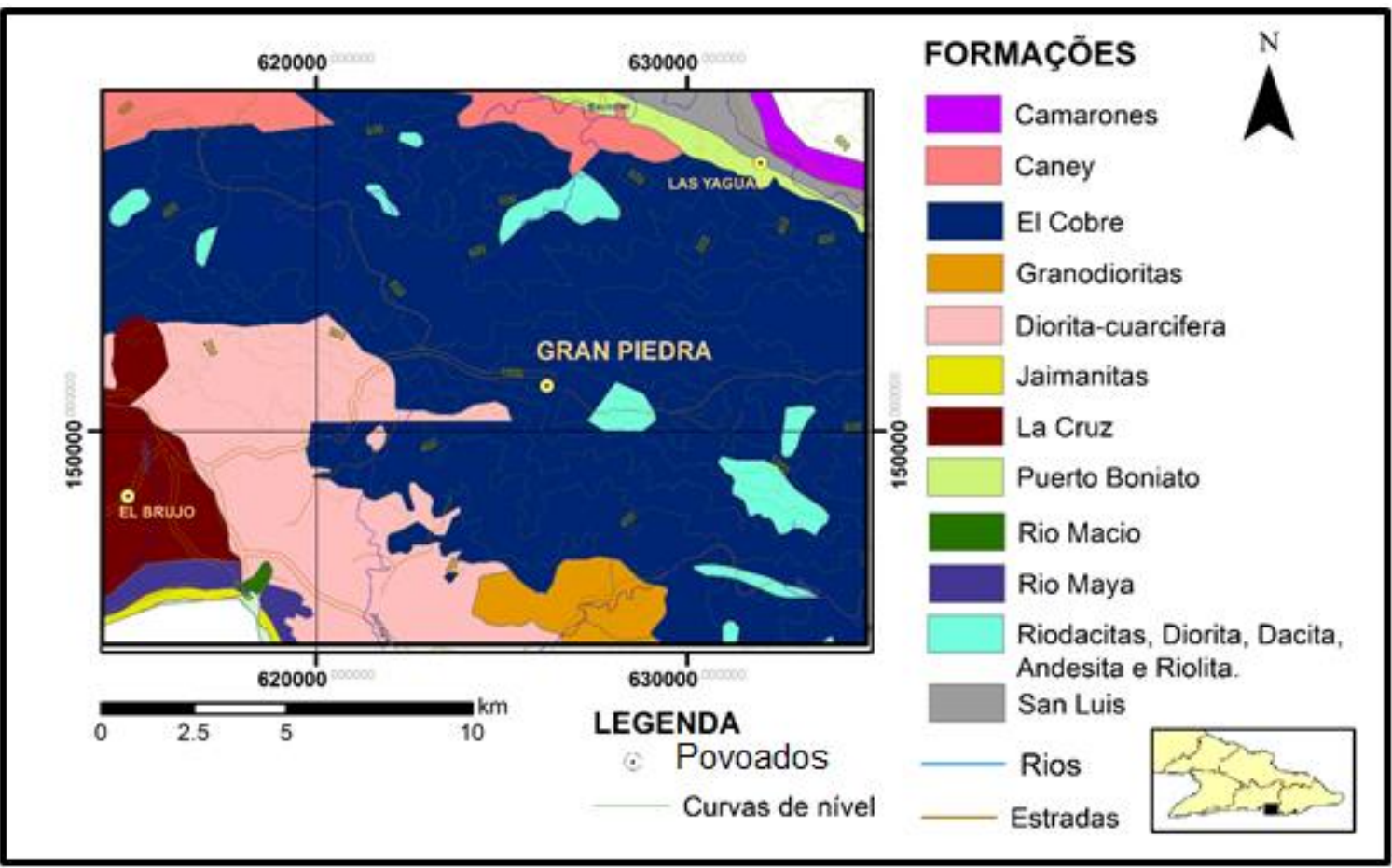

Figura 4.14 - Mapa geológico da região "Gran Piedra”.

Diferentes formações geológicas foram identificadas e foram procuradas na literatura propriedades para solos residuais, derivados deste tipo de formações geológicas, ver Fig. 4.15 e Tabelas do Apêndice C.

A área de estudo apresenta 12 formações geológicas diferentes, depois de analisar a composição geológica de cada uma delas, foram agrupadas em distritos homogêneos, atendendo à sua composição mineralógica ou estratigrafia, resultando em um total de 7 regiões homogéneas que são mostradas na Fig. 4.16. 


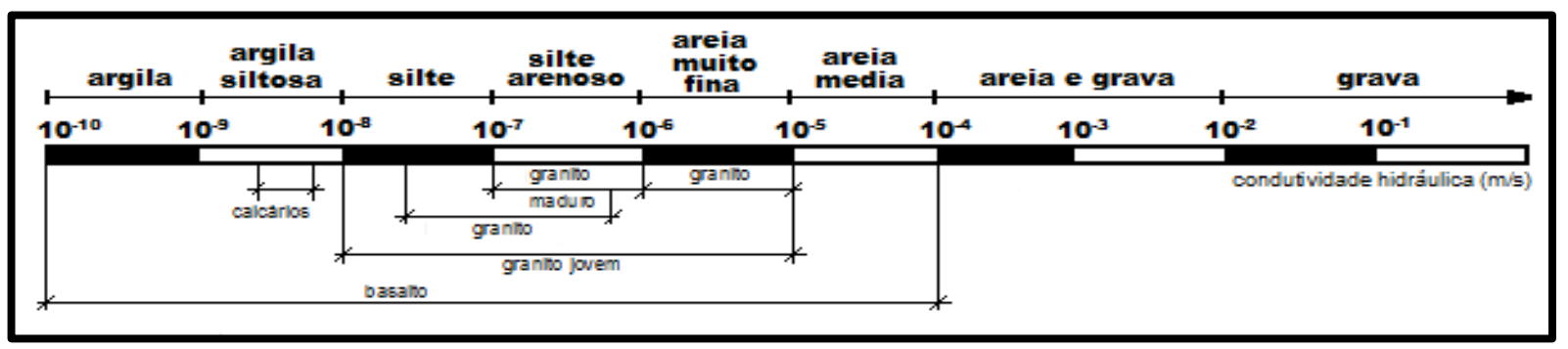

Figura 4.15 - Permeabilidades saturadas típicas em solos residuais, modificado de Schnaid et al. (2004); Coutinho e Silva (2006) citado por Viana da Fonseca (2009) com a inclusão de solos residuais do Brasil e solos residuais de granito do Porto.

\section{Região 1:}

Formação "Jaimanitas": Aglomerados polimícticos, com clastos de calcários, metavulcanitas, silicitas e ultramafitas. Calcários biodetríticos, carsificadas, fosilíferas com conchas bem preservadas.

Formação "Rio Maya": Calizas biohérmicas dolomitizada, arcillas e intercalaciones de conglomerados polimícticos.

Formação "San Luis": Areniscas polimícticas, limolitas, margas, arcillas, calizas arcillosas, calizas biodetríticas, calizas arenosas e conglomerados polimícticos.

Formação "Puerto Boniato": Alternância de calizas e margas, com intercalações de sílice.

Formaçao "Camarones": Areniscas e conglomerados polimícticas,

Formação "La Cruz": Calizas, calcarenitas e margas, conglomerados, areniscas polimícticas e limolitas.

Região 2: Formação "Caney": Alternância de tobas, tufitas, calizas tobáceas, lapilitas e intercalações de lavas e aglomerados.

Região 3: Granidioritas

Região 4: Formação "El Cobre": Rocas vulcanógenas e vulcanógeno- sedimentares em desiguais correlações e combinações variáveis.

Região 5: Dioritas

Região 6: Formação "Rio Macio": Depósitos em vales aluviais de composição e granulometria heterogénea.

Região 7: Andesitas, Dacitas, Riolitas, Riodacitas e Dioritas. 


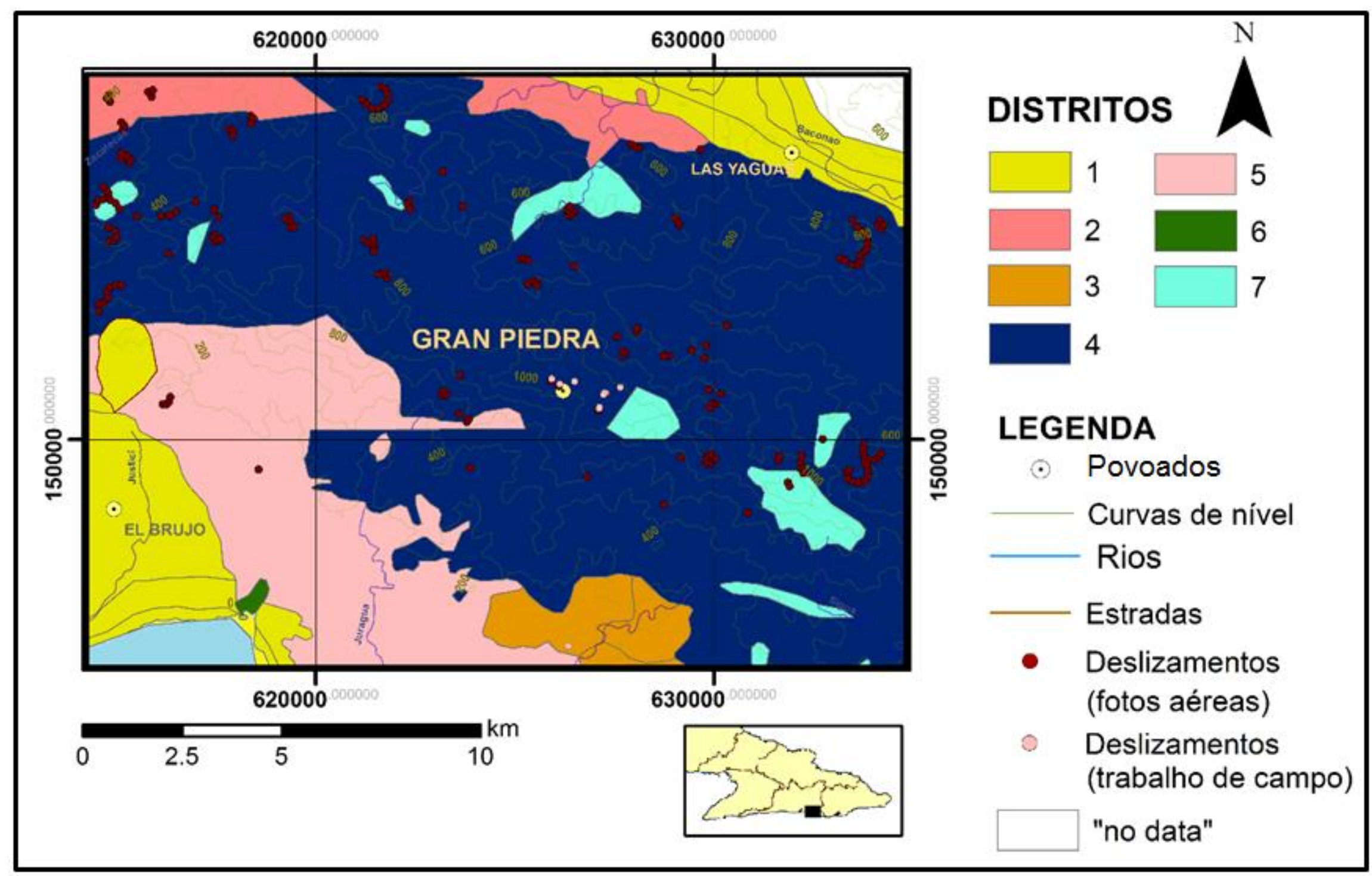

Figura 4.16 - Distritos homogéneos da área de estudo com o inventário de deslizamentos. 
Cada região homogênea vai ter iguais valores de coesão c', ângulo de atrito interno $\boldsymbol{\varphi}$, peso específico do solo $\gamma_{\mathbf{s}}$ e condutividade hidráulica k. Tab. 4.3. Para alcançar estes valores, foi obtida a média dos parâmetros dos solos residuais derivados das diferentes formações geológicas (Apêndice C) eliminando os valores extremos "outlier".

O valor da espessura do solo foi fixado em cinco metros $(5 \mathrm{~m})$ para todos os distritos. Este valor foi observado repetidamente nos escorregamentos inventariados durante o trabalho de campo. Também é preciso um valor fixo já que o modelo escolhido aplica a hipótese de talude infinito e pressupõe uma espessura de solo fixa para cada talude.

Tabela 4.3- Parâmetros do solo, adotados para os distritos homogêneos.

\begin{tabular}{|c|c|c|c|c|c|c|}
\hline Distritos & $\mathbf{Z}(\mathbf{m})$ & $\begin{array}{c}\gamma_{\mathbf{s}} \\
\left(\mathbf{k N} / \mathbf{m}^{3}\right)\end{array}$ & $\boldsymbol{\varphi}(\mathbf{(})$ & $\mathbf{c}^{\prime}(\mathbf{k P a})$ & $\begin{array}{c}\mathbf{K} \mathbf{x} \\
(\mathbf{m m} / \mathbf{s})\end{array}$ & $\begin{array}{c}\mathbf{K}_{\mathbf{z}} \\
(\mathbf{m m} / \mathbf{s})\end{array}$ \\
\hline $\mathbf{1}$ & 5 & 15 & 20 & 45 & 0.01 & 0.01 \\
\hline $\mathbf{2}$ & 5 & 15 & 10 & 25 & 0.05 & 0.05 \\
\hline $\mathbf{3}$ & 5 & 17 & 25 & 23 & 0.05 & 0.05 \\
\hline $\mathbf{4}$ & 5 & 17 & 22 & 24 & 0.01 & 0.01 \\
\hline $\mathbf{5}$ & 5 & 17 & 21 & 21 & 0.05 & 0.05 \\
\hline $\mathbf{6}$ & 5 & 17.5 & 24 & 18 & 0.01 & 0.01 \\
\hline $\mathbf{7}$ & 5 & 17 & 19 & 22 & 0.05 & 0.05 \\
\hline
\end{tabular}

Dada a vastidão da região 4, e que a região 7 está conformada por pequenas áreas contidas na região 4, além da semelhança entre os valores das regiões 4 e 7 , decidiu-se unificá-las em uma região homogênea, desaparecendo a região 7.

\subsubsection{Determinação do parâmetro de calibração ( $\left.D_{0}\right)$.}

De acordo com Papa et al. (2011), o parâmetro de calibração do modelo é a difusividade hidráulica característica Do. Este parâmetro é calibrado com um inventário de deslizamento. Depois de georreferenciar o inventário de deslizamentos de terra no mapa de regiões homogêneas (Fig. 4.16), observa-se que a maioria dos deslizamentos estão localizados na Região 4 e que não há informação suficiente para calibrar as restantes regiões. Por isso, foi decidido trabalhar apenas com a Região 4.

Segundo Papa et al. (2011), o parâmetro de calibração do modelo é a razão entre a $\mathbf{D}_{\mathbf{0}}$ difusividade máxima característica e $\mathbf{k}_{\mathbf{z}}$ a condutividade hidráulica em 
relação a direção normal da encosta que governa a transmissão da carga hidráulica quando o solo está próximo da saturação. Logo Papa et al. (2013), advertem que o $\mathbf{D}_{\mathbf{0}}$ é estimado como a razão entre a $\mathbf{k}_{\mathbf{z}}$ e $\mathbf{C}_{\mathbf{0}}$ mudança no conteúdo volumétrico da água por unidade de carga hidráulica, quando o solo está perto da saturação.

Segundo van Genuchten (1980), na Fig. 4.17 é representada a gráfica de difusividade hidráulica do solo em função do conteúdo de agua para um solo com condutividade hidráulica $\mathbf{k}$ igual $0.01 \mathrm{~mm} / \mathrm{s}$, o $\mathbf{D}_{0}$ admite valores que variam entre $10^{-3}$ e $10^{-9} \mathrm{~m}^{2} / \mathrm{s}$ e o valor de $10^{-9} \mathrm{~m}^{2} / \mathrm{s}$ se corresponde com o valor saturado de conteúdo de agua desse solo.

De acordo com Mora et al. (1992) citado por Aguller, (2008), na região leste de Cuba, o valor mensal de precipitação inferior a 125 milímetros não leva ao aumento da umidade do solo, enquanto precipitações por cima de 250 milímetros levam à alta umidade do solo.

Tendo em conta que o solo analisado (Região 4) tem a mesma condutividade hidráulica que o solo mostrado na Fig. 4.17, onde os valores de difusividade variam $10^{-3}$ e $10^{-9} \mathrm{~m}^{2} / \mathrm{s}$ e o valor de $10^{-9} \mathrm{~m}^{2} / \mathrm{s}$ se corresponde com o valor saturado de conteúdo de agua desse solo, passamos a avaliar o inventário de escorregamento para esta faixa de valores $D_{0}$.

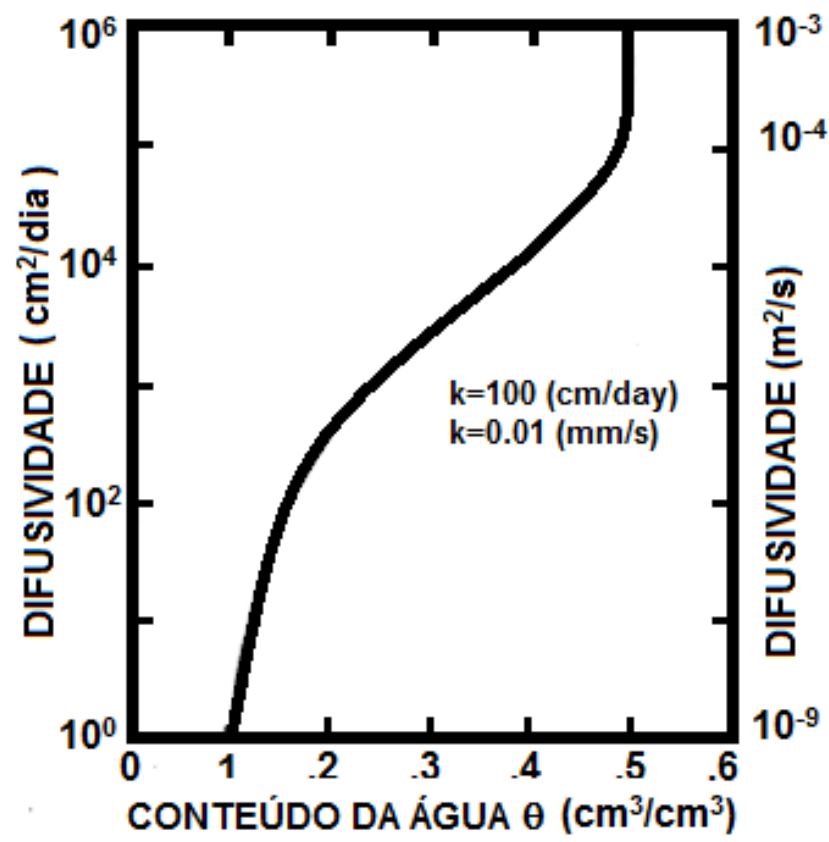

Figura 4.17 - Relação entre a difusividade hidráulica do solo e o conteúdo da água. (Modificado, van Genuchten,1980) 
A Tab. 4.4 representa os eventos meteorológicos extremos registrados em Cuba e obtidos do Atlas Nacional de Cuba, Kochiachivili (1989). O furacão Flora é considerado por esta fonte o segundo evento de chuva mais intenso que se conhece.

Tabela 4.4 - Intensidades de precipitações extremas durante a passagem de furacões, Atlas Nacional de Cuba, modificado Kochiachivili (1989).

\begin{tabular}{|c|c|c|c|c|c|c|c|}
\hline \multirow{2}{*}{$\begin{array}{l}\text { Nome do Furacão } \\
\text { Província afetada } \\
\text { Data }\end{array}$} & & \multicolumn{6}{|c|}{ Intervalos de Tempo (horas) } \\
\hline & & $1 \mathrm{~h}$ & $1.5 \mathrm{~h}$ & $2.5 \mathrm{~h}$ & $5 \mathrm{~h}$ & $12 \mathrm{~h}$ & $24 h$ \\
\hline \multirow{2}{*}{$\begin{array}{l}\text { * } \\
\text { LH,CLH } \\
\text { 20/X/1926 } \\
\end{array}$} & $(\mathrm{mm})$ & 115 & 130 & 162 & 216 & 278 & -- \\
\hline & I (mm/h) & 115 & 86.67 & 64.8 & 43.2 & 23.17 & -- \\
\hline \multirow{2}{*}{$\begin{array}{l}\text { Flora } \\
\text { GT,LT,HL,GR,SC } \\
4-8 / X / 63\end{array}$} & $(\mathrm{~mm})$ & 72 & 99 & 138 & 239 & 445 & 684 \\
\hline & $I(\mathrm{~mm} / \mathrm{h})$ & 72 & 66 & 55.2 & 47.6 & 37.08 & 28.5 \\
\hline \multirow{2}{*}{$\begin{array}{l}\text { Laura } \\
\text { IJ } \\
14-18 / X / 71\end{array}$} & $(\mathrm{~mm})$ & 150 & 200 & 240 & 320 & 396 & -- \\
\hline & I (mm/h) & 150 & 133 & 96 & 64 & 33 & -- \\
\hline \multirow{2}{*}{$\begin{array}{l}\text { Frederick } \\
\text { LH,CLH } \\
9-10 / I X / 79 \\
\end{array}$} & $(\mathrm{~mm})$ & 64 & 90 & 132 & 223 & 415 & 495 \\
\hline & I (mm/h) & 64 & 60 & 52.8 & 44.6 & 34.58 & 20.6 \\
\hline \multirow{2}{*}{$\begin{array}{l}\text { Alberto } \\
\text { PR } \\
2-4 / \mathrm{VI} / 62\end{array}$} & $(\mathrm{~mm})$ & 127 & 172 & 255 & 400 & 620 & 740 \\
\hline & I (mm/h) & 127 & 115 & 102 & 80 & 51.67 & 30.8 \\
\hline
\end{tabular}

Para fazer a calibração do modelo, foi escolhido o evento do furação "Flora" como referência. $\mathrm{O}$ evento completo foi decomposto em seis eventos representativos dele, gerando-se uma gráfica de intensidade $\mathrm{I}_{\mathbf{z}}$ em função do tempo $\mathrm{T}$, que se mostra na Fig. 4.18. Para simulá-lo na área de estudo, foi considerada a intensidade da

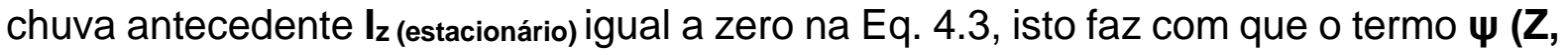
0) seja zero na Eq. 4.4. Na obtenção do $F S$, fornecida pela Eq. 4.1, o termo $\boldsymbol{\Psi}(\mathbf{Z}, \mathbf{t})$, dependente da $\mathbf{I}_{\mathbf{z}}$, foi calculado para cada intervalo da gráfica da Fig. 4.18, considerando em cada intervalo o aporte acumulativo que faz a $\boldsymbol{\Psi}(\mathbf{Z}, \mathbf{t})$ no cálculo do intervalo seguinte. 


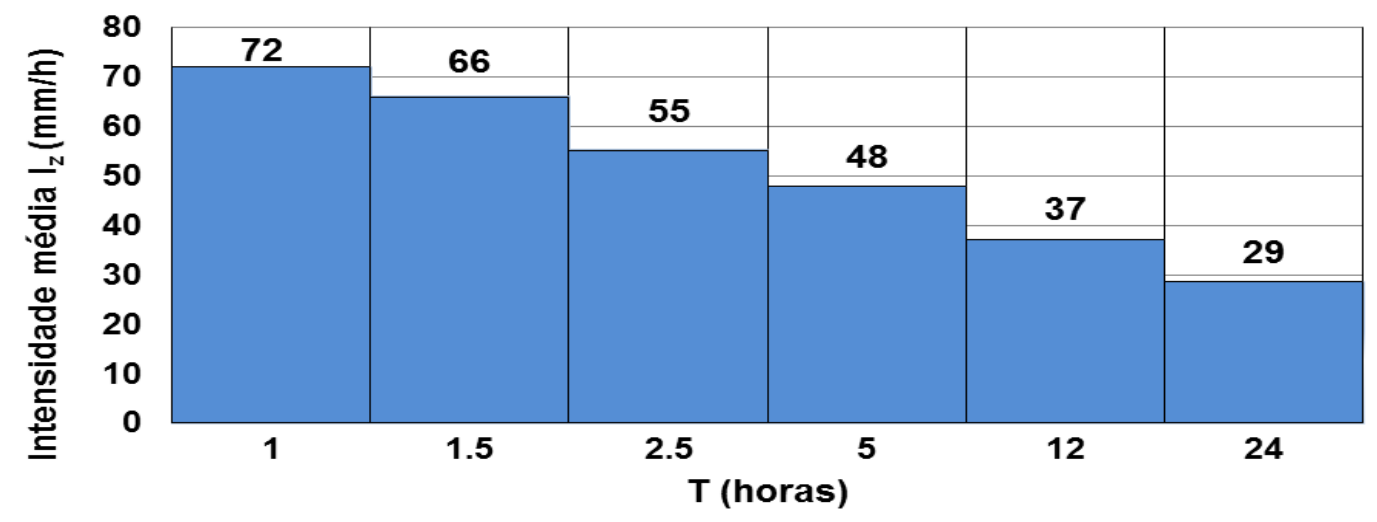

Figura 4.18 - Gráfica do evento do furacão "Flora".

Durante o processo de calibração, a distribuição das intensidades das chuvas na região da "Gran Piedra" foi realizada tomando como base o resultado do trabalho realizado pelo "Grupo de Ameaça, Vulnerabilidade e Risco por intensas chuvas" da “Delegação Provincial de Recursos Hidráulicos de Santiago de Cuba”, no ano 2011, (Fig. 4.19). Nesta figura, são representadas as distribuições das intensidades das precipitações máximas anuais que podem ocorrer em 24 horas, para uma probabilidade de ocorrência do $2 \%$ equivalente a um período de recorrência de 50 anos. O uso desta distribuição de intensidades dentro da área de estudo melhora a precisão dos resultados.

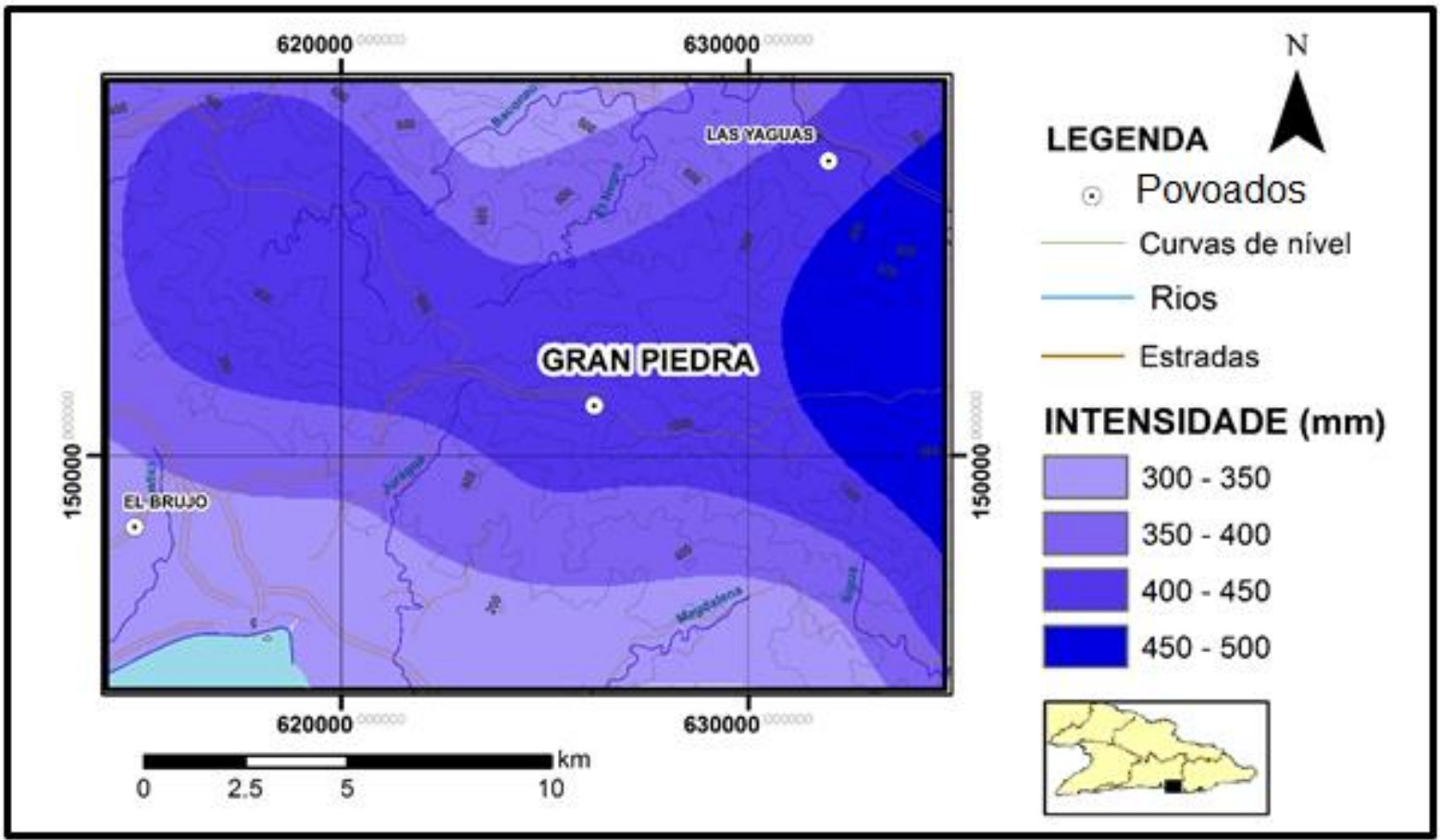

Figura 4.19 - Distribuições de chuva máximas anuais em 24h para uma probabilidade de ocorrência de $2 \%$. 
Para esta distribuição das chuvas, foram simulados os seis eventos representativos do furacão "Flora", nas 228 células do inventário de deslizamentos pertencentes à Região 4 e obtidos os valores da média e do desvio padrão do FS, estes valores são presentados na Tab.4.5. Na escolha do parâmetro $D_{0}$ foi analisado que a média do FS fosse próxima de um, que representa o valor critico de estabilidade.

Tabela 4.5 - Valores da média e do desvio padrão do FS para os diferentes valores

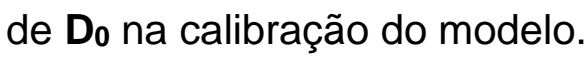

\begin{tabular}{|c|c|c|c|c|c|c|}
\hline & Evento 1 & Evento 2 & Evento 3 & Evento 4 & Evento 5 & Evento 6 \\
\hline $\begin{array}{l}D_{0} \\
\left(\mathrm{~m}^{2} / \mathrm{s}\right)\end{array}$ & $\begin{array}{l}t=1 \mathrm{~h} \\
\mathrm{I}=72 \mathrm{~mm} / \mathrm{h}\end{array}$ & $\begin{array}{l}t=1.5 \mathrm{~h} \\
\mathrm{I}=66 \mathrm{~mm} / \mathrm{h}\end{array}$ & $\begin{array}{l}\mathrm{t}=2.5 \mathrm{~h} \\
\mathrm{l}=55.2 \mathrm{~mm} / \mathrm{h}\end{array}$ & $\begin{array}{l}\mathrm{t}=5 \mathrm{~h} \\
\mathrm{l}=47.8 \mathrm{~mm} / \mathrm{h}\end{array}$ & $\begin{array}{l}t=12 \mathrm{~h} \\
\mathrm{I}=37 \mathrm{~mm} / \mathrm{h}\end{array}$ & $\begin{array}{l}\mathrm{t}=24 \mathrm{~h} \\
\mathrm{I}=28.5 \mathrm{~mm} / \mathrm{h}\end{array}$ \\
\hline \multirow{2}{*}{$1 \times 10^{-2}$} & 0.88 & 0.72 & 0.53 & 0.14 & -0.32 & -0.62 \\
\hline & 0.09 & 0.07 & 0.04 & 0.00 & 0.06 & 0.09 \\
\hline \multirow{2}{*}{$5 \times 10^{-3}$} & 1.14 & 1.03 & 0.90 & 0.63 & 0.29 & 0.06 \\
\hline & 0.13 & 0.11 & 0.10 & 0.06 & 0.02 & 0.01 \\
\hline \multirow{2}{*}{$1 \times 10^{-3}$} & 1.32 & 1.31 & 1.28 & 1.20 & 1.05 & 0.93 \\
\hline & 0.17 & 0.16 & 0.16 & 0.14 & 0.12 & 0.11 \\
\hline \multirow{2}{*}{$8 \times 10^{-4}$} & 1.32 & 1.32 & 1.30 & 1.24 & 1.11 & 1.00 \\
\hline & 0.17 & 0.16 & 0.16 & 0.15 & 0.13 & 0.12 \\
\hline \multirow{2}{*}{$5 \times 10^{-4}$} & 1.33 & 1.33 & 1.32 & 1.29 & 1.20 & 1.11 \\
\hline & 0.17 & 0.17 & 0.16 & 0.16 & 0.14 & 0.13 \\
\hline \multirow{2}{*}{$1 \times 10^{-4}$} & 1.33 & 1.33 & 1.33 & 1.33 & 1.32 & 1.31 \\
\hline & 0.17 & 0.17 & 0.17 & 0.17 & 0.17 & 0.16 \\
\hline
\end{tabular}

O $D_{0}$ é a difusividade máxima característica e governa a transmissão da carga hidráulica quando o solo está próximo da saturação e o valor de $D_{0}$ igual a $10^{-3} \mathrm{~m}^{2} / \mathrm{s}$ se corresponde com o valor que adota o $\mathrm{D}_{0}$ na gráfica da Fig. 4.17 quando o solo está representado por uma condição saturada. Nessa mesma figura é possível observar como os valores do $D_{0}$ entre $10^{-4} \mathrm{e} 10^{-3} \mathrm{~m}^{2} / \mathrm{s}$ analisados na Tabela 4.5 se localizam na curva superior e se estabilizam em $10^{-3} \mathrm{~m}^{2} / \mathrm{s}$ que é quando o solo muda de uma condição não saturada até adquirir o estado saturado. Finalmente, depois de analisar os valores das médias e os desvios padrões do FS foi escolhido o valor de $\mathbf{D}_{0}$ igual a $10^{-3} \mathrm{~m}^{2} / \mathrm{s}$. 


\section{Capitulo 5: Aplicação.}

Neste capítulo é apresentada a aplicação da metodologia proposta por Papa et al. (2011) na região que pertence também ao "Parque Nacional Sierra Maestra", município "Guamá”, Província "Santiago de Cuba”.

\subsection{Identificação de células provavelmente instáveis.}

Numa primeira tentativa de validação do modelo, foram obtidos valores de fator de segurança FS entre -1080 e 150.

De acordo com Aristizábal (2013), existem condições do solo para nas quais, a presença da água não interfere na estabilidade ou instabilidade do talude, portanto, é preciso definir quais células presentam estas características especiais dentro da área analisada.

Para avaliar a estabilidade de taludes em cada célula da área de estudo, utilizando o modelo de Papa et al. (2011), só é preciso aplicar a fórmula para o cálculo do fator de segurança FS em cada célula da área analisada, e comparar o resultado com o valor crítico do fator de segurança (FS =1); os valores superiores a 1 indicam estabilidade nas células analisadas, enquanto os valores inferiores e iguais a 1 , indicam instabilidade nas células analisadas.

Aristizabal et al. (2013) sugere que devem ser calculadas as espessuras máximas $\mathbf{Z}_{\max }$ e mínimas $\mathbf{Z}_{\min }$ para o solo residual.

Esta análise irá delimitar as células dentro da área de estudo que são estáveis ou instáveis incondicionalmente, uma vez que estes dois estados são independentes do teor de água.

A Fig. 5.1 mostra a suscetibilidade aos escorregamentos de terra em função da espessura do solo $\mathbf{Z}$ e da declividade do terreno $\boldsymbol{\alpha}$, onde $\boldsymbol{\alpha}_{0}$ é a declividade máxima até onde o solo sempre será estável, independentemente da espessura do solo, $\boldsymbol{\varphi}$ é o ângulo de atrito interno, $\mathbf{Z}_{\min }$ e $\mathbf{Z}_{\max }$ são valores limites da espessura do solo entre os quais as células analisadas são susceptíveis aos escorregamentos de terras produzidos por chuvas.

Se este processo é realizado antes de iniciar a modelagem, fornece um aumento na eficiência computacional. 


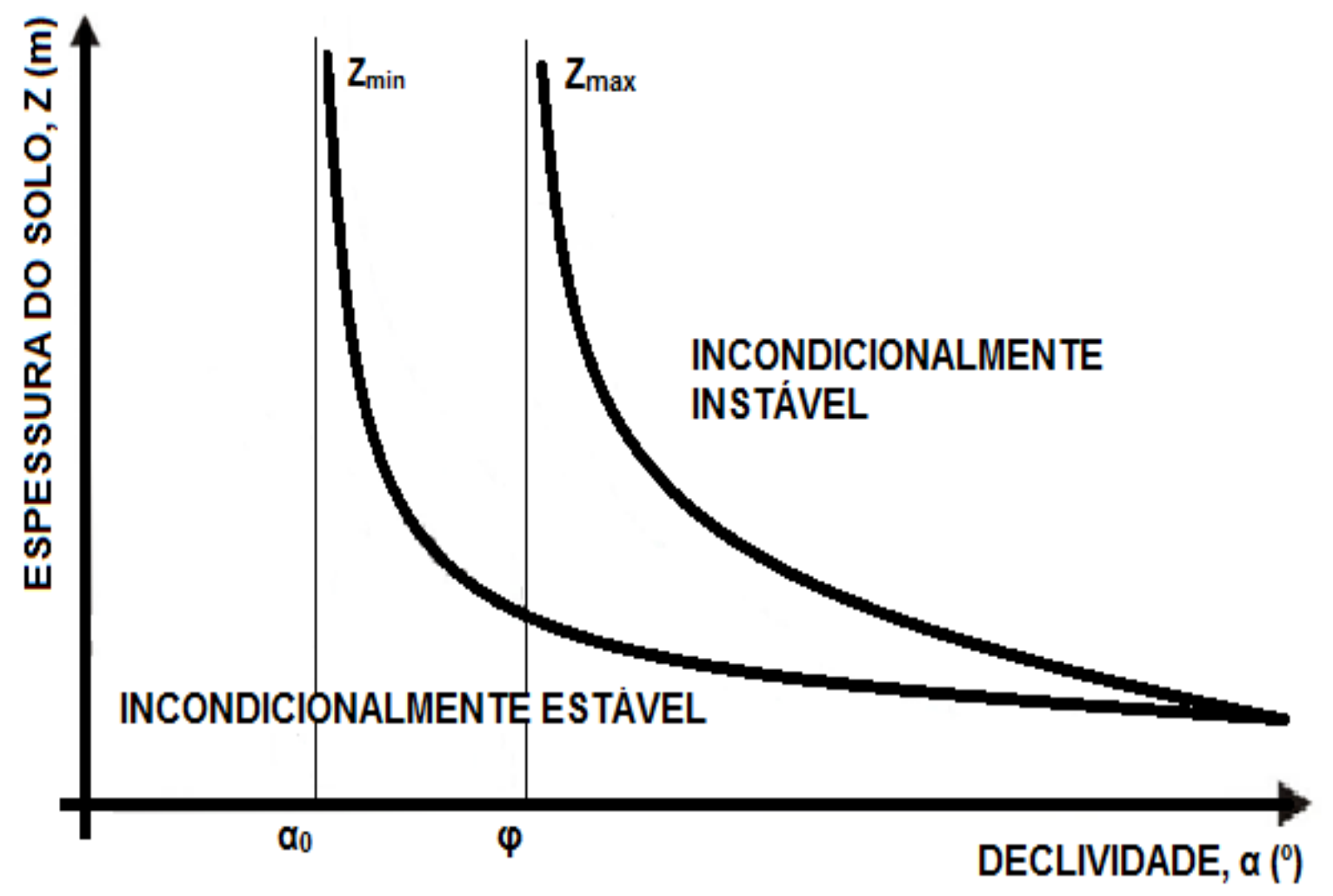

Figura 5.1 - Susceptibilidades aos escorregamentos em função da espessura do solo e da declividade (modificado de Aristizabal et al. 2013)

Aristizabal et al. (2013) propõe para o cálculo de $\mathbf{Z}_{\mathbf{m i n}}$, igualar a carga hidráulica total com a espessura do solo $\boldsymbol{\Psi}(\mathbf{Z}, \mathbf{t})=\mathbf{Z}$ na equação do $\mathbf{F S}$, Eq. 4.1 para $F S=1$ e isolar a espessura do solo, para obter o valor de $Z_{\min }$ Eq. 5.1

$$
Z_{\min }=\frac{c}{\left[\left(1-\frac{\tan \varphi}{\tan \alpha}\right) \cdot\left(\gamma_{s} \cdot \operatorname{sen} \alpha \cdot \cos \alpha\right)+\gamma_{w} \cdot \tan \varphi\right]}
$$

lida, (1999), citado por Aristizabal et al. (2013) adverte que a profundidade saturada do solo sempre vai ser menor do que a espessura do solo residual $(\boldsymbol{\Psi}(\mathbf{Z}, \mathbf{t})$ $\leq \mathbf{Z}$ ), portanto, quando $\mathbf{Z}<\mathbf{Z}_{\min }$, as células serão sempre estáveis, independentemente da pluviosidade.

O mesmo ocorre para certo valor de espessura de solo $\mathbf{Z}_{\max }$, onde a profundidade saturada suficiente para provocar escorregamentos, independentemente da presença da água, é considerado $\boldsymbol{\Psi}(\mathbf{Z}, \mathbf{t})=\mathbf{0}$, portanto nas 
células onde a espessura do solo $\mathbf{Z}>\mathbf{Z}_{\max }$, o solo vai ser sempre instável, independentemente da pluviosidade.

Para obter $\mathbf{Z}_{\max }$, igualamos $\boldsymbol{\Psi}(\mathbf{Z}, \mathbf{t})=\mathbf{0}$ na equação do $\mathbf{F S}$, Eq. 4.1 para $F S=1$, isolando a espessura do solo, obteremos o valor de $\mathbf{Z}_{\max }$ Eq. 5.2

$$
Z_{\max }=\frac{c}{\left(1-\frac{\tan \varphi}{\tan \alpha}\right) \cdot \gamma_{\mathrm{s}} \cdot \operatorname{sen} \alpha \cdot \cos \alpha}
$$

Além disso, é necessário achar o valor máximo da declividade $\boldsymbol{\alpha}_{0}$ até onde o comportamento das encostas será sempre estável, independentemente da presença da água, porque seria necessária uma profundidade do solo saturado $(\boldsymbol{\Psi}(\mathbf{Z}, \mathbf{t}))$ maior do que a espessura do solo (Z), para provocar um deslizamento.

O valor de $\boldsymbol{\alpha}_{0}$ é obtido quando é considerado o solo $\operatorname{sim}$ coesão $\mathbf{c}=\mathbf{0}$, e a profundidade saturada do solo adquire valor máximo $\Psi(\mathbf{Z}, \mathbf{t})=\mathbf{Z}$ na equação do $F S$, Eq. 4.1 para $F S=1$. Assim, quando $\alpha_{0} \leq \boldsymbol{\alpha}$, a encosta sempre será estável.

$$
1=\frac{\tan \varphi \cdot\left(\gamma_{s} \cdot \cos \alpha^{2}+\gamma_{w}\right)}{\gamma_{s} \cdot \sin \alpha \cdot \cos \alpha}
$$

Não foi possível isolar a variável ao por métodos simples na equação Eq. 5.3, a obtenção do valor de $\alpha_{0}$ foi mediante aproximações sucessivas até conseguir a igualdade proposta na equação. $O$ valor final para $\alpha_{0}$ foi $\alpha_{0}=10.04$

Finalmente, fica definida a metodologia a implementar para a obtenção das células provavelmente instáveis aos escorregamentos produzidos por eventos de chuva, aplicada ao modelo de Papa et al. (2011).

$\mathrm{Na}$ Fig. 5.2, é representado o processo explicitado até agora, partindo da obtenção das equações de $\mathbf{Z}_{\max }$ e $\mathbf{Z}_{\min }$, a comparação delas com a espessura do solo $\mathbf{Z}$, a comparação da declividade $\boldsymbol{\alpha}$ com $\boldsymbol{\alpha}_{0}$, até obter as células que satisfazem as condições de incondicionalmente estáveis, incondicionalmente instáveis e provavelmente instáveis aos escorregamentos produzidos por eventos de chuva. 


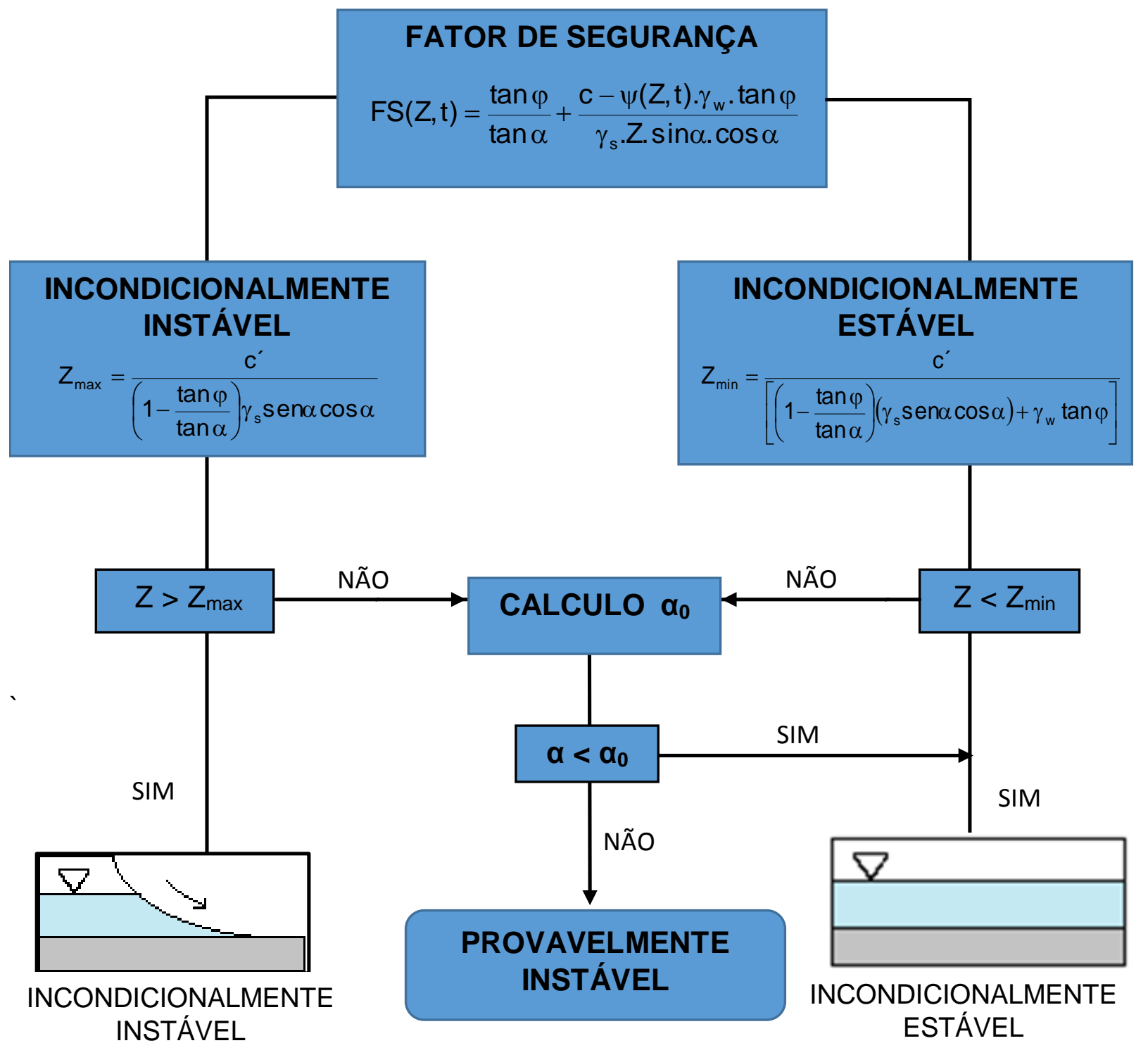

Figura 5.2 - Metodologia para obter células provavelmente instáveis, aplicada ao modelo de Papa et al. (2011) (modificado de Aristizabal et al. 2013)

\subsection{Aplicação do Modelo}

A área escolhida para fazer a aplicação está localizada ao oeste da "Gran Piedra" e presentam os mesmos parâmetros de solo da "Região 4" da "Gran Piedra", pois estão localizadas na mesma formação geológica, por esta razão são assumidos os mesmos parâmetros de solo e o valor do $D_{0}$ obtido na calibração. 
A região da "Sierra Maestra" abrange uma área aproximada de $300 \mathrm{~km}^{2}$, a elevação máxima é o "Pico Turquino", ponto de maior altitude em Cuba, com 1974 m sobre o nível médio do mar.

Os elementos requeridos para fazer os cálculos na etapa de validação são os listados no sub-item 4.3, do Capitulo 4, referente aos dados de entrada do modelo.

A representação matricial e o processamento das variáveis estáticas e dinâmicas, foram obtidos da mesma forma já explicada no Capitulo 4.

$\mathrm{Na}$ área escolhida, região "Sierra Maestra", existe um inventário de escorregamentos produzidos pela passagem do furação Flora no ano 1963 (Fig. 5.3), tomado do Atlas de ameaças da província de Guamá, Reyes \& Seisdedos, (2001).

É conhecido pela referência que os deslizamentos que aparecem no inventario citado são deslizamentos de grandes dimensões.

A fonte desta informação tem uma escala muito grande; a escala do MDE que está sendo usado, tem uma escala mais detalhada, e ao georeferenciar o inventário de deslizamentos no MDE, não é possível obter pontos, pelo contrário, foram obtidas pequenas zonas encerradas em círculos.

Segundo Seisdedos \& Reyes, (2001), no Atlas de ameaças da província de Guamá, a passagem do furação Flora produziu um forte impacto ambiental na região da "Sierra Maestra", especialmente no município "Guama".

Esta afetação, presente na atualidade, tem a ver com a formação de represas naturais nas montanhas, produto dos numerosos escorregamentos de terras ocorridos durante a passagem deste furação (Seisdedos \& Reyes, 2001).

A ação natural das correntes fluviais quebrou as represas provocando fluxo de agua, rochas, lama, arrastando a vegetação até as planícies e gerando grandes inundações e a obstrução dos leitos dos rios, diminuindo a sua capacidade de transportação e causando repentinas inundações, problema este frequente na atualidade no município "Guama". 


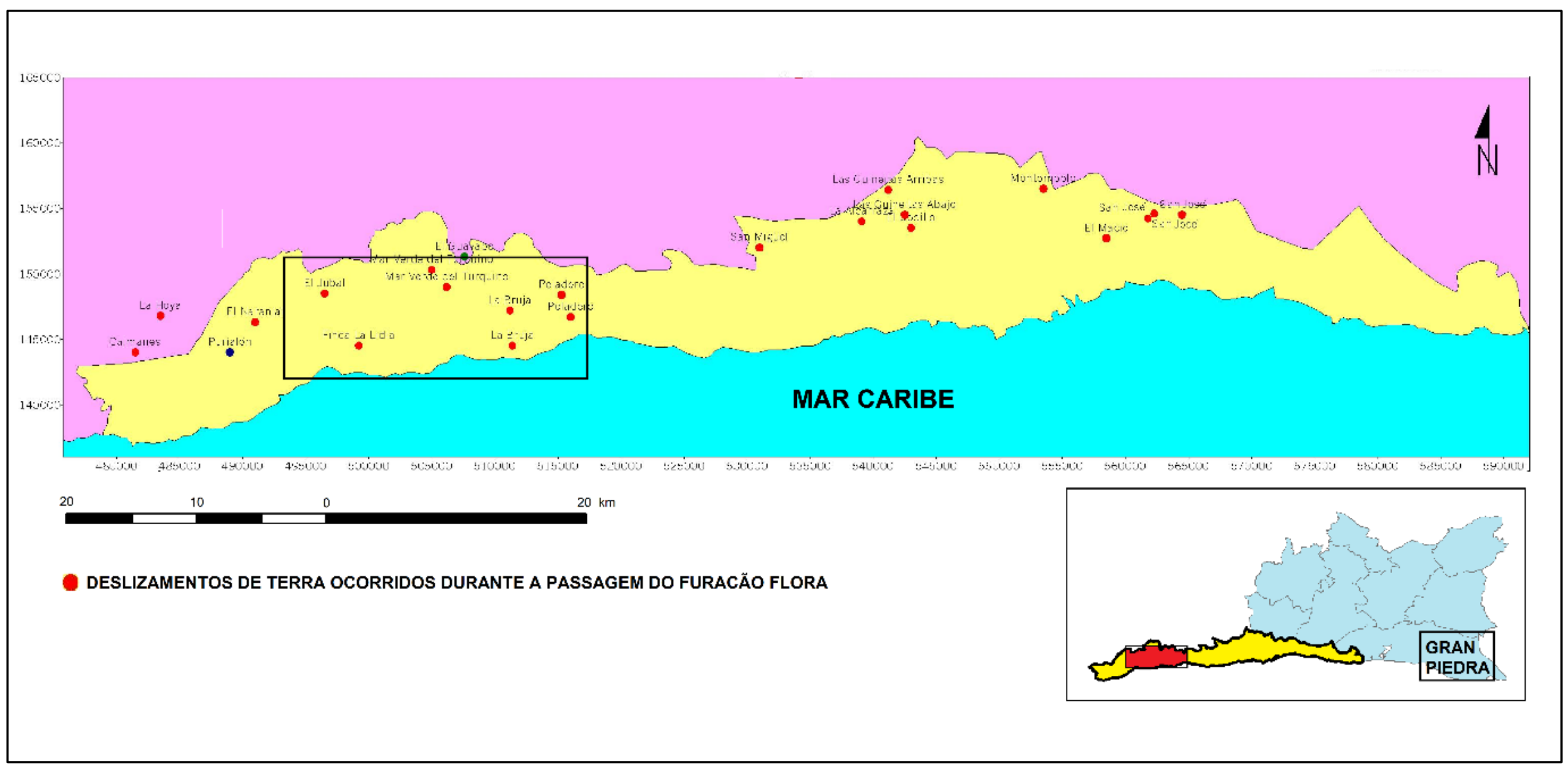

Figura 5.3 - Inventário de escorregamentos produzidos pelo furação "Flora", tomado do Atlas de ameaças da província de Guamá, Seisdedos \& Reyes, (2001). 
Outra afetação foi o impacto social, já que foi uma das causas do êxodo para as cidades vizinhas da população que morava nas montanhas.

De salientar que este impacto ambiental, conhecido como o mais notável acontecido em toda a "Sierra Maestra", tem sido pouco documentado, talvez, porque muitos mais danos foram produzidos ao mesmo tempo por inundações na província vizinha.

A passagem do furação "Flora" provocou a morte de 1.157 pessoas, destruição de 10.000 casas, afetando 20.000 moradias e desabrigando 175.000 pessoas (EMNDC, 2007), citado por (Castellanos 2008).

No caso da aplicação das intensidades das chuvas, foi utilizado o mesmo evento do furação Flora como descrito na Tab. 4.6 do Capitulo 4.

Depois de concluída a tarefa de processar os dados de entrada, já se se pode aplicar o modelo na região da "Sierra Maestra".

Na simulação do evento do furacão "Flora" na região da "Sierra Meatra", também foi considerada a intensidade da chuva antecedente $\mathbf{I}_{\mathbf{z}}$ (estacionário) igual a zero na Eq. 4.3; isto faz com que o termo $\boldsymbol{\Psi}(\mathbf{Z}, \mathbf{0})$ seja zero na Eq. 4.4.

$\mathrm{Na}$ obtenção do FS fornecido pela Eq. 4.1, o termo $\boldsymbol{\Psi}(\mathbf{Z}, \mathbf{t})$ dependente da intensidade do evento $\mathrm{lz}$ foi calculado para cada intervalo da Tabela 4.6 de $1 \mathrm{~h}, 1.5 \mathrm{~h}$, $2.5 \mathrm{~h}, 5 \mathrm{~h}, 12 \mathrm{~h}$ e $24 \mathrm{~h}$.

Ao contrário da calibração, não é preciso considerar em cada intervalo a contribuição acumulativa que faz a $\boldsymbol{\Psi}(\mathbf{Z}, \mathbf{t})$, uma vez que as intensidades da Tabela 4.6 já são acumulativas no tempo.

A seguir, as Fig. 5.4 a Fig. 5.9, são o resultado do comportamento das encostas na região "Sierra Maestra" produzido pela simulação do evento do furação "Flora.

Estas simulações foram realizadas para as intensidades de chuvas de $72 \mathrm{~mm} / \mathrm{h}$ em $1 \mathrm{~h}, 66 \mathrm{~mm} / \mathrm{h}$ em $1.5 \mathrm{~h}, 55 \mathrm{~mm} / \mathrm{h}$ em 2.5h, $48 \mathrm{~mm} / \mathrm{h}$ em $5 \mathrm{~h}, 37 \mathrm{~mm} / \mathrm{h}$ em $12 \mathrm{~h}$ e 28.5 $\mathrm{mm} / \mathrm{h}$ em $24 \mathrm{~h}$. 


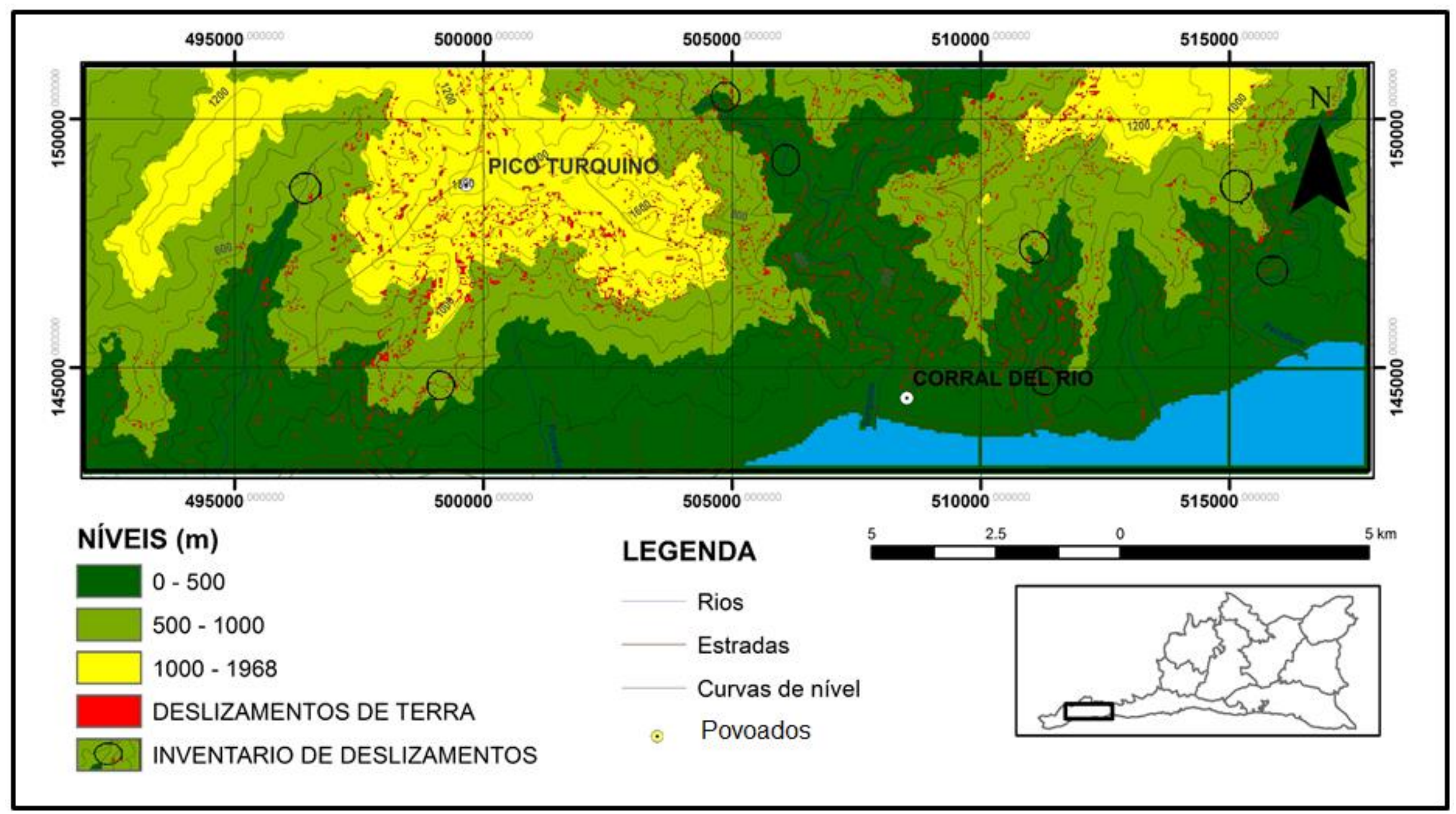

Figura 5.4 - Comportamento das ladeiras durante a simulação do furação "Flora" em "Sierra Maestra" para uma I=72mm/h em $1 \mathrm{~h}$. 


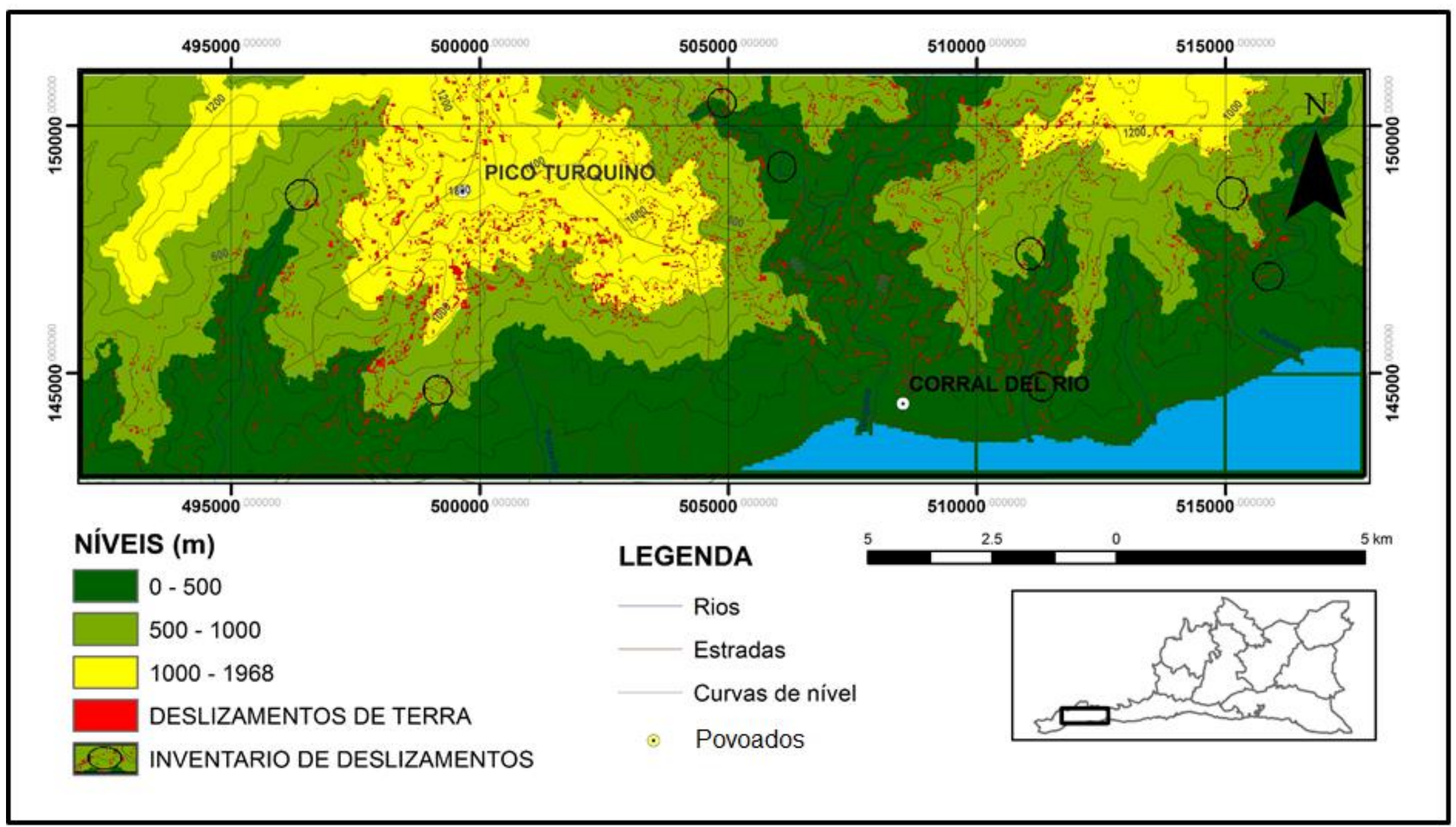

Figura 5.5 - Comportamento das ladeiras durante a simulação do furação "Flora" em "Sierra Maestra" para uma I=66 mm/h em 1.5h. 


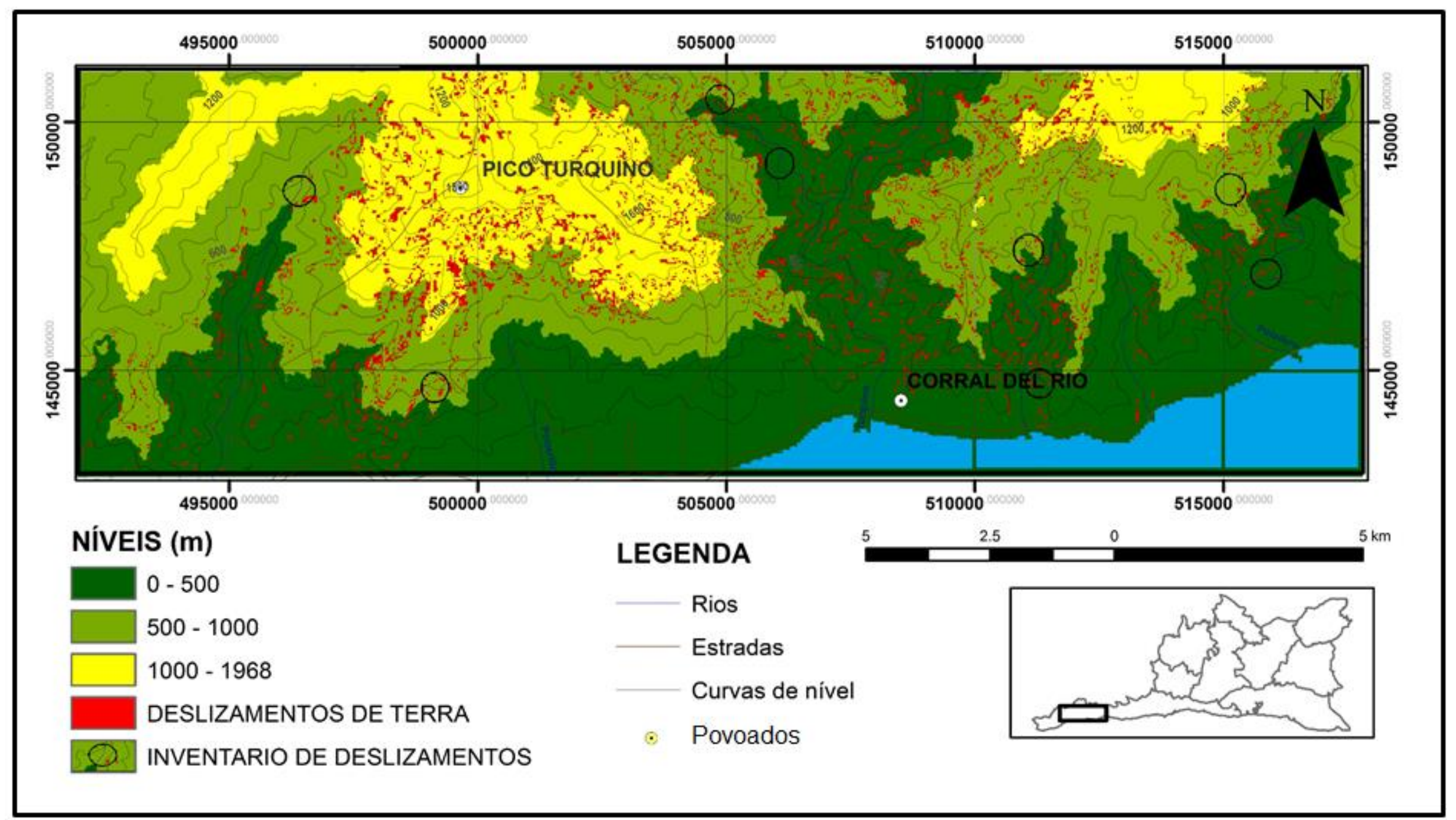

Figura 5.6 - Comportamento das ladeiras durante a simulação do furação "Flora" em "Sierra Maestra" para uma l=55mm/h em 2.5h. 


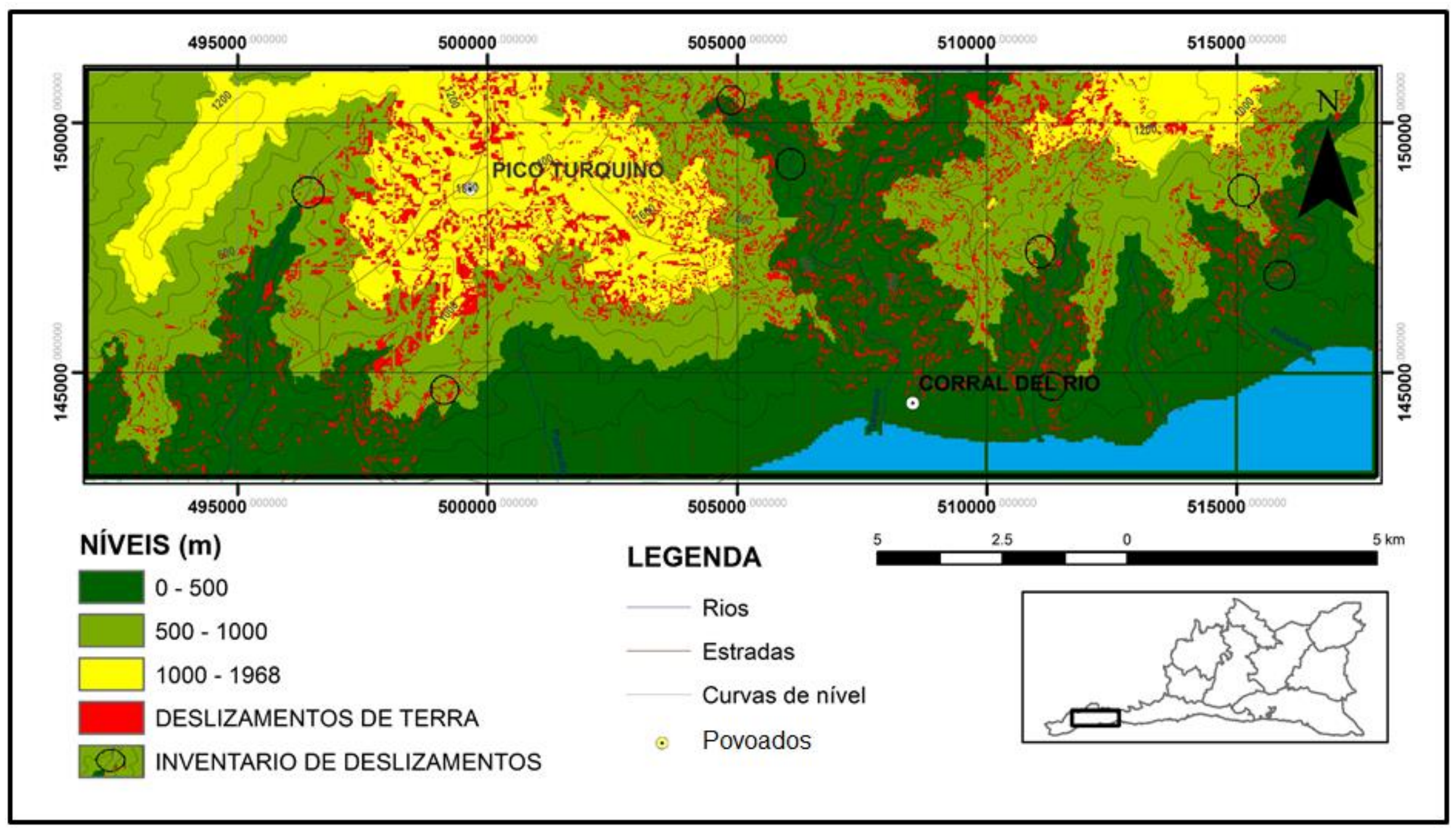

Figura 5.7 - Comportamento das ladeiras durante a simulação do furação "Flora” em "Sierra Maestra” para uma I=48mm/h em 5h. 


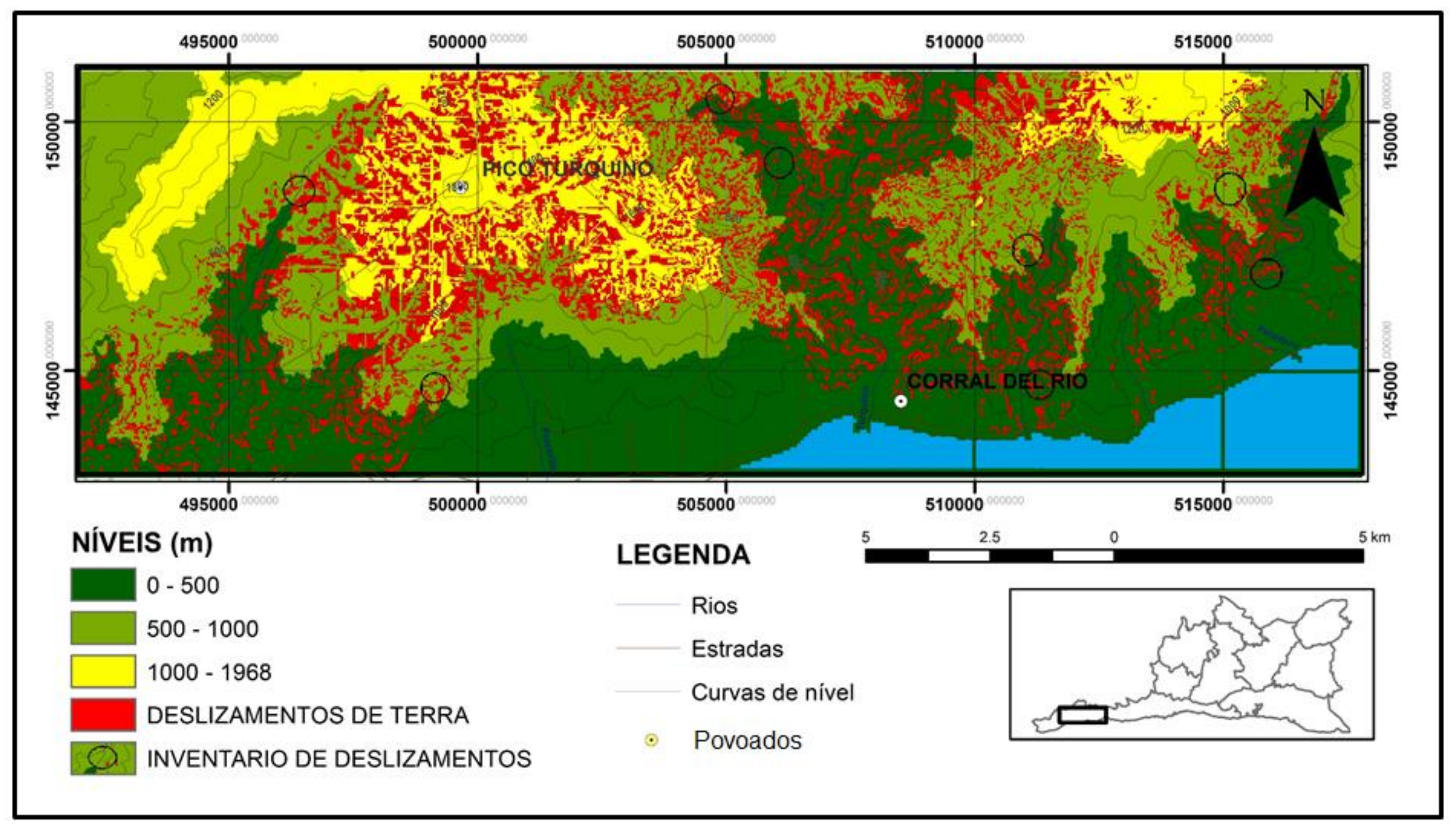

Figura 5.8 - Comportamento das ladeiras durante a simulação do furação "Flora" em "Sierra Maestra" para uma I=37mm/h em 12h. 


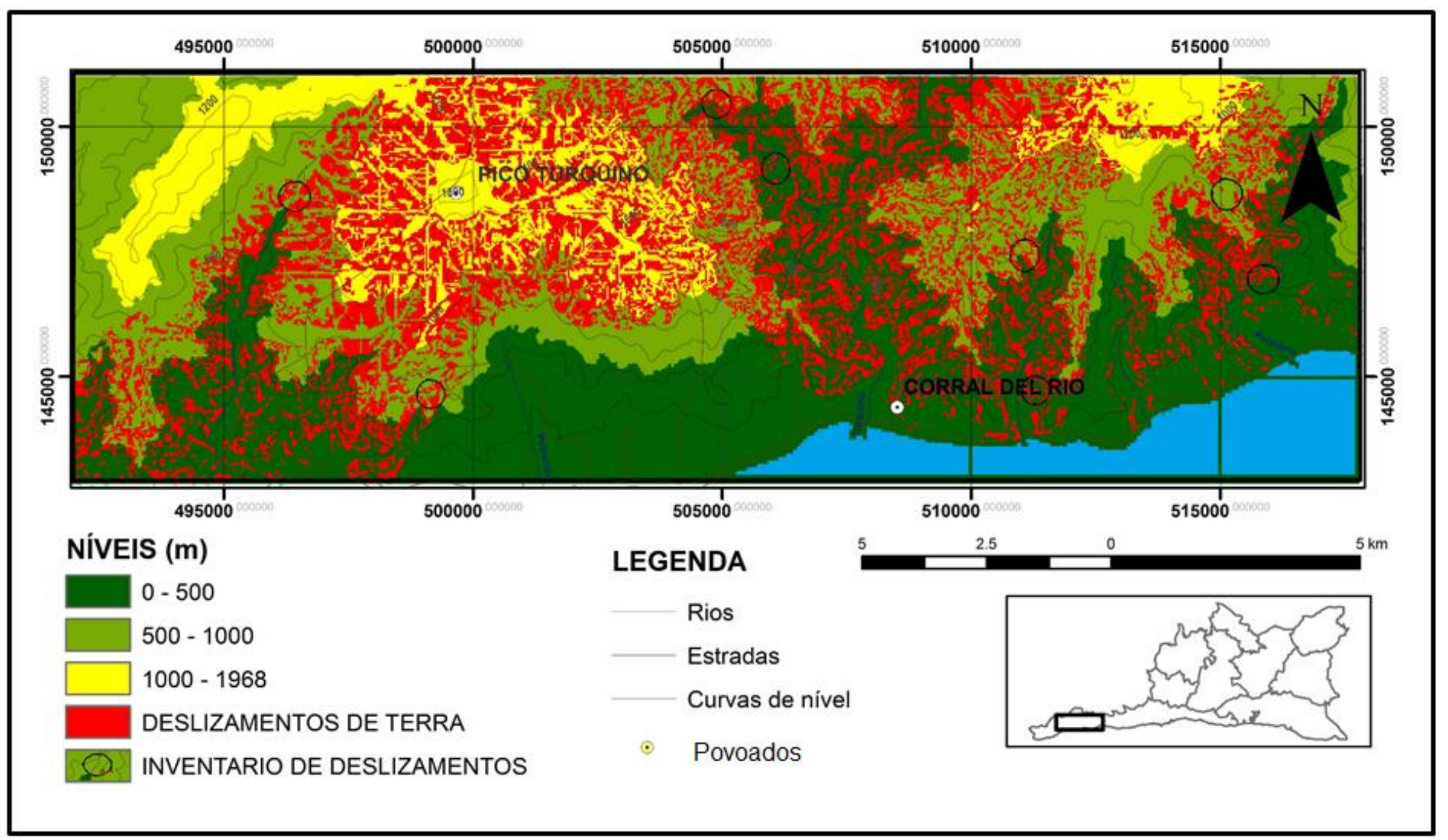

Figura 5.9 - Comportamento das ladeiras durante a simulação do furação "Flora" em "Sierra Maestra" para uma I=28.5mm/h em 24h. 
Na gráfica da Fig. 5.10, são apresentados os resultados das simulações do evento do furação "Flora", realizadas para as intensidades de chuvas $I_{\mathbf{z}}$ de $72 \mathrm{~mm} / \mathrm{h}$ em $1 \mathrm{~h}, 66 \mathrm{~mm} / \mathrm{h}$ em 1.5h, $55 \mathrm{~mm} / \mathrm{h}$ em 2.5h, $48 \mathrm{~mm} / \mathrm{h}$ em $5 \mathrm{~h}, 37 \mathrm{~mm} / \mathrm{h}$ em $12 \mathrm{~h}$ e 28.5 $\mathrm{mm} / \mathrm{h}$ em $24 \mathrm{~h}$ representadas pelas Fig. 5.4 a Fig. 5.9. Para cada uma destas simulações, foi calculada a porcentagem de células com probabilidade de ruptura PR, representada em porcentagem na Fig. 5.10, e o volume de terras movimentadas por fluxo de detritos em milhões de metros cúbicos, verificando o aumento destes com o passo do tempo. Com cada simulação, é possível observar o comportamento das encostas nas zonas escolhidas pelo inventario de escorregamento, na medida em que aumenta a quantidade de precipitação com o tempo, é possível observar um aumento na quantidade das células falhadas, aumentando a porcentagem de células com probabilidade de ruptura, e a probabilidade de ocorrência de deslizamentos. De salientar que o cálculo da PR foi feito só para o total de células provavelmente instáveis, obtidas pela metodologia explicada na Fig. 5.2, deste capitulo.

$$
\mathrm{PR}(\%)=\frac{\sum \text { células FS } \leq 1}{\text { total de células }} \times 100
$$

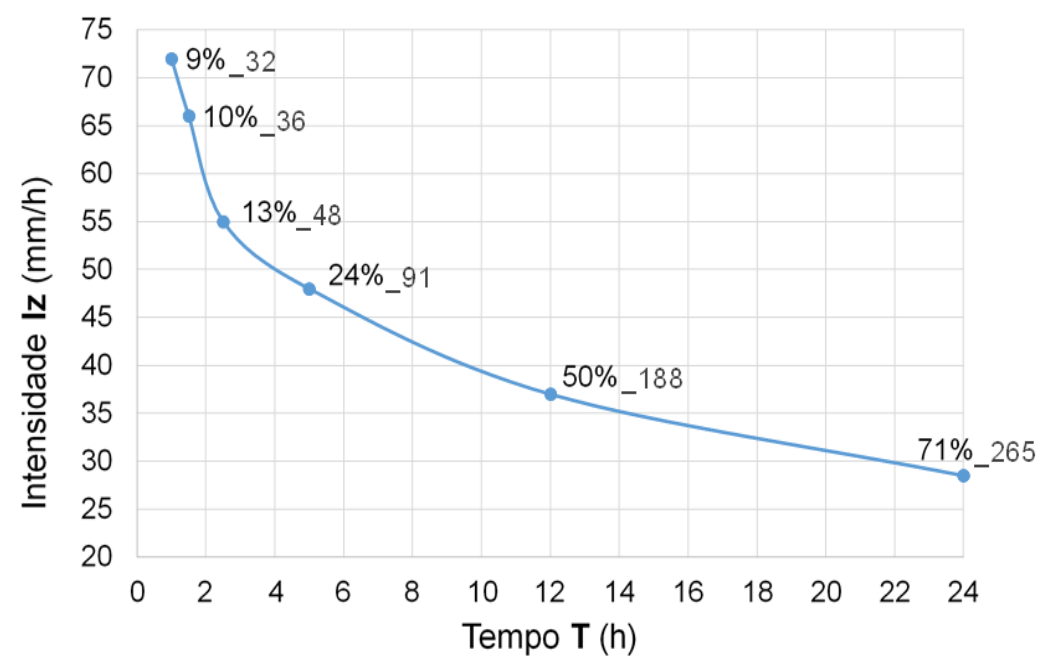

Figura 5.10 - Curva de Intensidade, Duração do furação "Flora".

Na Fig. 5.9 se observa a possibilidade da existência de erro propagado em forma de malha em toda a área analisada, por esta razão, foi decidido fazer um mapa de curvas de nível do MDE, utilizado na modelagem, cujo resultado é mostrado na Fig. 5.11 . 


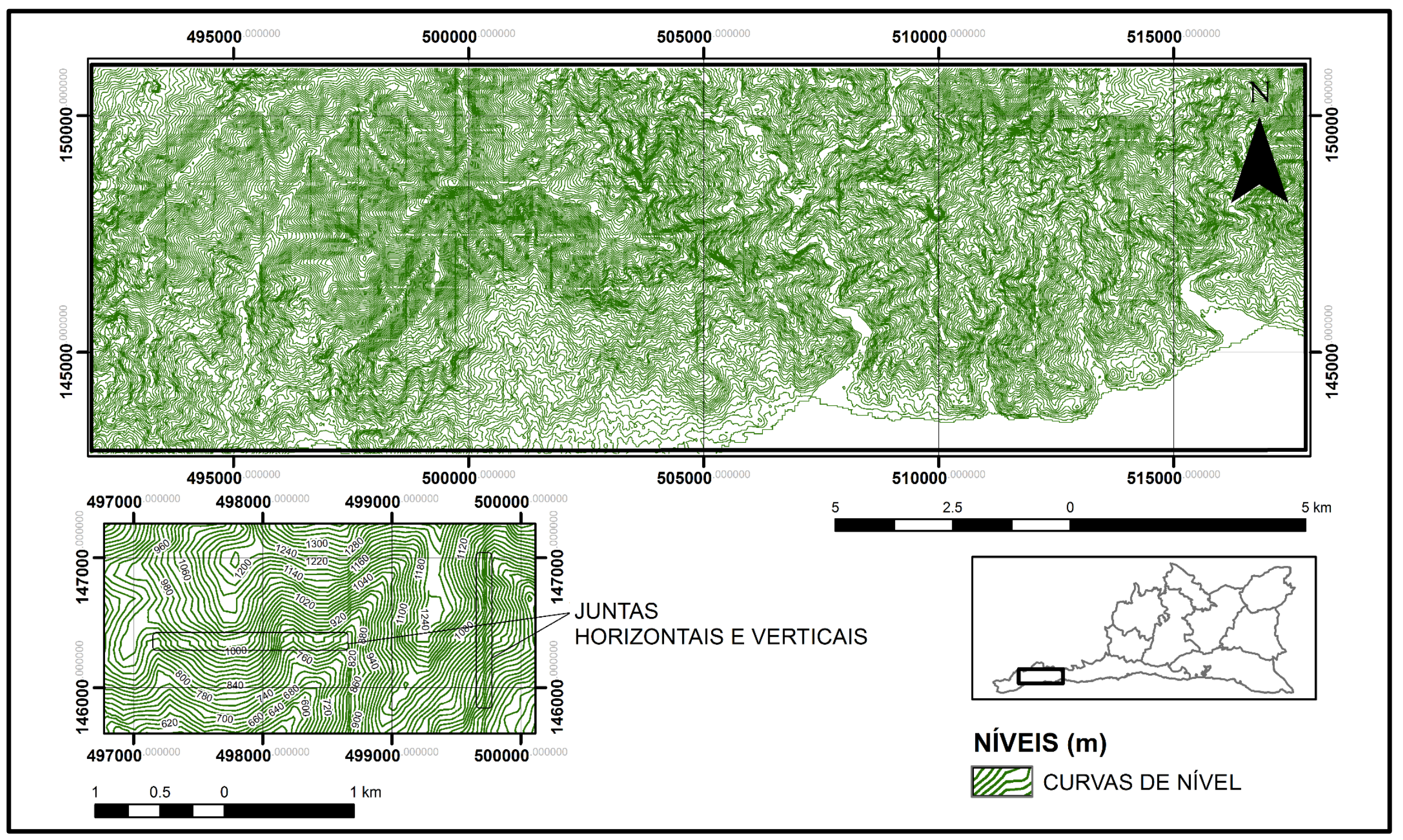

Figura 5.11 - Mapa de curvas de nível da região "Sierra Maestra". 


\subsection{Sistema de Alerta.}

Uma forma eficiente na aplicação deste método é quando aplicado como ferramenta de alerta, a partir das simulações dos possíveis valores de intensidade das precipitações no tempo, que podem acontecer numa região determinada.

O objetivo desta vez é monitorar o comportamento das encostas de uma região durante a passagem de um evento meteorológico qualquer.

Neste caso, conta-se com as curvas de Intensidade Duração e Frequência (IDF) da região da "Gran Piedra", onde foi feita a calibração, para os períodos de retorno $T$ de 2, 5, 10, 25, 50, 100 e 500 anos (Fig. 5.12).

Estas curavas IDF contém todos os possíveis valores de intensidade das precipitações no tempo que podem ocorrer na região da "Gran Piedra".

Esta forma de aplicação do modelo permite criar com antecedência bases de dados de o comportamento das ladeiras.

Para cada valor de chuva é obtida a reposta das encostas em termos a porcentagem de células com probabilidade de ruptura PR e/ou o volume de terras movimentadas por fluxo de detritos em essa região.

Desta forma é possível monitorar a região durante a passagem de algum evento meteorológico, observando como na medida que variam as chuvas, vai mudando o valor de porcentagem de células com probabilidade de ruptura PR e/ou o volume de terras movimentadas por fluxo de detritos, podendo se prever as possíveis consequências.

Então é possível obter o risco total para esse evento de chuva, aplicando por exemplo a formulação do capítulo 1 (Eq. 1.1), onde o risco vai depender dos elementos em risco $(E)$, a ameaça $(H)$ relacionada com a probabilidade de ocorrência de um evento danoso e a vulnerabilidade (V) referente as perdas resultantes da ocorrência de esse evento danoso.

$$
R_{t}=(E) \cdot(H \cdot V)
$$

Neste caso assumiremos como elementos em risco que 40 pessoas podem ser afetadas pela ocorrência de fluxo de detritos. Com antecedência se deve ter o censo da população localizada na região e/ou as atividades econômicas. 
A vulnerabilidade deve ser calculada, neste caso assumiremos o valor 0.2.

No caso da ameaça, sabendo que tem chovido $60 \mathrm{~mm} / \mathrm{h}$ em 8 h, na Fig. 5.13 para T-500 anos esse ponto é localizado.

Com antecedência foi calculada a porcentagem de células com probabilidade de falha e para esse ponto o valor foi de $49 \%$. Isto significa que o $49 \%$ das células tem FS $\leq 1$ e que pelo menos o $50 \%$ desses $49 \%$ das células podem falhar. Por tanto o valor da ameaça para o cálculo vai ser 0.245 .

$\mathrm{R}_{\mathrm{t}}=(40) \cdot(0.245 \cdot 0.2)=1.96 \approx 2$ pessoas.

O resultado indica que pelo menos duas pessoas podem chegar a ser afetadas totalmente pela ocorrência desse evento.

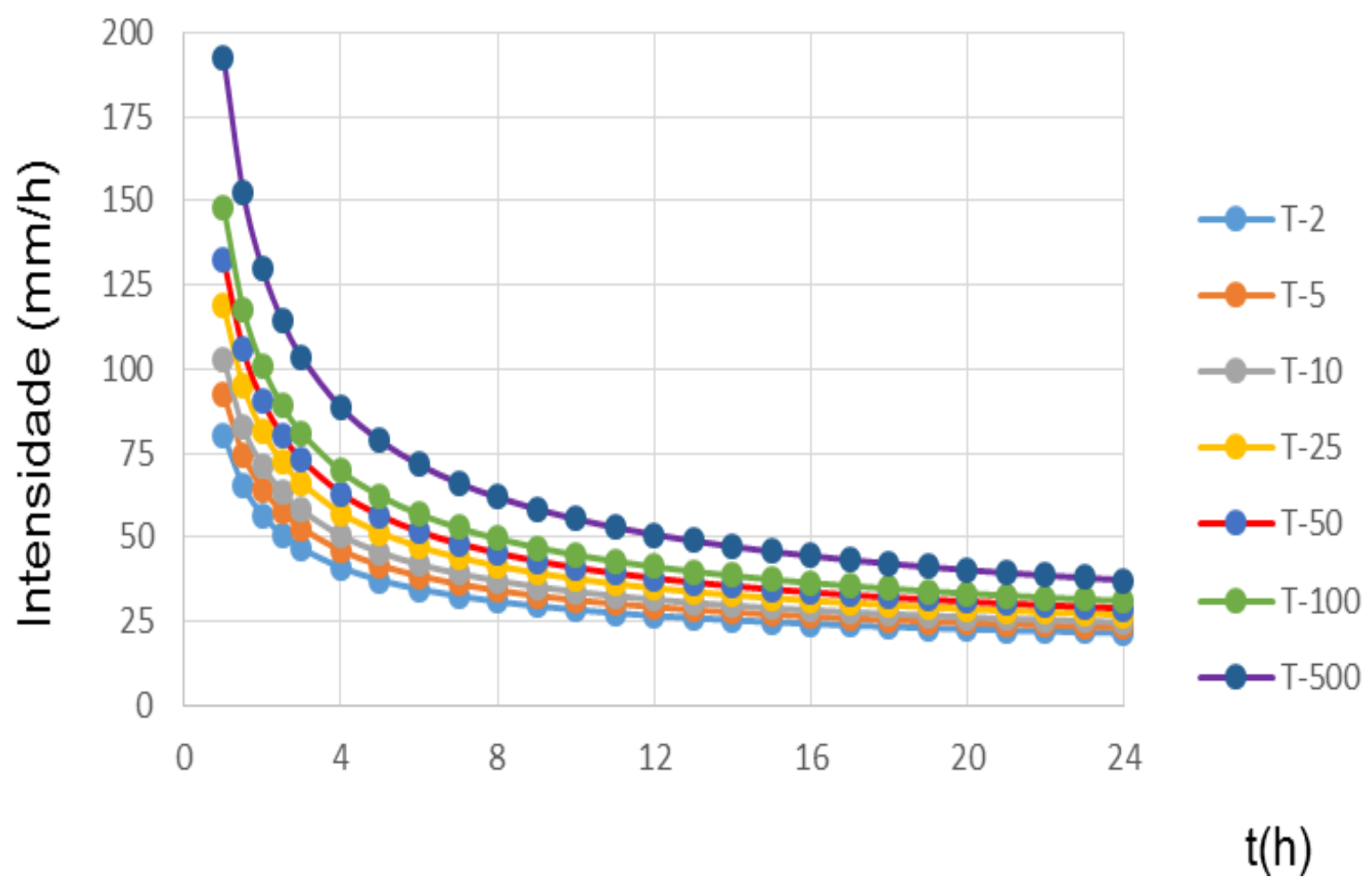

Figura 5.12 - Gráfica de curvas IDF para a região da "Gran Piedra", com períodos de retorno $T$ de 2, 5, 10, 25, 50, 100 e 500 anos. 


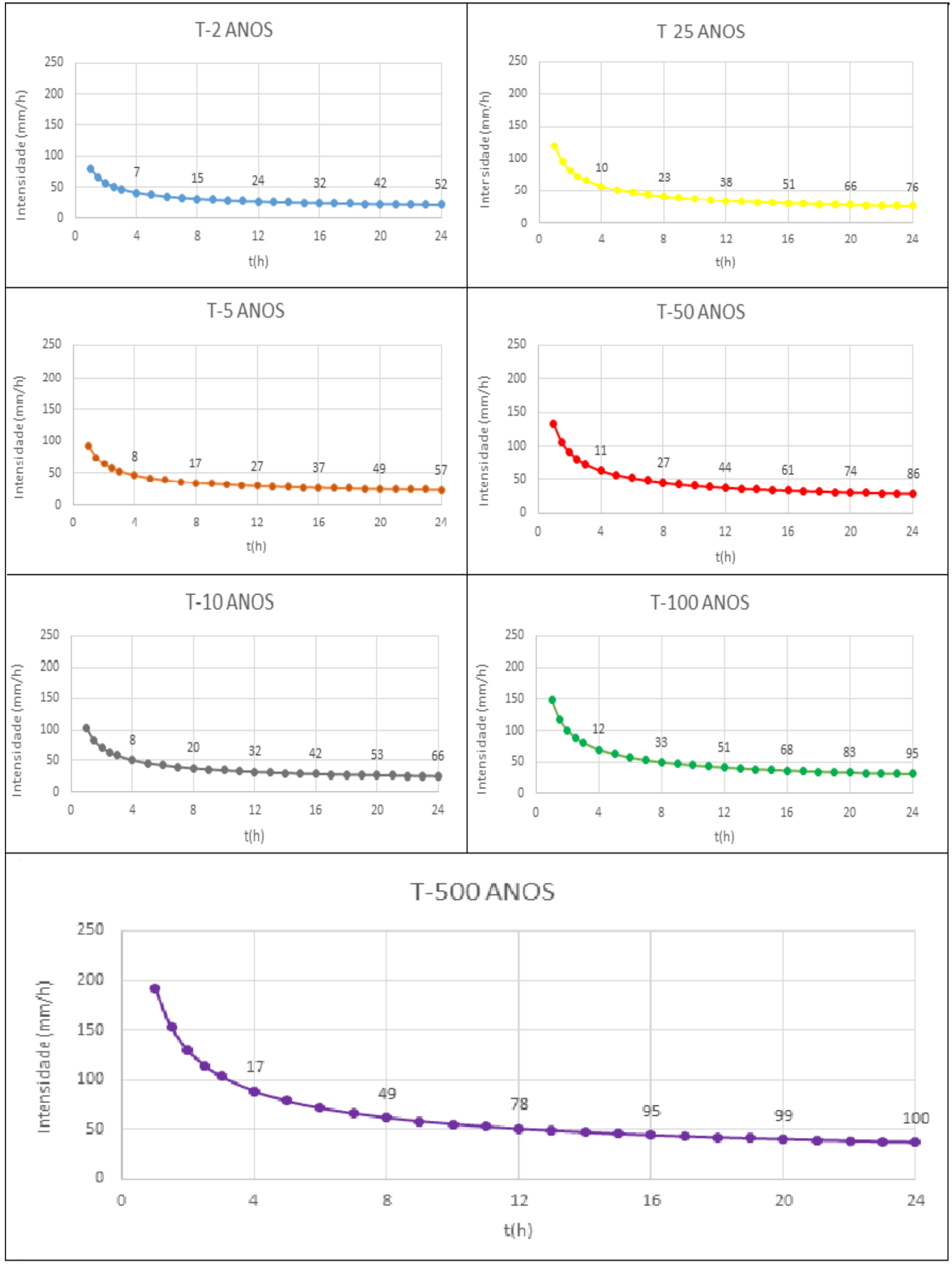

Figura 5.13 - Gráficas do comportamento da PR na região da "Gran Piedra para as diferentes probabilidades de chuva. 


\section{Capitulo 6: Conclusões}

\subsection{Conclusões}

No presente estudo, foi aplicado em uma região tropical e montanhosa de Cuba, um modelo, (Papa et al., 2011) com base na solução analítica da equação de Richards válida na hipótese de uma infiltração vertical (Iverson, 2000).

Este modelo de previsão da iniciação de fluxo de detritos, é baseado em um sistema capaz de alertar a ocorrência de fluxos de detritos através das simulações de estabilidade feitas previamente, para qualquer combinação possível de ocorrência de precipitações em termos de intensidade e duração das chuvas que podem gerar ou não fluxos de detritos na região analisada. Estas simulações levam em consideração uma precipitação antecedente cujos efeitos são calculados pela hipótese de condições de estado estacionário (Montgomery e Dietrich, 1994).

Como resultado, o modelo pode ser utilizado como uma ferramenta de alerta, que avalia a possível instabilidade do terreno de forma extremamente rápida em tempo real, podendo-se monitorar o comportamento das encostas durante a ocorrência de um evento meteorológico. O sistema de alerta também pode ser utilizado como ferramenta de planificação para o ordenamento territorial de uma determinada região, uma vez que identifica regiões com ameaça de ocorrência de escorregamentos de terra, onde não deveria ser desenvolvida nenhuma atividade social ou econômica.

Uma vantagem importante no uso da metodologia é que podem ser identificados um conjunto de limiares críticos de precipitações, cada um deles correspondente ao nível fixo de risco do fluxo de detrito, que podem ser analisados em termos de porcentagem de células das encostas com probabilidade de ruptura ou em volumes aproximados de solo espalhado pela ocorrência de fluxo de detritos.

Esta metodologia de simulação é extremamente simplificada, exigindo um curto período de tempo utilizado no processamento computacional e um conjunto limitado de insumos básicos.

Antes da aplicação do modelo em uma região determinada, é preciso ter feito previamente a calibração do modelo para essa área, mediante o parâmetro $\mathrm{D}_{\mathbf{0}}$. 
No caso desta dissertação, a calibração foi feita apenas para um tipo de solo, utilizando um só evento de chuva.

É recomendado fazer ensaios laboratoriais que permitam validar os parâmetros de solo obtidos na literatura $\left(\gamma_{\mathbf{s}}, \varphi, \mathbf{c}^{\prime}, \mathbf{K}_{\mathbf{x}} \in \mathbf{K} \mathbf{z}\right)$, neste trabalho não foram realizados mas na prática é preciso validar esta informação.

Foi simulado o evento mais extremo que se conheça, ocorrido na região de estudo, e comparado com um inventário unificado de deslizamentos ocorridos para diferentes eventos meteorológicos.

Para a obtenção do mapa de chuvas contou-se apenas com a informação proveniente de uma estação meteorológica, por esta razão se decidiu utilizar isoietas para melhorar a resolução espacial das chuvas dentro da área de análise. A aplicação de mapas de zonas de vida, é uma prática que se vem desenvolvendo na obtenção de mapas de precipitações quando se carece de informação direta. As curvas de zonas de vida de uma região estão delimitadas por parâmetros climáticos como as precipitações e a temperatura e guardam relação com a altitude, por tanto no caso de trabalhos futuros onde não se conte com informação que provejam uma boa resolução espacial das chuvas, se recomenda o uso deste tipo de mapas.

Durante o processo de calibração e validação, não foi considerada nos cálculos a contribuição da chuva antecedente, então é preciso calibrar e testar o modelo em outros casos onde seja válida a contribuição deste parâmetro.

Foi localizado um erro propagado em forma de malha no MDE; este erro foi detectado ao final da validação sem oportunidade de trocar o MDE para obter novos resultados. O erro no MDE afeta o resultado final mas só nas células situadas nas linhas horizontais e verticais que conformam a malha de erros, uma vez que o modelo proposto por Papa et al, (2011) é aplicado em esta dissertação para cada célula independente, sendo que o cálculo final do FS é independente para cada célula.

A informação obtida no percurso de campo ajudou na conclusão de que o solo residual predominante na região é solo residual de rochas ígneas, principalmente vulcânica, ajudando na escolha definitiva do parâmetro de solo. 
A escala das fotografias de voos aéreos, utilizadas na obtenção do inventário de escorregamentos, é muito grande, fato que atrapalha a identificação de deslizamentos de pequenas dimensões, dado que o evento do furação "Flora" simulado na calibração do modelo, foi um evento que gerou grandes deslizamentos de terra. A informação adquirida na fotointerpretação das imagens aéreas passou a ser aceita.

A aplicação da metodologia para a identificação de células provavelmente instáveis ante os eventos de chuva é muito importante, pois uma vez que são suprimidas da análise, as células incondicionalmente instáveis e as incondicionalmente estáveis que são aquelas que vão ter essa condição independemente da ocorrência do evento de chuva, o processo de cálculo é mais rápido, tornando-se mais eficiente a aplicação do modelo. As curvas obtidas pela ferramenta utilizada são calculadas desta vez para um volume total fixo proporcionado pelos elementos provavelmente instáveis dentro da área analisada, com esta hipótese é possível definir curvas de limiares críticas para volumes de fluxo de detritos real produzido por eventos meteorológicos.

Foi obtido para a região da "Gran Piedra" uma ferramenta que pode ser usada como sistema de alerta, que avalia a possível instabilidade do terreno de forma extremamente rápida em tempo real, em termos de porcentagem de células das encostas com probabilidade de ruptura ou em volumes de solo deslizados pela ocorrência de fluxo de detritos, uma vez que foi avaliada a região para a curvas IDF. 


\section{Referências Bibliográficas}

ABNT (2009). Gestão de riscos - Princípios e diretrizes. NBR ISO 31000, Associação Brasileira de Normas Técnicas, Rio de Janeiro, RJ, 32 p.

ARISTIZÁBAL, E.V. (2014). SHIA_LANDSLIDE: Developing a Physically Based Model to Predict Shallow Landslides Triggered by Rainfall in Tropical Environments. Doctor of Engineering Thesis, Universidad Nacional de Colombia, Medellín, Colombia, 223p.

ARISTIZÁBAL, E., VALENCIA, Y., GUERRA, A., VÉLEZ, M. \& ECHEVERRI, O. (2011). Caracterización geotécnica de perfiles de meteorización desarrollados sobre rocas ígneas en ambientes tropicales. Boletín de Ciencias de la Tierra, 30 pp47-60

ASOUDEH, A. \& OH, E. (2014). Strength parameter selection in stability analysis residual soil nailed walls. Geomate 7(1):950-954.

ASSIS, A.P., ESPÓSITO, T.J., GARDONI, M.G., SILVA, P.D.E.A. \& MAIA, J.A. (2012). Métodos estatísticos e probabilísticos em geotecnia. Apostila Publicação G.AP-002/2012, UnB, Brasília, Distrito Federal, 278 p.

AZEVEDO, G.F. (2011). Análise da Relação Chuva-Escorregamentos em Regiões Tropicais Montanhosas Urbanas, Caso de Estudo Rio de Janeiro, Brasil. Dissertação de Mestrado, Universidade de Brasília, Brasília, Distrito Federal, 120p.

AZEVEDO, G.F. (2015). Sistema de análise quantitativa de risco por escorregamentos rasos deflagrados por chuvas em regiões tropicais, Brasil. Tese de doutorado, Universidade de Brasília, Brasília, Distrito Federal, 399 p.

BATHURST, J.C., BURTON, A., CLARKE, B.G. \& GALLART, F. (2006). Application of the SHETRAN basin-scale, landslidesediment yield model to the Llobregat basin, Spanish Pyrenees. Hydrological Processes, 20:3119-3138.

BASTOS, C.A. (1999). Estudo geotécnico sobre a erodebilidade de solos residuais não saturados. Doutorado em Engenharia. Universidade Federal do Rio Grande do Sul. Porto Alegre, Brasil. 303p

BORGA, M., DAlla FONTANA, G., GREGORETTI, C. \& MARCHI, L. (2002). Assessment of shallow landsliding by using a physically based model of hillslope stability. Hydrol Process, 16:2833-2851.

BRABB, E.E. \& HARROD, B.L. (eds). (1989). Landslides: Extent and Economic Significance. Balkema: Rotterdam.

BREGOLI, F., MEDINA, V., CHEVALIER, G., HÜRLIMANN, M. \& BATEMAN, A. (2015) Debris-flow susceptibility assessment at regional scale: Validation on an alpine environment. Landslides, 12:437-454. 
CASERTA, A., MARTINO, S., BOZZANO, F., GOVONI, A. \& MARRA, F. (2012). Dynamic properties of low velocity alluvial deposits influencing seismically-induced shear strains: the Grottaperfetta valley test-site (Rome, Italy). Bull Earthquake Eng 10:1133-1162.

CASTELLANOS, E.A. (2003). La cartografía y evaluación de amenaza a deslizamientos de terreno: VI Congreso Internacional sobre Desastres. Habana, Cuba.

CASTELLANOS, E.A. (2005). "Processing SRTM DEM data for national landslide hazard assessment”. VI Congreso de Geología y Minería. Simposio de sismicidad y riesgos geológicos. $12 \mathrm{p}$.

CASTELLANOS, E.A. \&. Van Westen, C. J. (2007). Generation of a landslide risk index map for Cuba using spatial multi-criteria evaluation. Landslides 4: pp 311-325

CASTELLANOS, E.A. (2008). Multi-Scale Landslide Risk Assessment in Cuba. Doctoral Dissertation. International Institute for Geo-information Science and Earth Observation, Enschede, The Netherlands. 273p

CHUY, T. J. (1999). Macrosísmica de Cuba y su utilización en los estimados de Peligrosidad y Microzonación Sísmica. Tesis en opción al grado de Doctor en Ciencias Geofísicas. Fondos del MES y del CENAIS.

CHUY, T.J. \& DESPAIGNE, G. (2001). Sismicidad y Peligro Sísmico. Altas de Peligros Naturales del municipio Guamá, provincia de Santiago de Cuba. Centro Nacional de Investigaciones Sismológicas. Editorial Academia, Cuba, pp. 10-17.

COLLINS, B., ZNIDARCIC, D. (1997). "Triggering Mechanisms of Rainfall Induced Debris Flows". II Simposio Panamericano de Deslizamientos, Río de Janeiro .pp. 277-286.

DEL PUERTO J. A. \& ULLOA D. (2003) "Identificación de los peligros geólogogeomorfológicos de la cuenca de Santiago de Cuba. V Taller Internacional de Ciencias de la Tierra y Medio Ambiente. V Congreso Cubano de Geología y Minería. Habana.

DHAKAL, S., AMADA, T. \& ANIYA, M. (2000). Databases and Geographic Information Systems for Medium Scale Landslide Hazard Evaluation: an Example from Typical Mountain Watershed in Nepal. Landslides in research, theory and practice. Tomas Telford. London. 1, 457-462 p.

FEBLES, D. \& RODRÍGUEZ, J. (2005). Mapa de susceptibilidad a los deslizamientos de la república de cuba a escala 1:250 000. VI Congreso de Geología y Minería. Simposio de sismicidad y riesgos geológicos.

FELL, R., HO, K.K.S., LACASSE, S. \& LEROI, E. (2005). A framework for landslide risk assessment and management. Landslide risk management, Proceedings of the International Conference on Landslide Risk Management, O. Hungr, R. Fell, R. Couture \& E. Eberhardt (eds.), Taylor and Francis, Londres, Inglaterra, pp. 3-25. 
FELL, R., COROMINAS, J., BONNARD, C., CASCINI, L., LEROI, E. \& SAVAGE, W.Z. (2008). Guidelines for landslide susceptibility, hazard and risk zoning for land use planning. Engineering Geology, 102(1): 85-98p.

GARCÍA GARCÍA, H.A. (2004). Avaliação da susceptibilidade aos movimentos de massa usando sistemas de informação geográfica e redes neurais artificiais. Caso de aplicação Medellín, Colômbia. Dissertação de Mestrado, Universidade de Brasília, Brasília, Distrito Federal, 141p

GODT, J.W., BAUM, R.L., SAVAGE, W.Z., SALCIARINI, D., SCH ULZ, W.H., HARP, E.L. \& RICH ARD, U. (2008). Transient deterministic shallow landslide modeling: Requirements for susceptibility and hazard assessments in a GIS frame work. Engineering Geology, 102: 214-226.

GONZÁlEZ díEZ, A., REMONDO, J., CENDRERO, A. (2005). Consideraciones sobre la relación entre movimientos de ladera y el Clima. VI Simposio Nacional sobre Taludes y Laderas Inestables. UPC Valencia. 3: 1103-1130.

GRAHAM, J. (1984). Methods of Stability Analysis. Slope Instability, D. Brunsden \& D.B. Prior (eds.), John Wiley \& Sons Ltd., Chichester, United Kingdom, pp. 171215.

GUZZETTI, F., REICHENBACH, P., ARDIZZONE, F., CARDINALI, M. \& GALLI, M. (2006). Estimating the quality of landslide susceptibility models. Geomorphology, 81:166-184.

HERNÁNDEZ, J. R. (1989). Geomorfología estructural del sistema montañoso de la Sierra Maestra y de las depresiones Graben adyacentes. Editorial Academia. La Habana, 45p

IAEG UNESCO (1976). Engineering geological map: A guide to their preparation. The UNESCO Press, Paris, $79 \mathrm{p}$

IIDA, T. (1999). A stochastic hydro-geomorphological model for shallow landsliding due to rainstorm. Catena 34. pp 293-313.

ITURRALDE \& VINENT, M. (1996). Cuban ophiolites and volcanic arcs. Project 364: geological correlation of ophiolites and volcanic arcs terranes in the circumcaribbean realm. Contribution 1:256

IVERSON, R.M. (2000). Landslide triggering by rain infiltration. Water Resources Research 36 (7): 1897-1910.

KOCHIACHIVILI (1989). Intensidades extremas de precipitaciones durante el paso de huracanes. Nuevo Atlas Nacional de Cuba. Instituto de Geografía de la Academia de Ciencias de Cuba, La Habana, Cuba, 85 pp.

KUZOVKOV, G., \& ARSENIEV, Y. (1977). Levantamiento Geológico 1:100 000 Sierra Maestra Sur". Archivos de Empresa Geominera de Oriente, Santiago de Cuba. 
LI, Z., NADIM, F., HUANG, H., UZIELLI, M. \& LACASSE, S. (2010). Quantitative vulnerability estimation for scenario-based landslide hazards. Landslides, 7(1):125134.

LUZI, L. \& FABBRI, A.G., (1995). Application of Favourability Modelling to Zoning of Landslide Hazard in the Fabriano Area, Central Italy. 1st. Joint European Conference and Exhibition on Geographical Information, The hague, NL. 398-403p.

MARTÍNEZ CARVAJAL, H.E. (2006). Modelagem constitutiva de areias Usando redes neurais artificiais. Tese de doutorado, Universidade de Brasília, Brasília, Distrito Federal, 250p

MONTGOMERY, D.R. \& DIETRICH, W.E. (1994). A physically based model for the topographic control on shallow landsliding. Water Resources Research, 30(4): 1153-1171.

MONTOYA, C.A.H. \& ASSIS, A.P. (2011). Tools for realiability analysis in geotechnical engineering: application (in Spanish). Revista Ingenierías Universidad de Medellín, 10(18): 79-86.

MULDER, H.F.H.M., (1991). Assessment of landslide hazard. Nederlandse Geografische Studies. PhD Thesis, University of Utrecht. $150 \mathrm{p}$.

NAKAMURA, SH., GIBO, S., EGASHIRA, K. \& KIMURA, SH. (2010). Platy layer silicate minerals for controlling residual strength in landslide soils of different origins and geology. Geology, 38(8):743-746.

PAPA, M.N., MEDINA, V. \& BATEMAN, A. (2011). Derivation of critical rainfall thresholds for debris flow warnings through mathematical and numerical modeling: 495-502.

PAPA, M.N., MEDINA, V., CIERVO, F. \& BATEMAN, A. (2013). Derivation of critical rainfall thresholds for shallow landslides as a tool for debris flow early warning systems. Hydrol. Earth Syst. Sci., 17(10): 4095-4107.

REIS, R.C. (2010). Estudo de estabilidade de taludes da mina de Tapira-MG. Dissertação de Mestrado, Programa de Pós-Graduação em Geotecnia, Universidade Federal de Ouro Preto, Ouro Preto, MG, 145 p.

RENGERS, N., SOETERS, R. \& VAN WESTEN, C.J. (1992). "Remote sensing and GIS applied to mountain hazard mapping". Episodes. 15 (1), 36-45 p.

REYES, C. R. \& SEISDEDOS, G. (2001). Deslizamientos. Altas de Peligros Naturales del municipio Guamá, provincia de Santiago de Cuba. Centro Nacional de Investigaciones Sismológicas. Editorial Academia, Cuba, pp. 18-26.

REYES, M.C. (2008). Cartografía de susceptibilidad por desprendimientos de rocas en un tramo de la carretera la plata-punta babujal, en el municipio guamá. Tesis de Maestría. Empresa Geominera Oriente, Cuba, 92p 
RIGO, M., PINHEIRO, R.J.B, BRESSANI, L.A, DAMIANI BICA, A.V. \& MORAES DA SILVEIRA, R. (2006). The residual shear strength of tropical soils. Can. Geotech. J. 43:431-447

SEISDEDOS, G. \& REYES, C. R., (2001). Huracanes y tormentas tropicales. Altas de Peligros Naturales del municipio Guamá, provincia de Santiago de Cuba. Centro Nacional de Investigaciones Sismológicas. Editorial Academia, Cuba, pp. 18-26.

SUAREZ DIAZ, J. (1998). Deslizamientos y estabilidad de taludes en zonas tropicales. Instituto de Investigaciones sobre Erosión y Deslizamientos. Ingeniería de Suelos Ltda. Bucaramanga, Colombia. 530p.

SUCHOMEL, R. \& M ŠIN, D. (2009). Comparison of different probabilistic methods for predicting stability of a slope in spatially variable $c-\theta$ soil. Computers and Geotechnics, 37(1): 132-140.

VAN GENUCHTEN, M. TH. (1980). A closed-form equation for predicting the hydraulic conductivity of unsaturated soils. Soil Sci. Soc. Am. J. 44:892-898.

VARNES, D.J. (1984). Landslide hazard zonation: a review of principles and practice. Nat. Hazards,.

VARNES, D.J. (1978). Slope movement types and processes. Lanslides, Analysis and Control, R. L. Schuster \& R. J. Krizek (eds.), Transportation Research Board Commission on Sociotechnical Systems - National Research Council, National Academy of Sciences, Washington, USA, pp. 11-33.

VEGA, M. B. (2005). Obtención del mapa de erosión de suelos a escala 1:250 000 en el ambiente de un SIG. VI Congreso Cubano de Geología y Minería. Geomática.

VIANA DA FONSECA, A. (2009). Caracterização de solos residuais em projecto geotécnico assistido por ensaios. Mestrado em Estruturas de Engenharia Civil. Faculdade de Engenharia, Universidade do Porto, Portugal, 90p

VILLALÓN, M. REYES C. R \& AGULLER M. C. (2012). Informe sobre los estudios de PVR deslizamientos, Centro Nacional de Investigaciones Sismológicas, Santiago de Cuba, Cuba, Archivos del CENAIS. 59p

VITHANA, SH., NAKAMURA, SH., GIBO, S., YOSHINAGA, A. \& KIMURA, SH. (2010). Correlation of large displacement drained shear strength of landslide soils measured by direct shear and ring shear devices. Landslides (2012) 9:305-314.

WIECZOREK G.F. \& GLADE T. (2005). Climatic Factors Influencing Occurrence of Debris Flows. In: Jakob M. \& Hungr O., eds., Debris-flow Hazards and Related Phenomena, Praxis, Springer, Chichester, UK, Ch. 14: 325-362.

ZAPATA, J. A. (1995). Utilización de variantes metodológicas de Microzonación Sísmica en la ciudad de Santiago de Cuba. Tesis en opción al Grado de Doctor en Ciencias Geofísicas. Fondos del CENAIS y del Instituto de Geofísica y Astronomía. Santiago de Cuba, Cuba, 115p 


\section{APÊNDICE A}

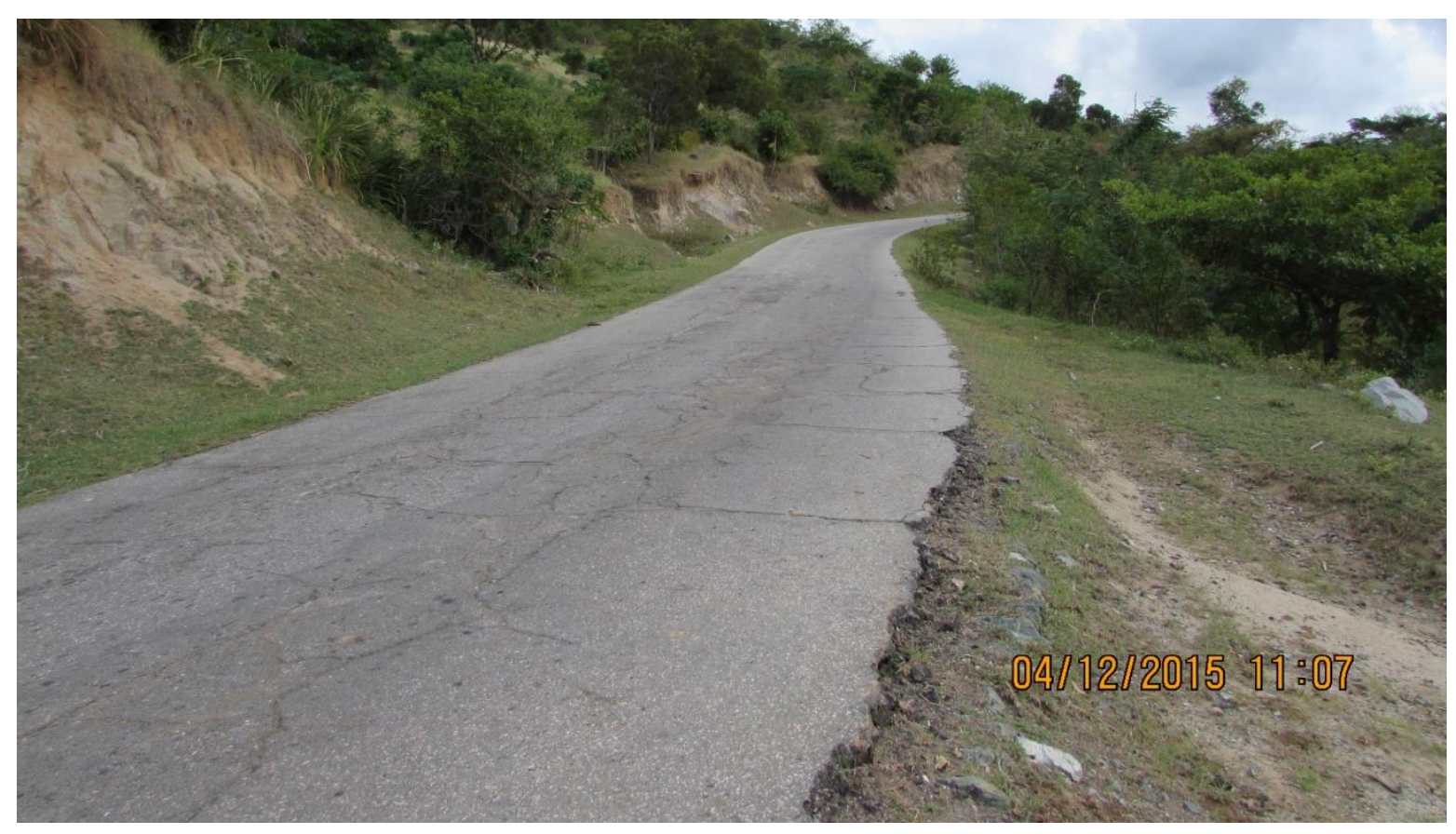

Fotografia_001

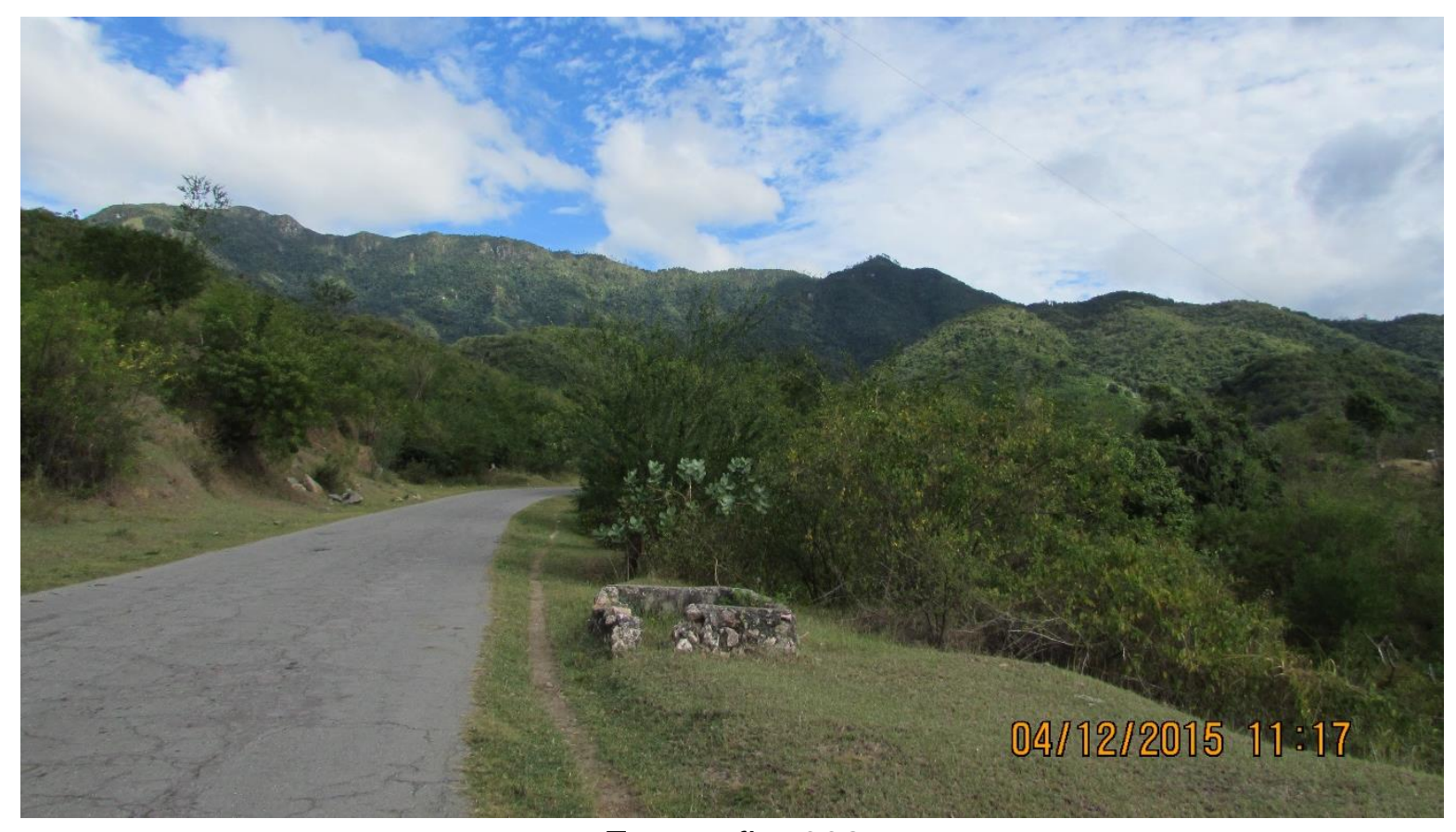

Fotografia_002 


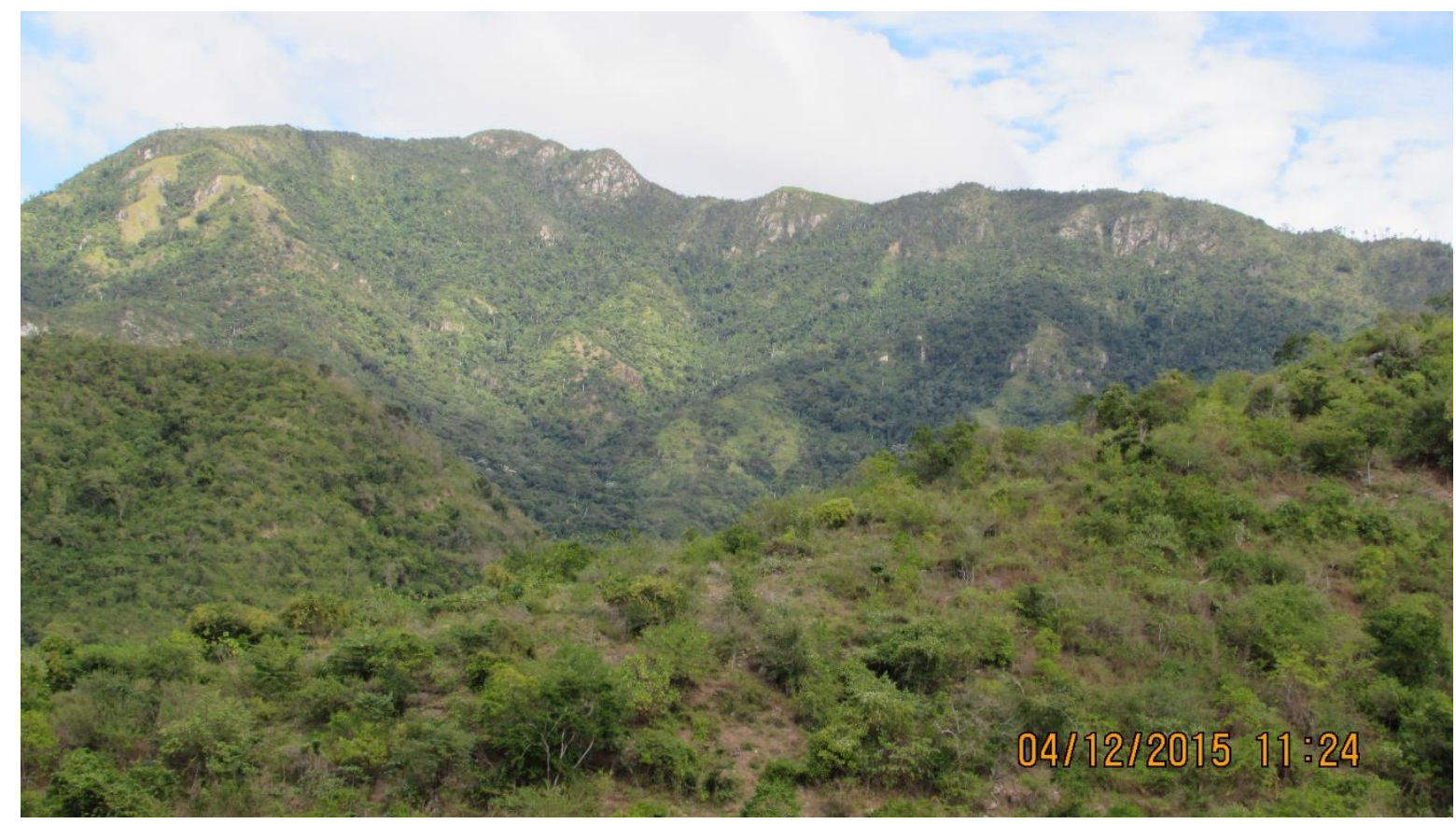

Fotografia_003

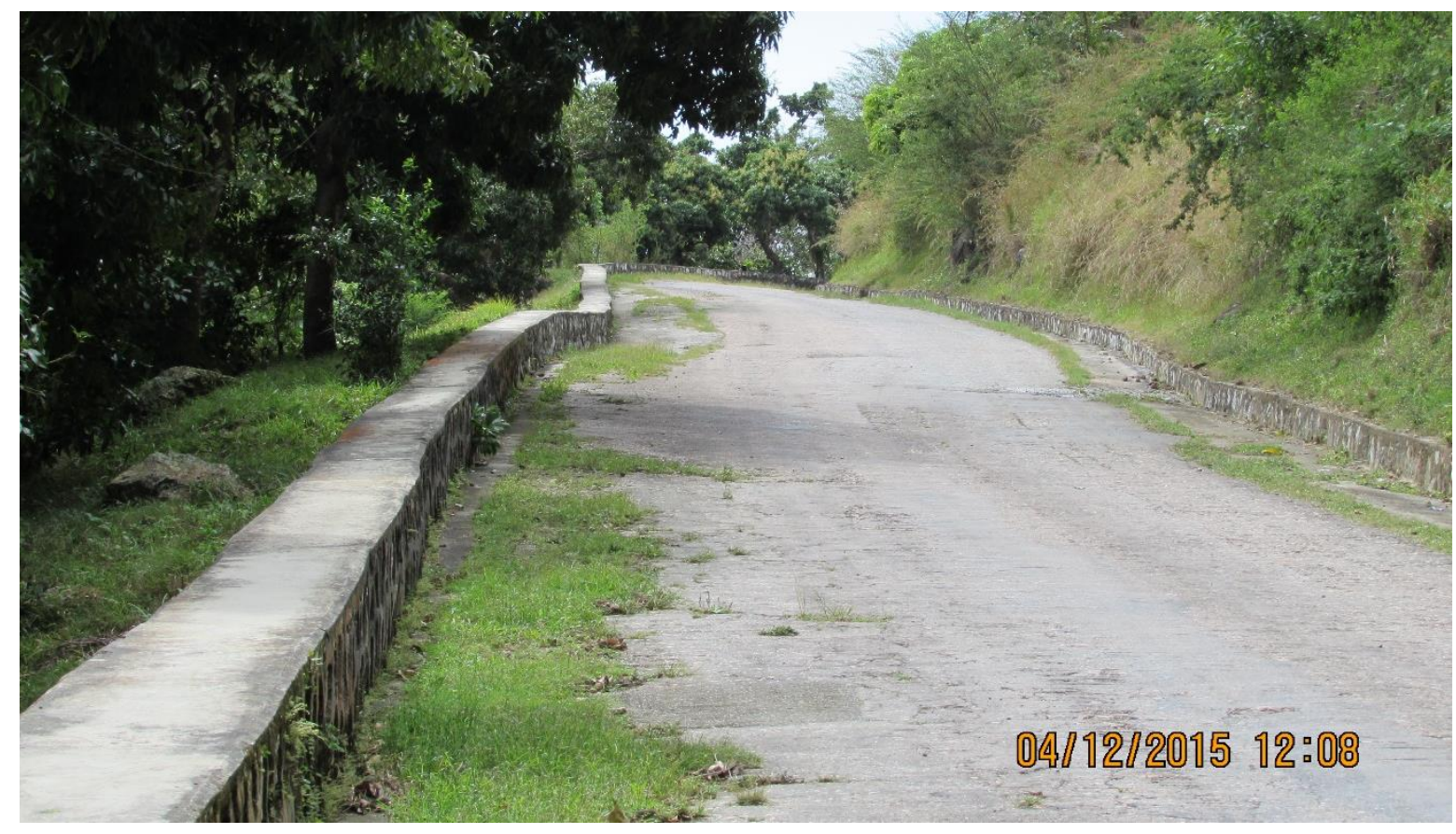

Fotografia_004 


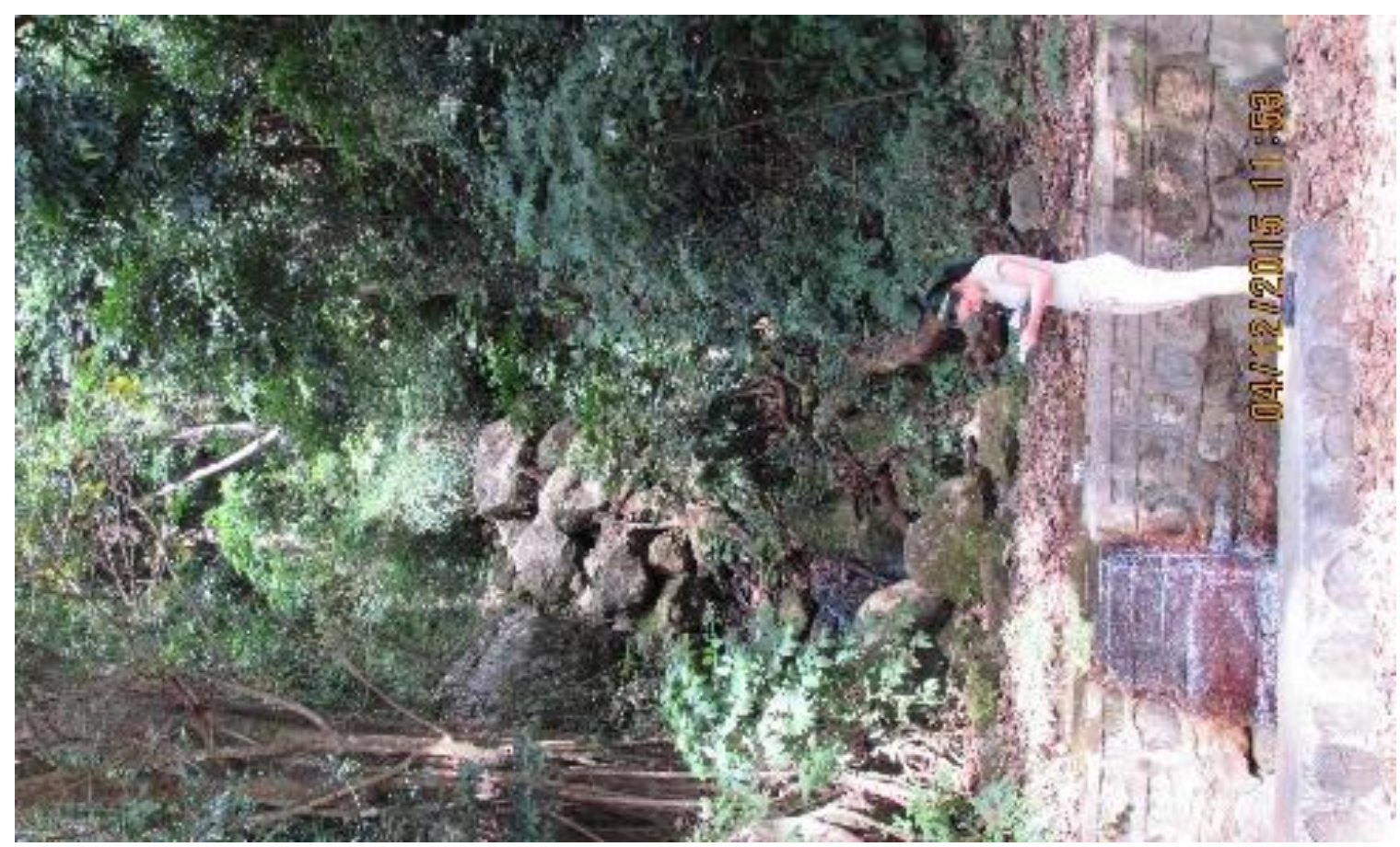

Fotografia_005

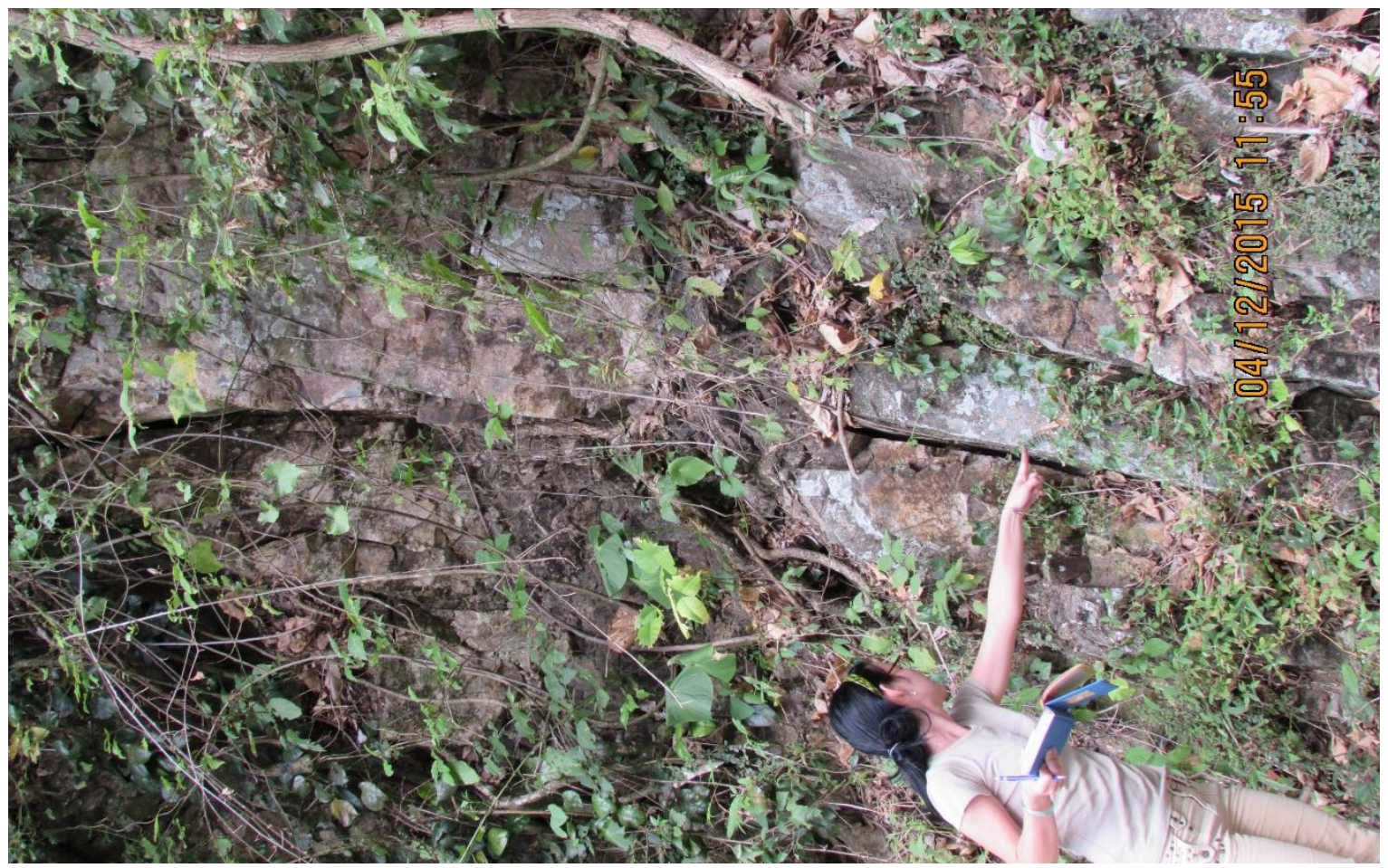

Fotografia_006 


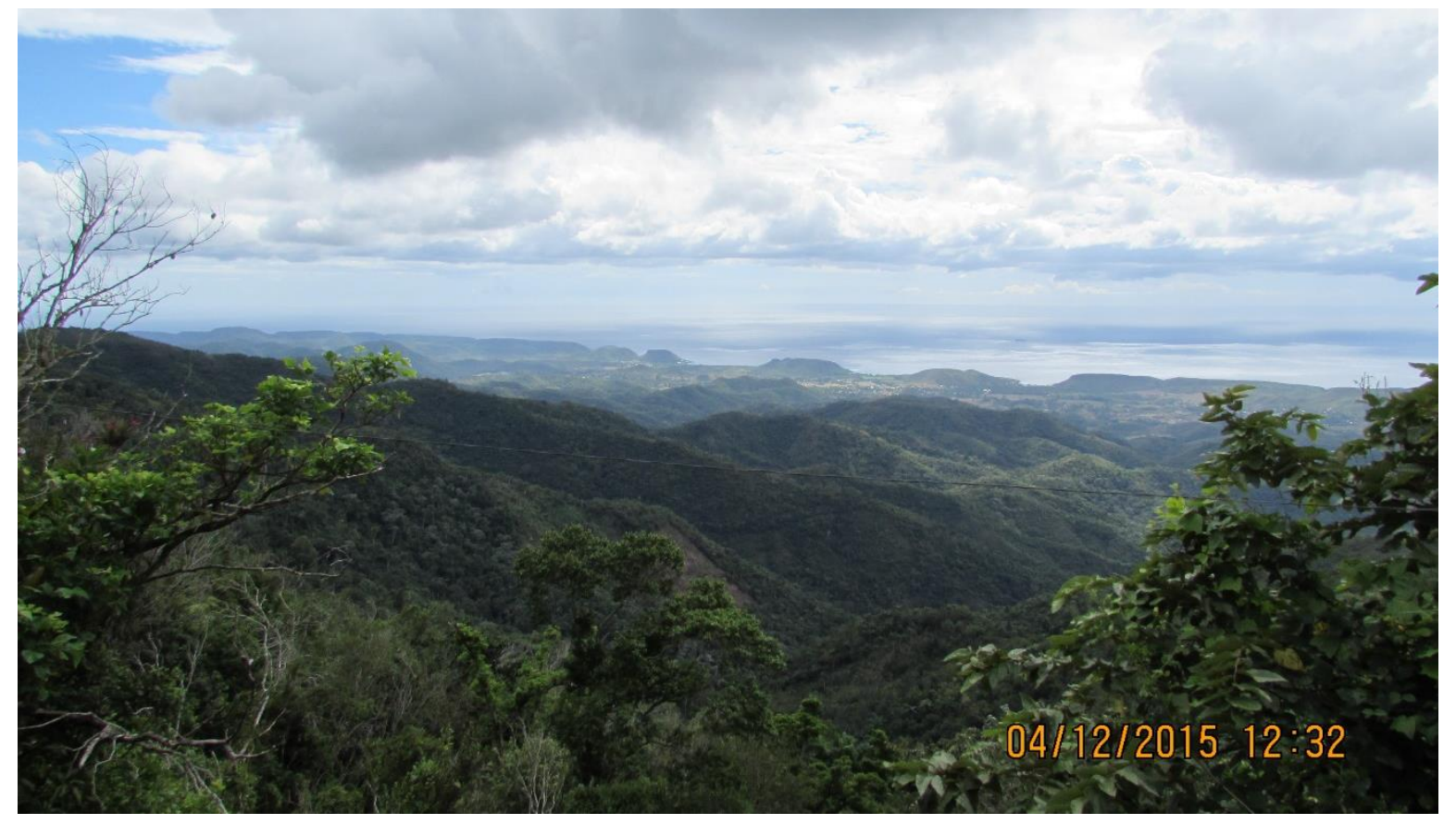

Fotografia_007

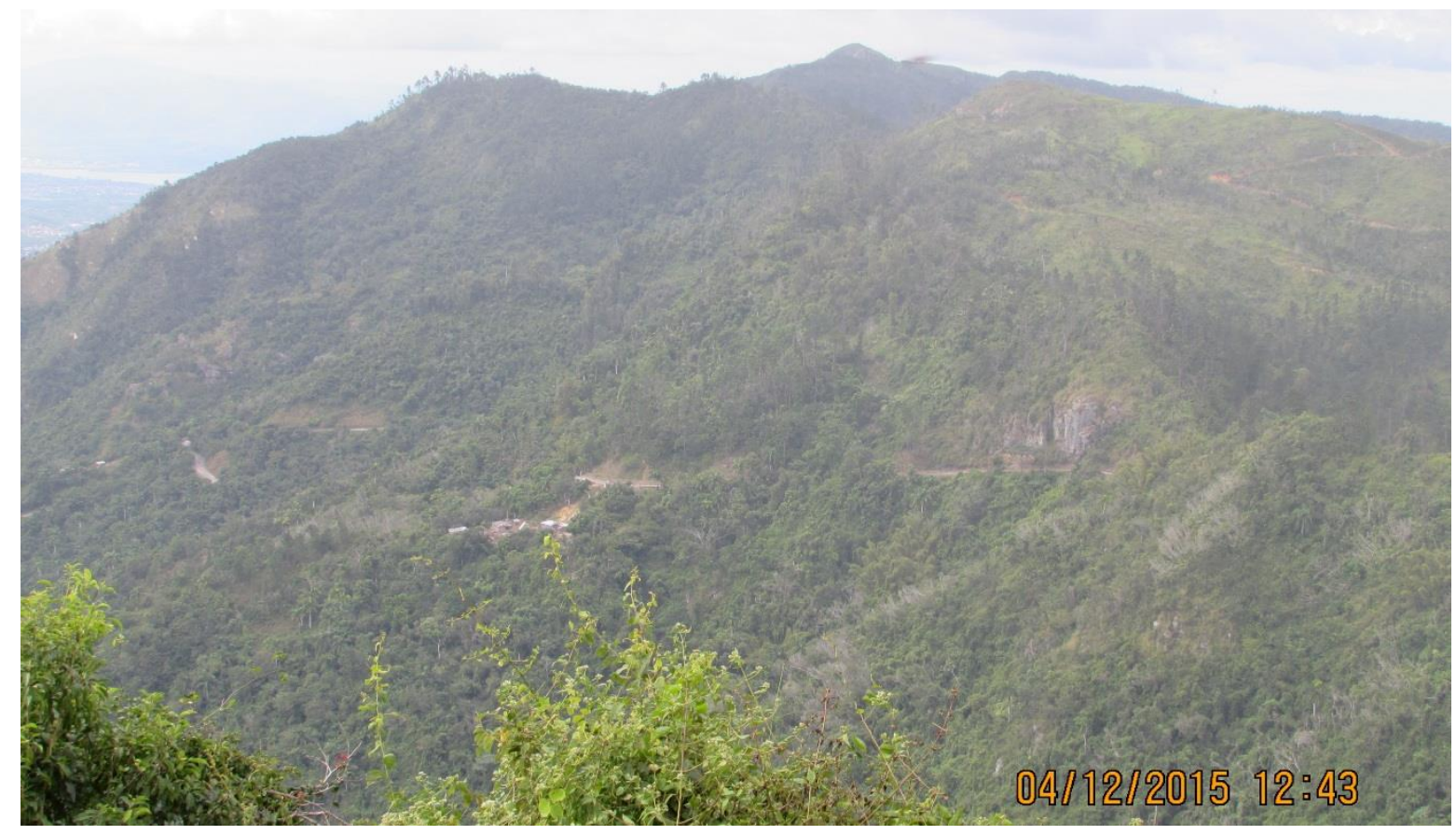

Fotografia_008 


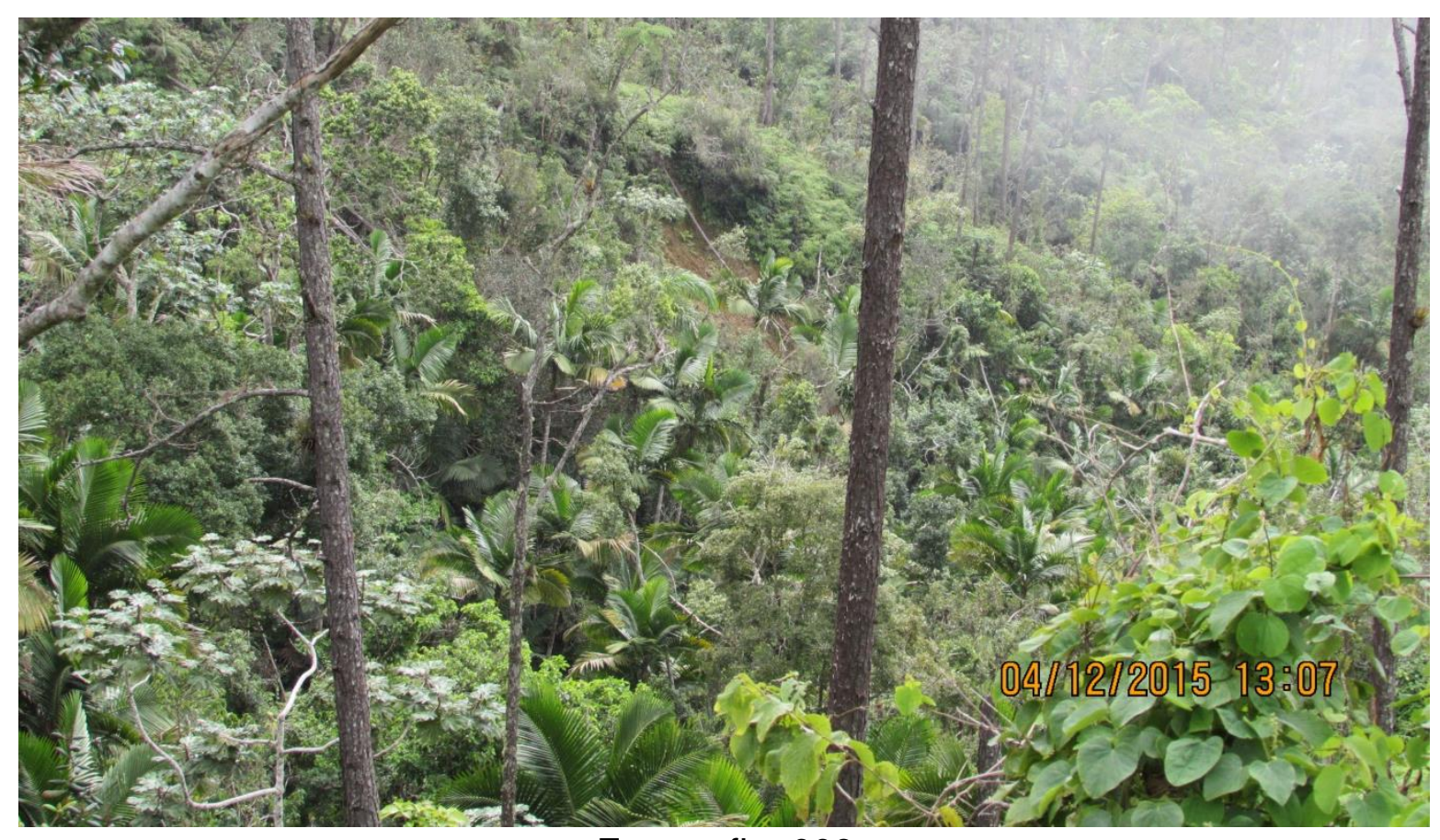

Fotografia_009

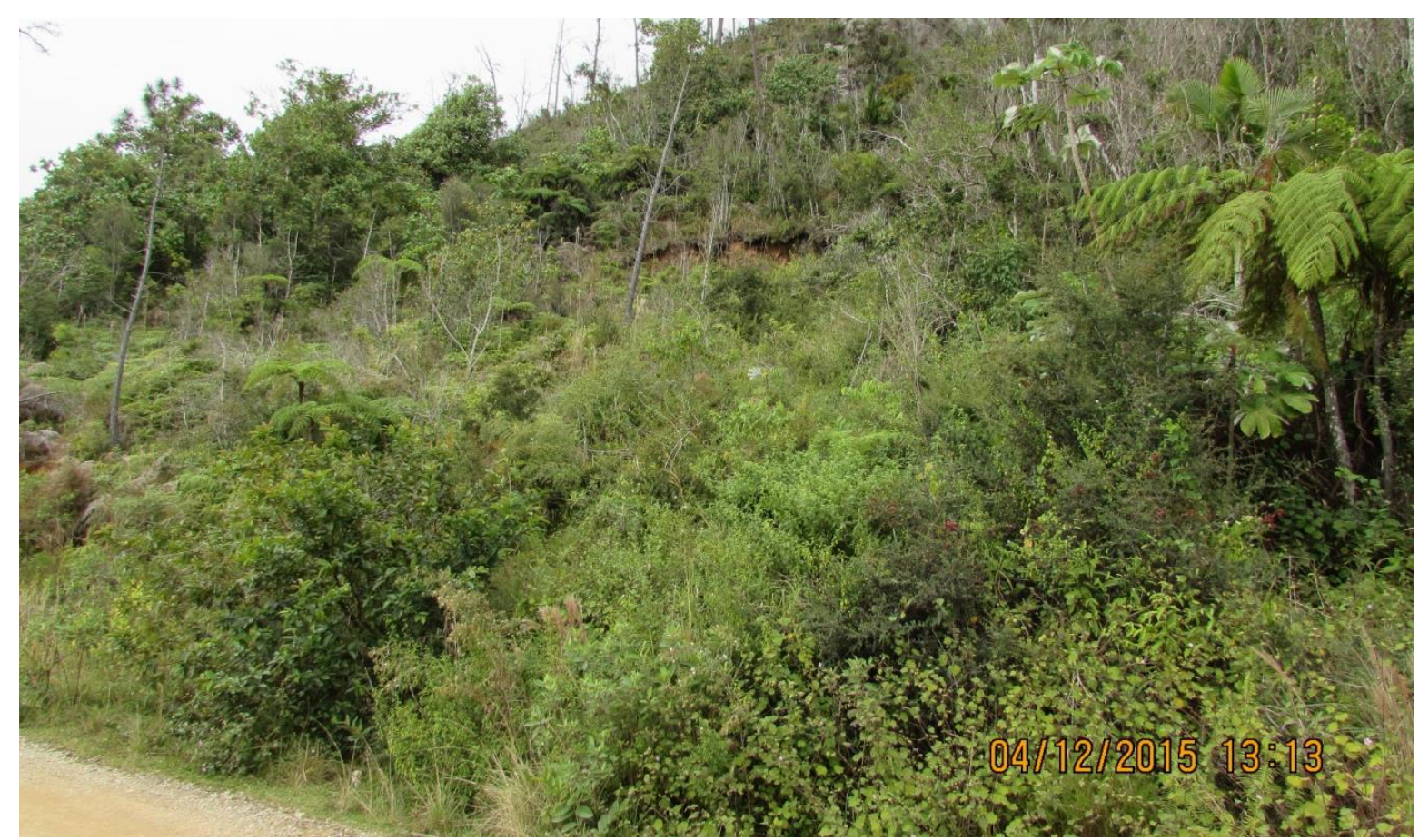

Fotografia_010 


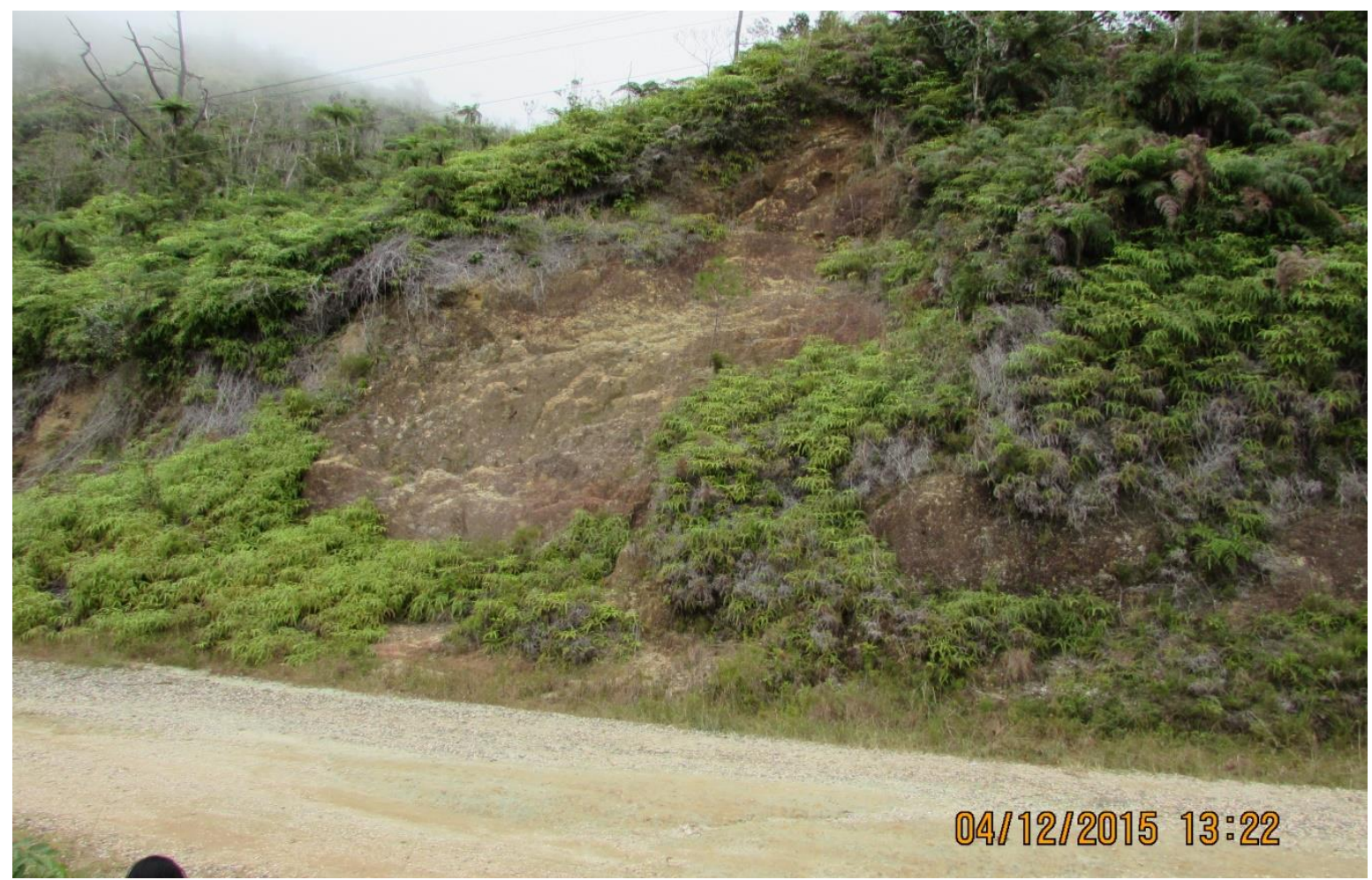

Fotografia_011

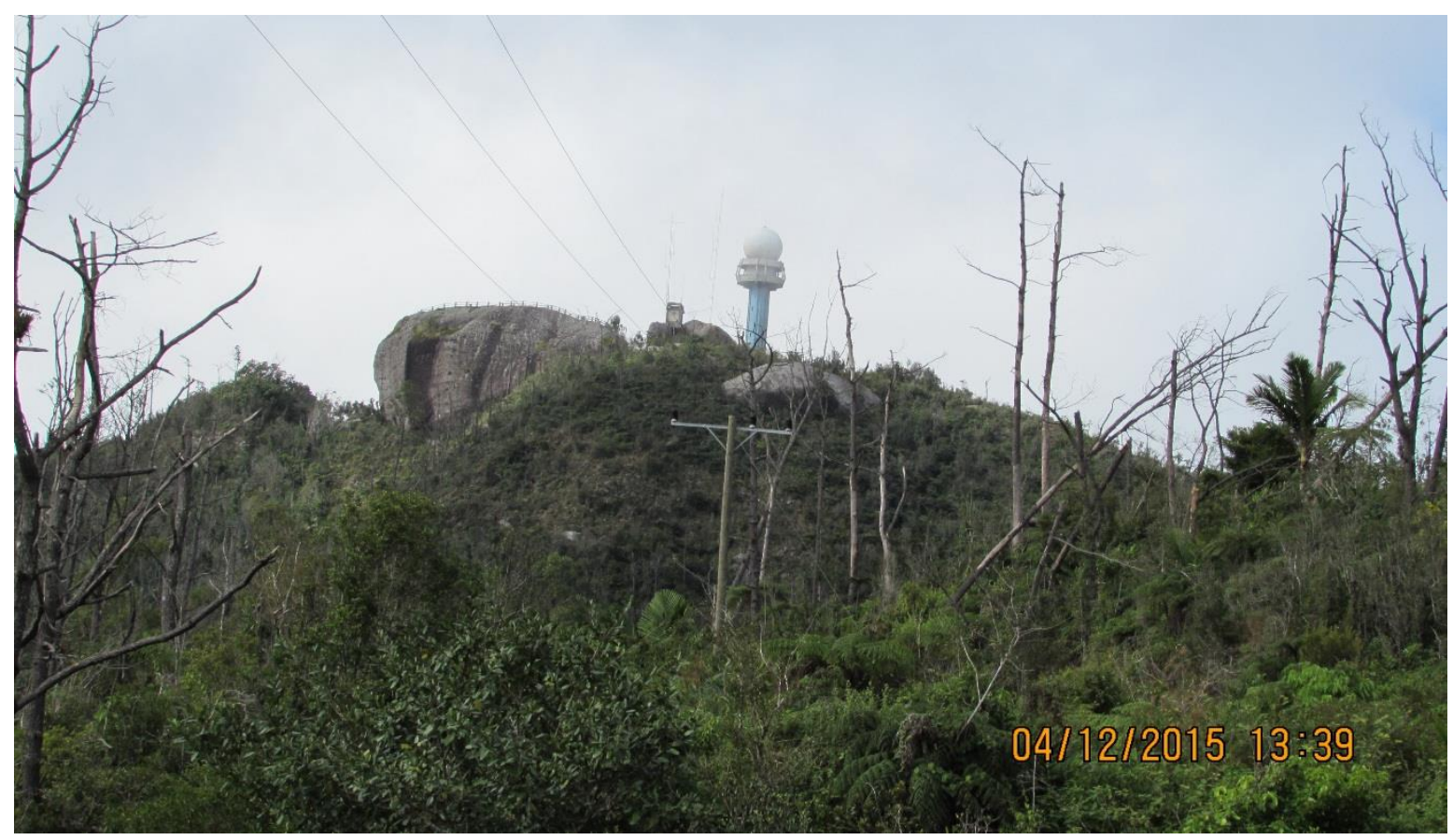

Fotografia_012 


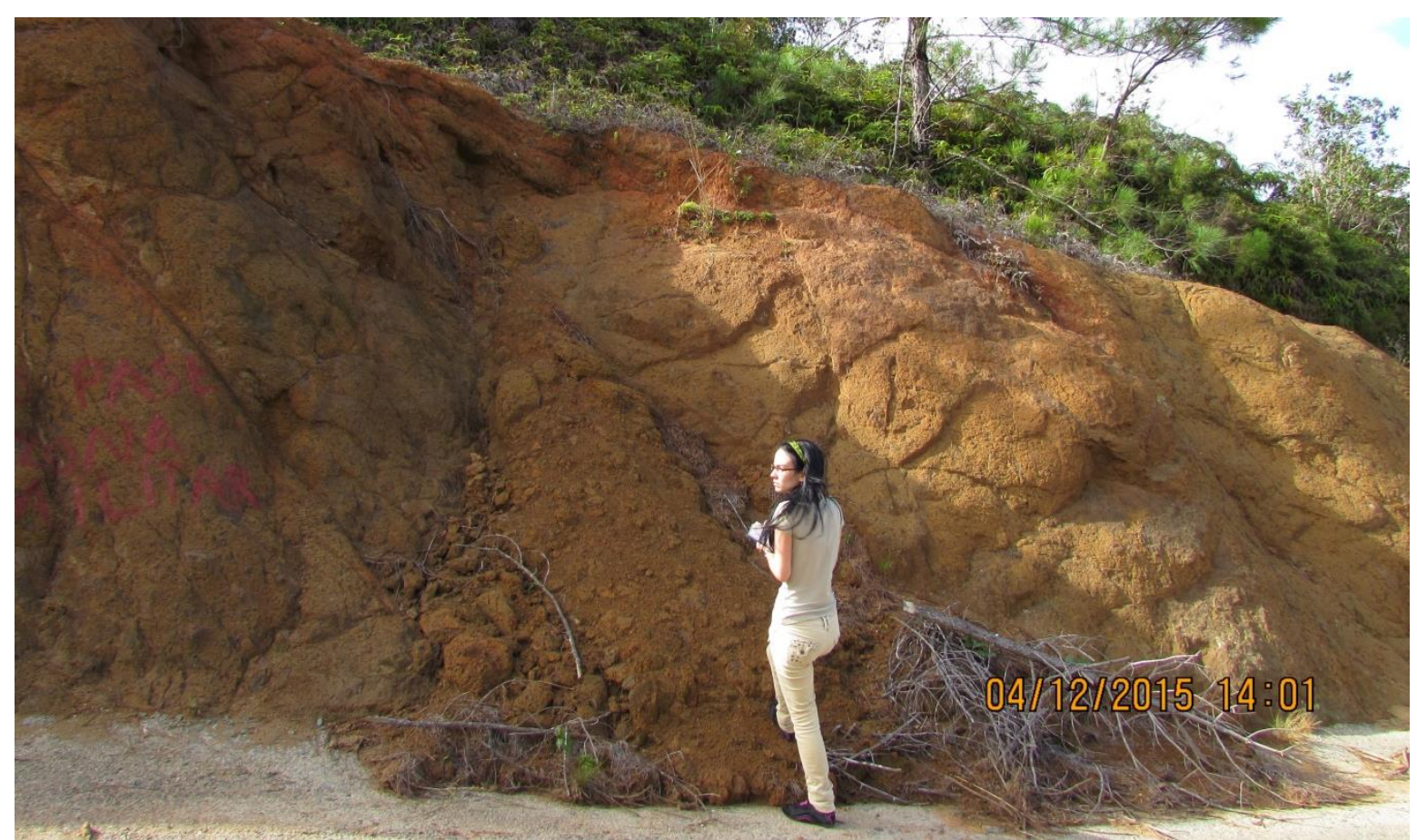

Fotografia_013

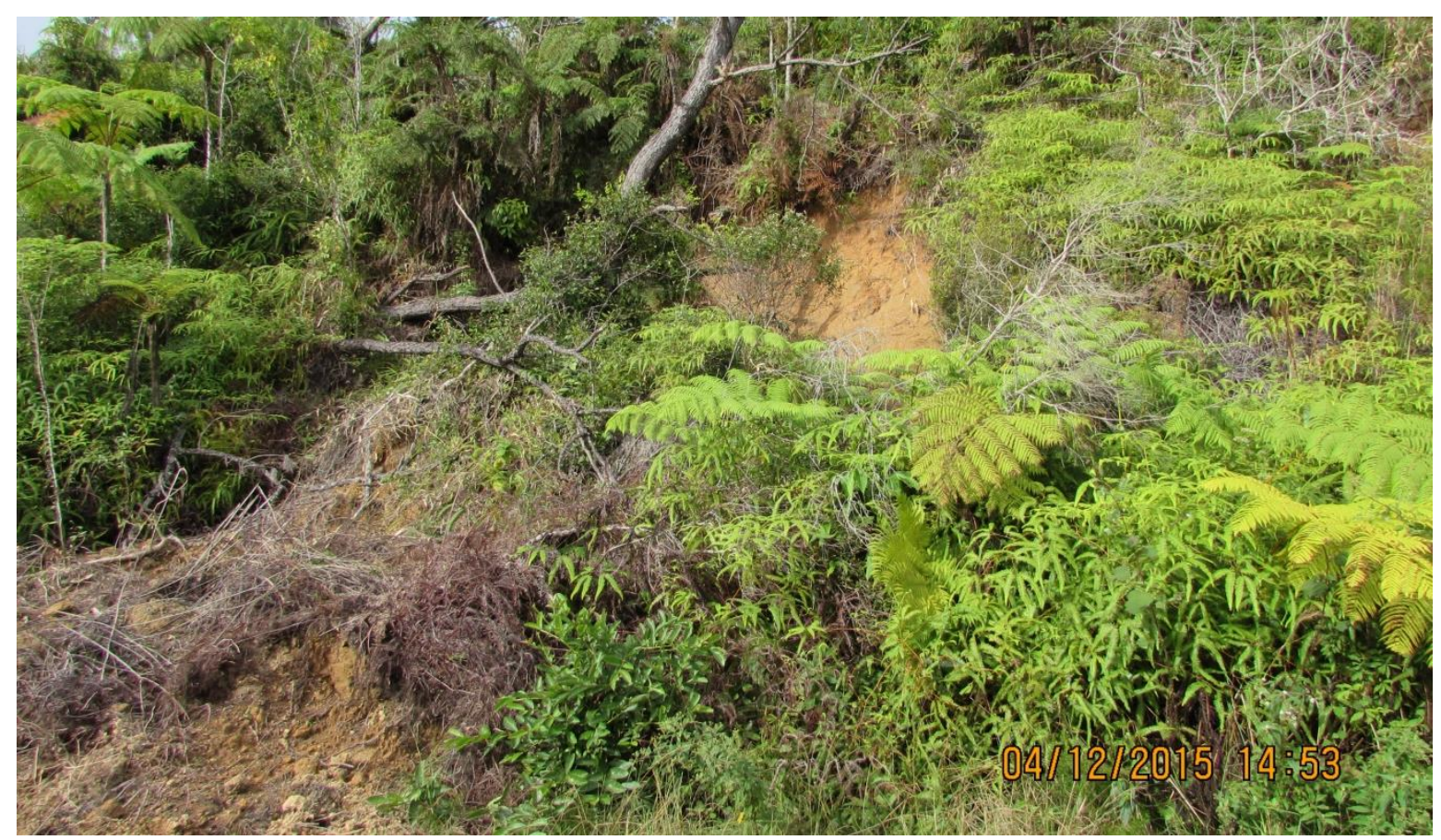

Fotografia_014 


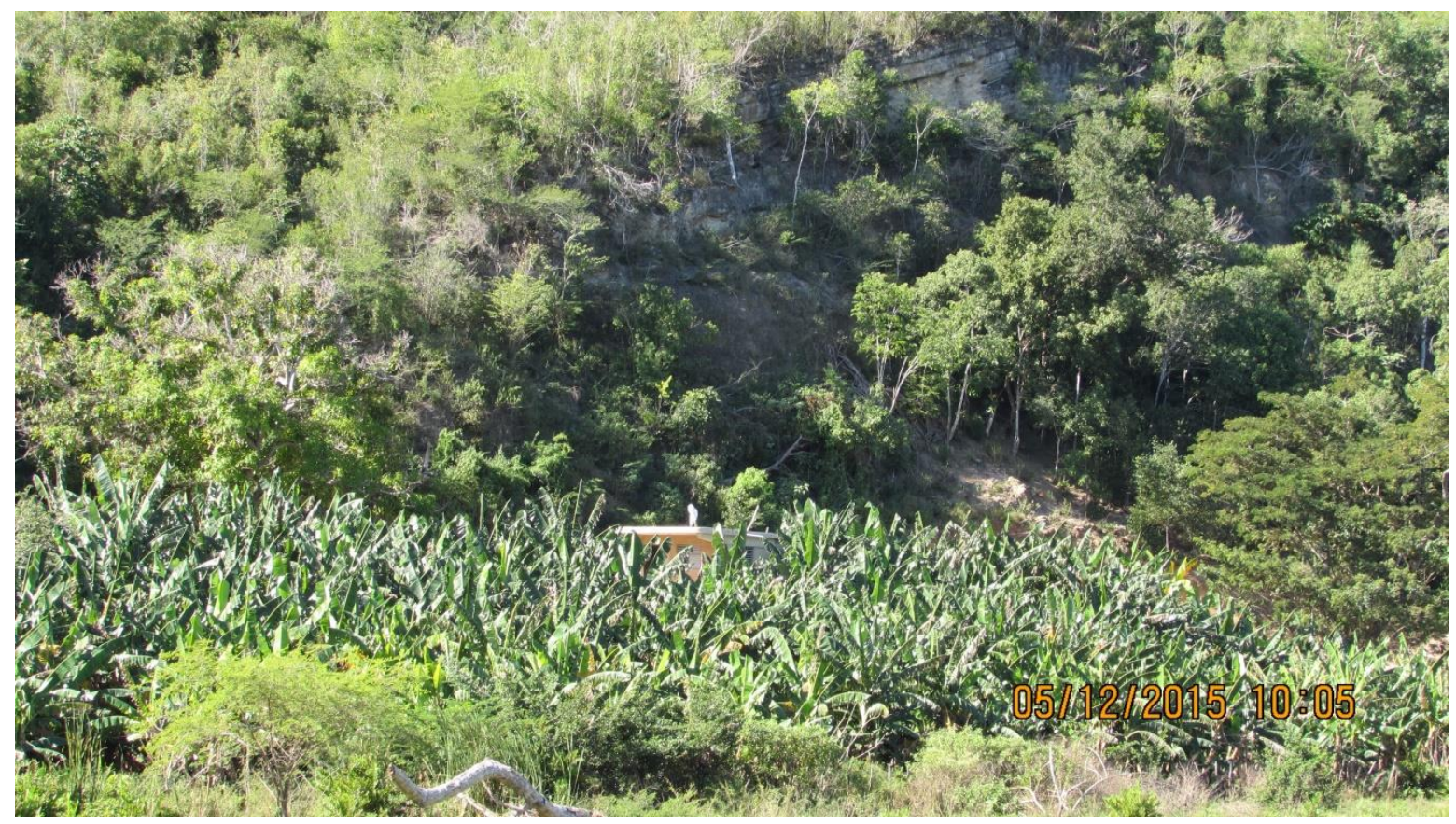

. Fotografia_015

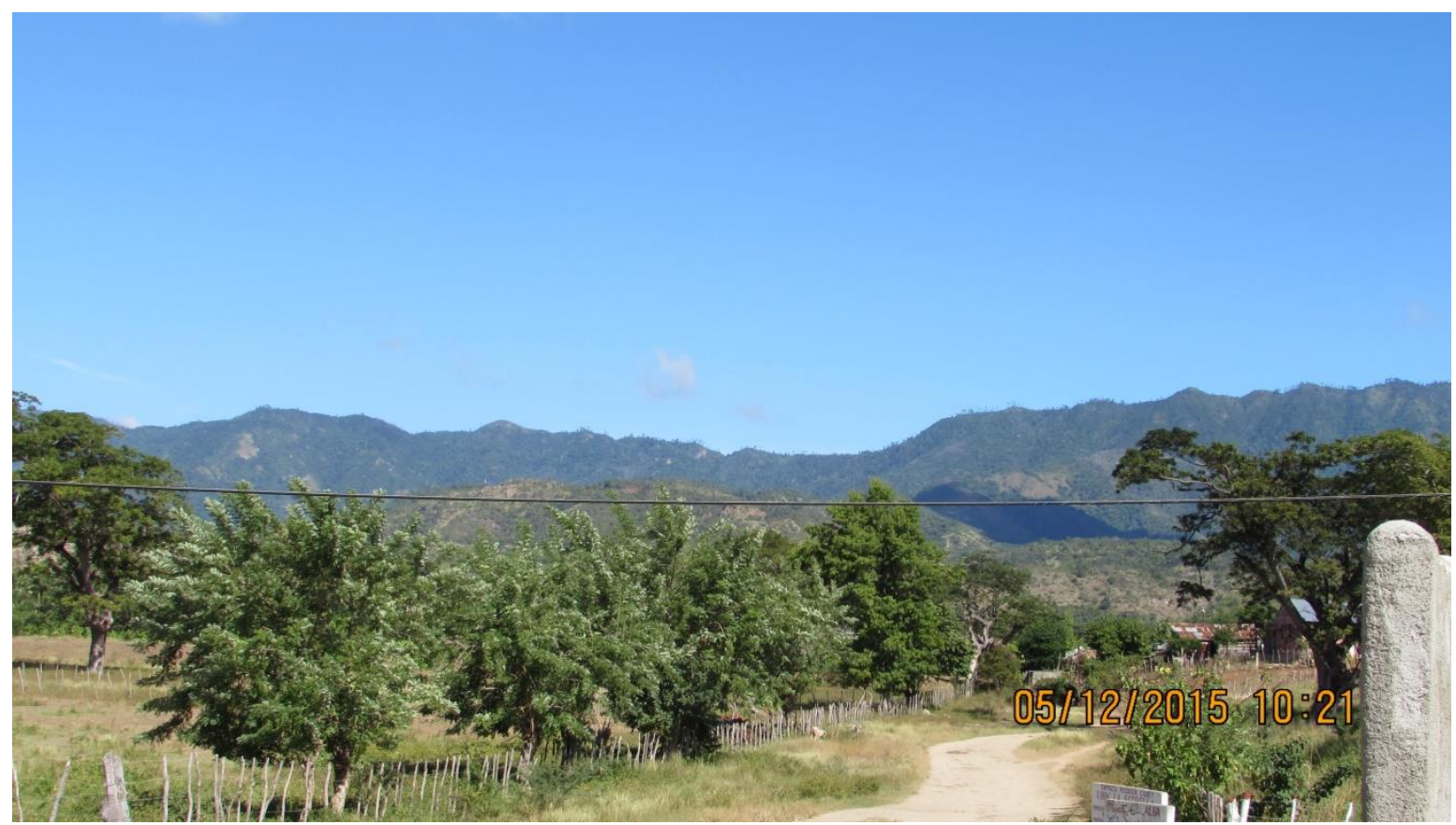

Fotografia_016 


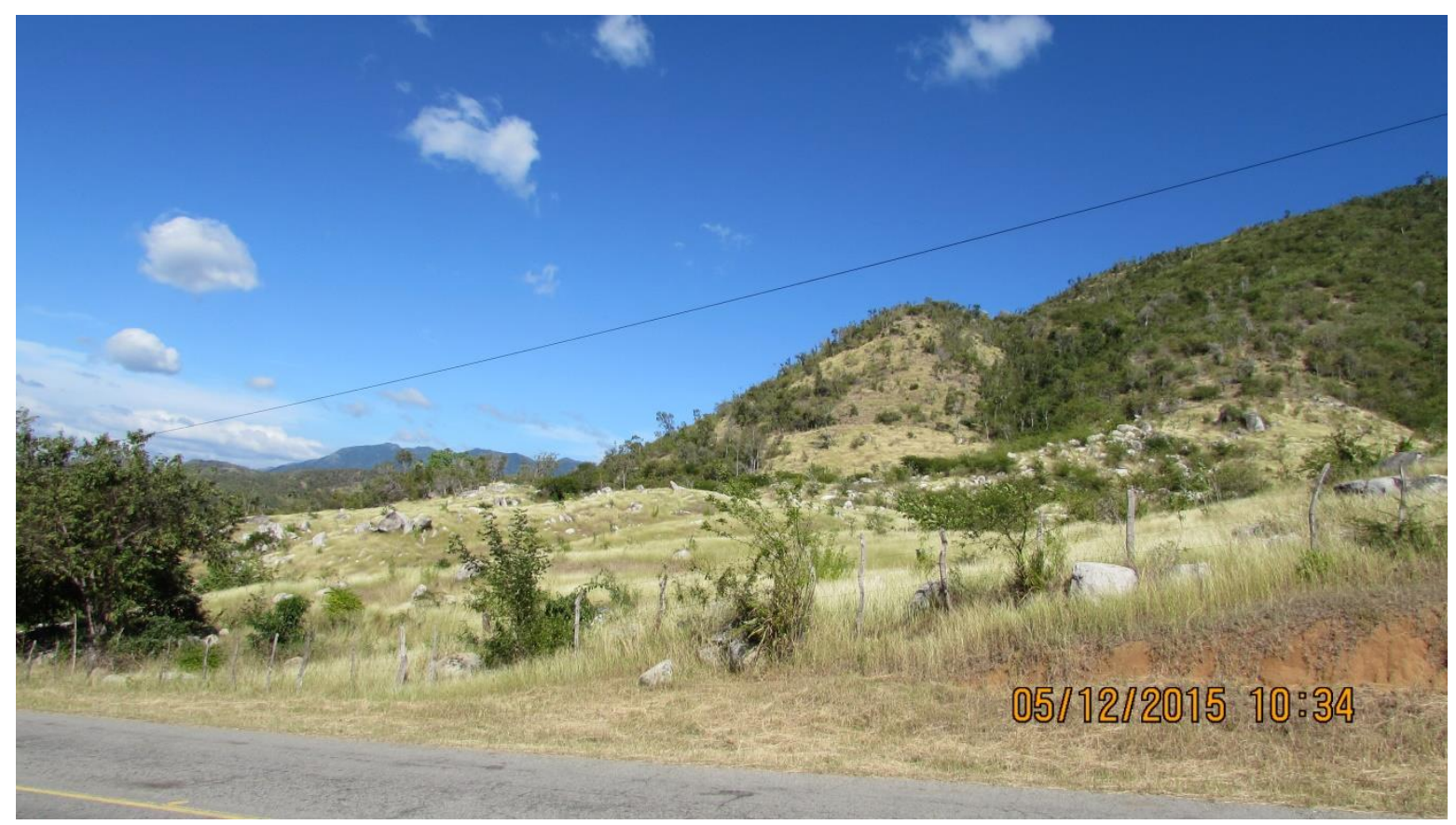

Fotografia_017

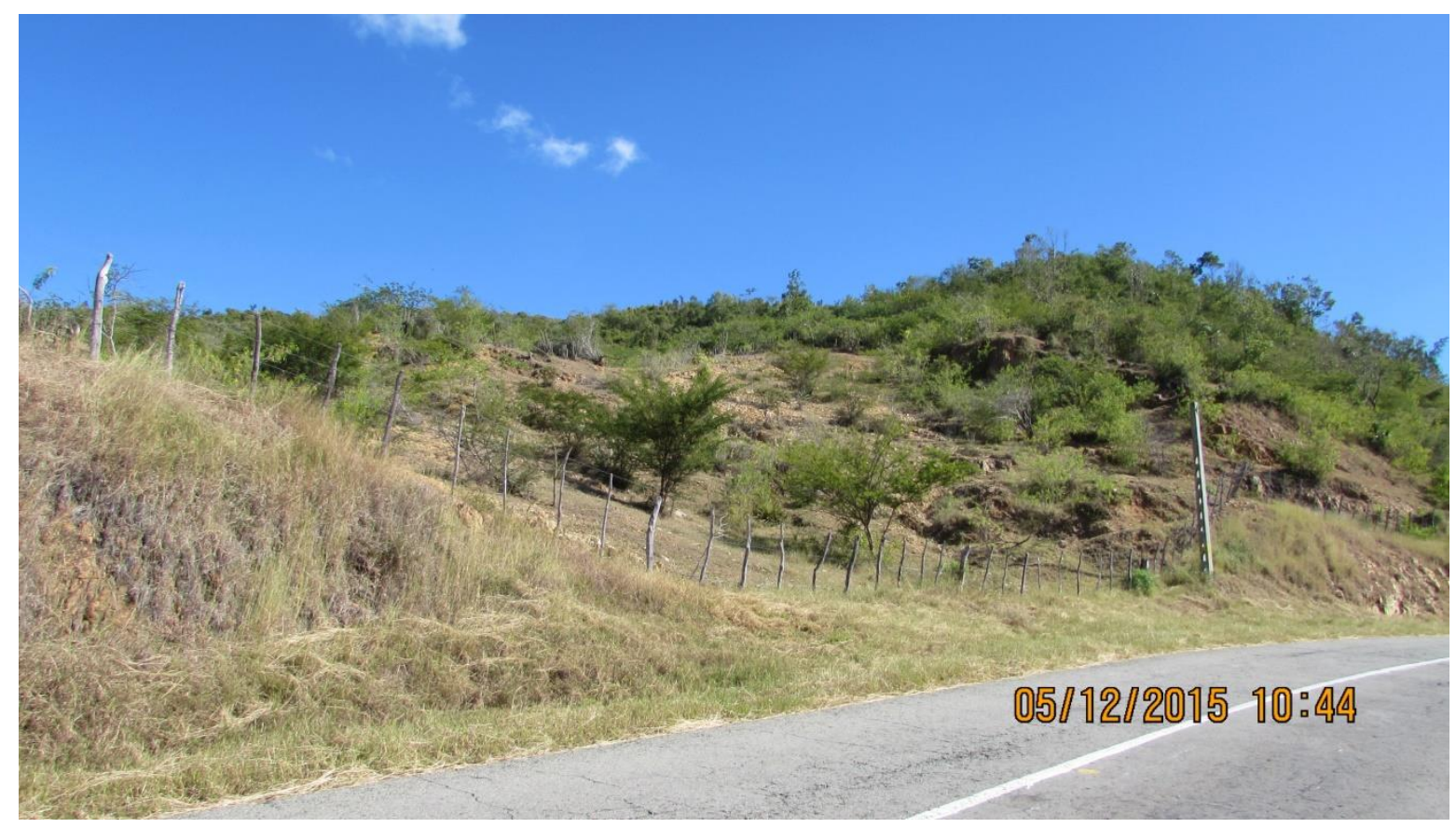

Fotografia_018 


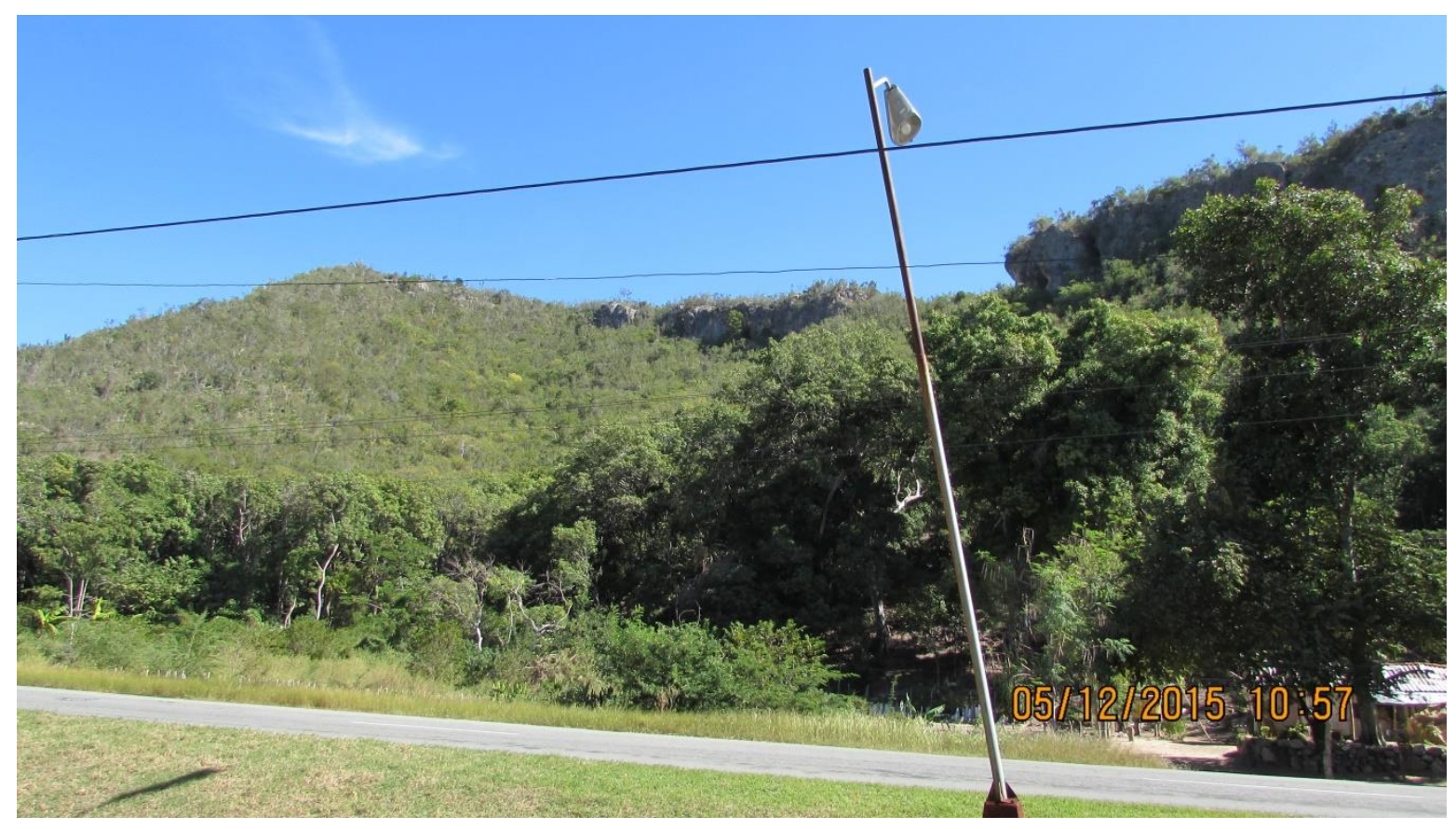

Fotografia_19

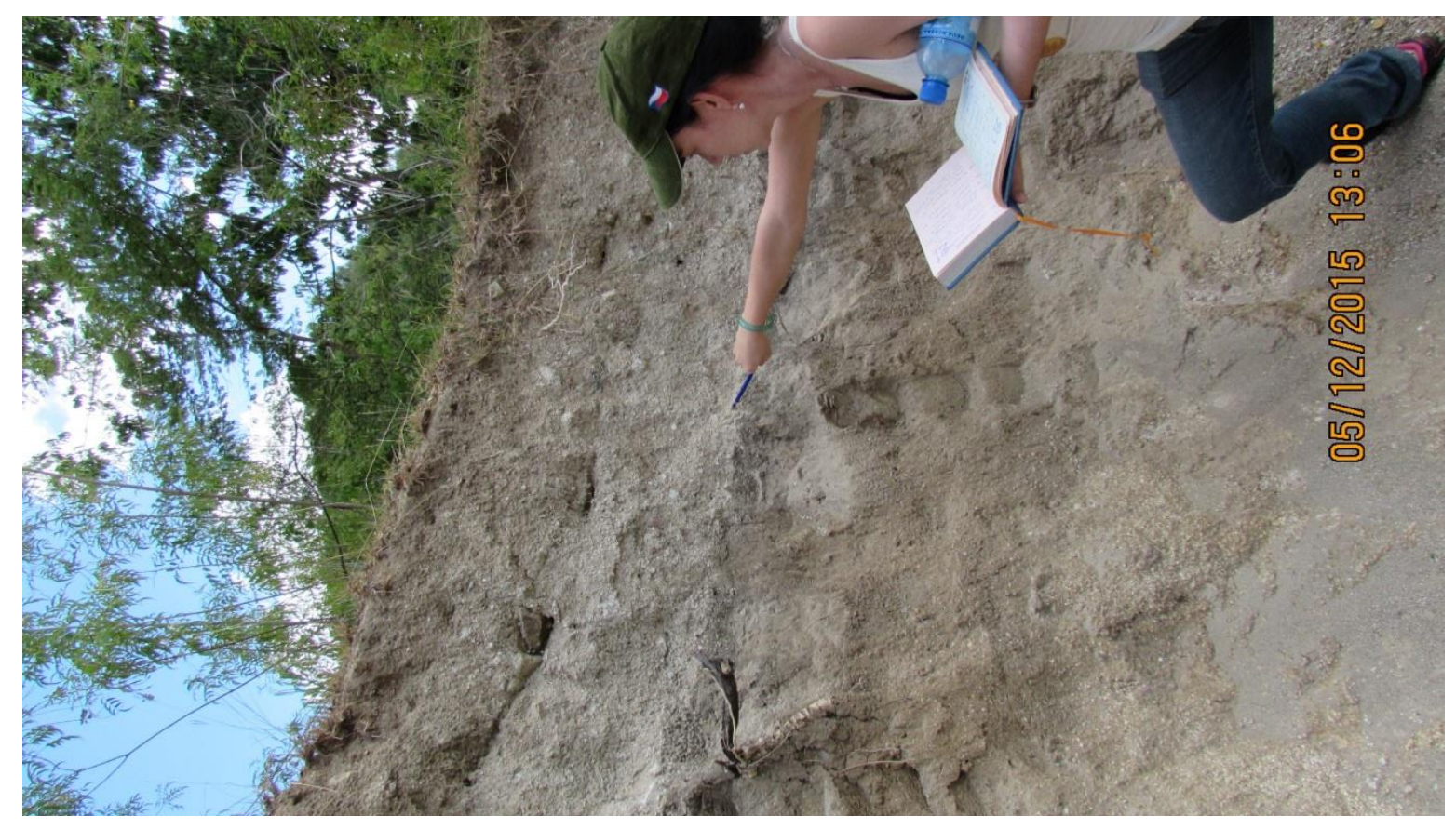

Fotografia_020 


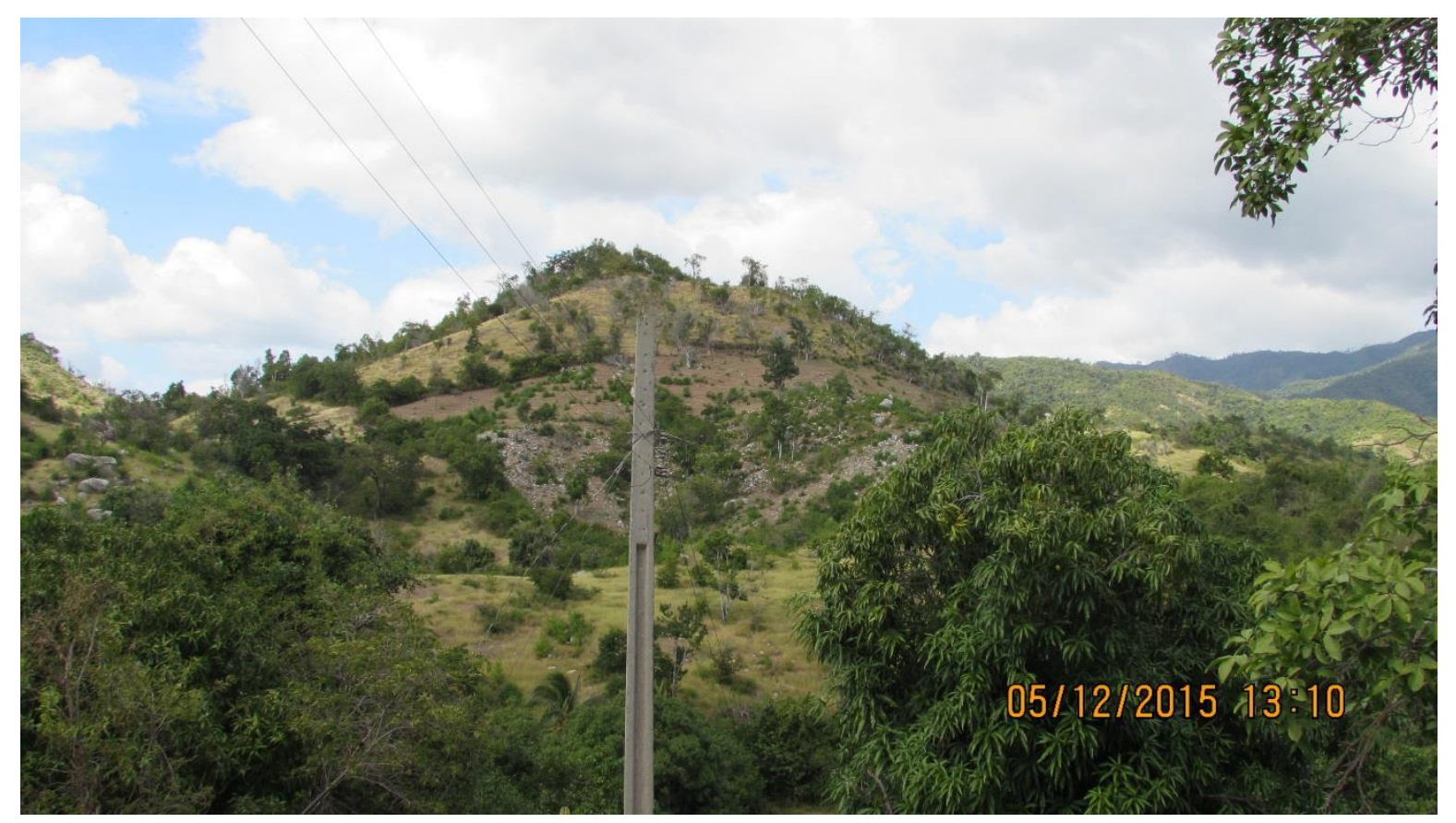

Fotografia_021

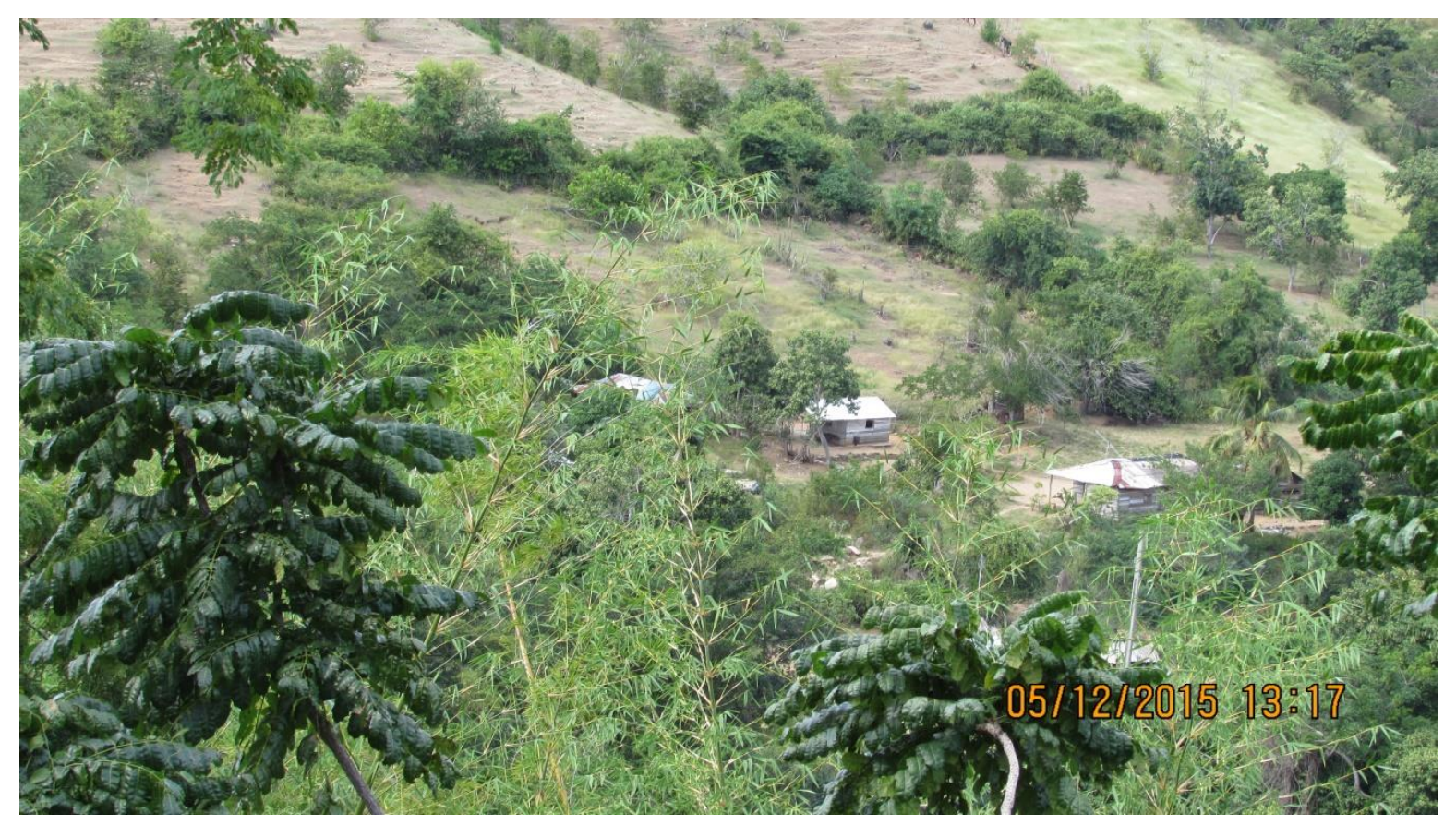

Fotografia_022 


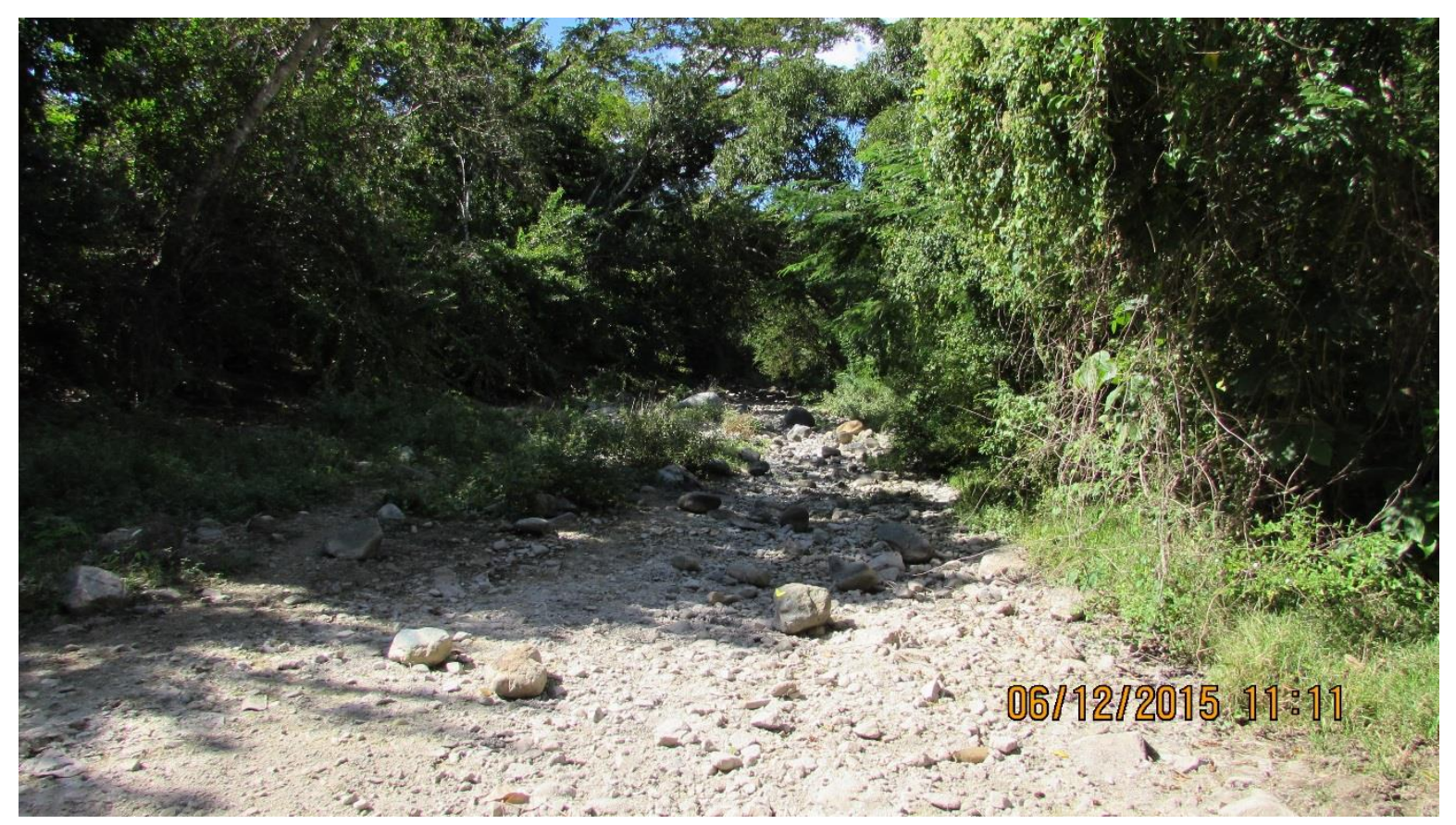

Fotografia_023

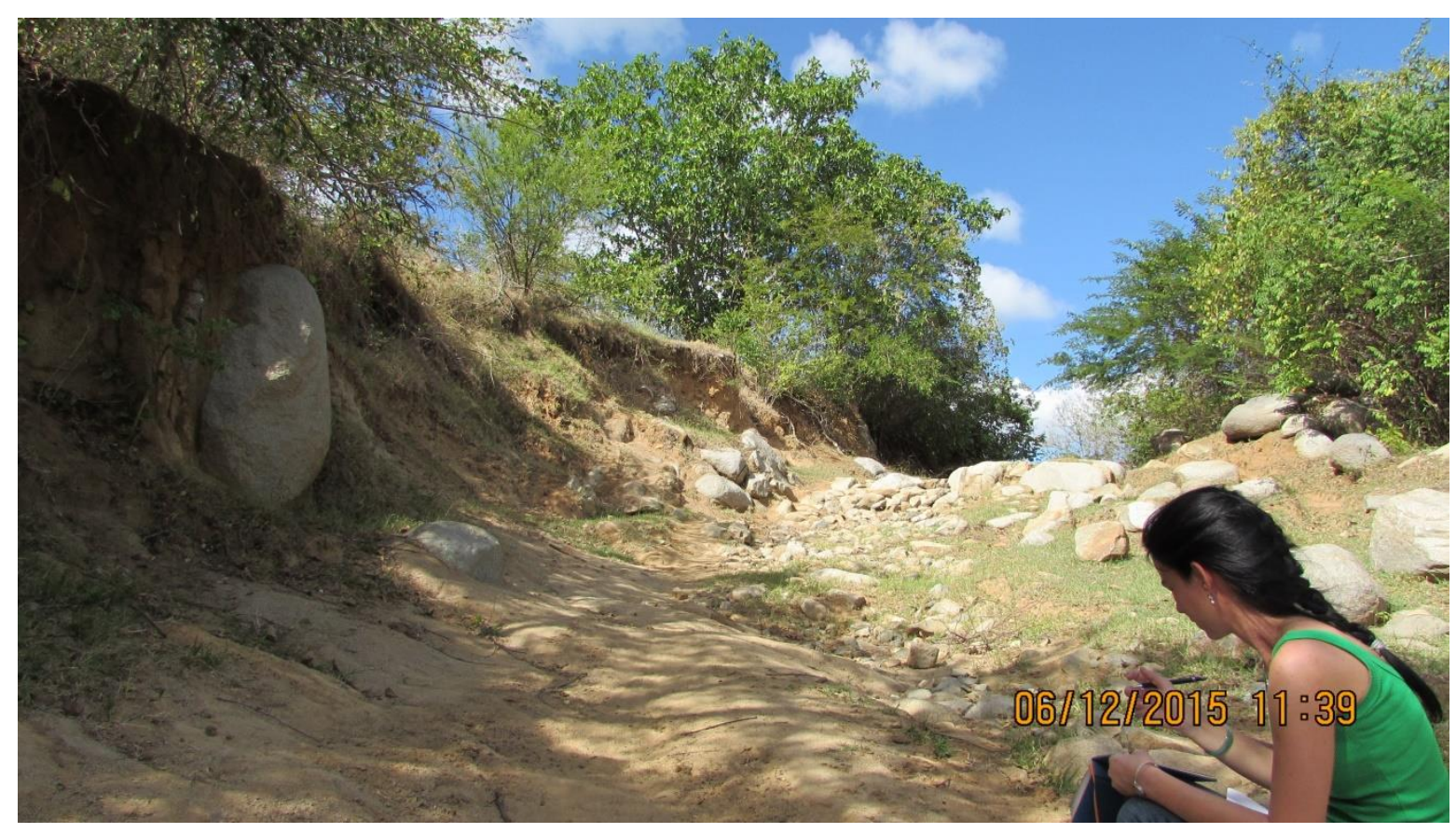

Fotografia_024 


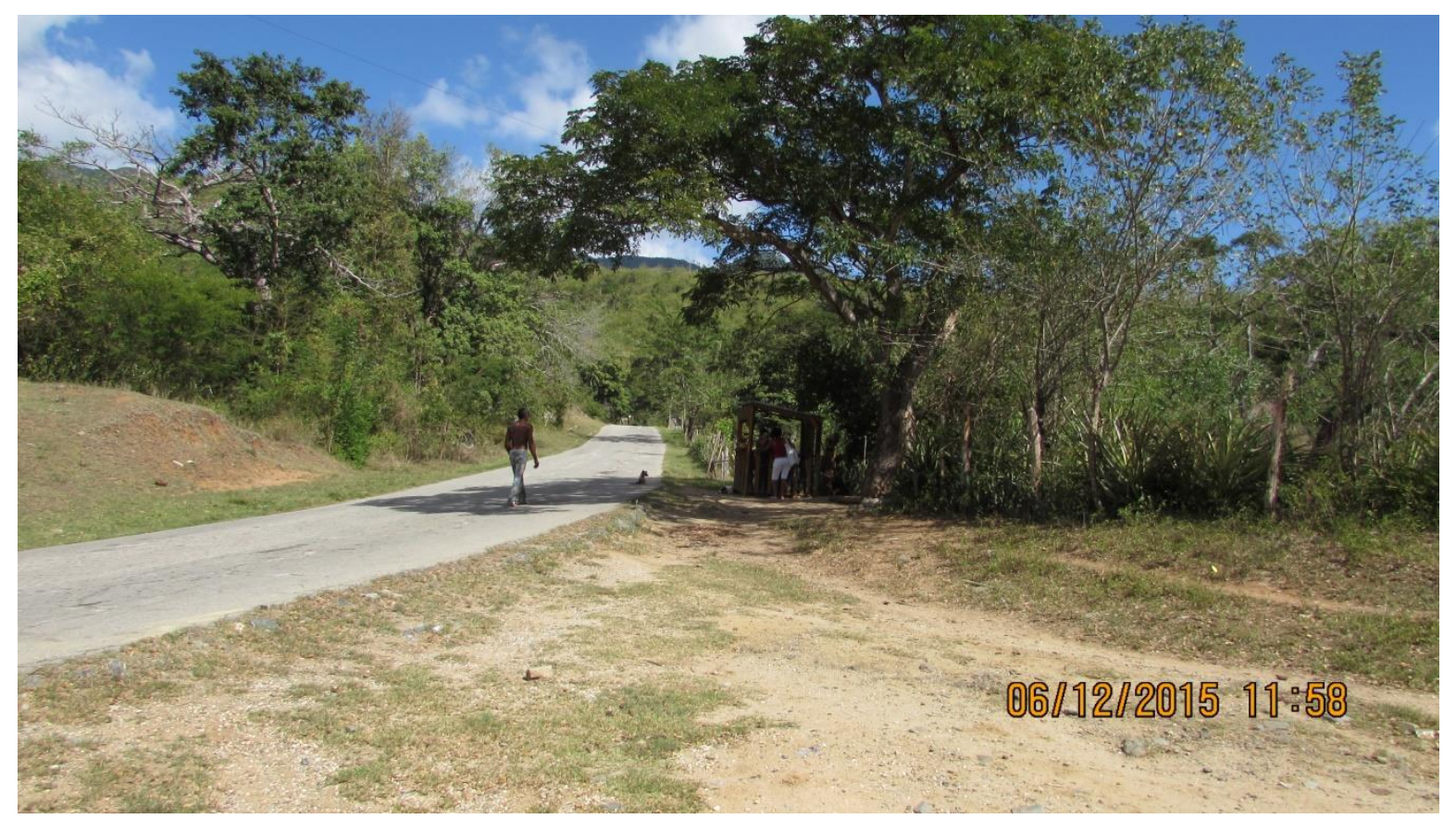

Fotografia_025

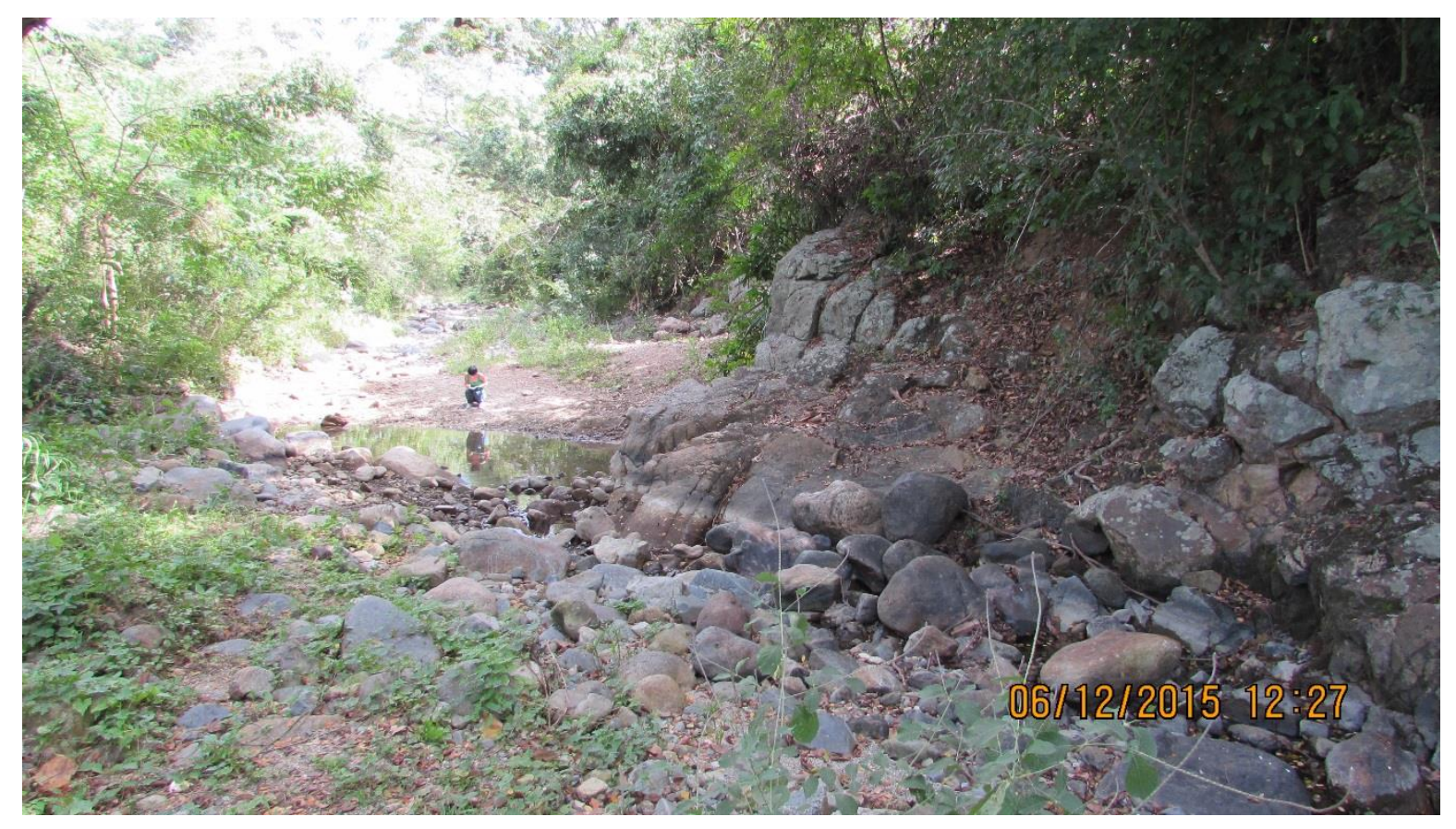

Fotografia_026 


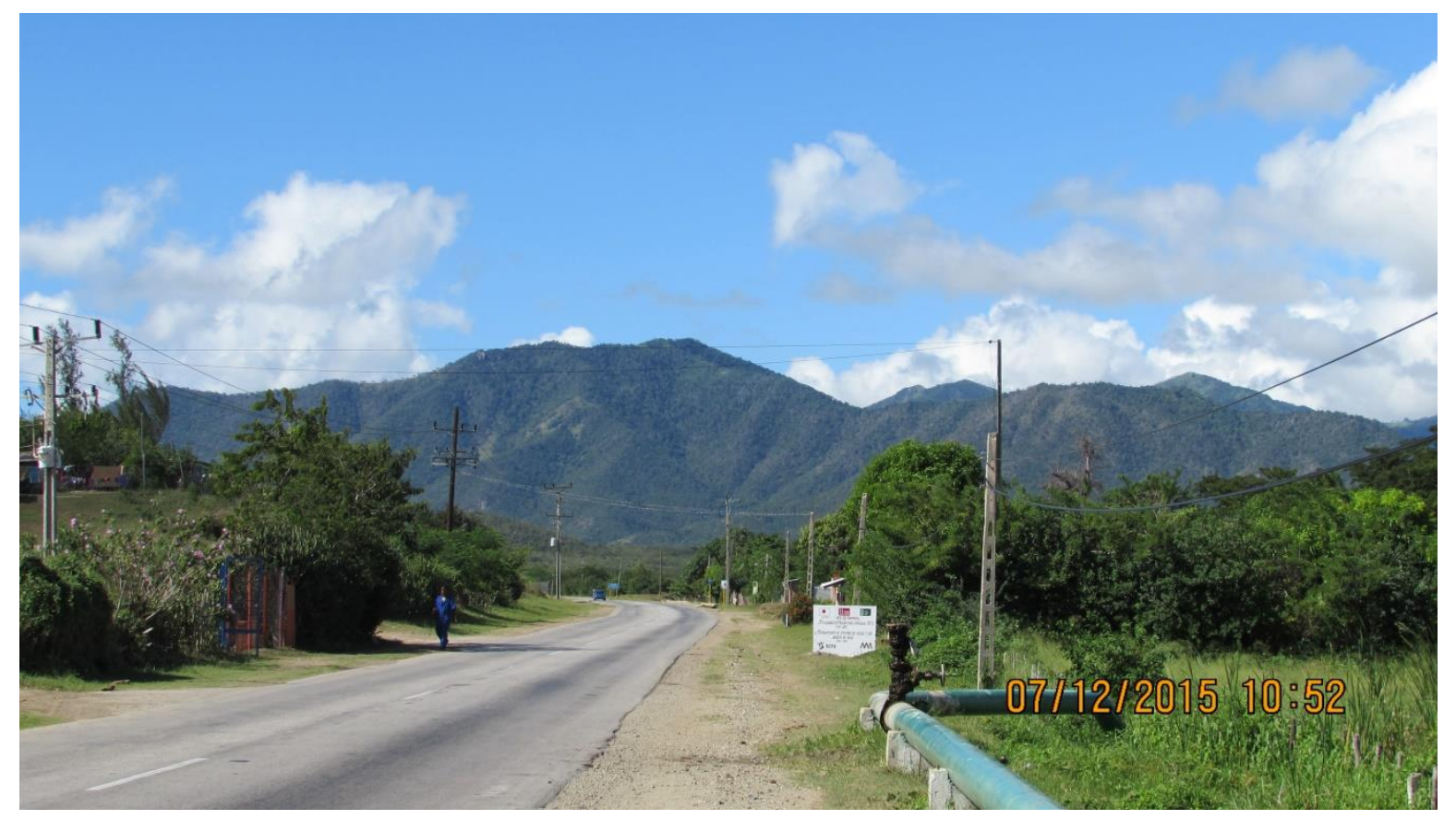

Fotografia_027

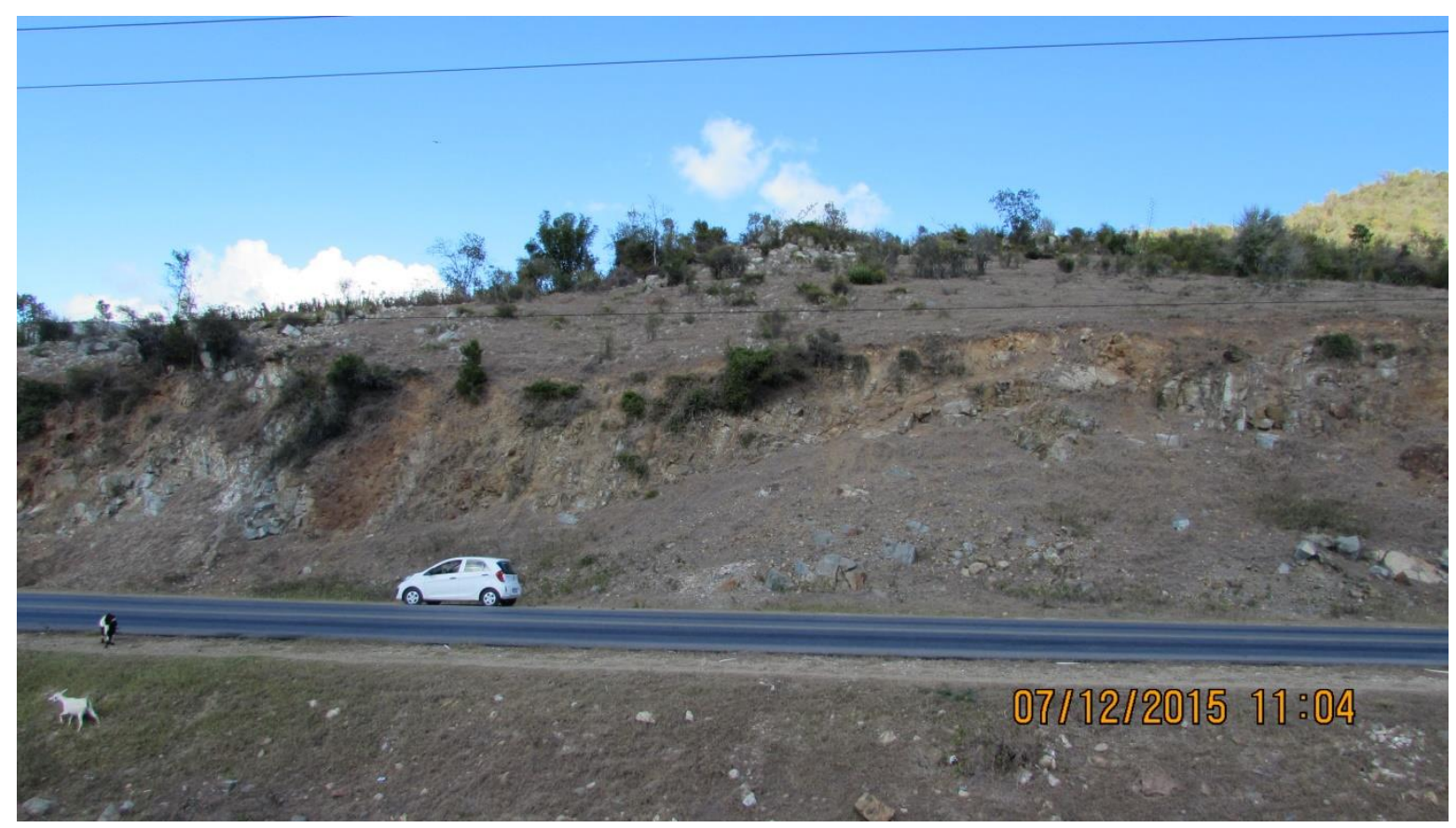

Fotografia_028 


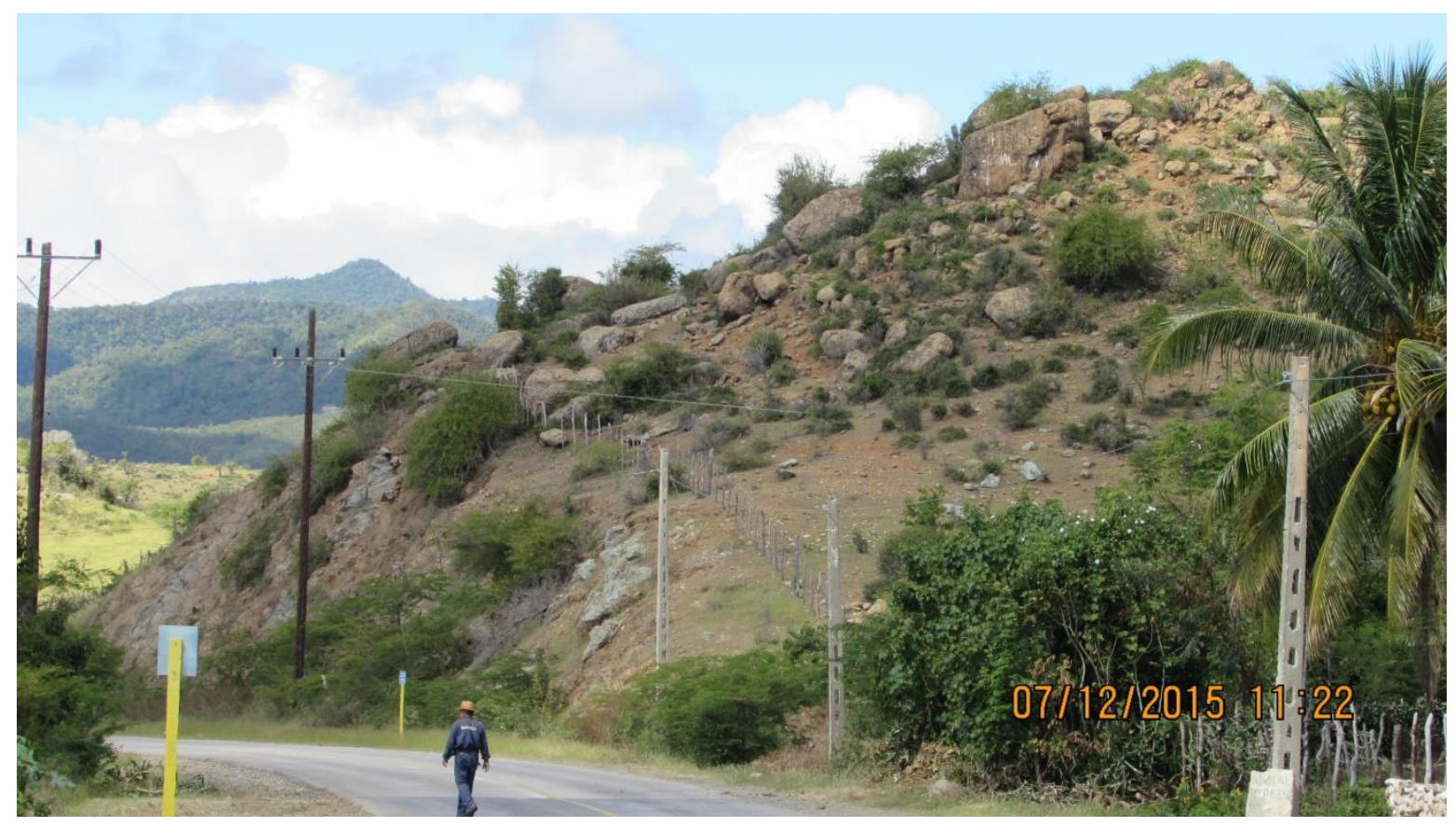

Fotografia_029

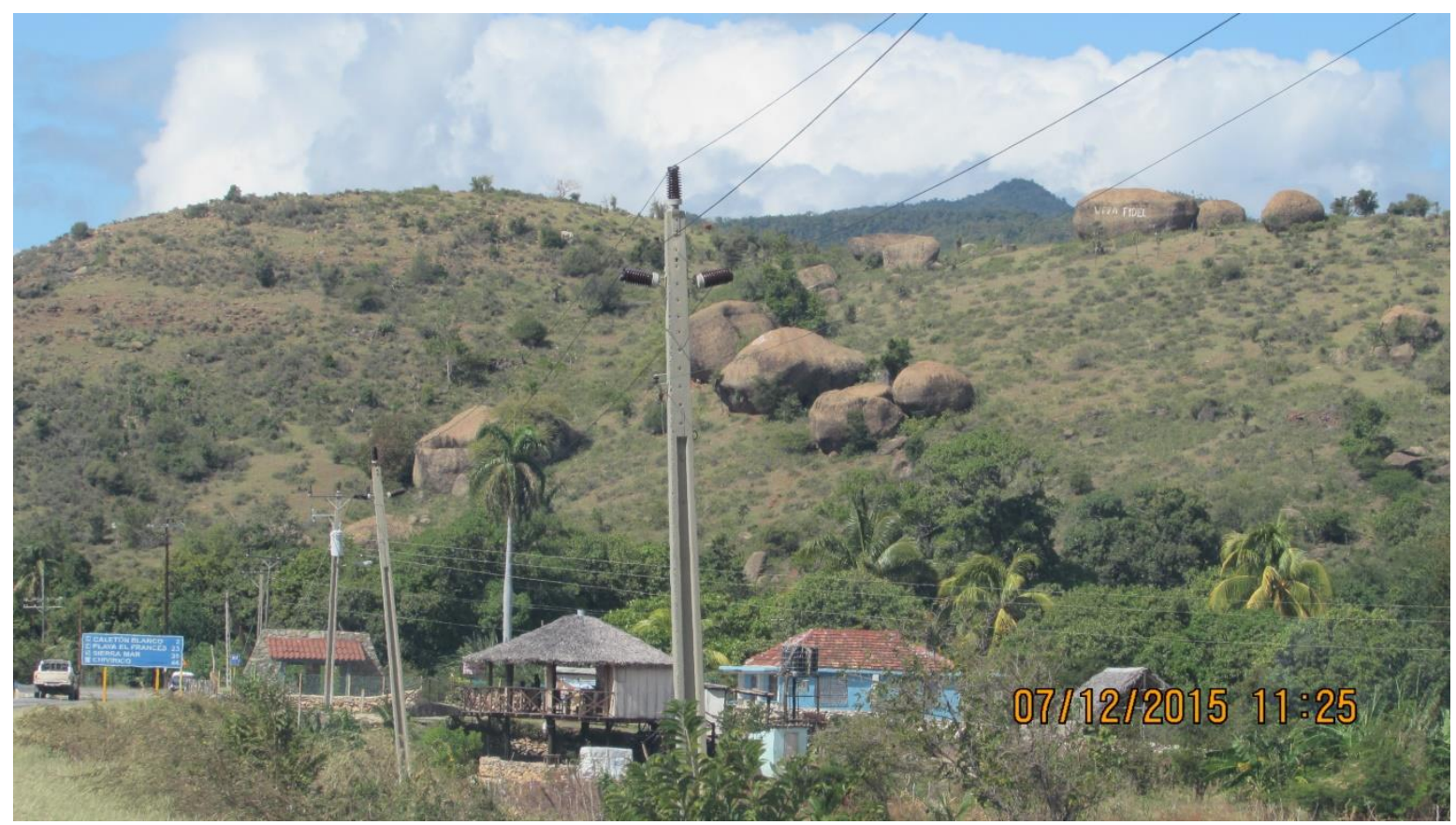

Fotografia_030 


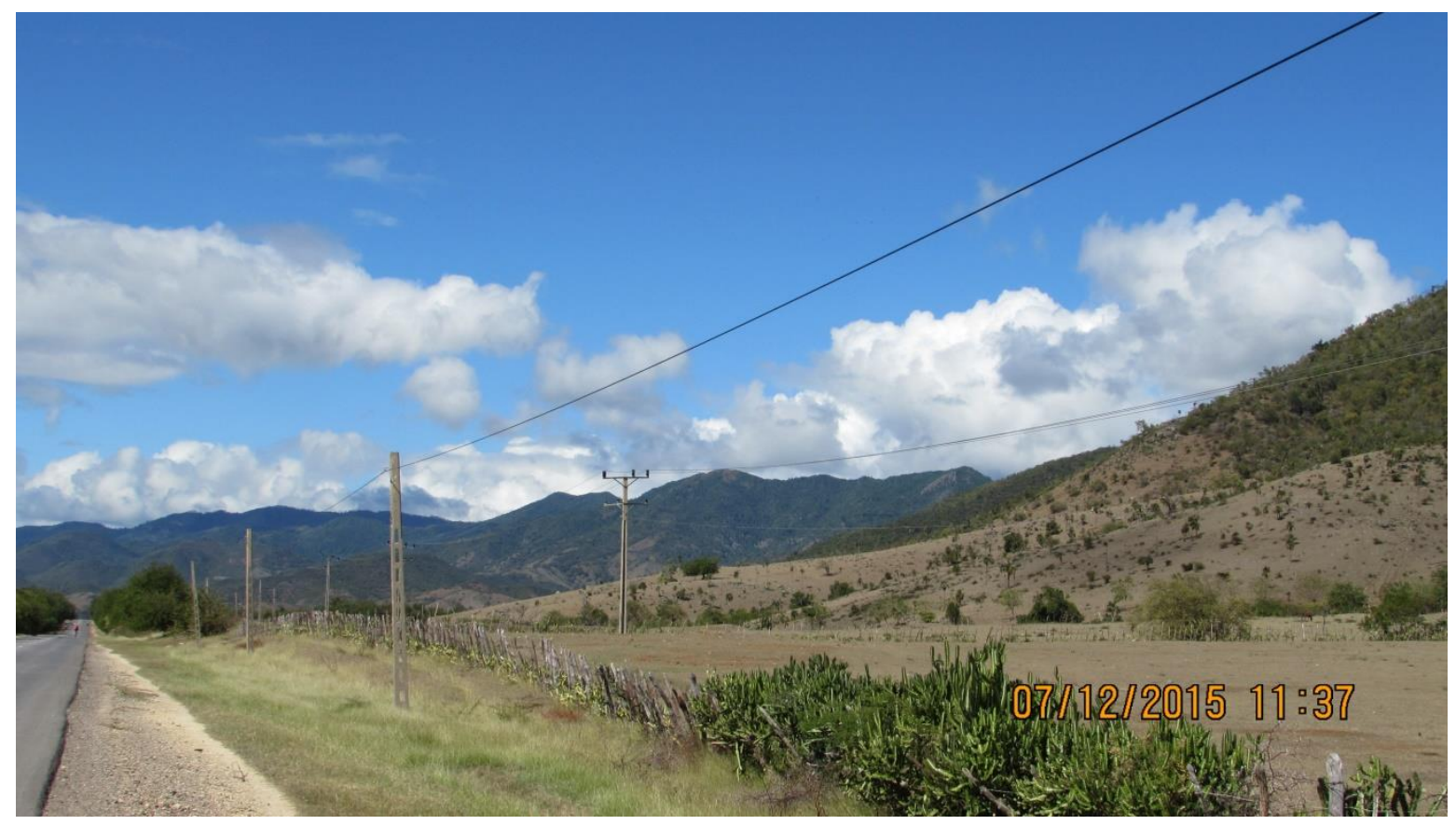

Fotografia_031

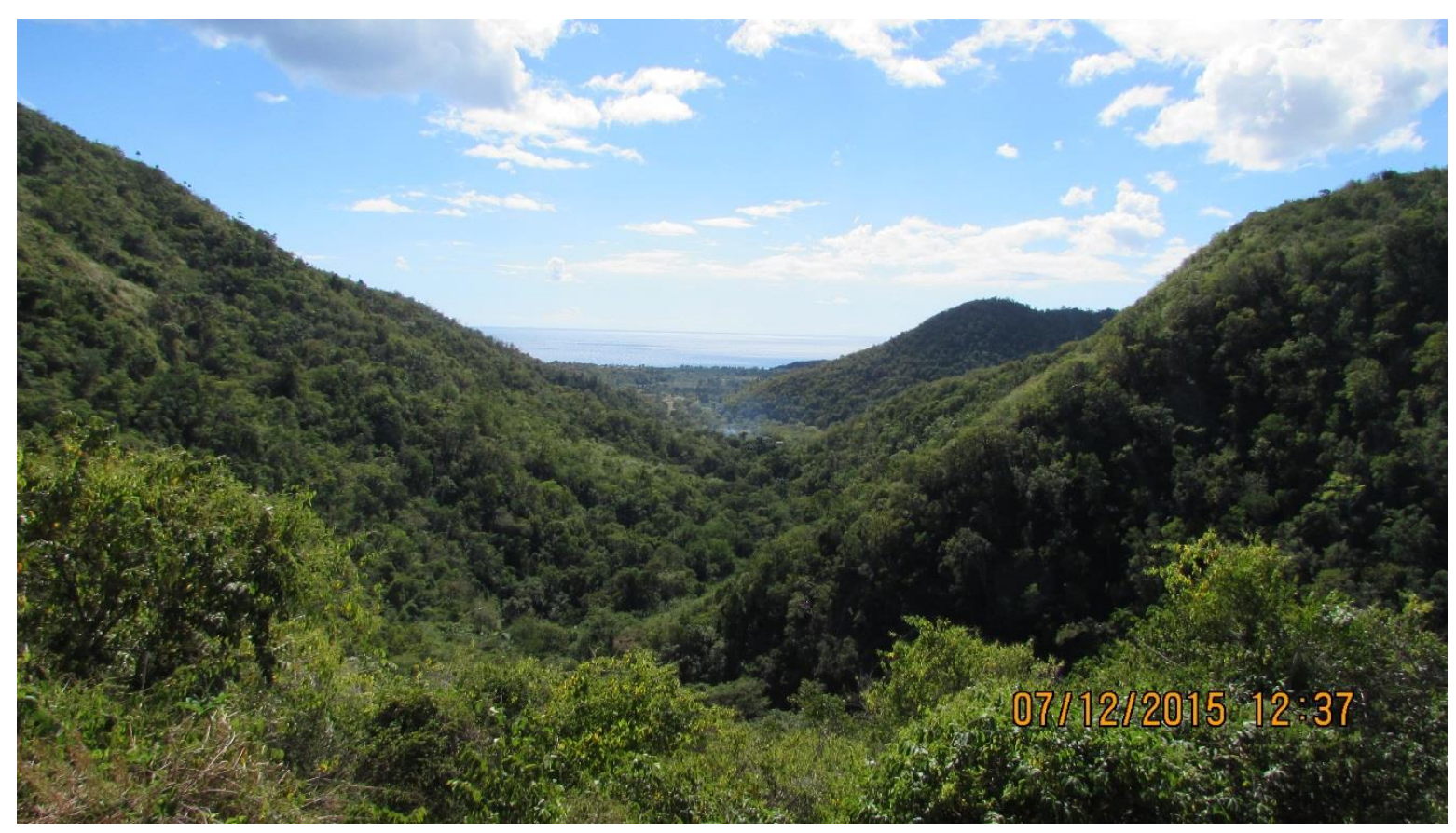

Fotografia_032 


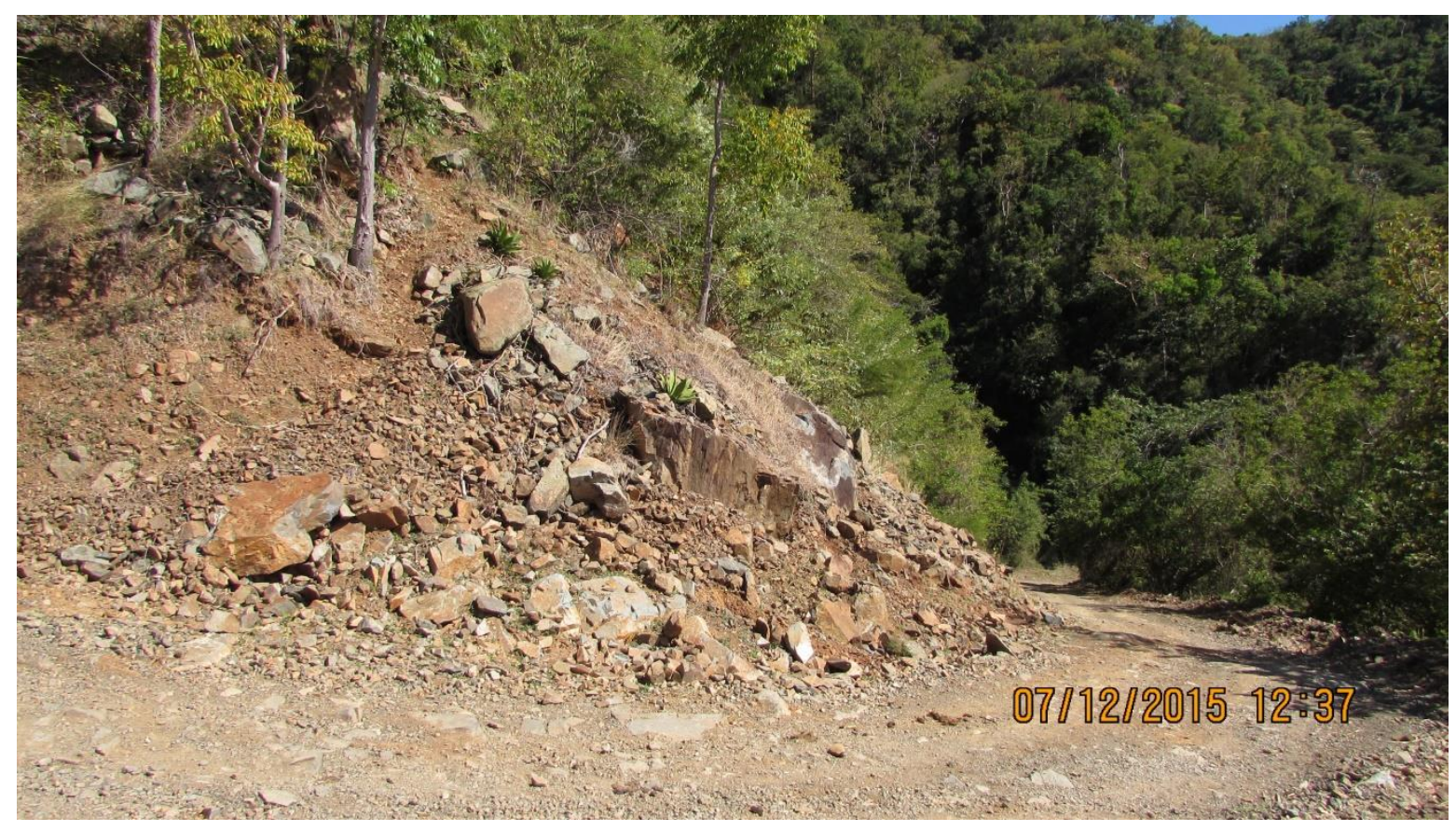

Fotografia_033

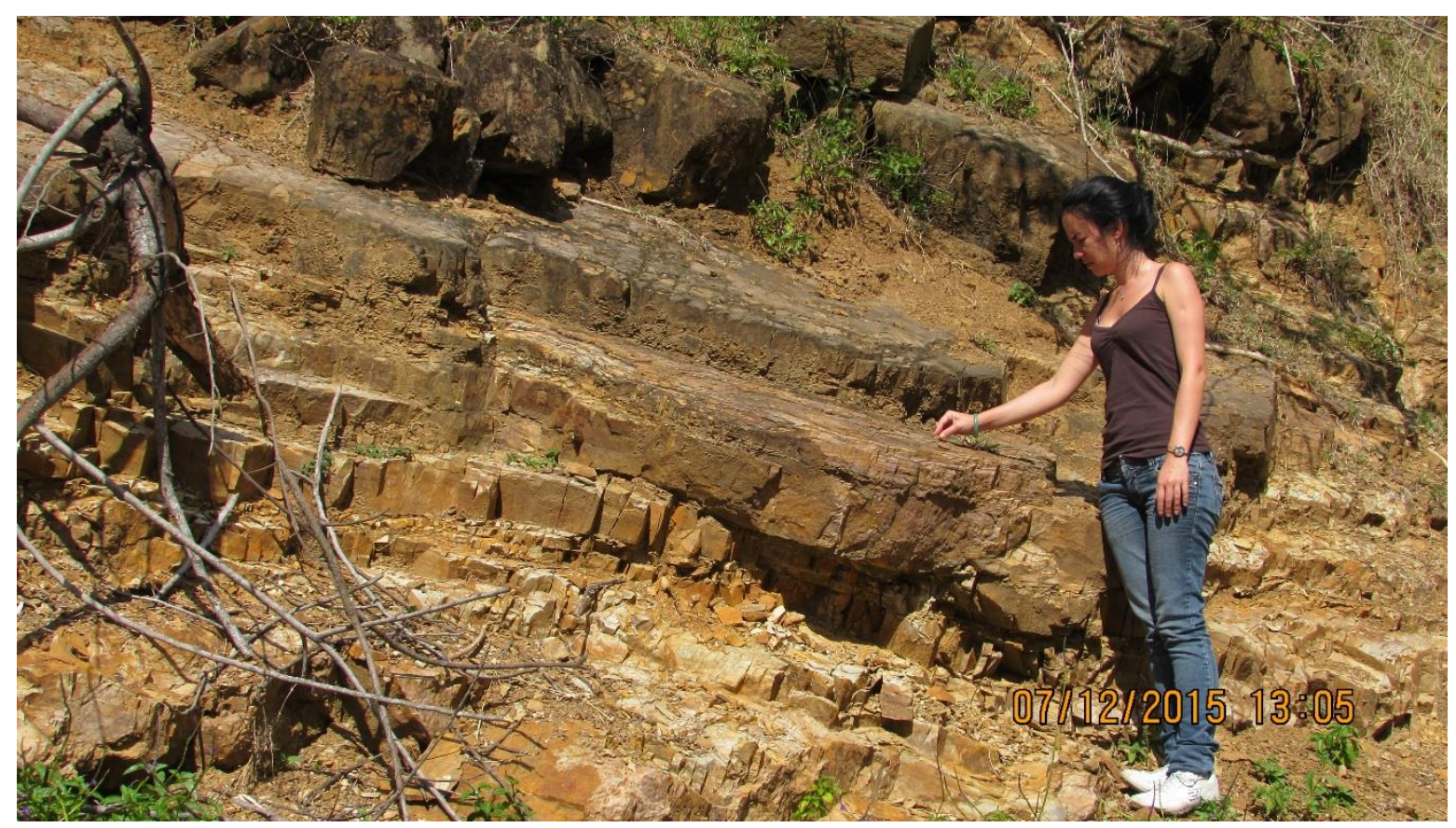

Fotografia_034 


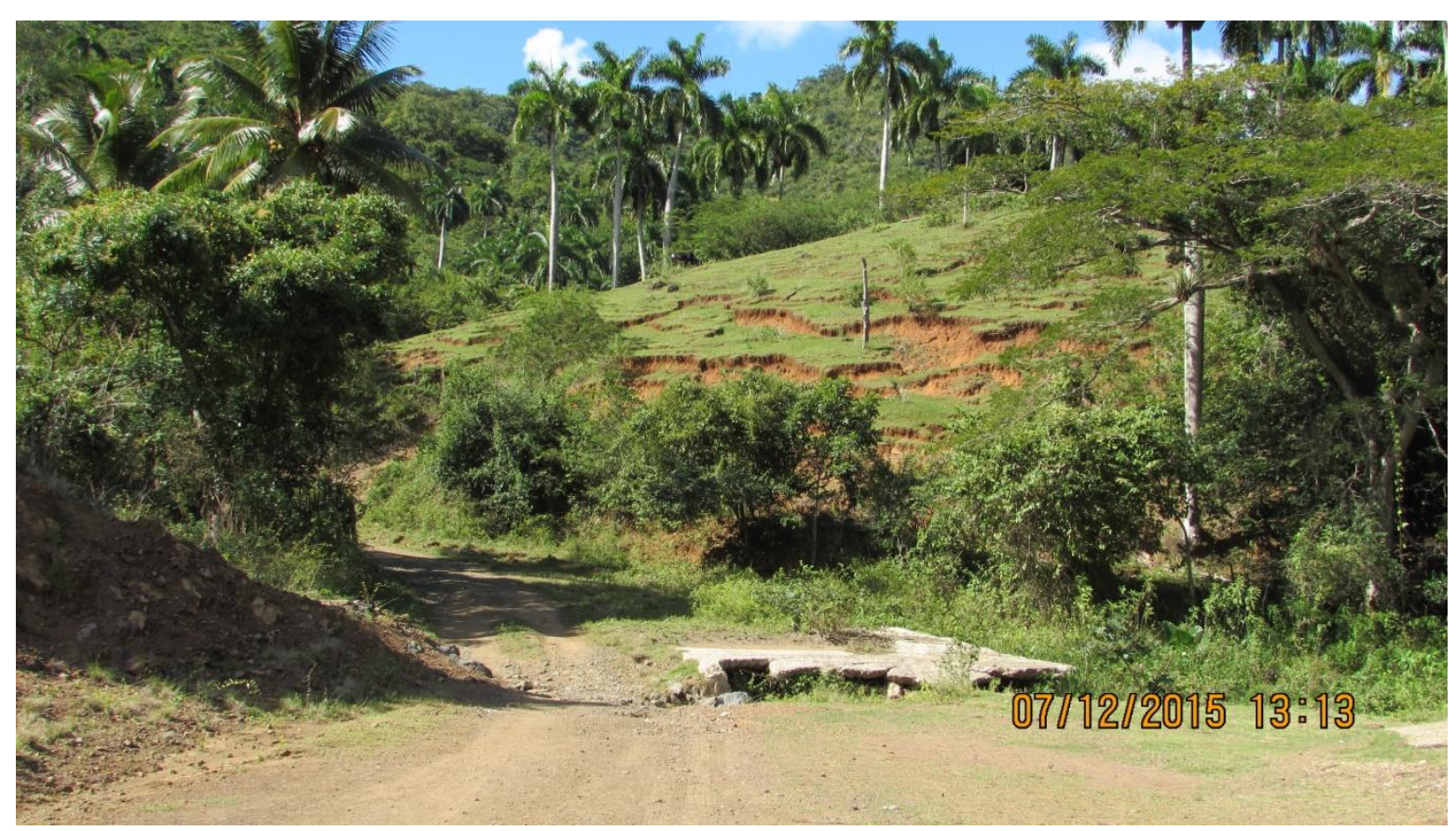

Fotografia_035

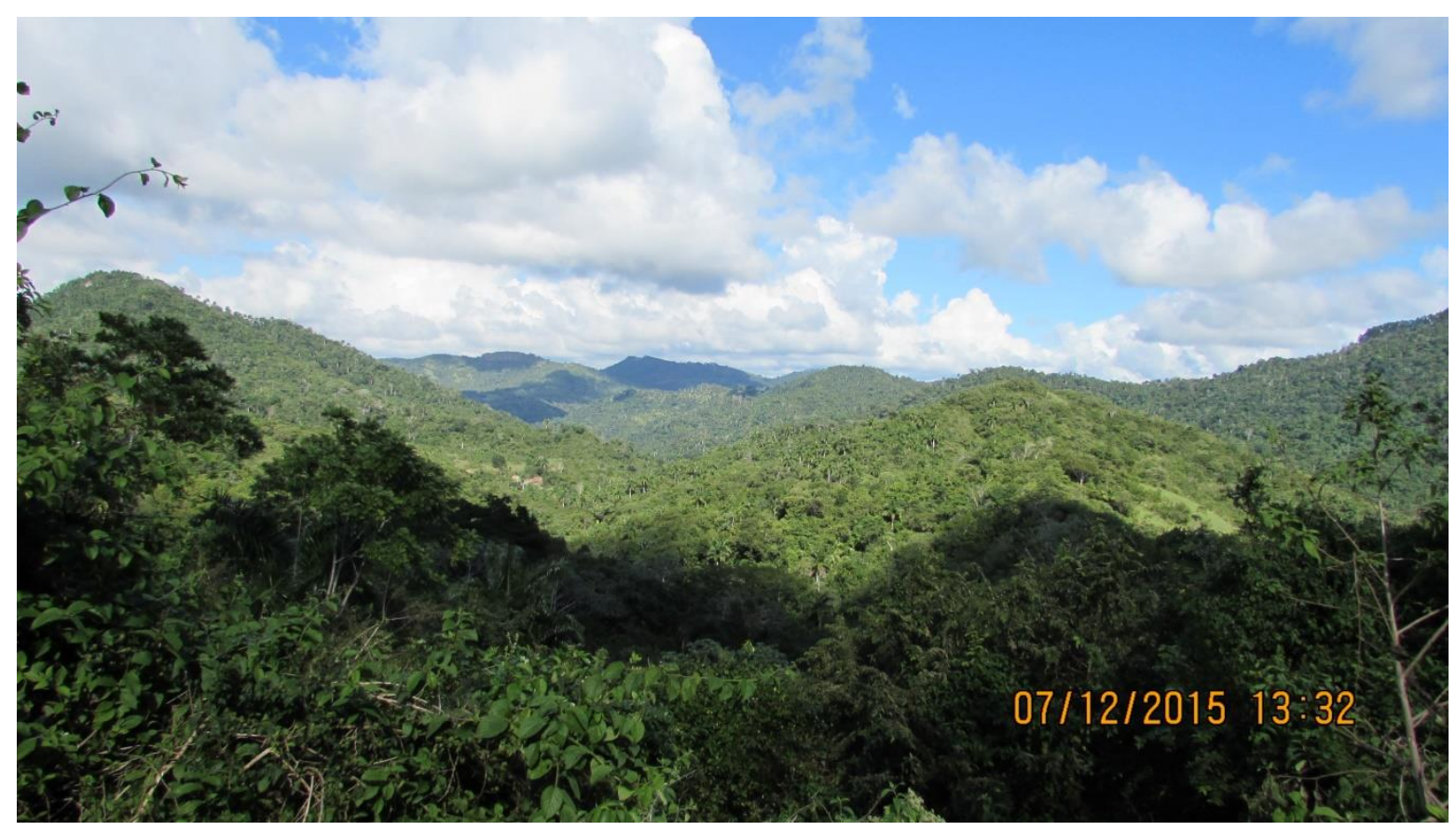

Fotografia_036 


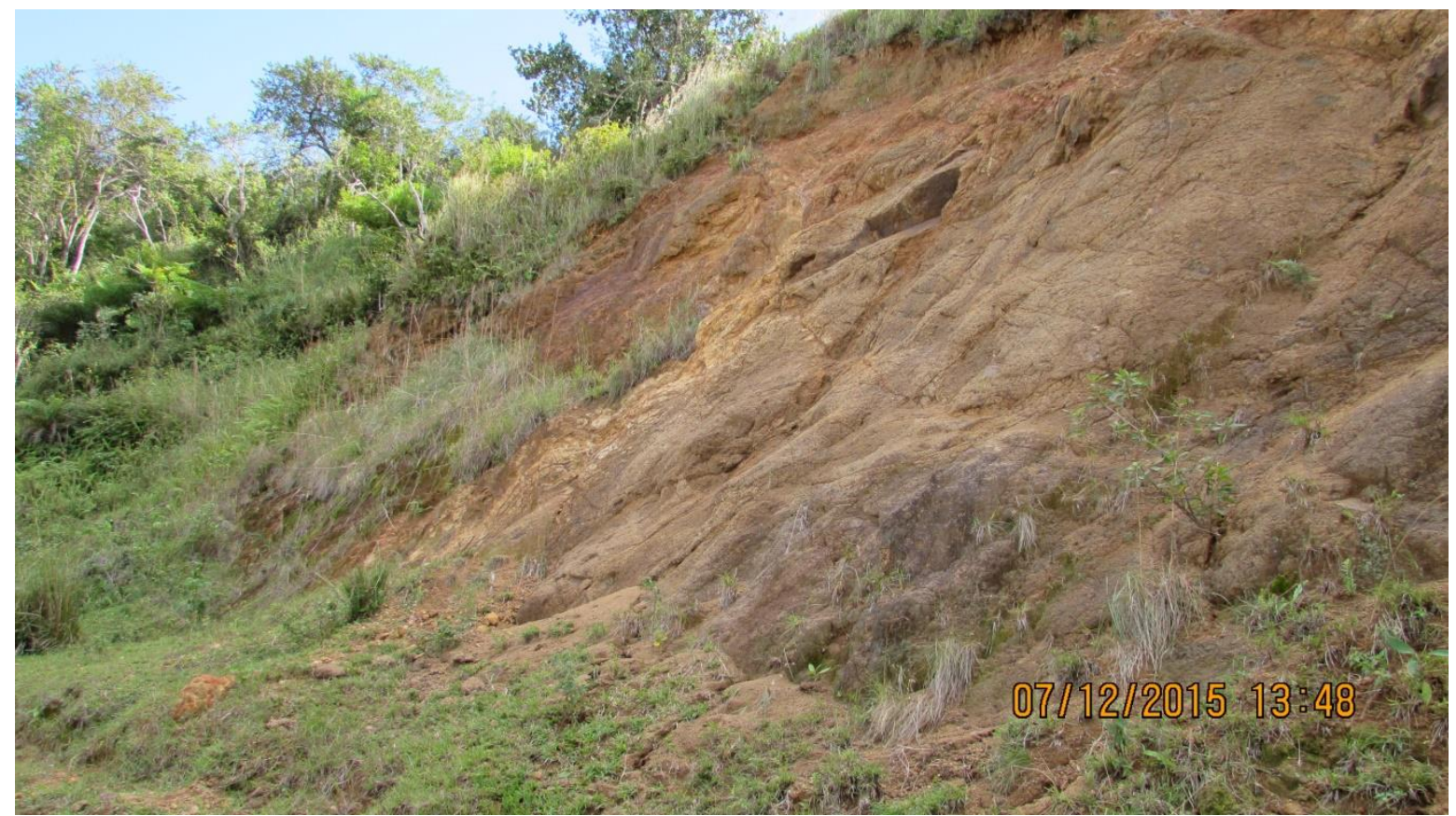

Fotografia_037

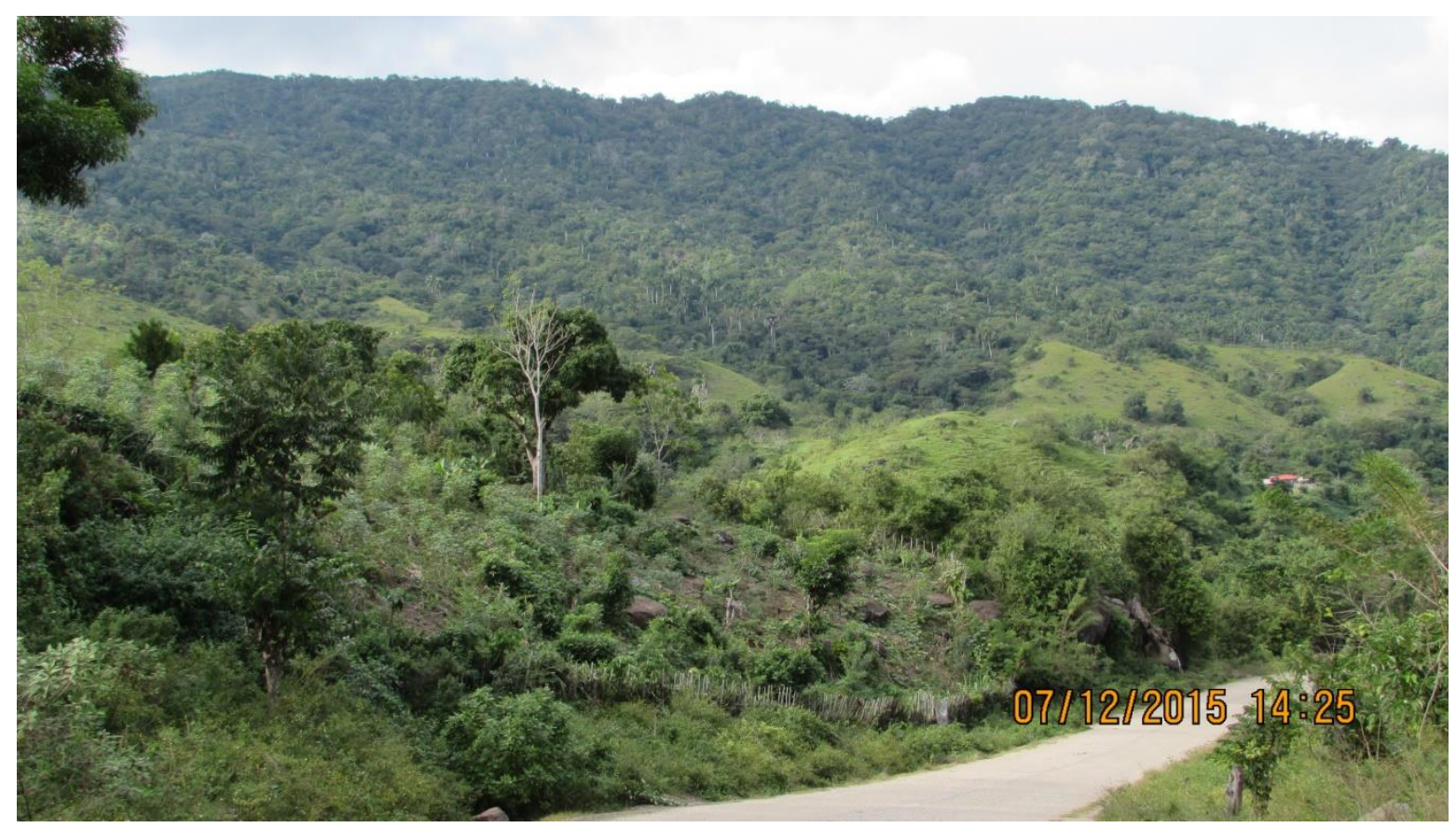

Fotografia_038 


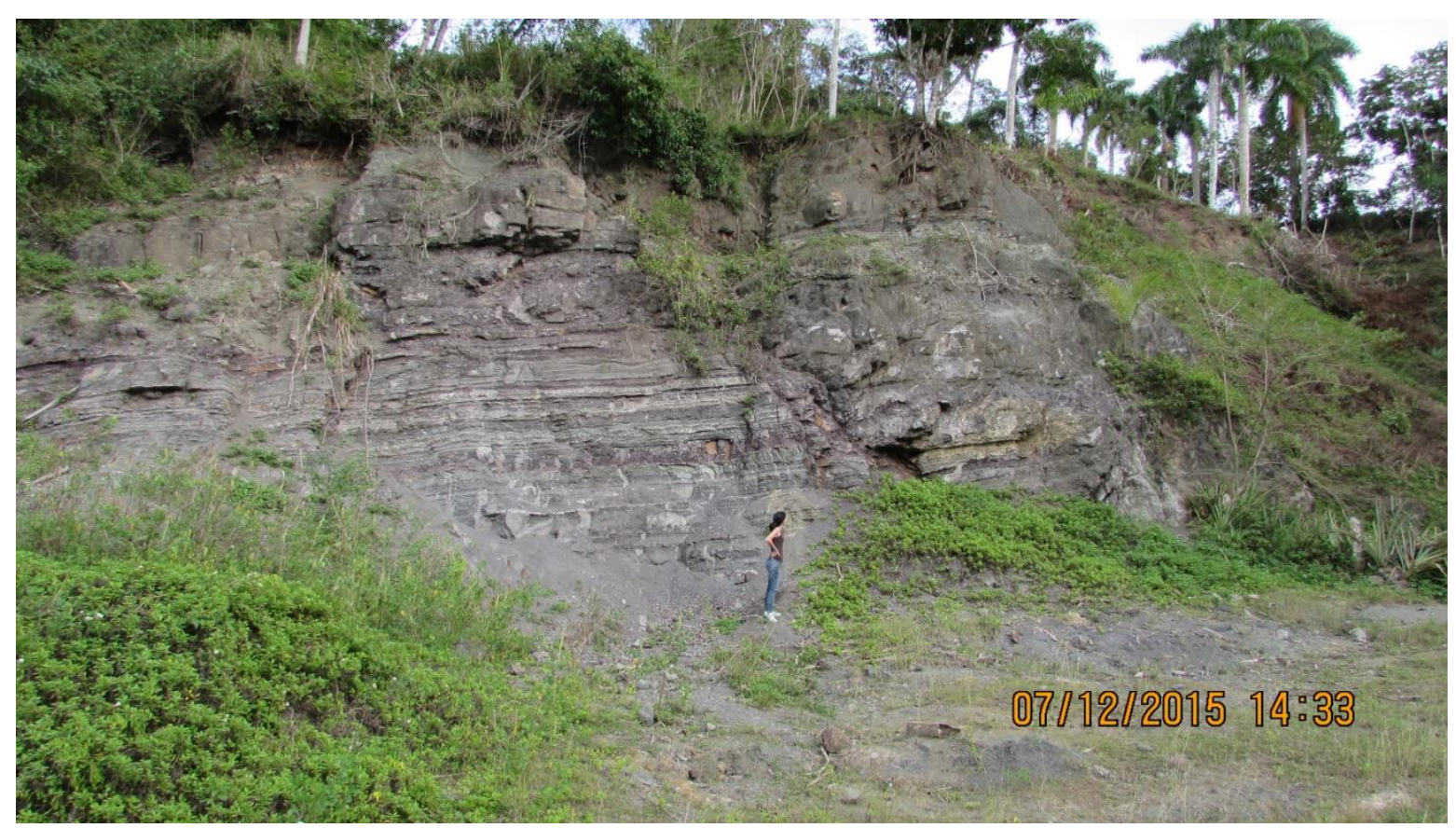

Fotografia_039

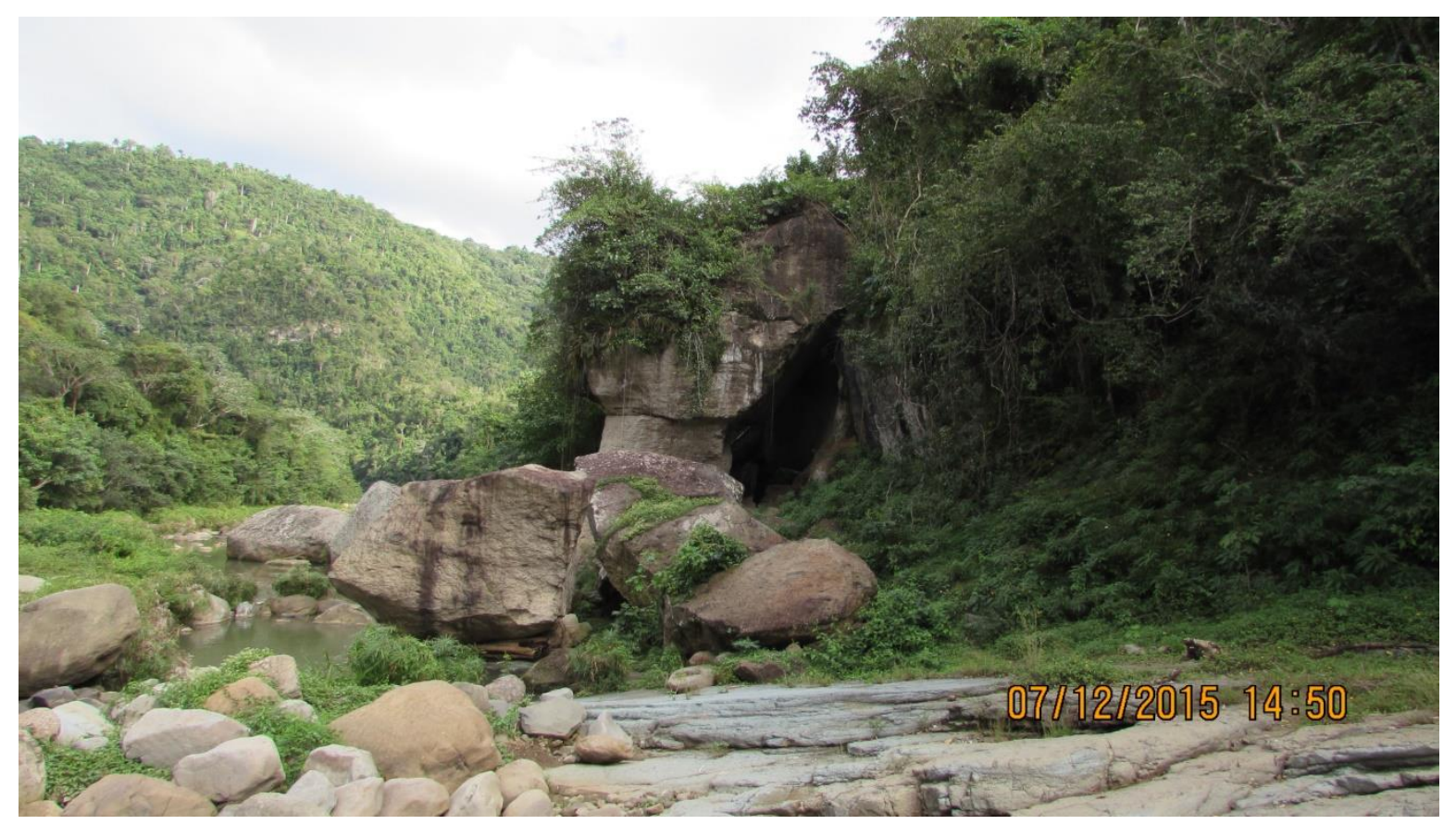

Fotografia_040 


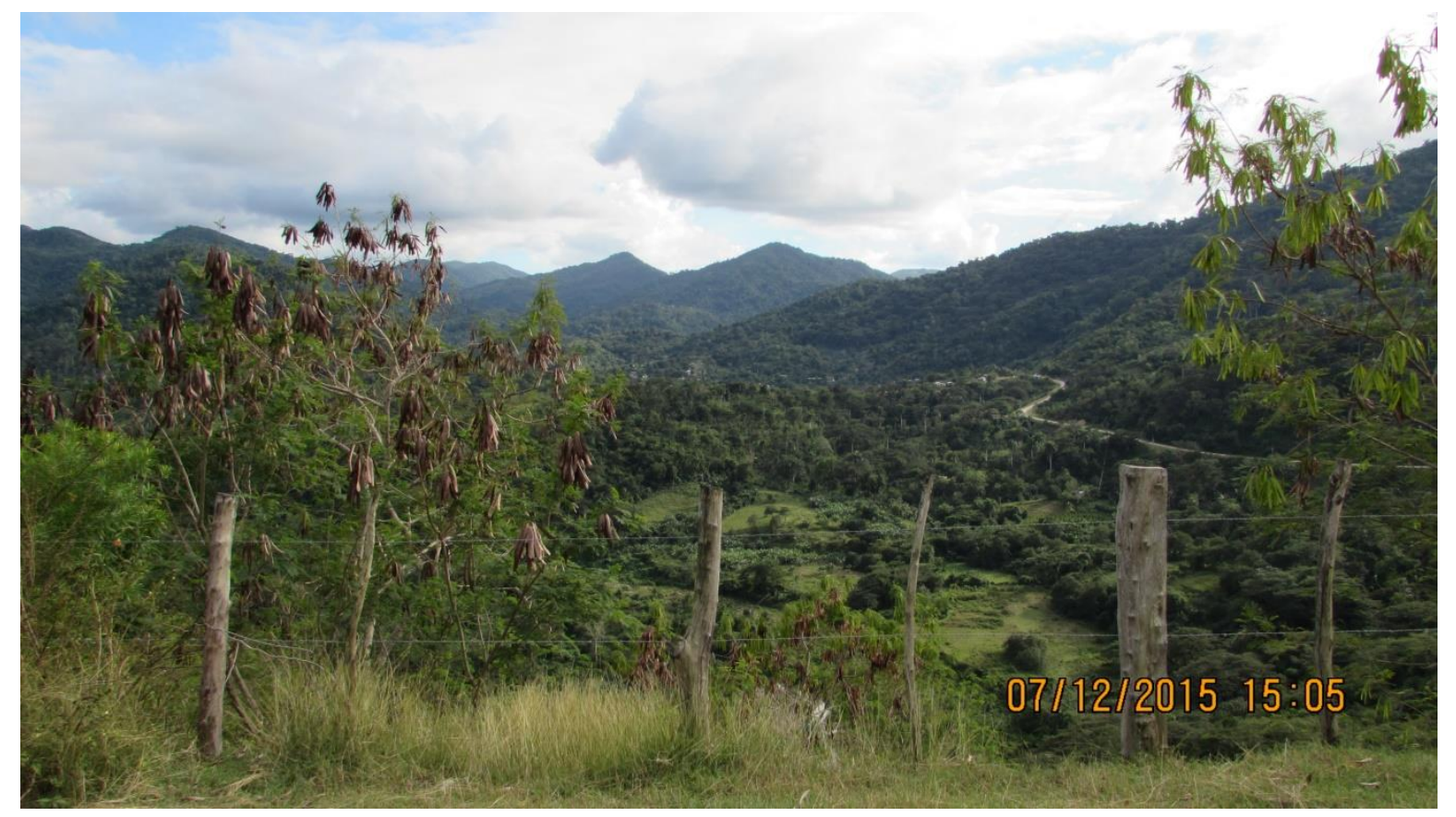

Fotografia_041

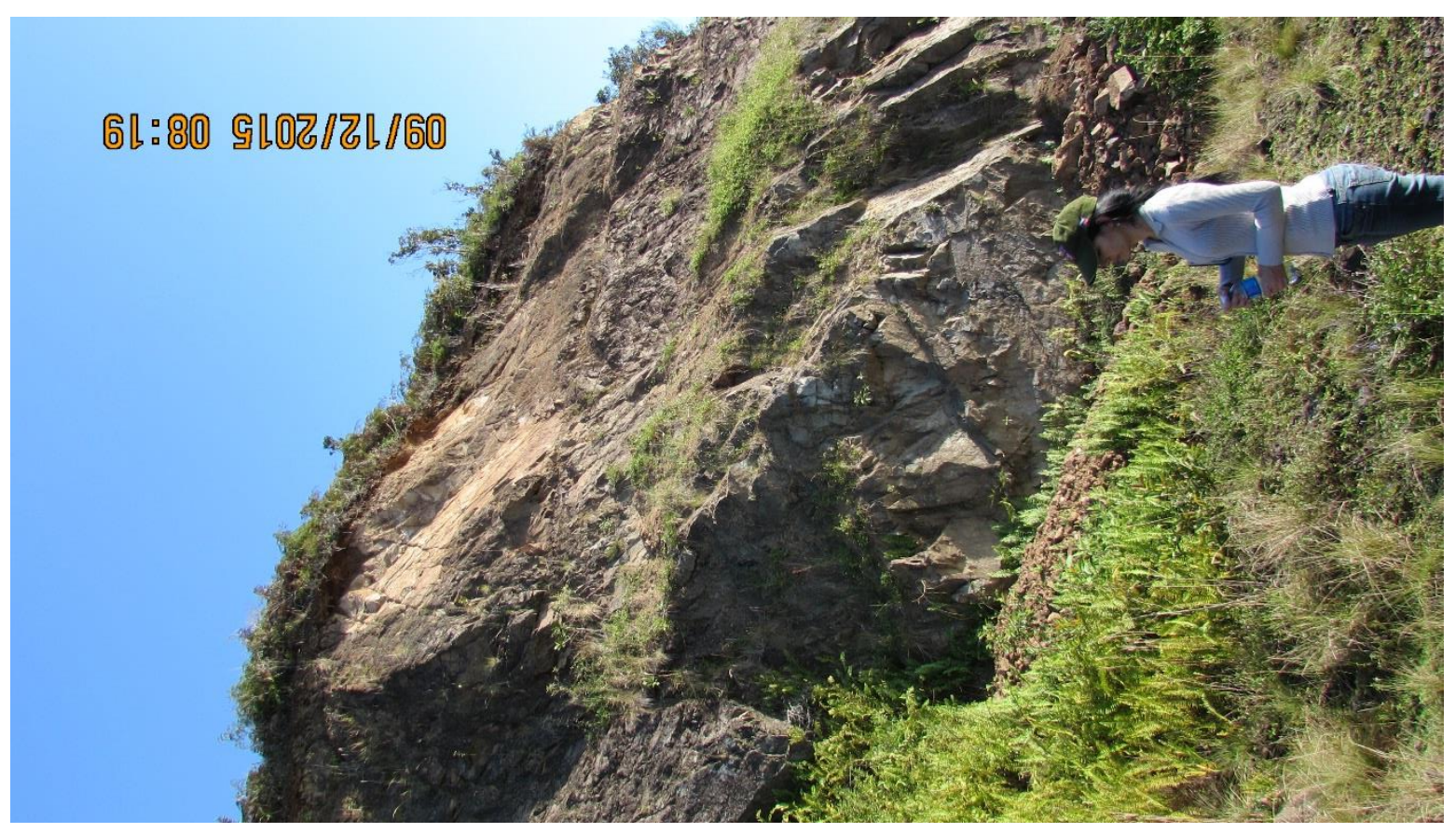

Fotografia_042 


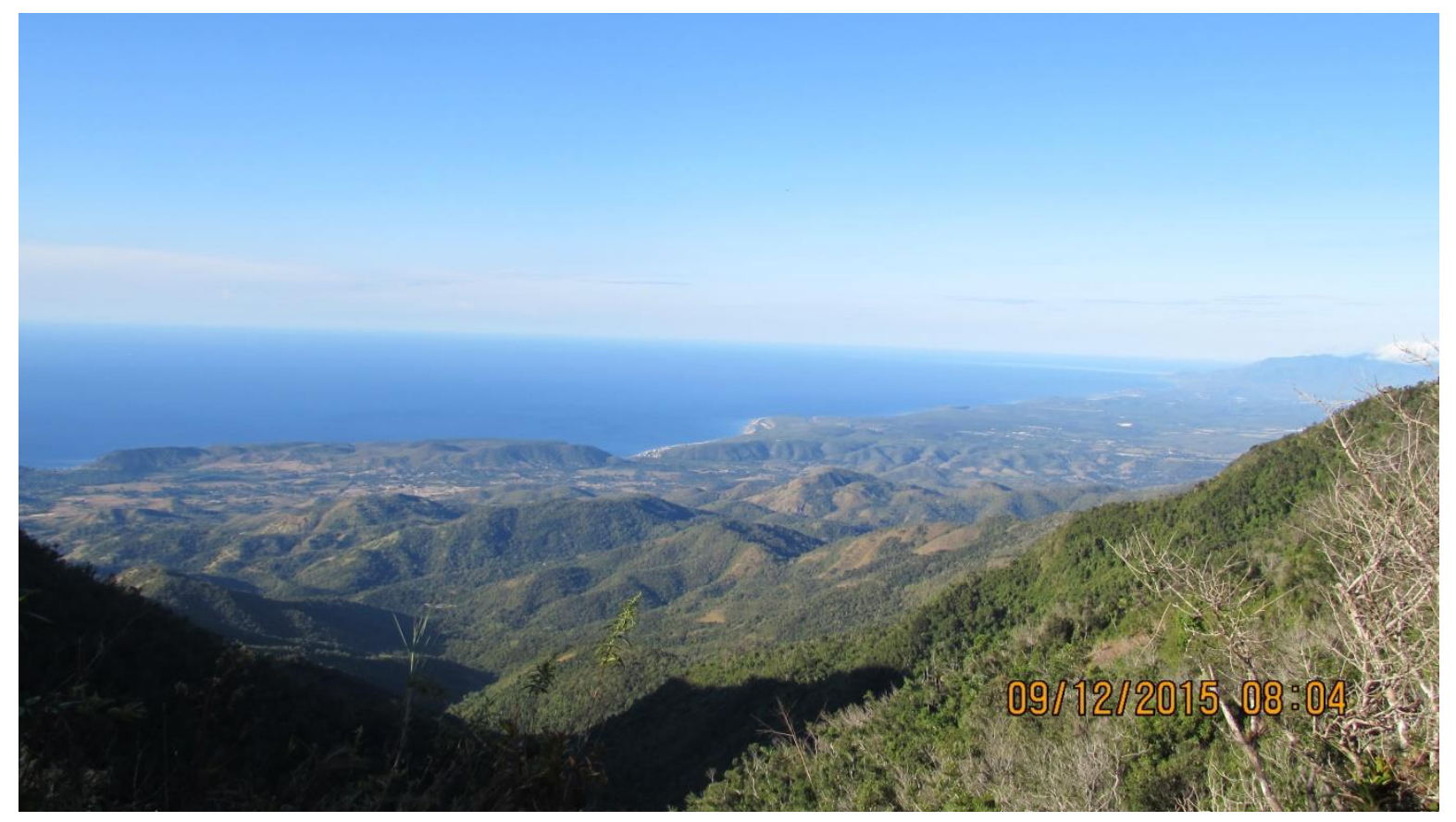

Fotografia_043

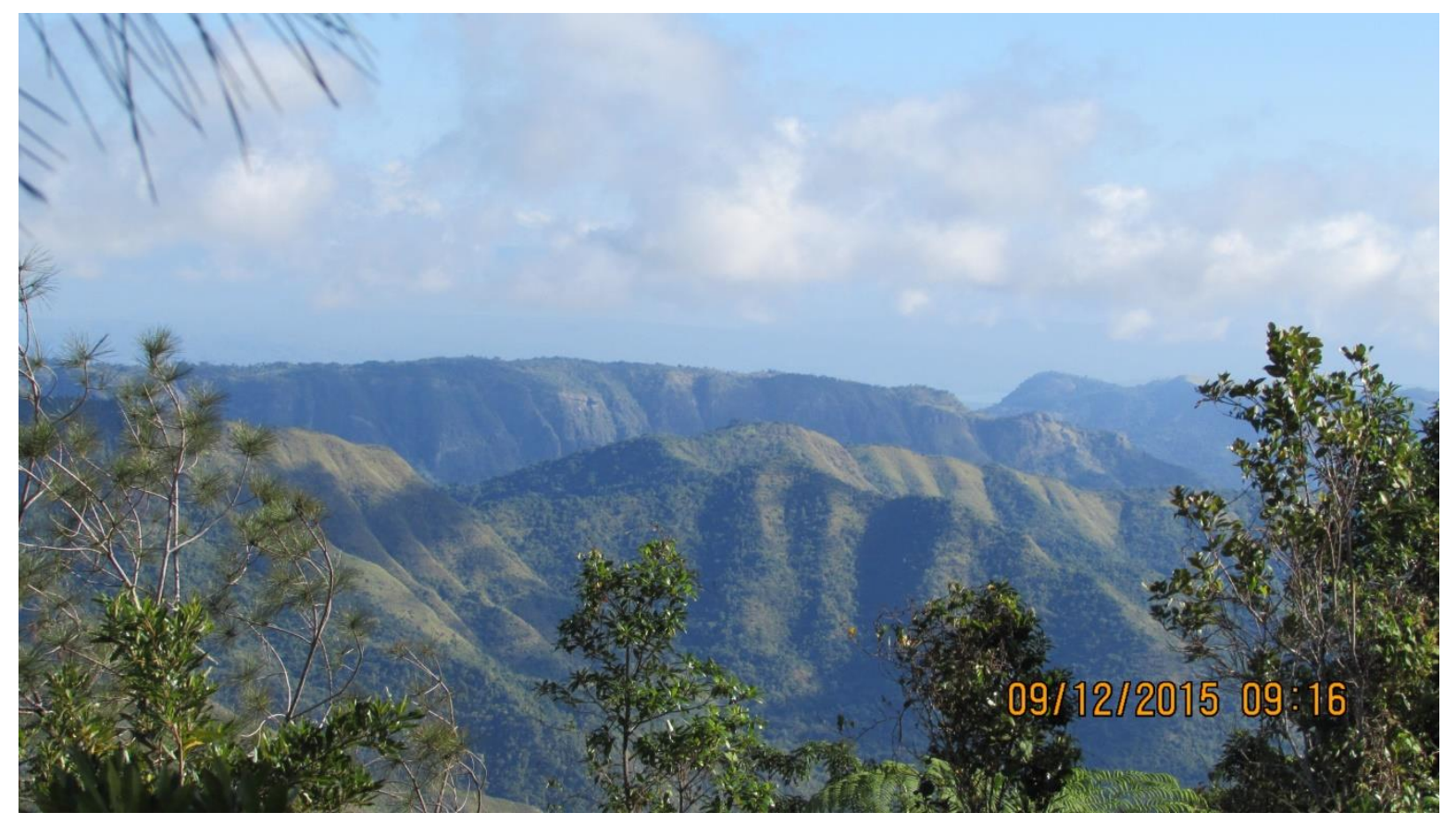

Fotografia_044 


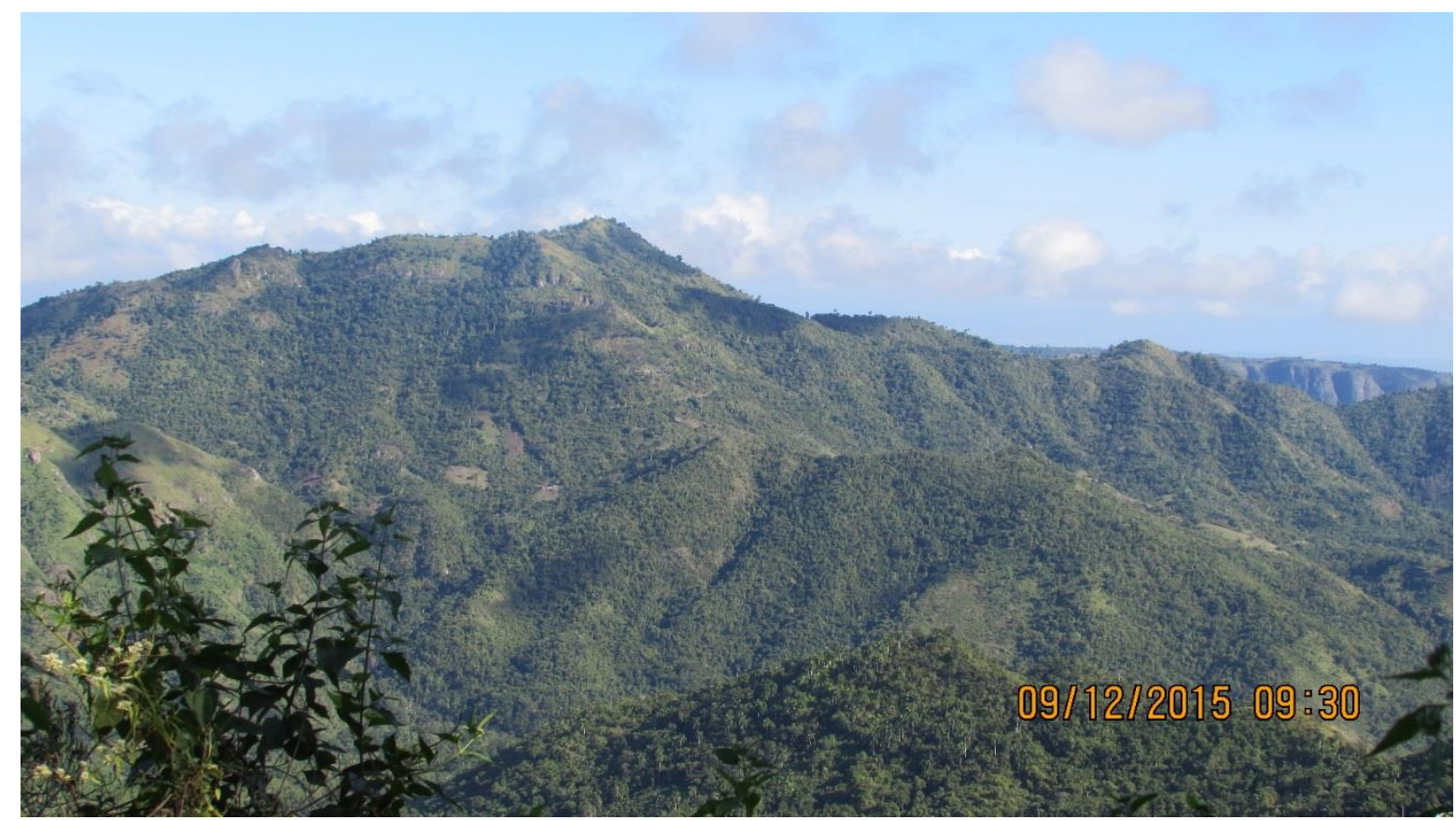

Fotografia_045

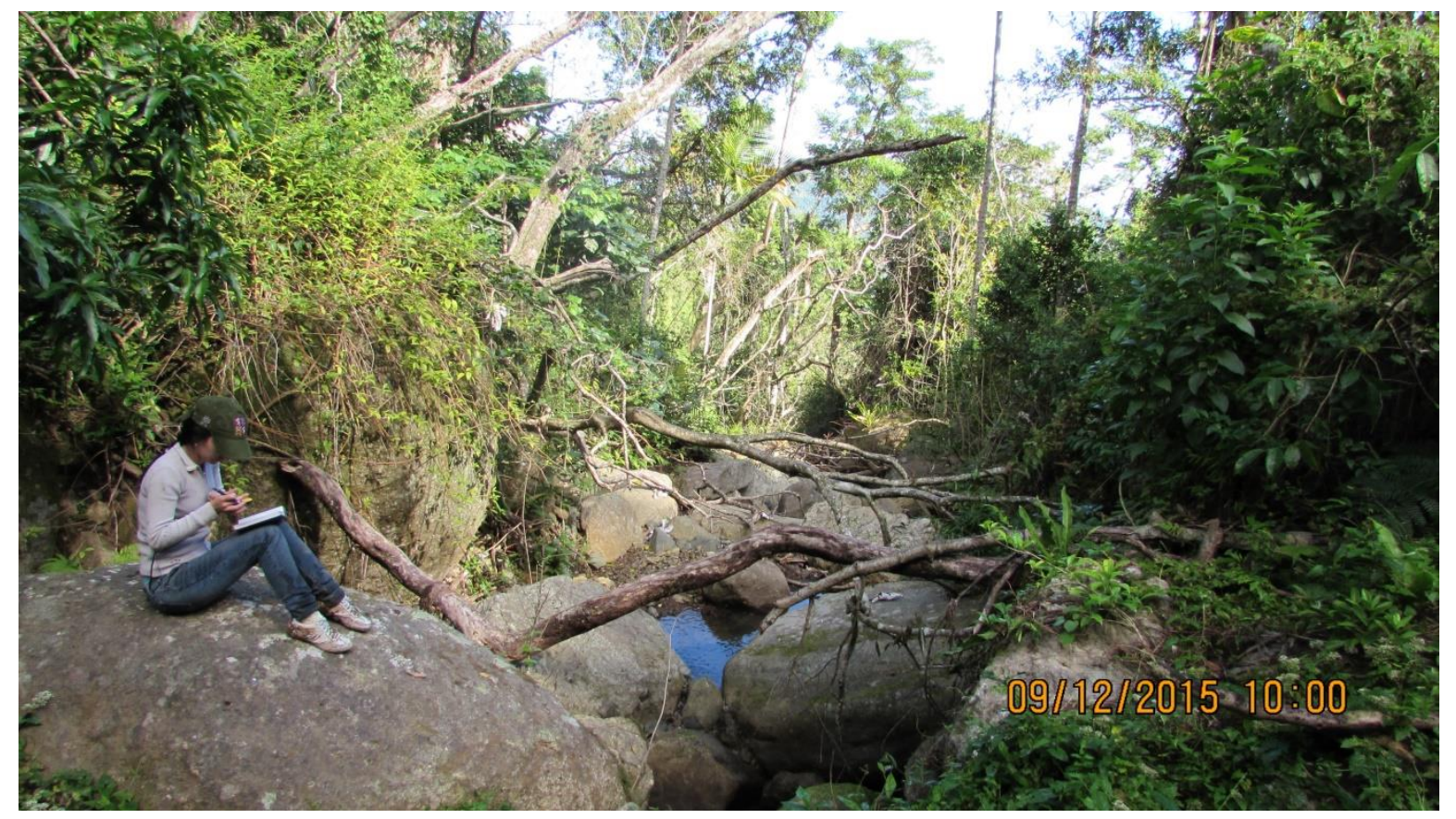

Fotografia_046 


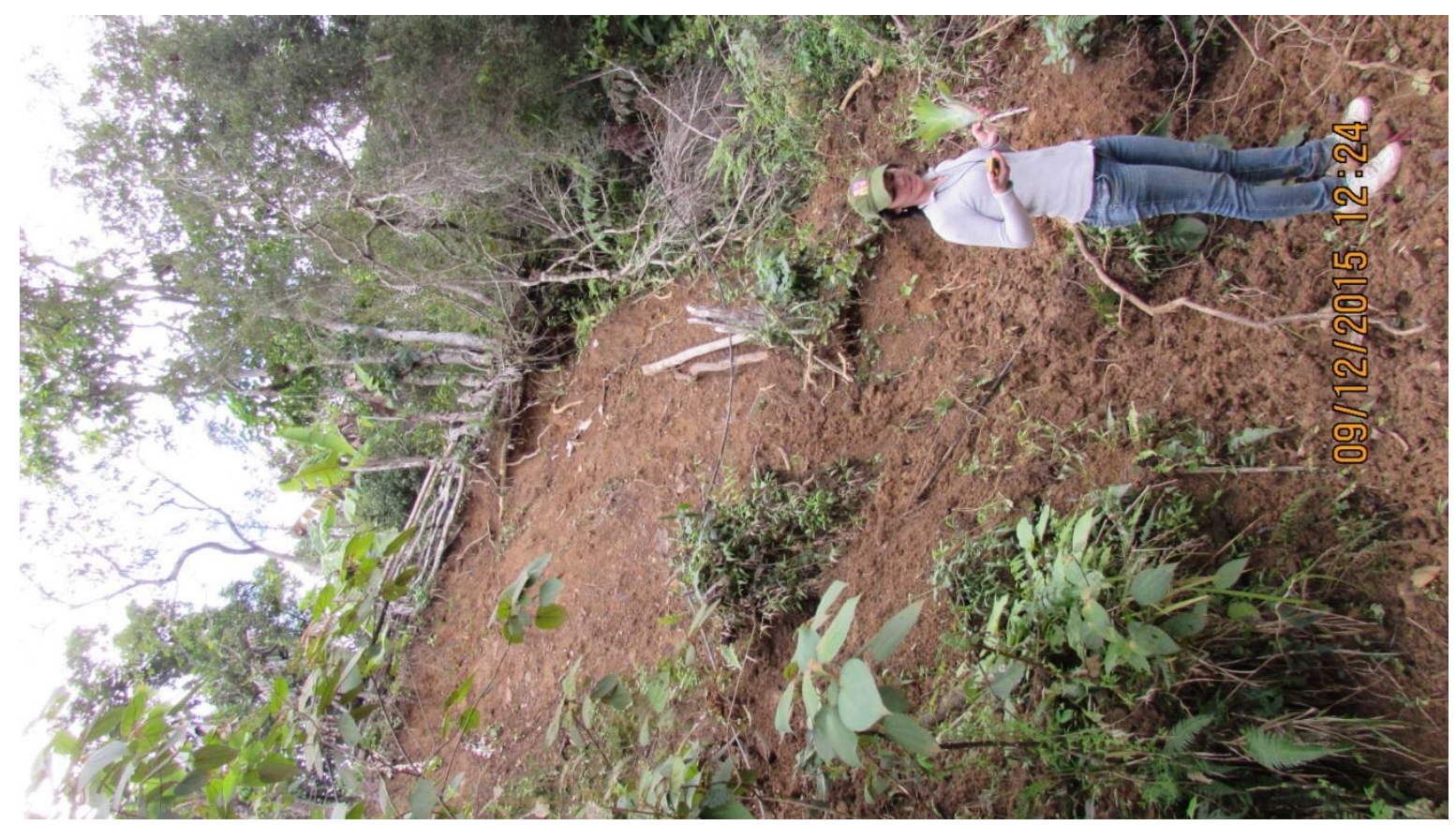

Fotografia_047

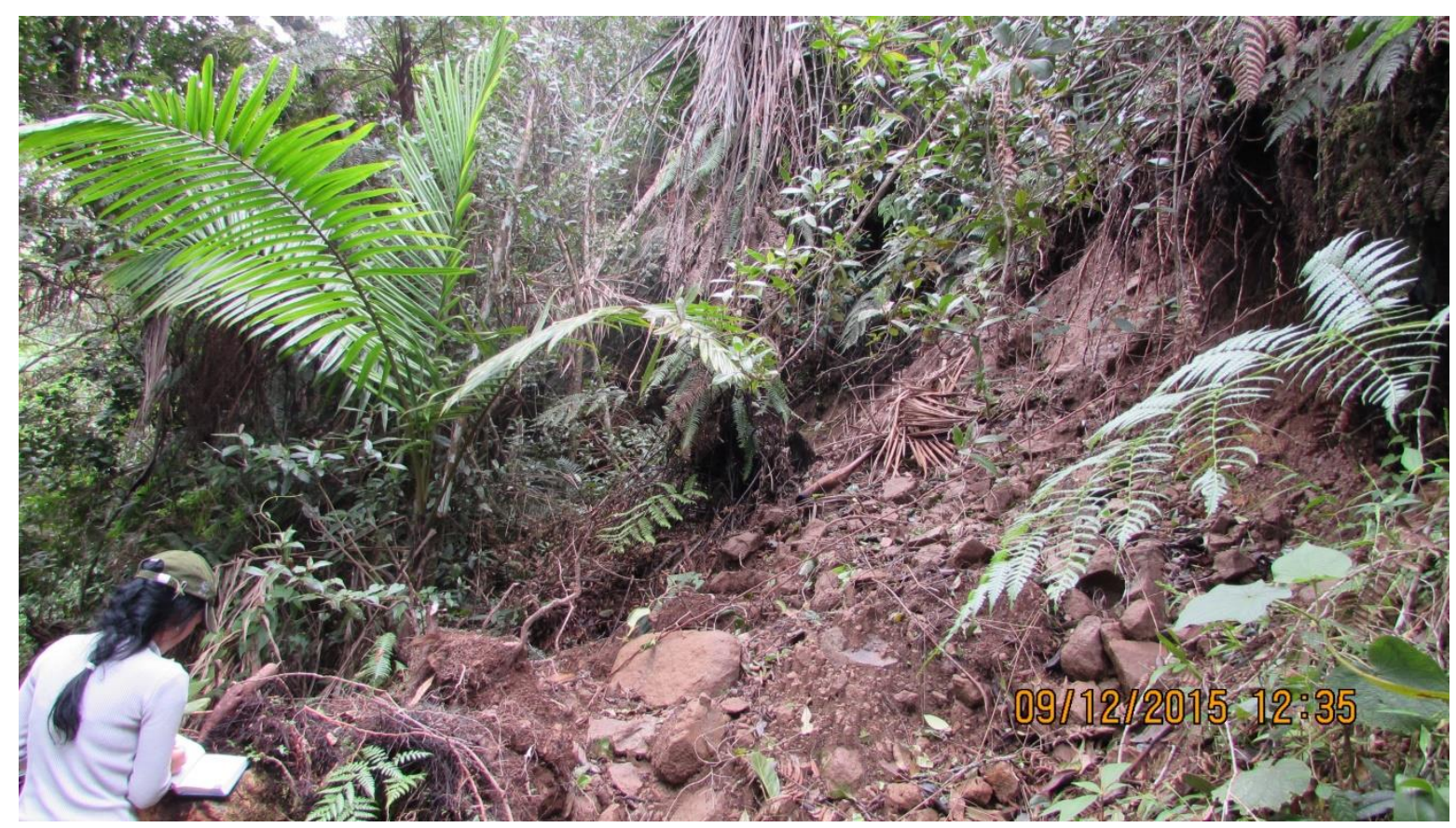

Fotografia_048 


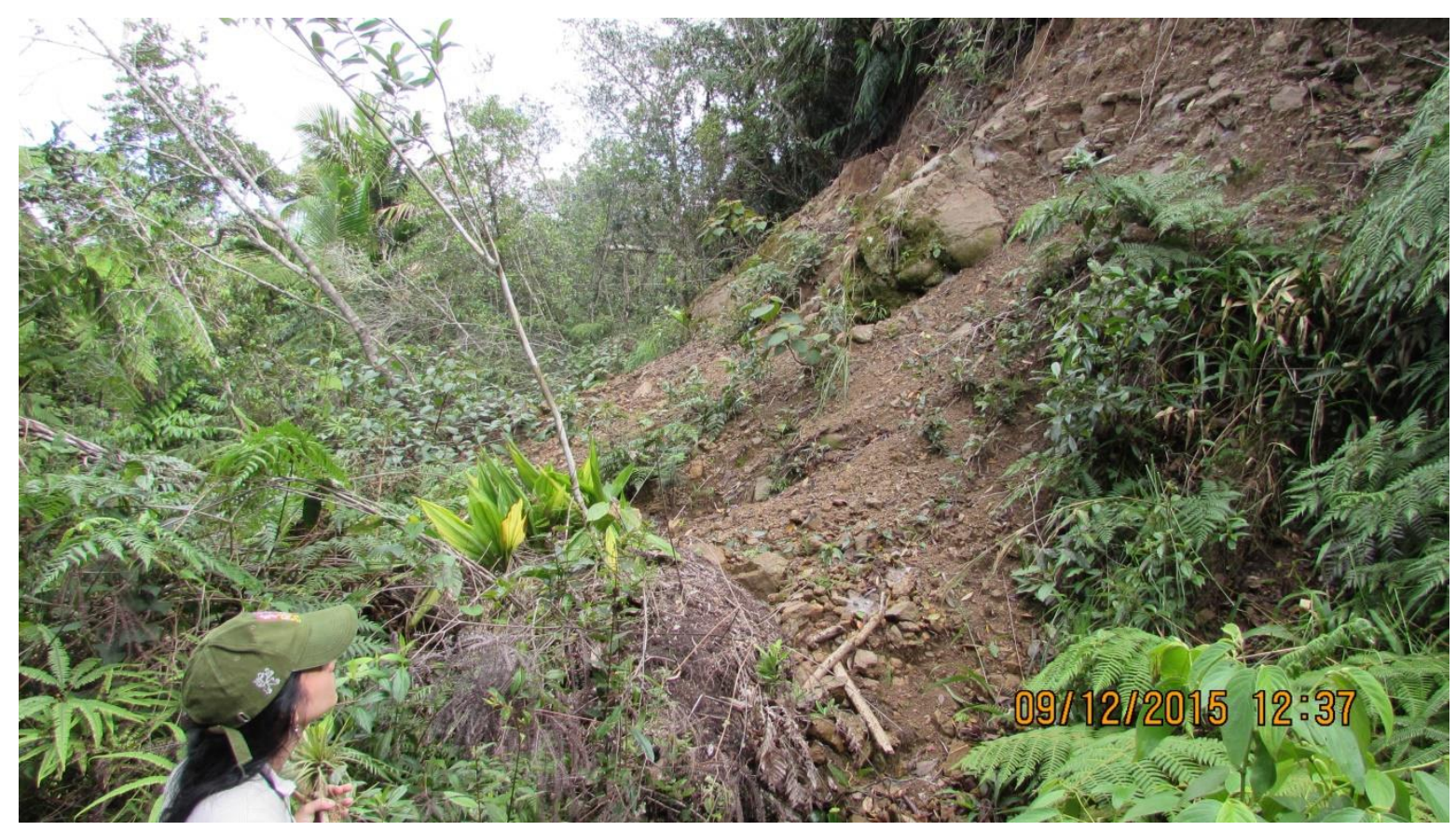

Fotografia_049

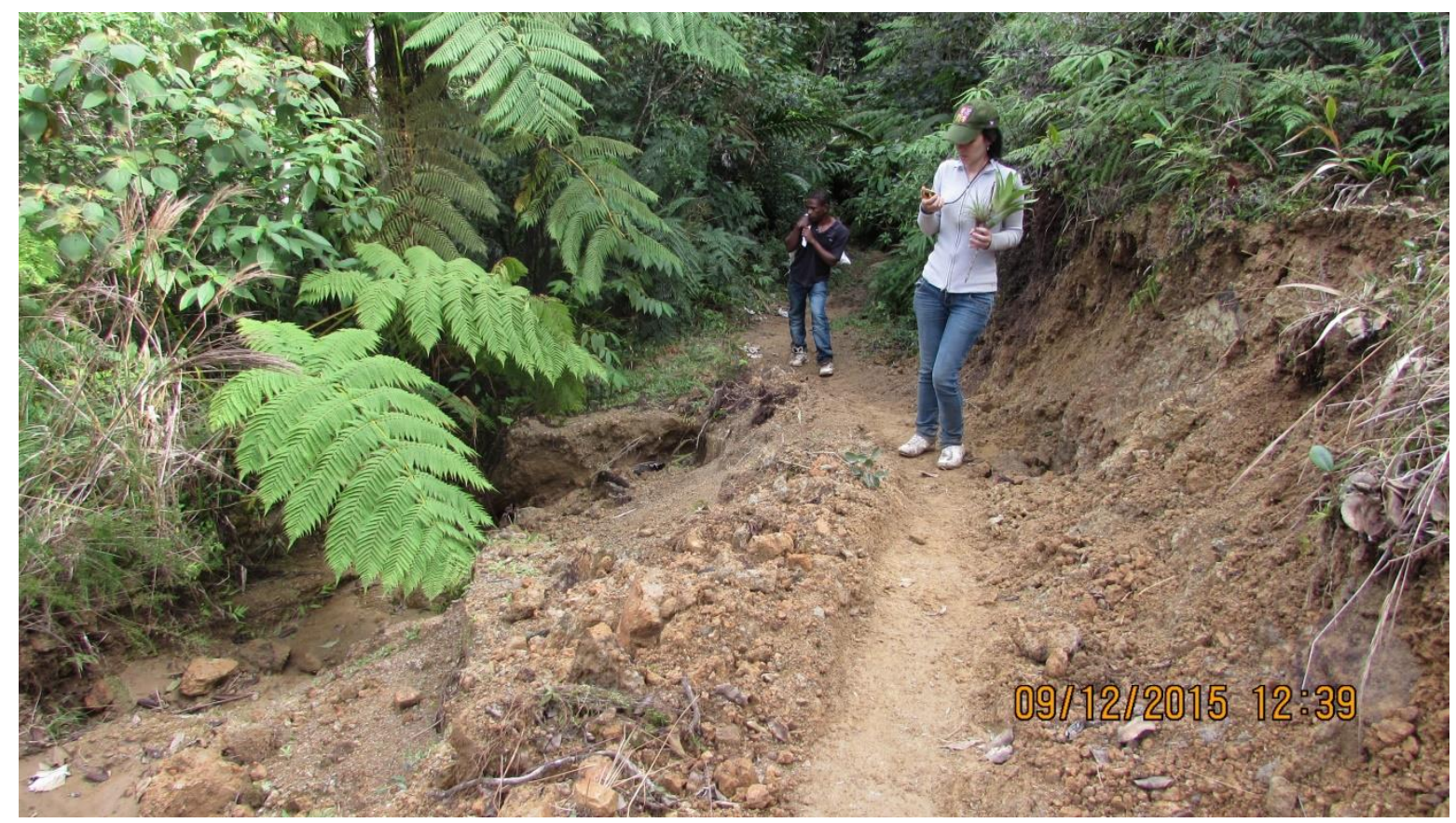

Fotografia_050 


\section{APÊNDICE B}

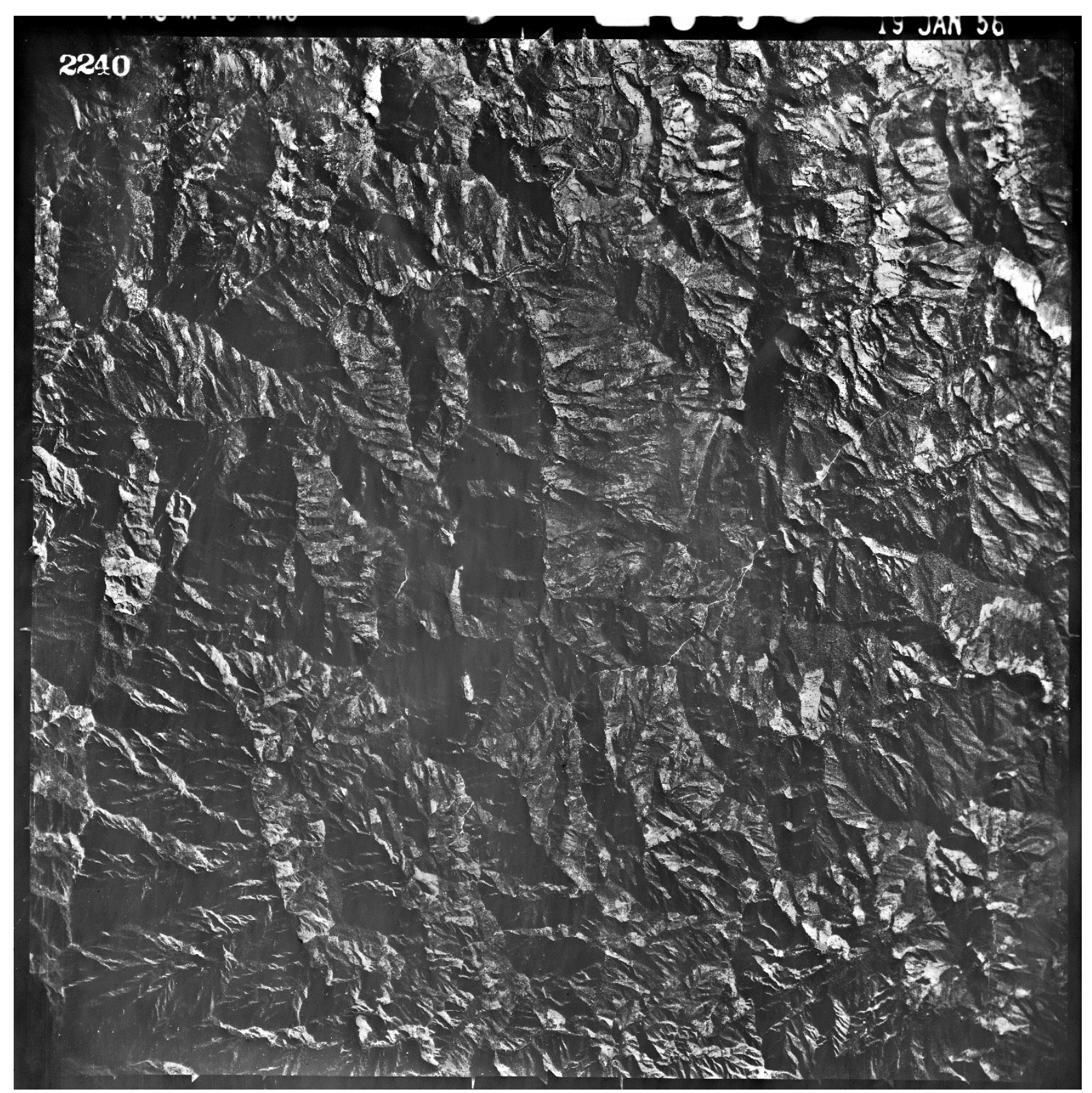

Imagem 2240 


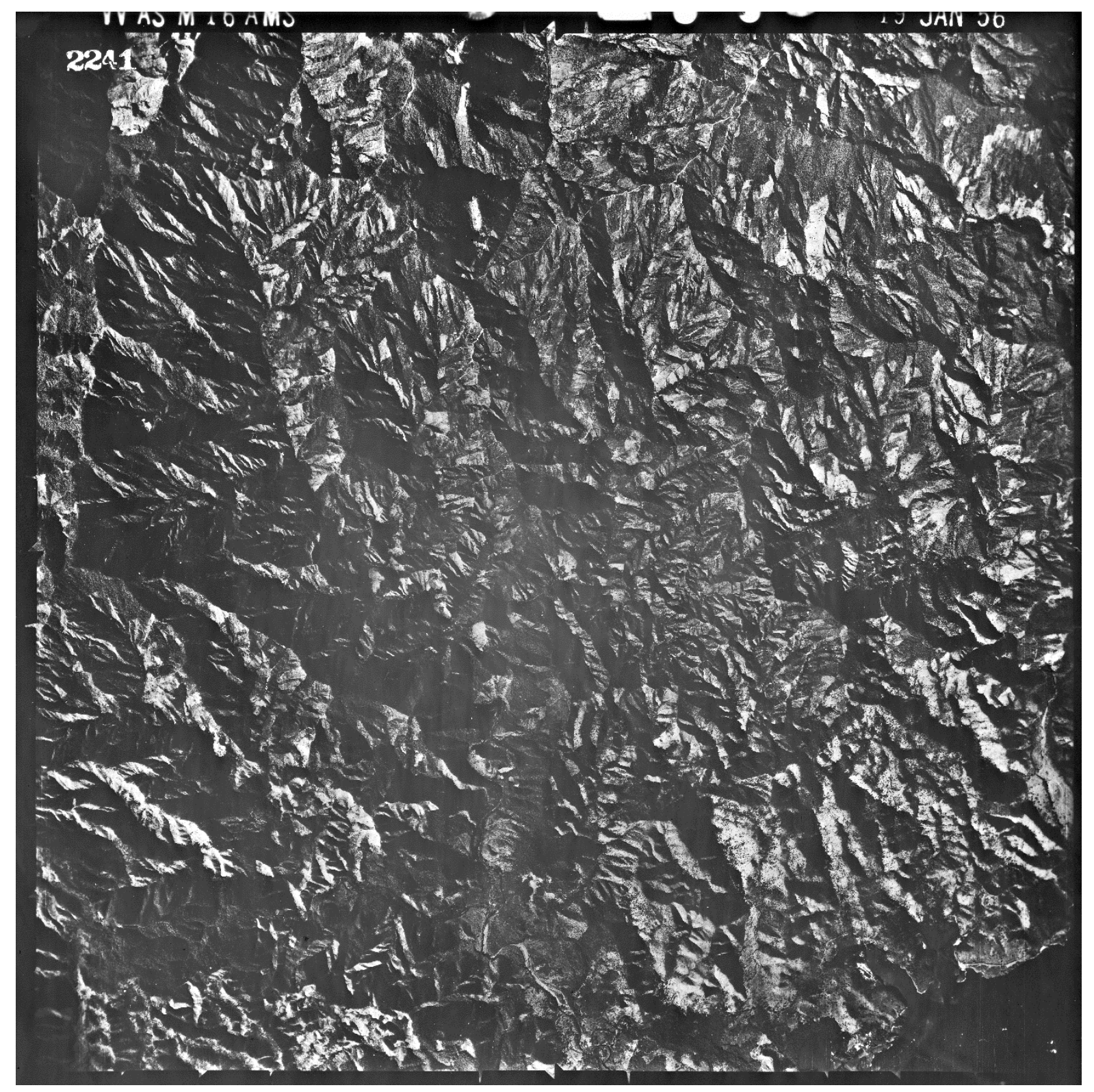

Imagem 2241 


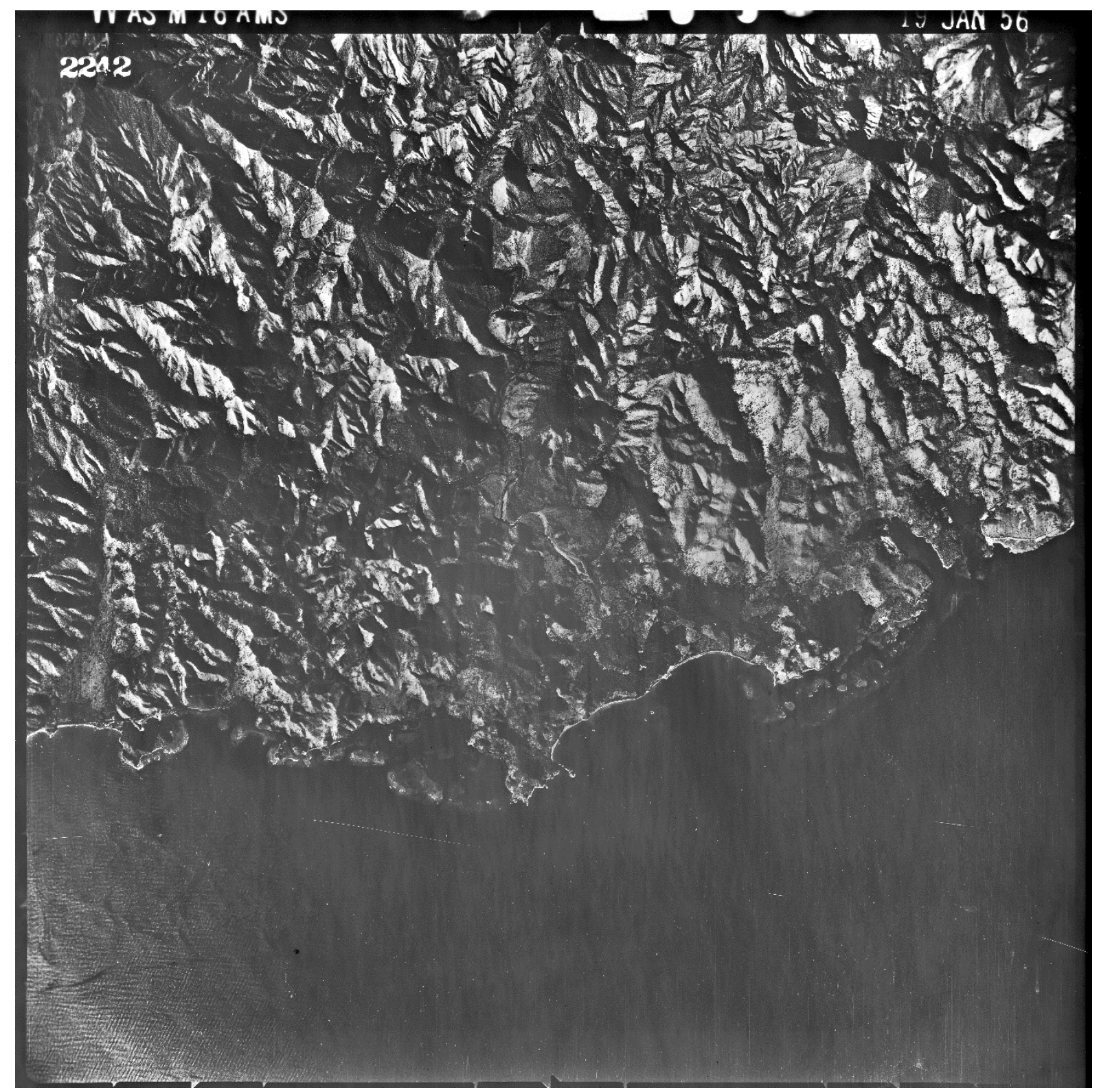

Imagem 2242 


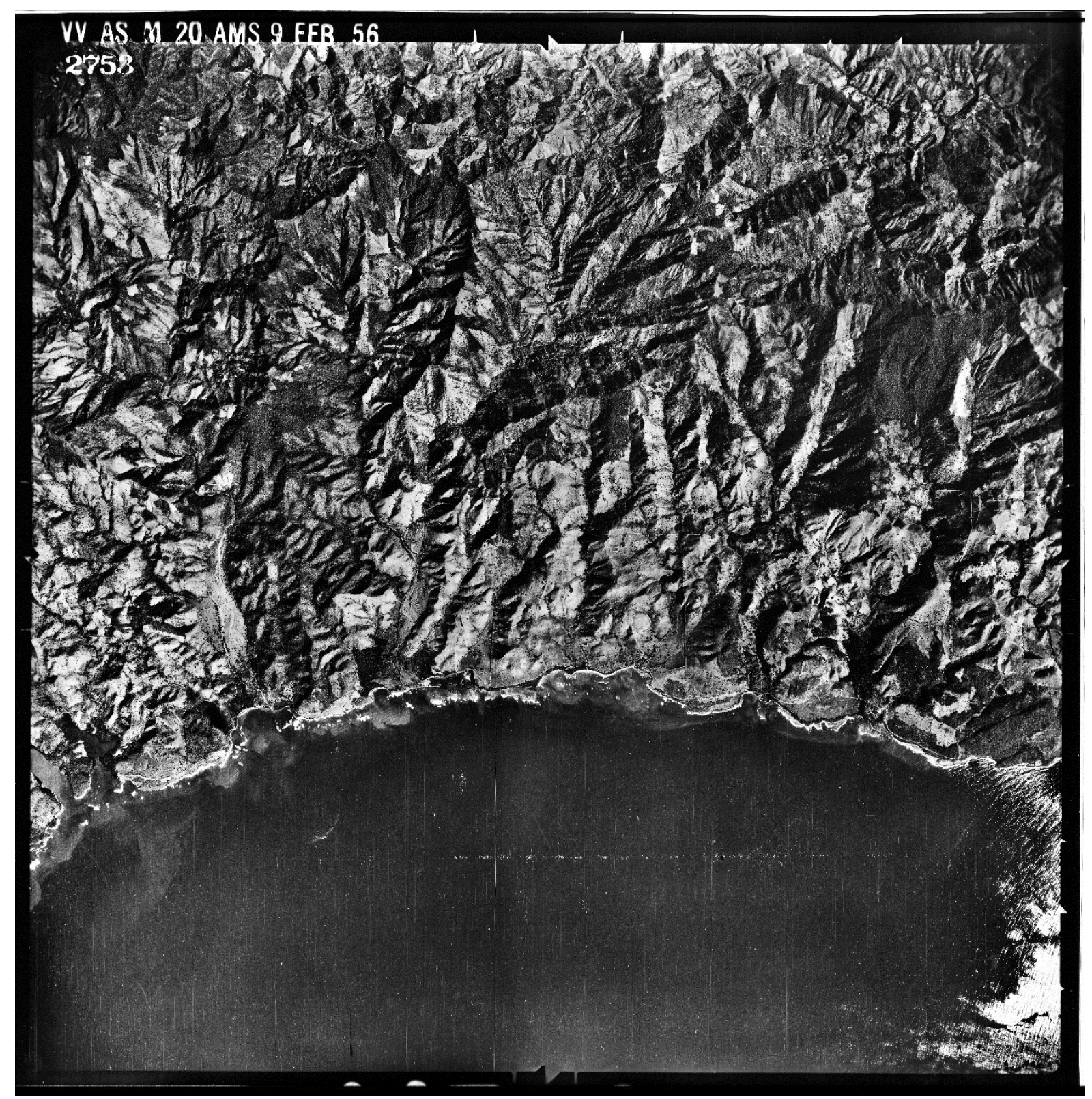

Imagem 2753 


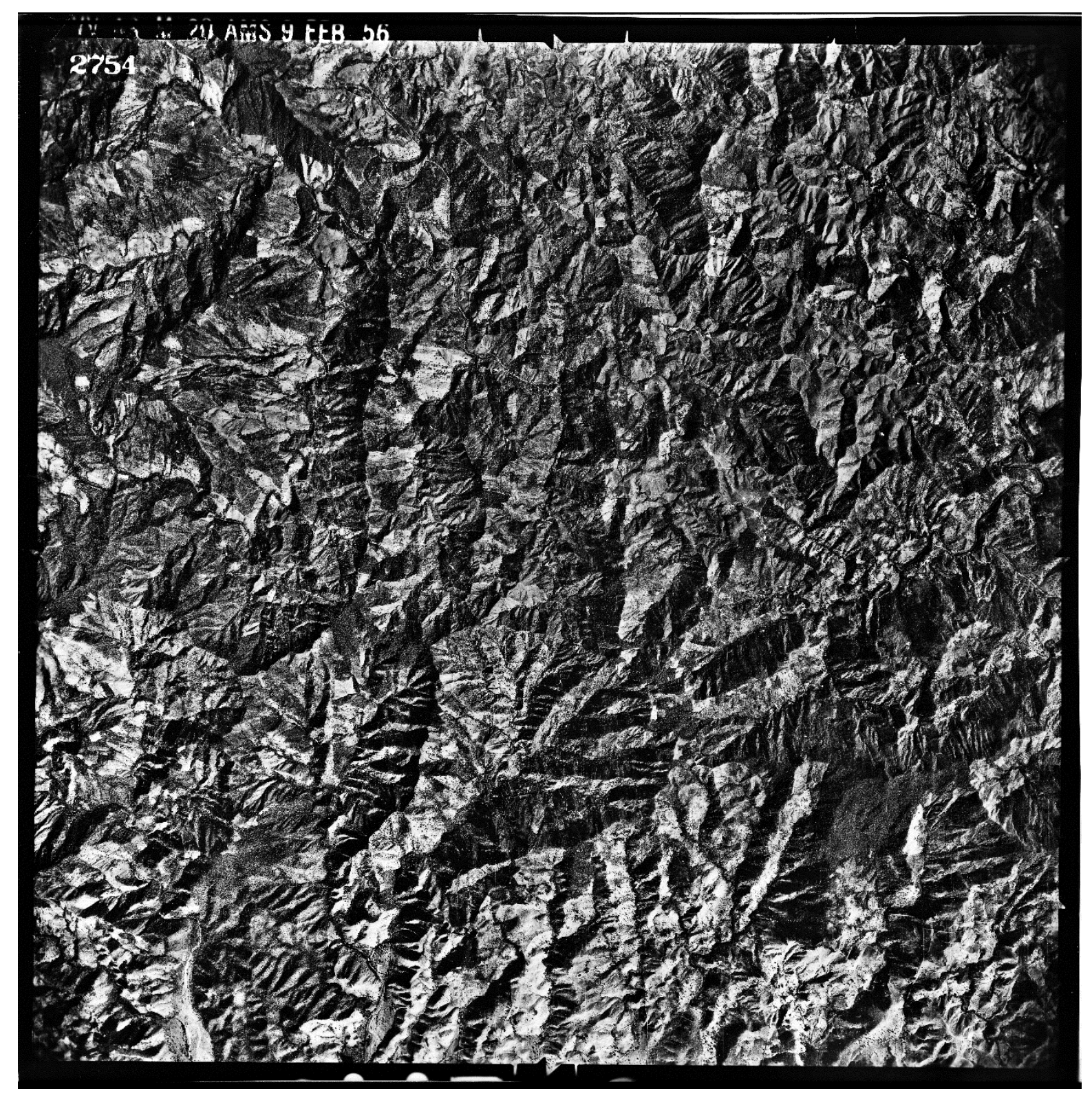

Imagem 2754 


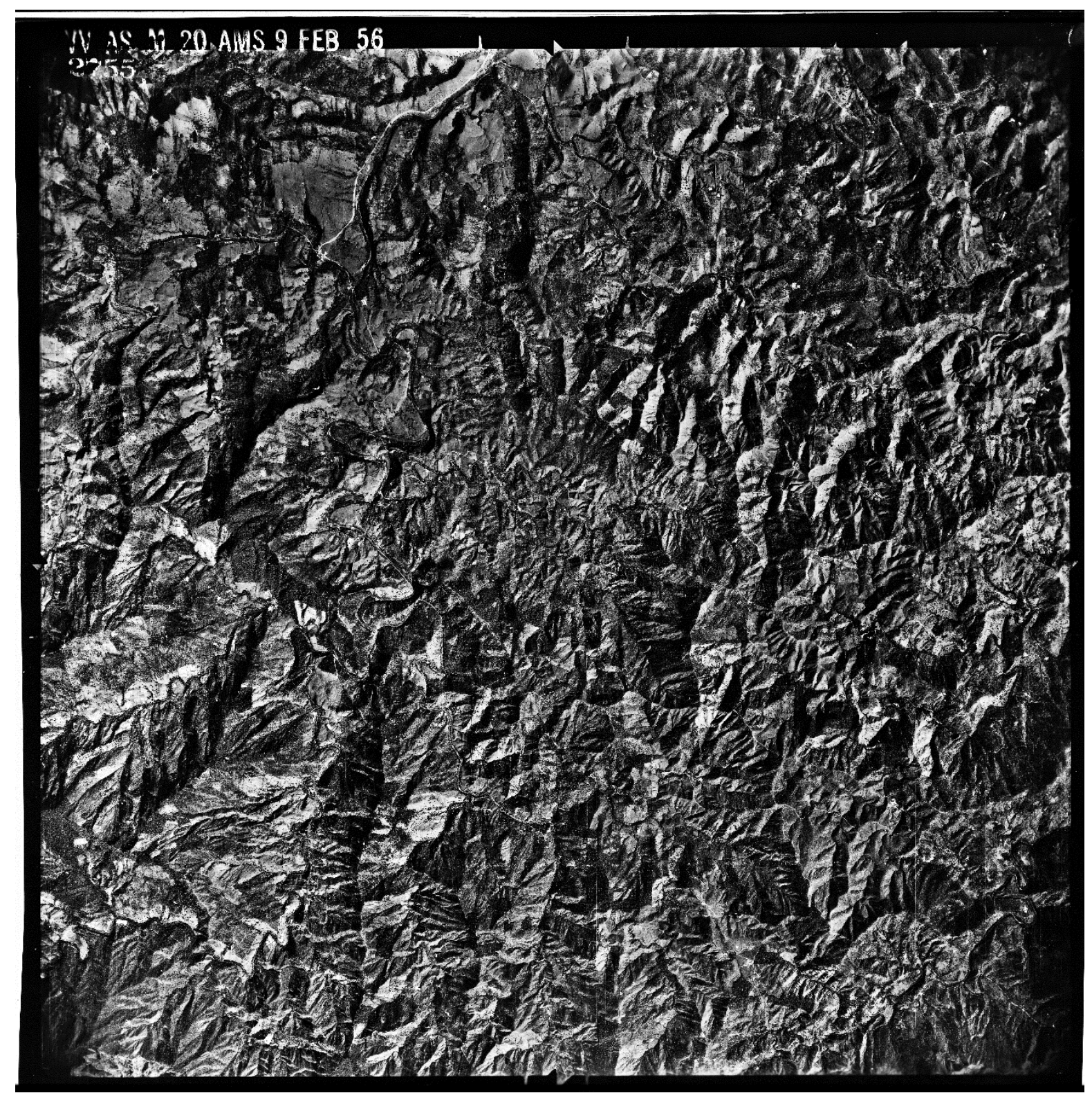

Imagem 2755 


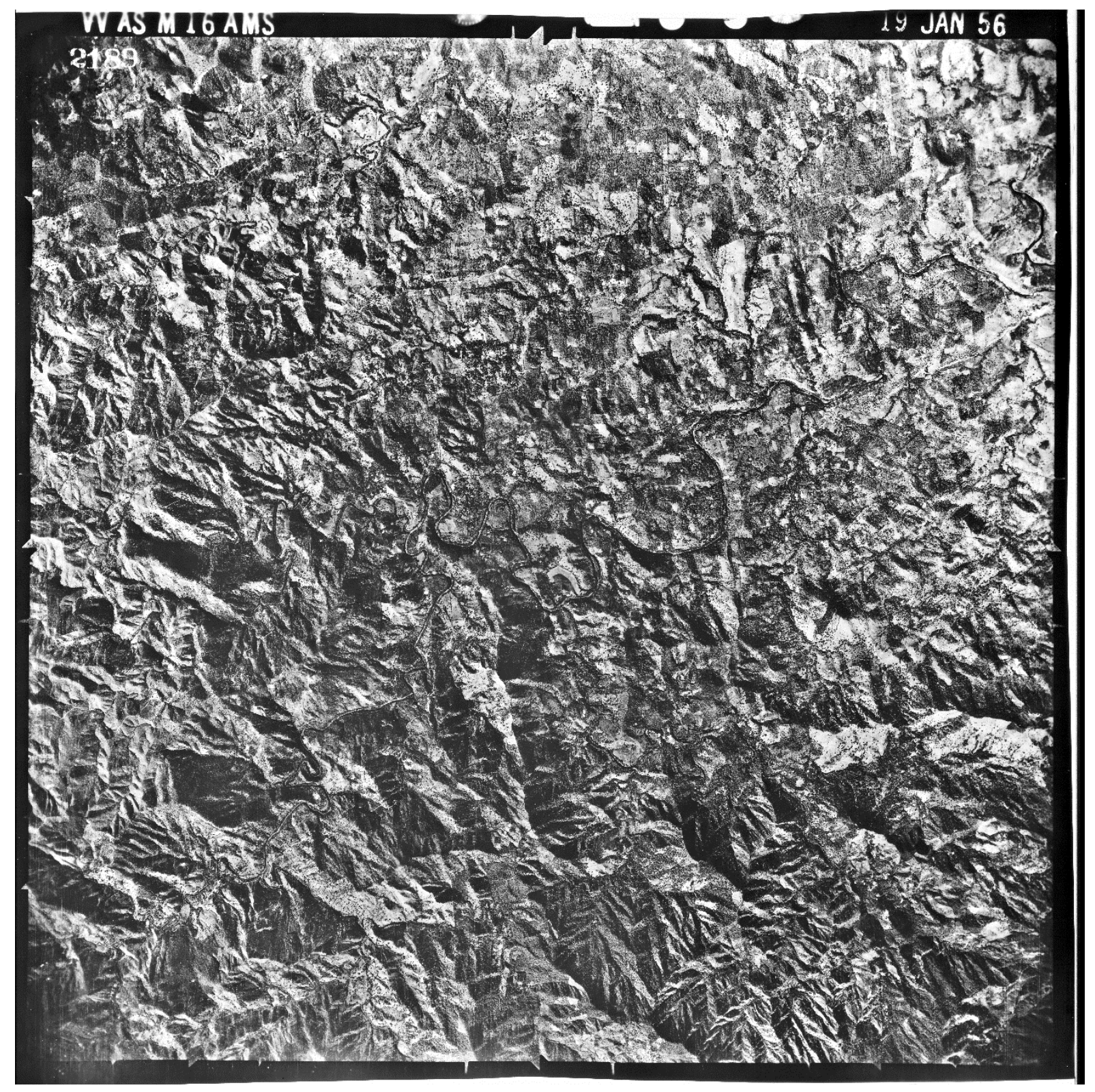

Imagem 2189 


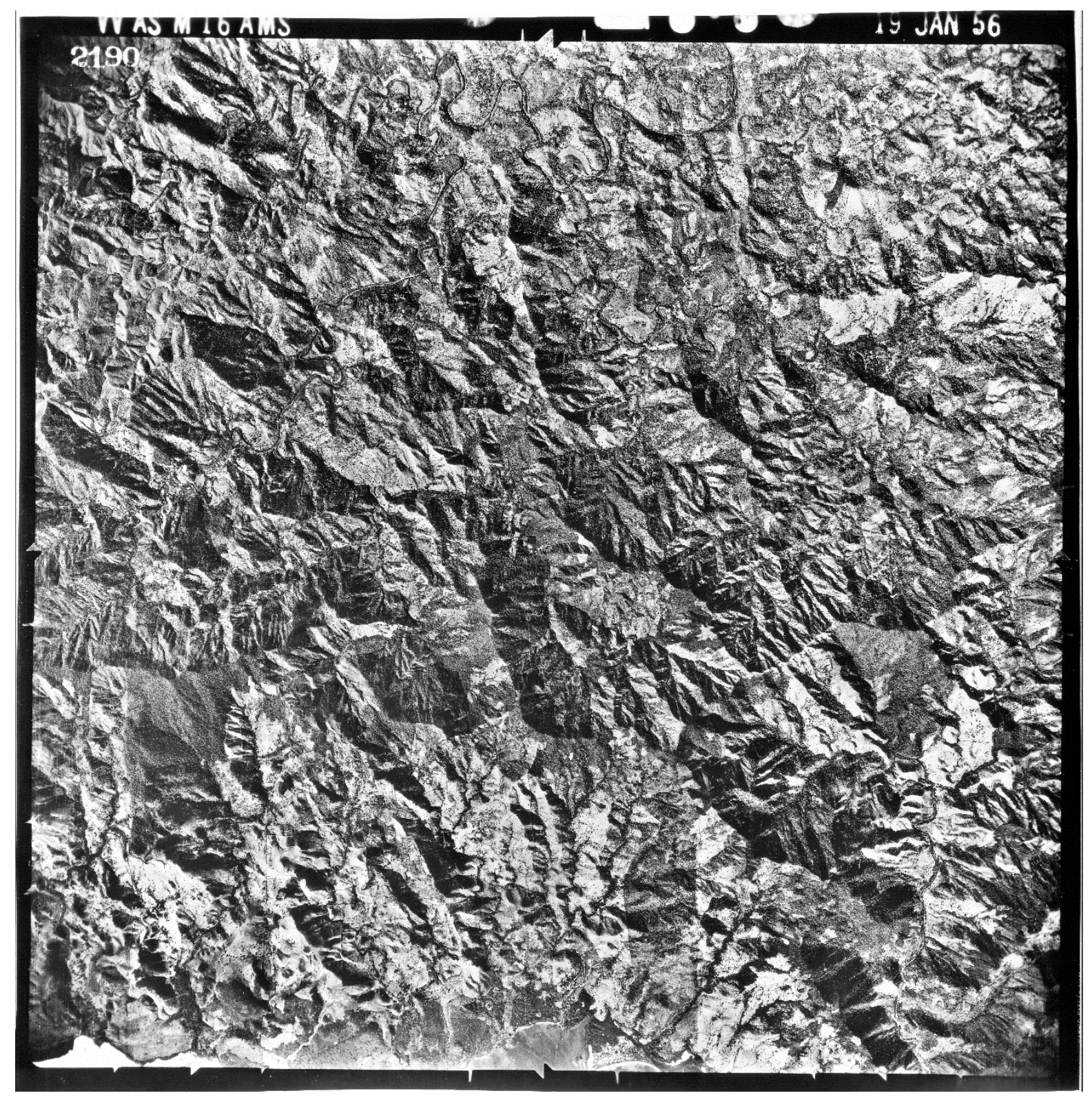

Imagem 2190 


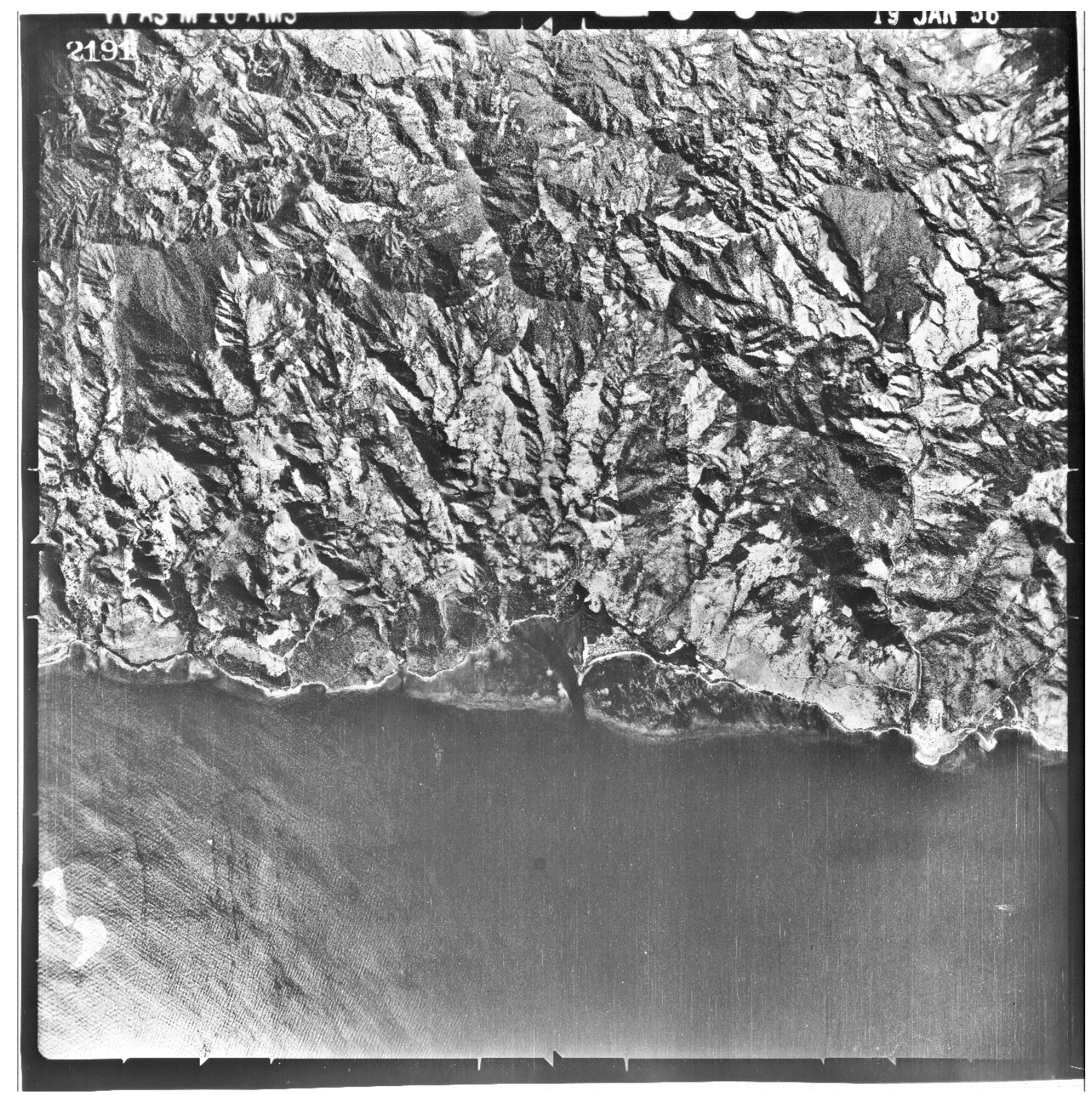

Imagem 2191 


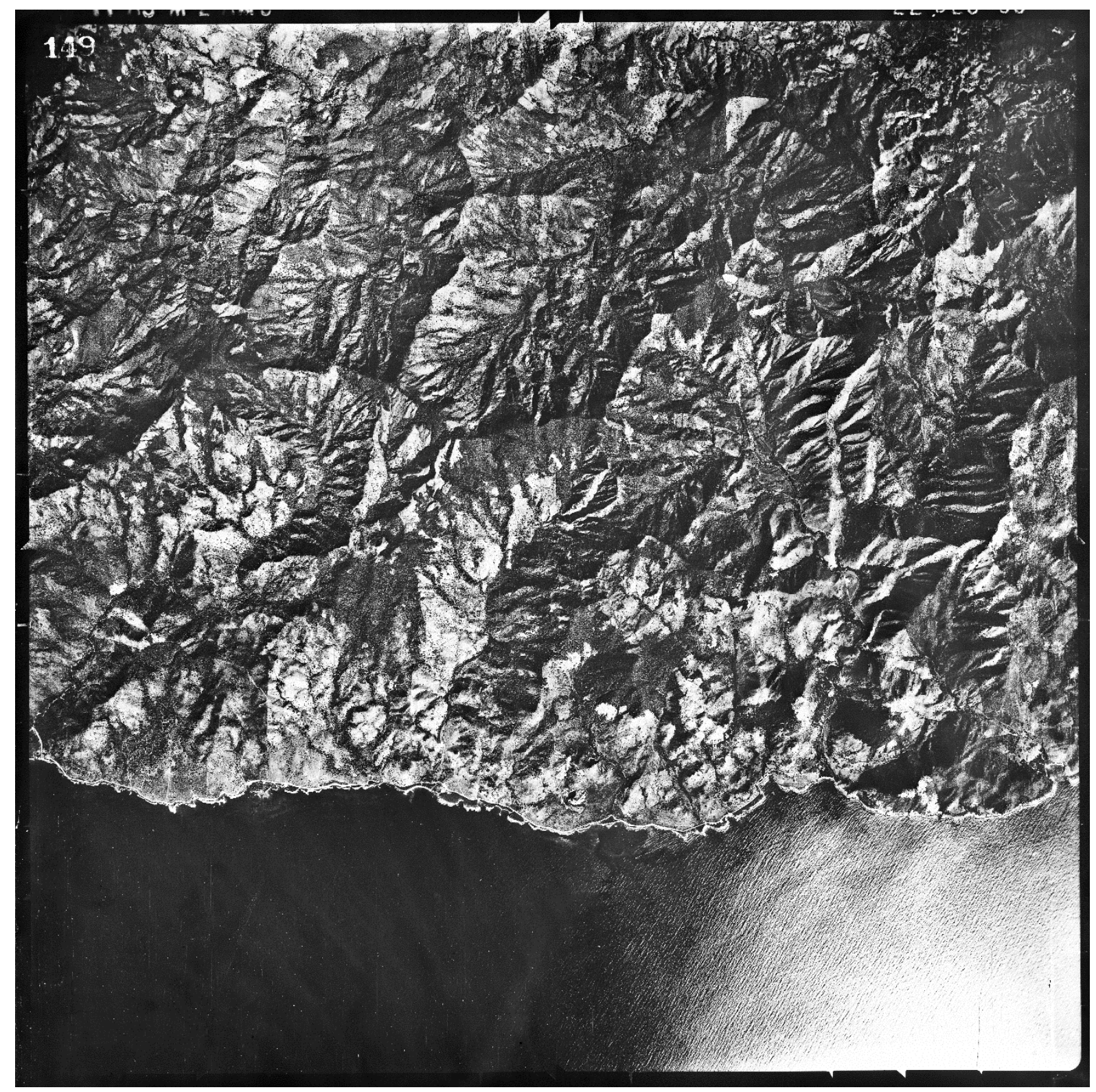

Imagem 149 


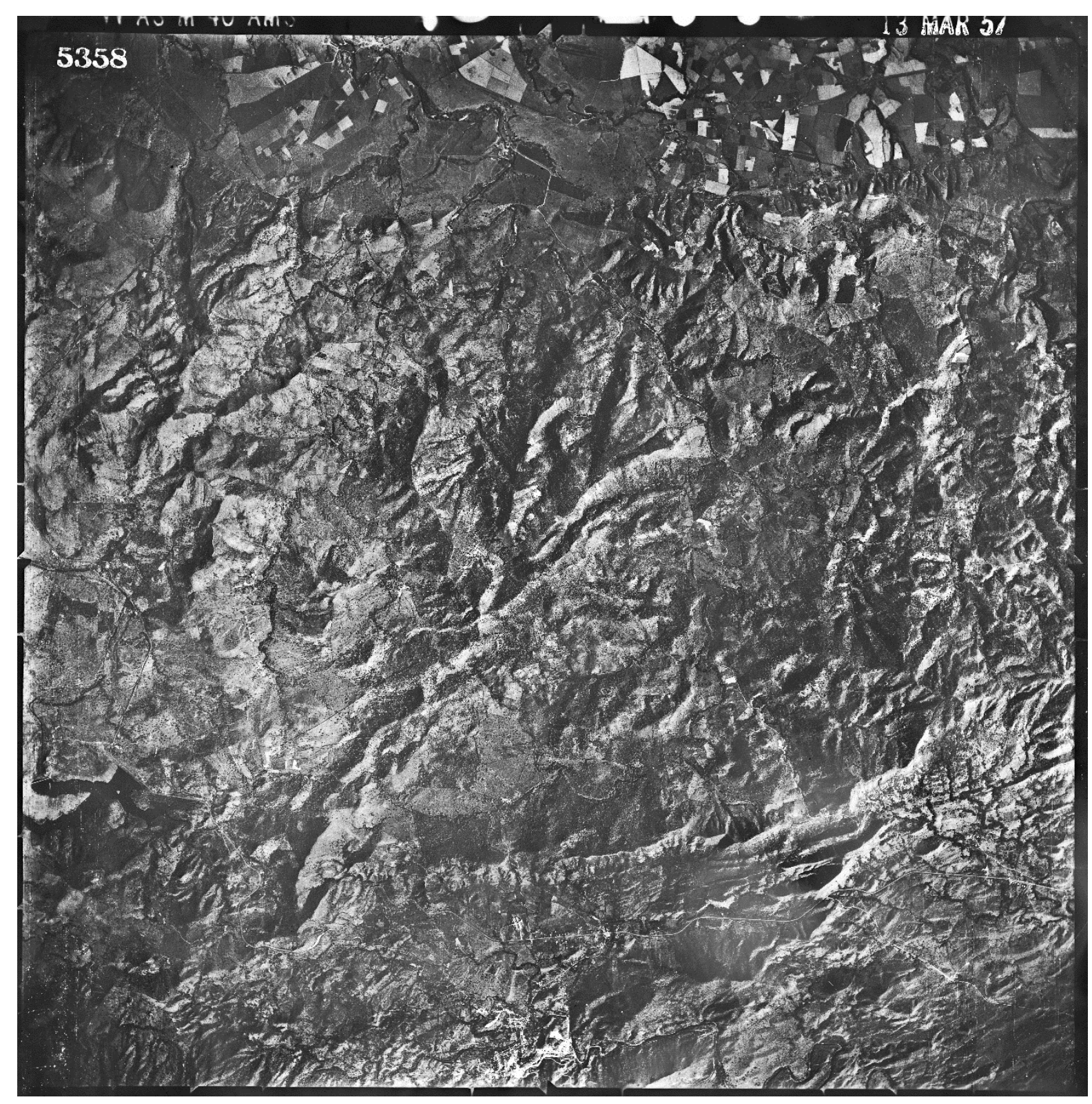

Imagem 5358 


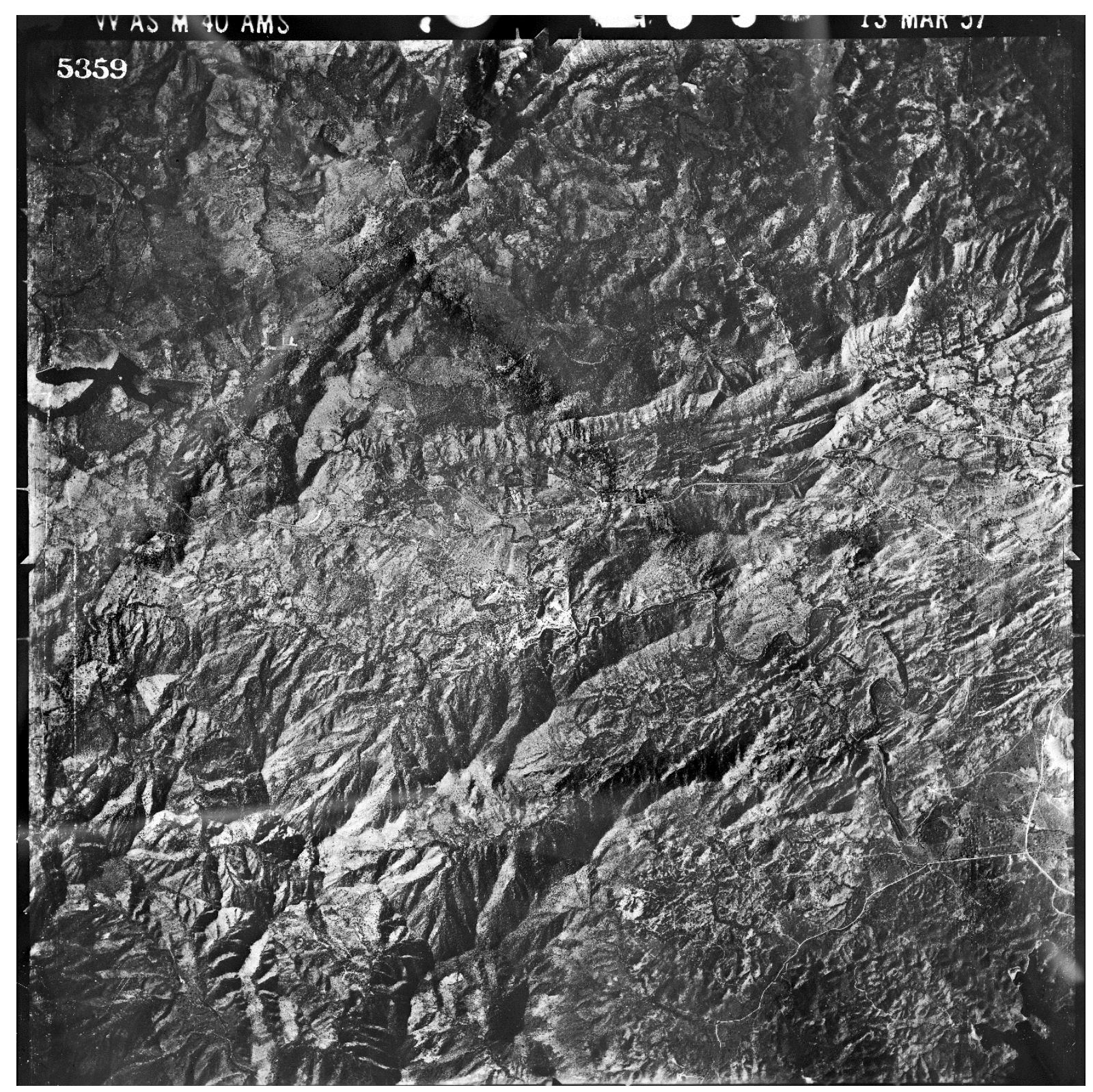

Imagem 5359 


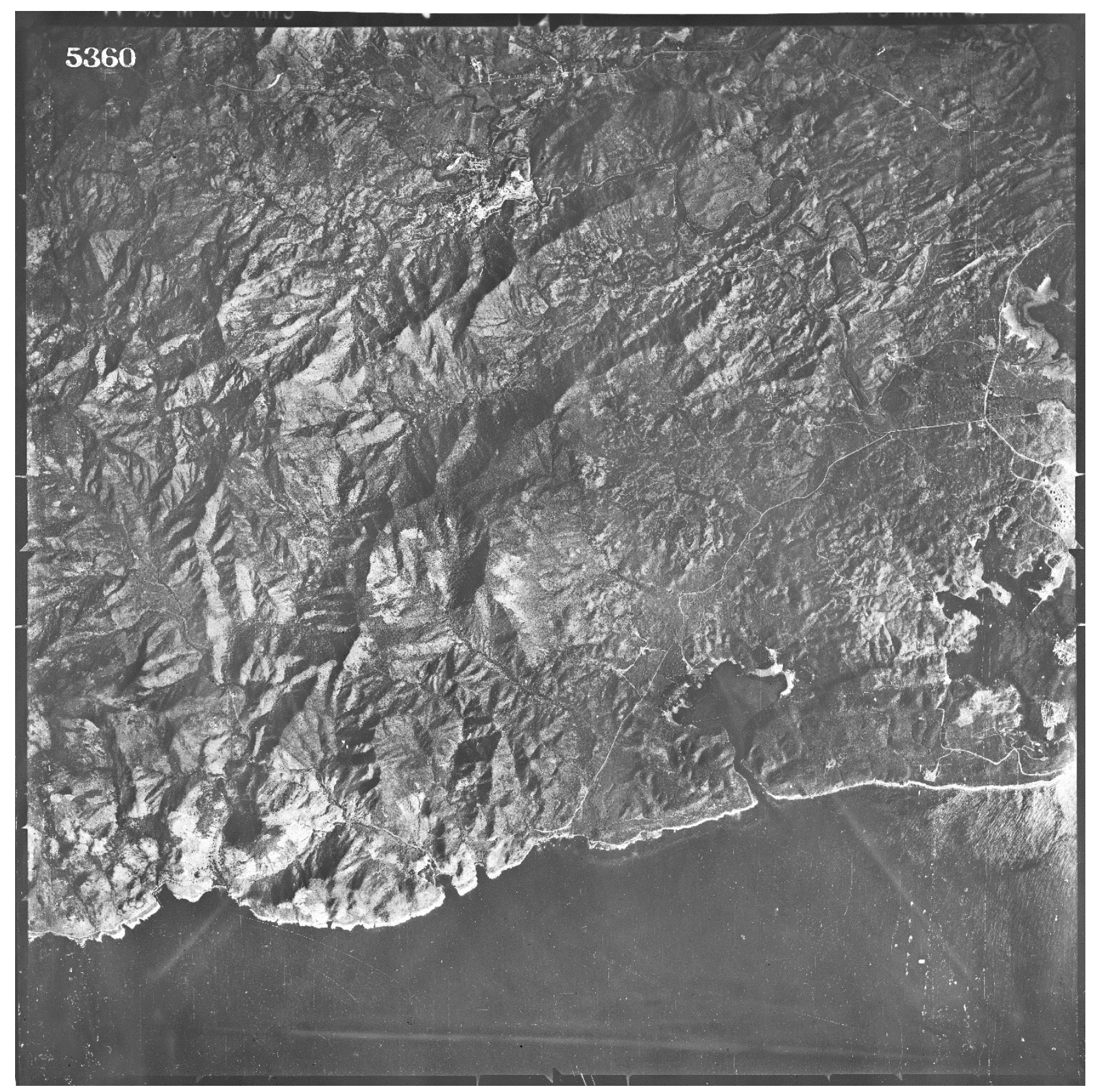

Imagem 5360 


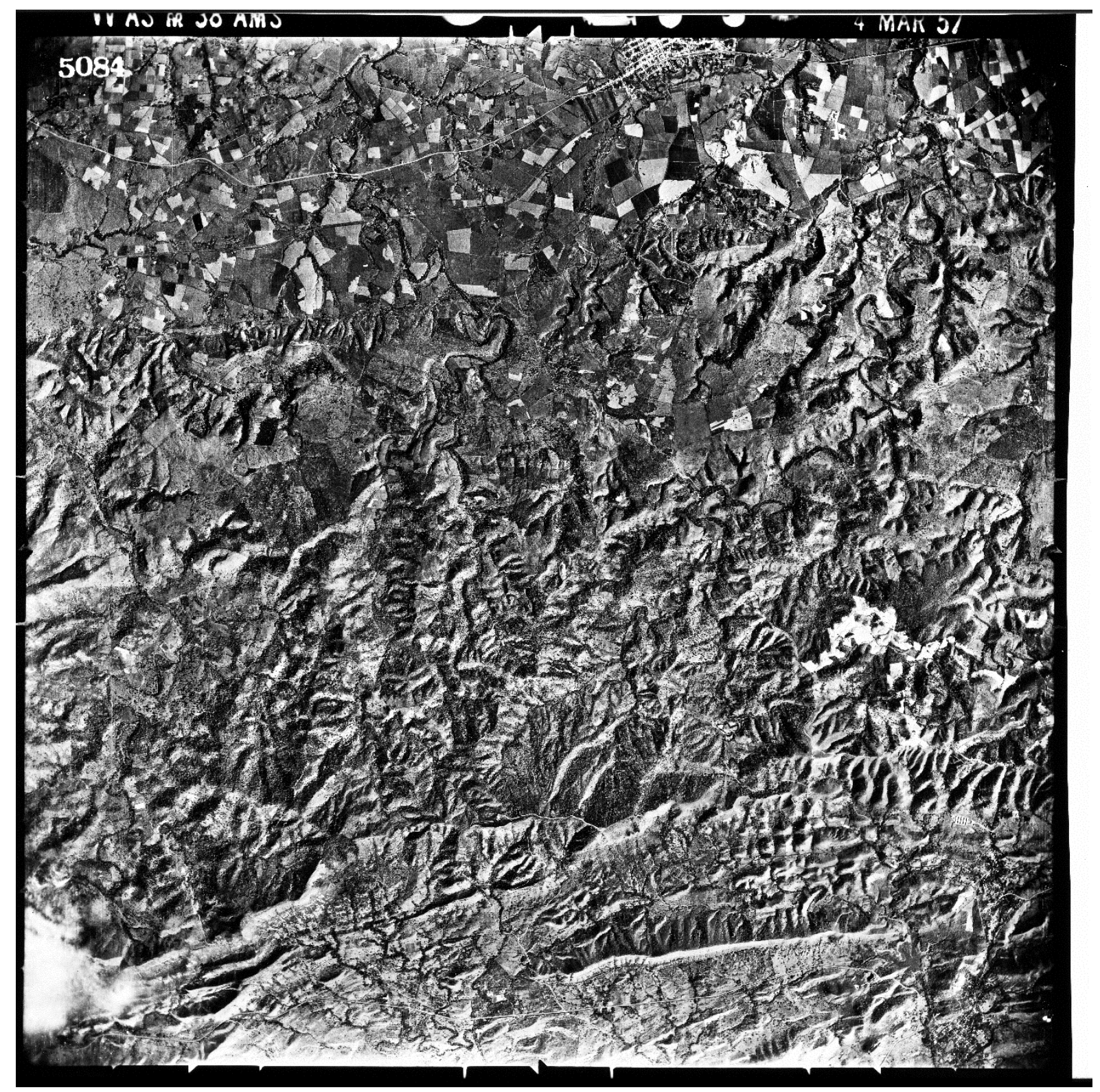

Imagem 5084 


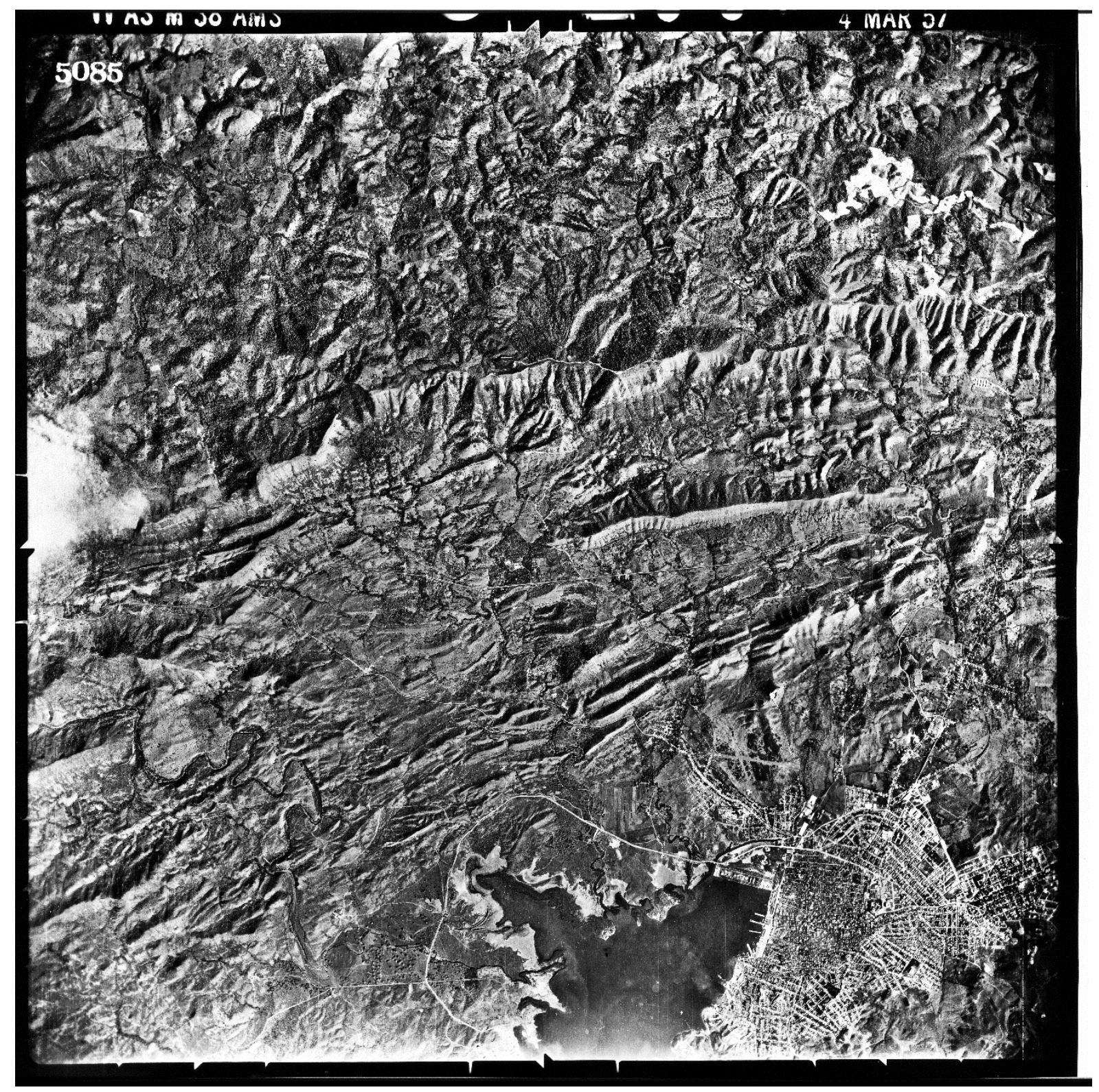

Imagem 5085 


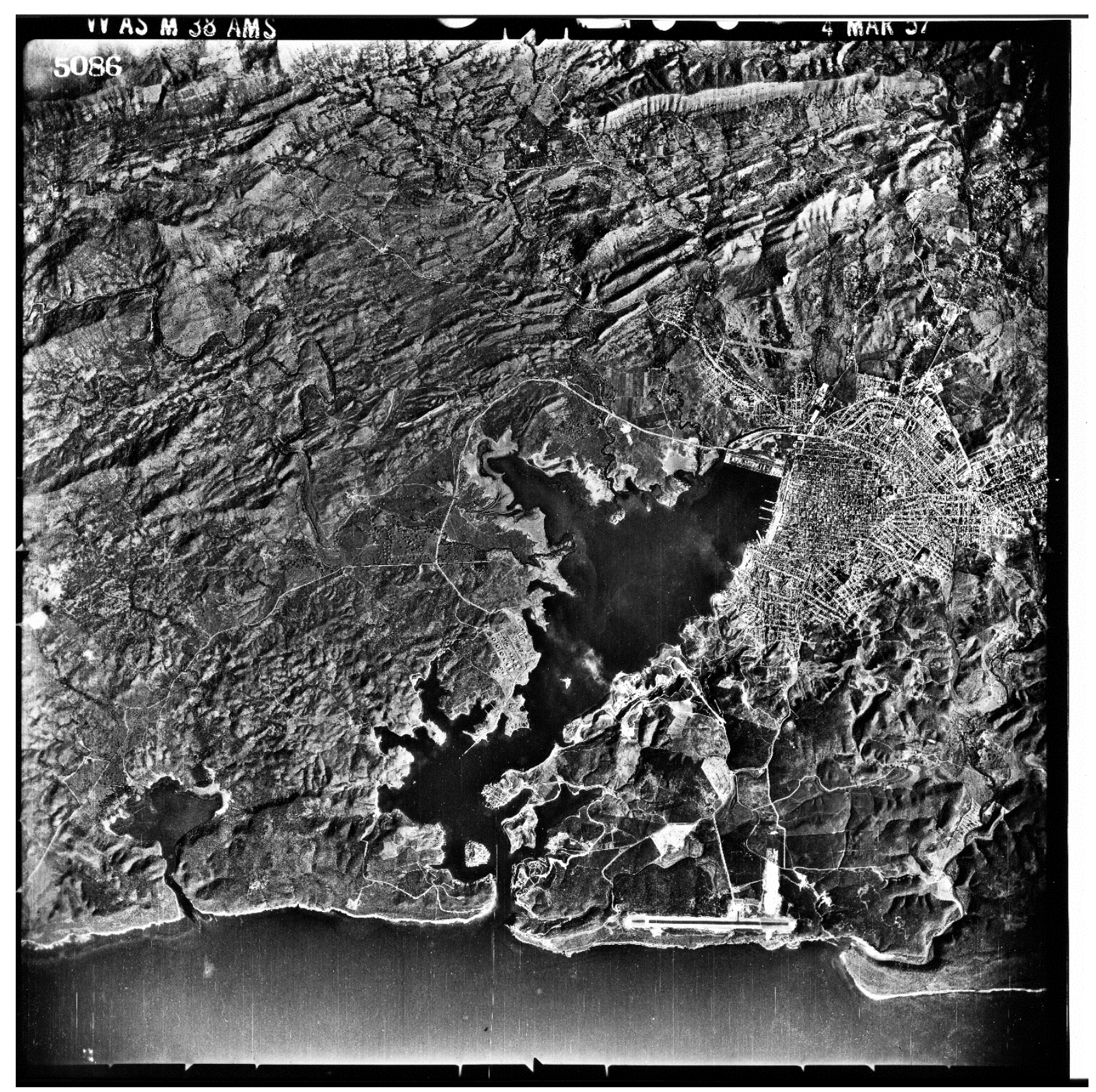

Imagem 5086 


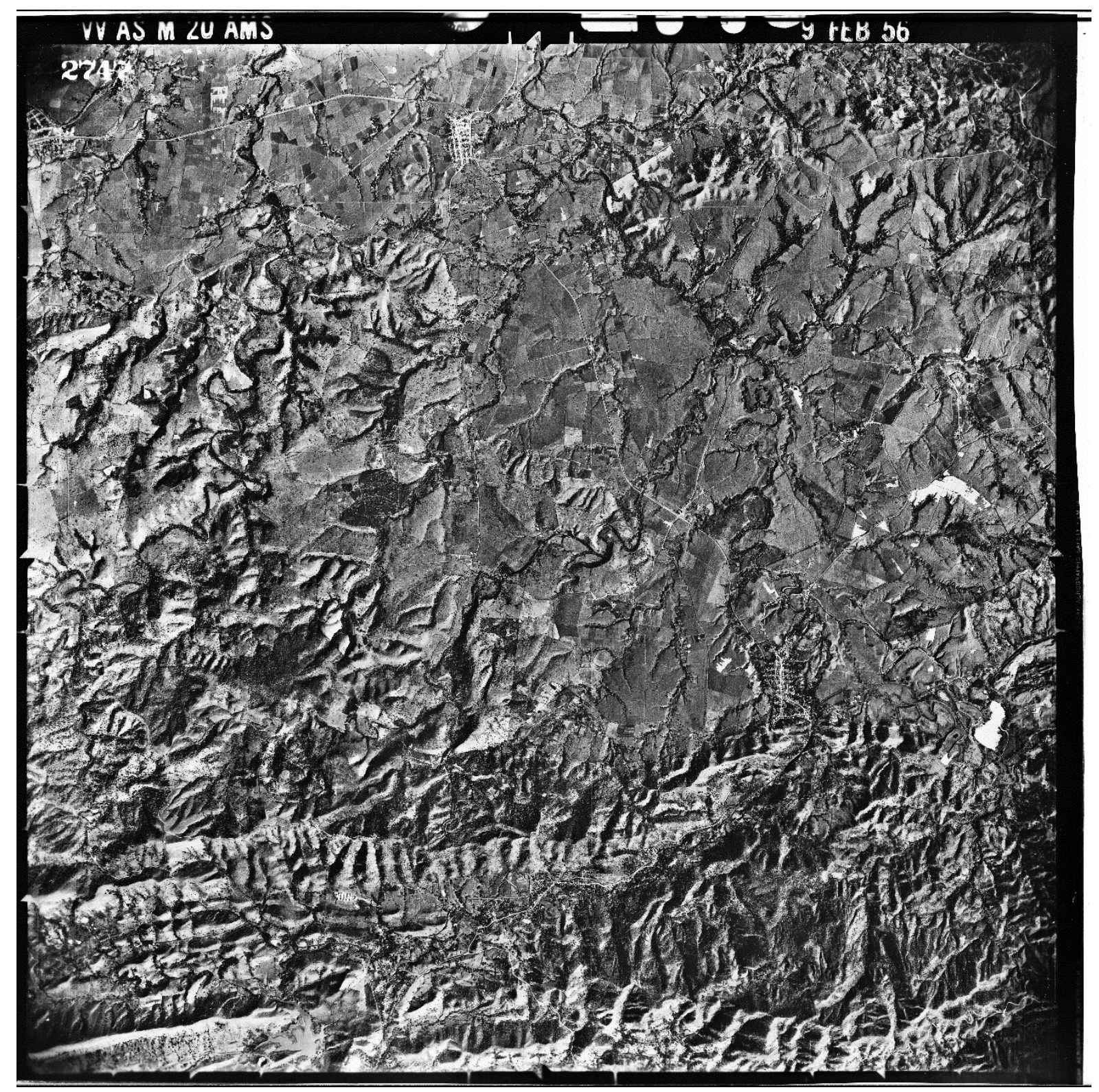

Imagem 2747 


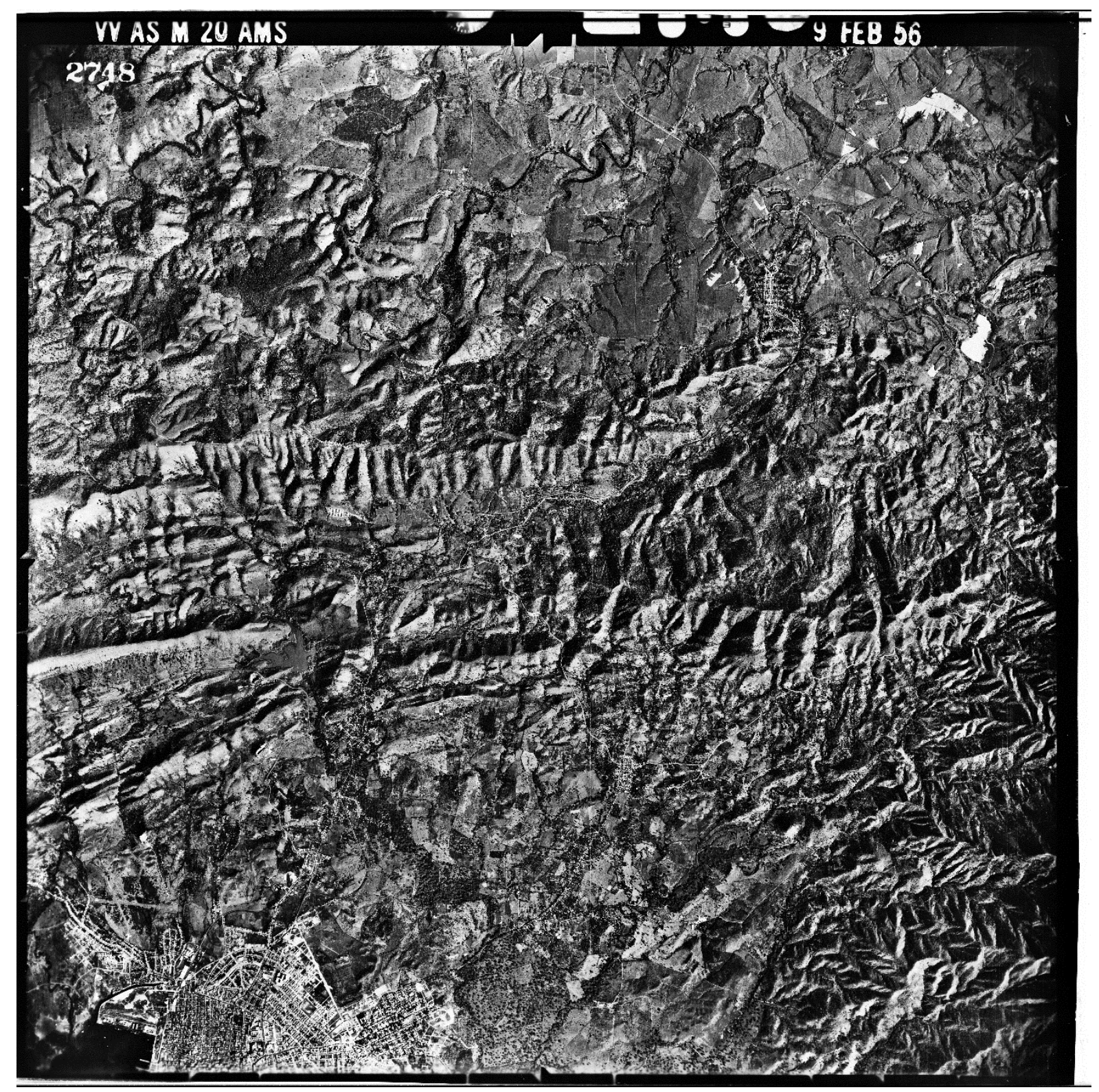

Imagem 2748 


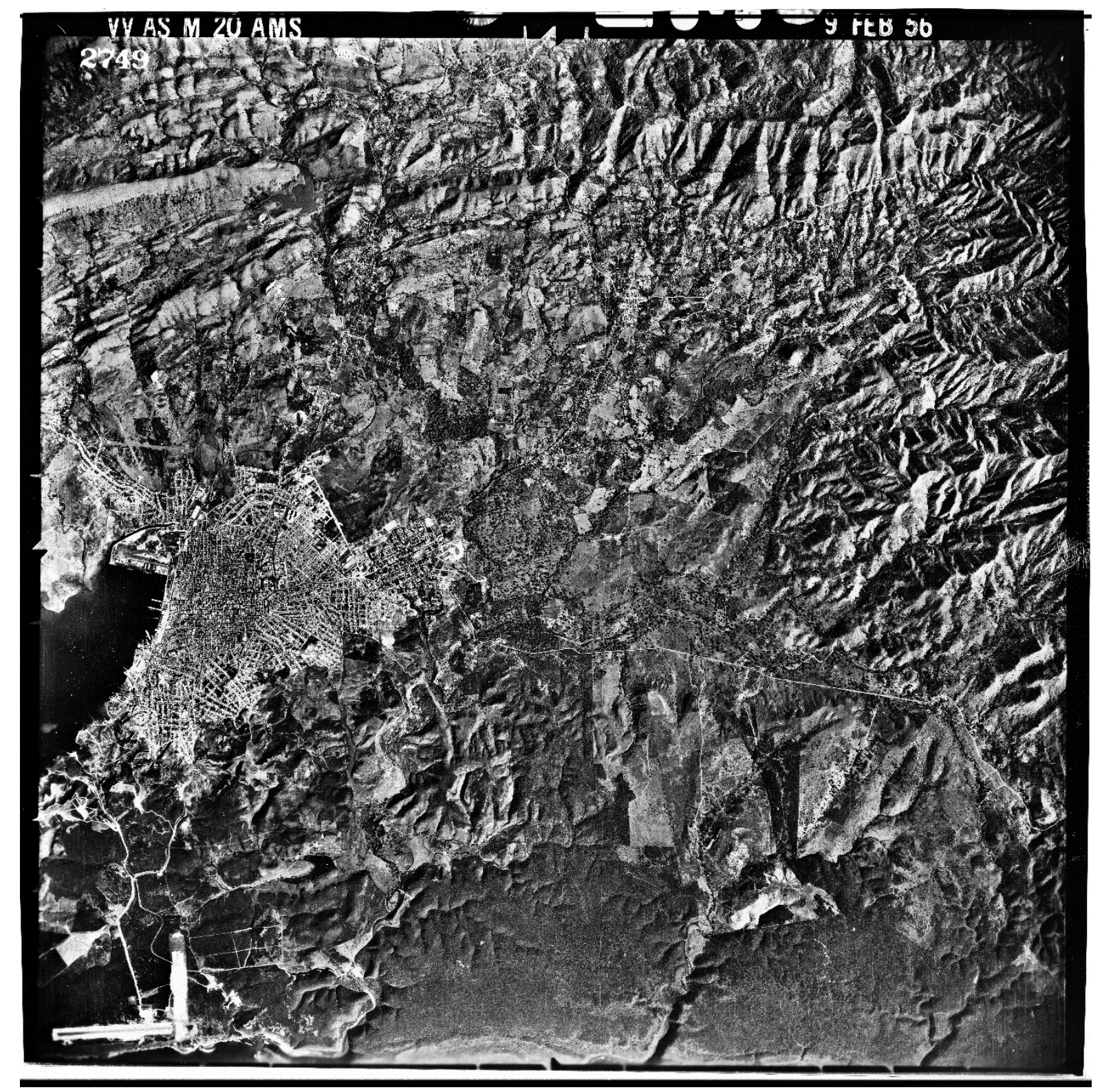

Imagem 2749 


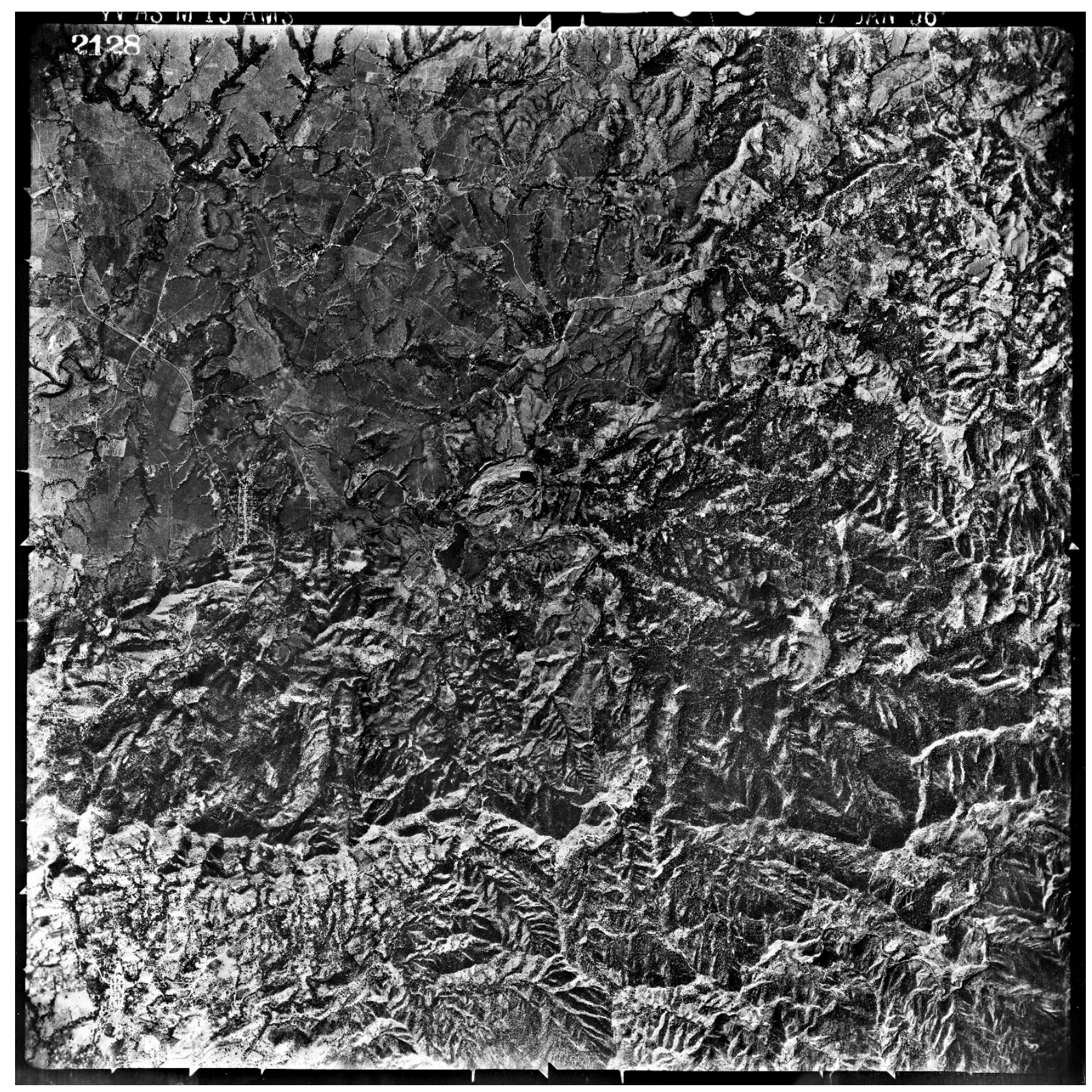

Imagem 2128 


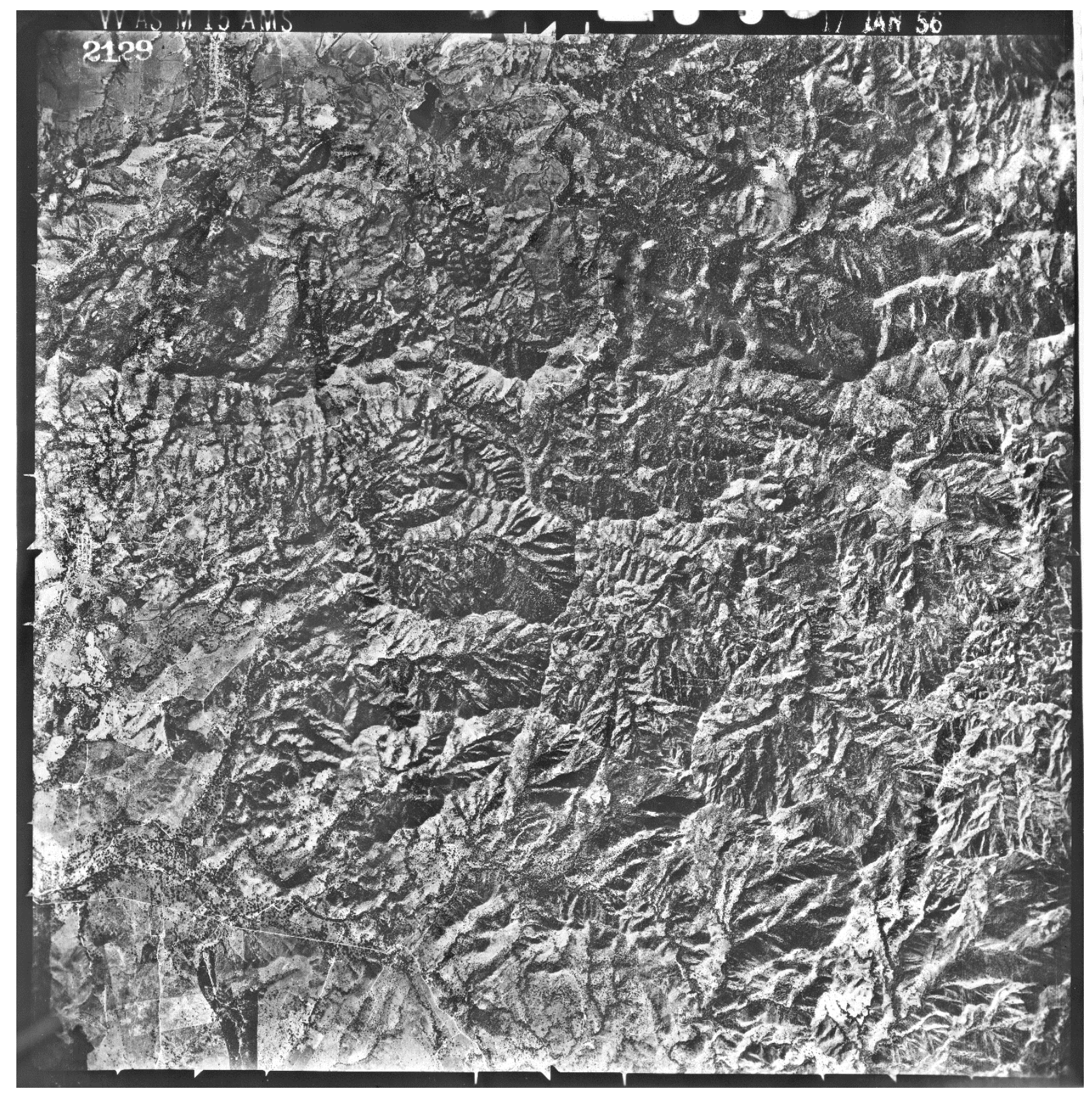

Imagem 2129 


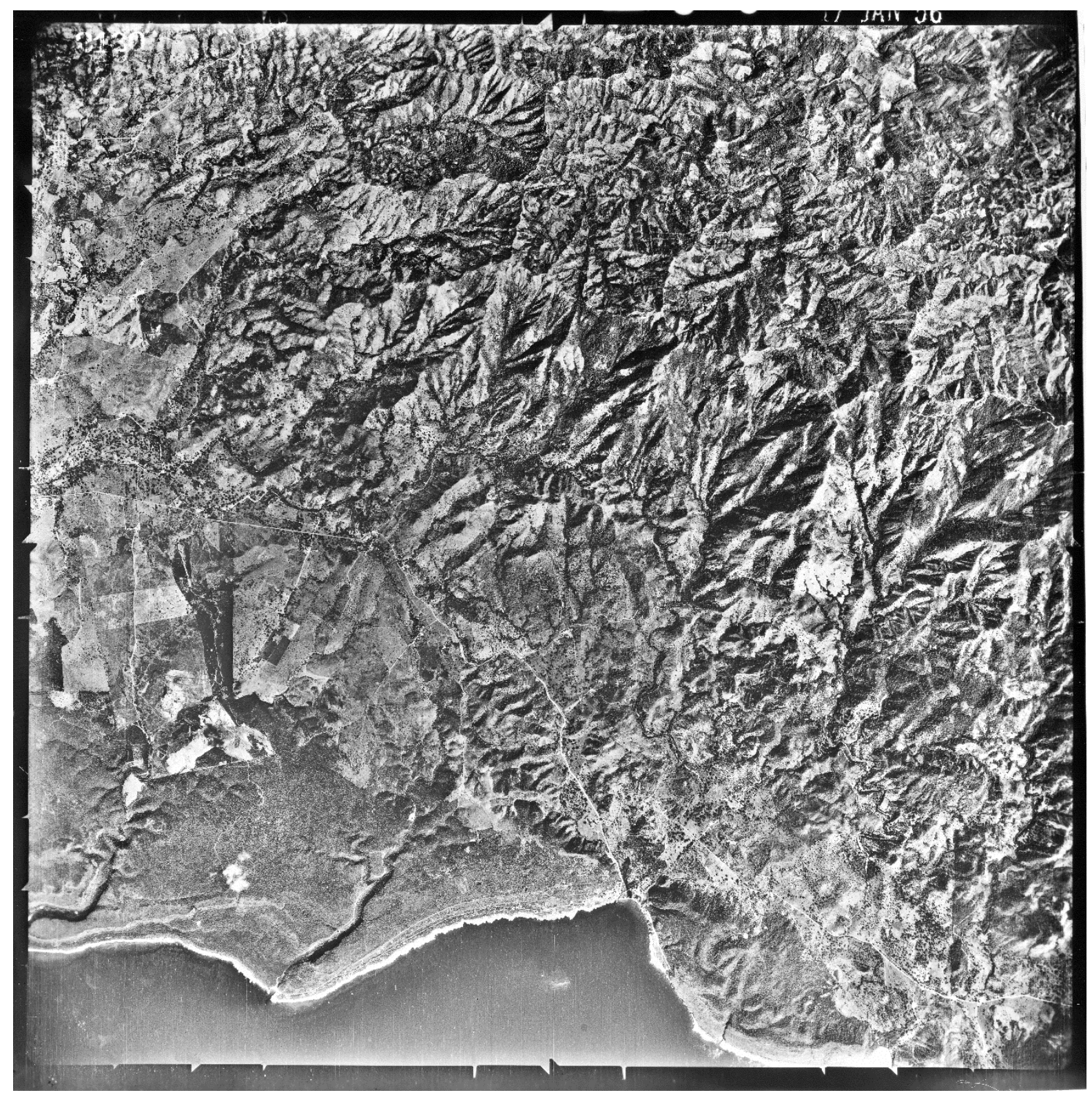

Imagem 2130 


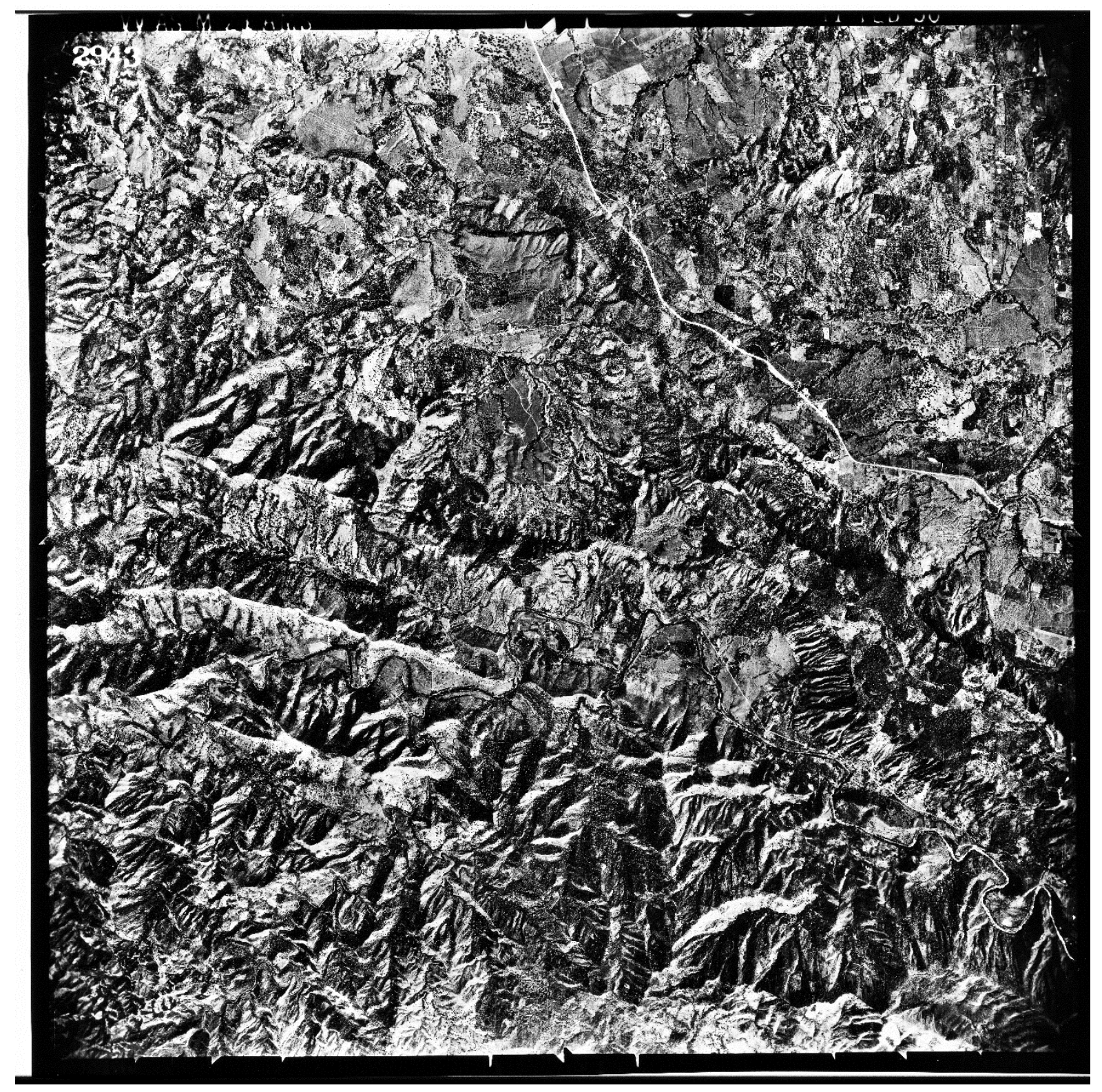

Imagem 2943 


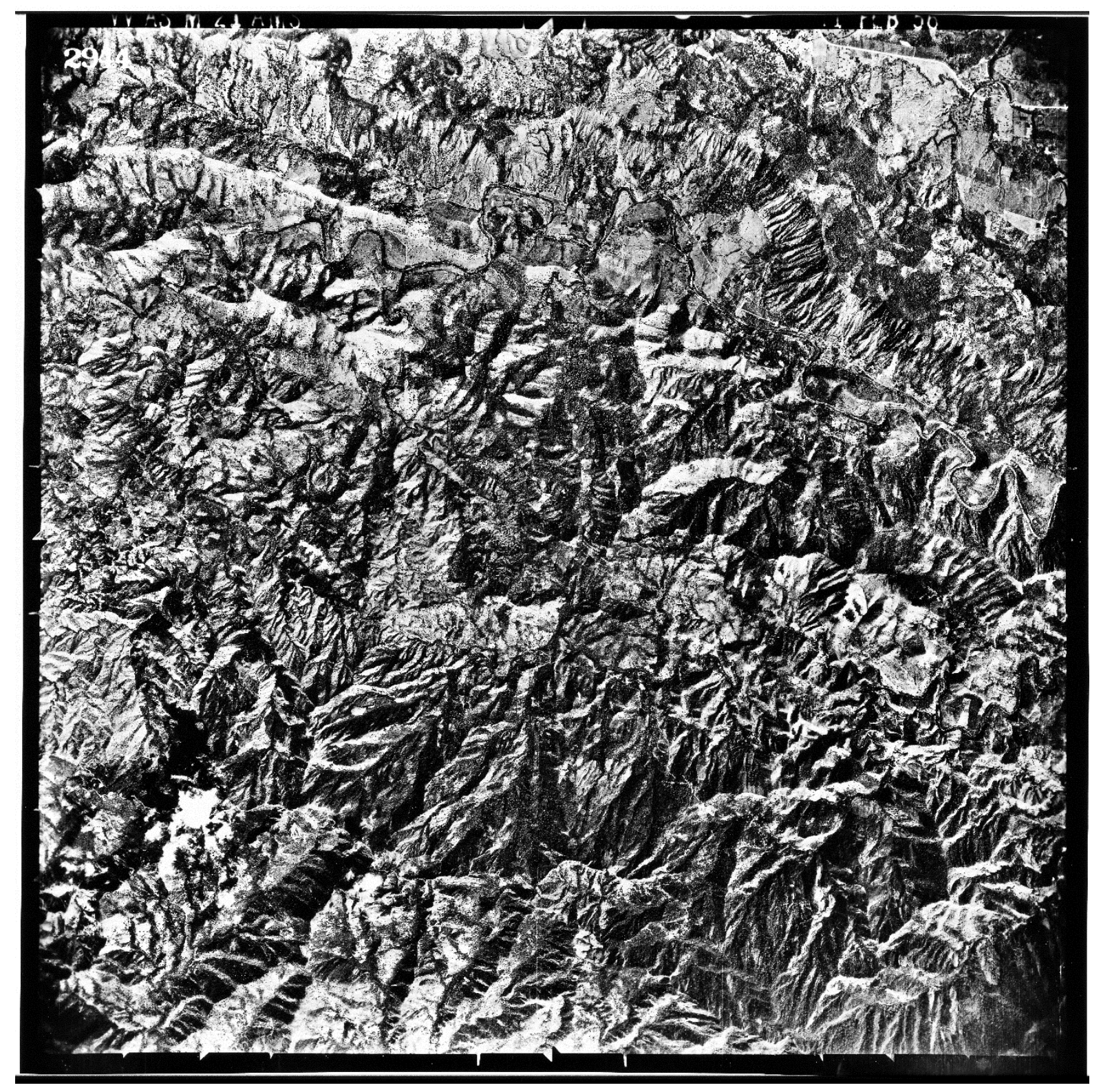

Imagem 2944 


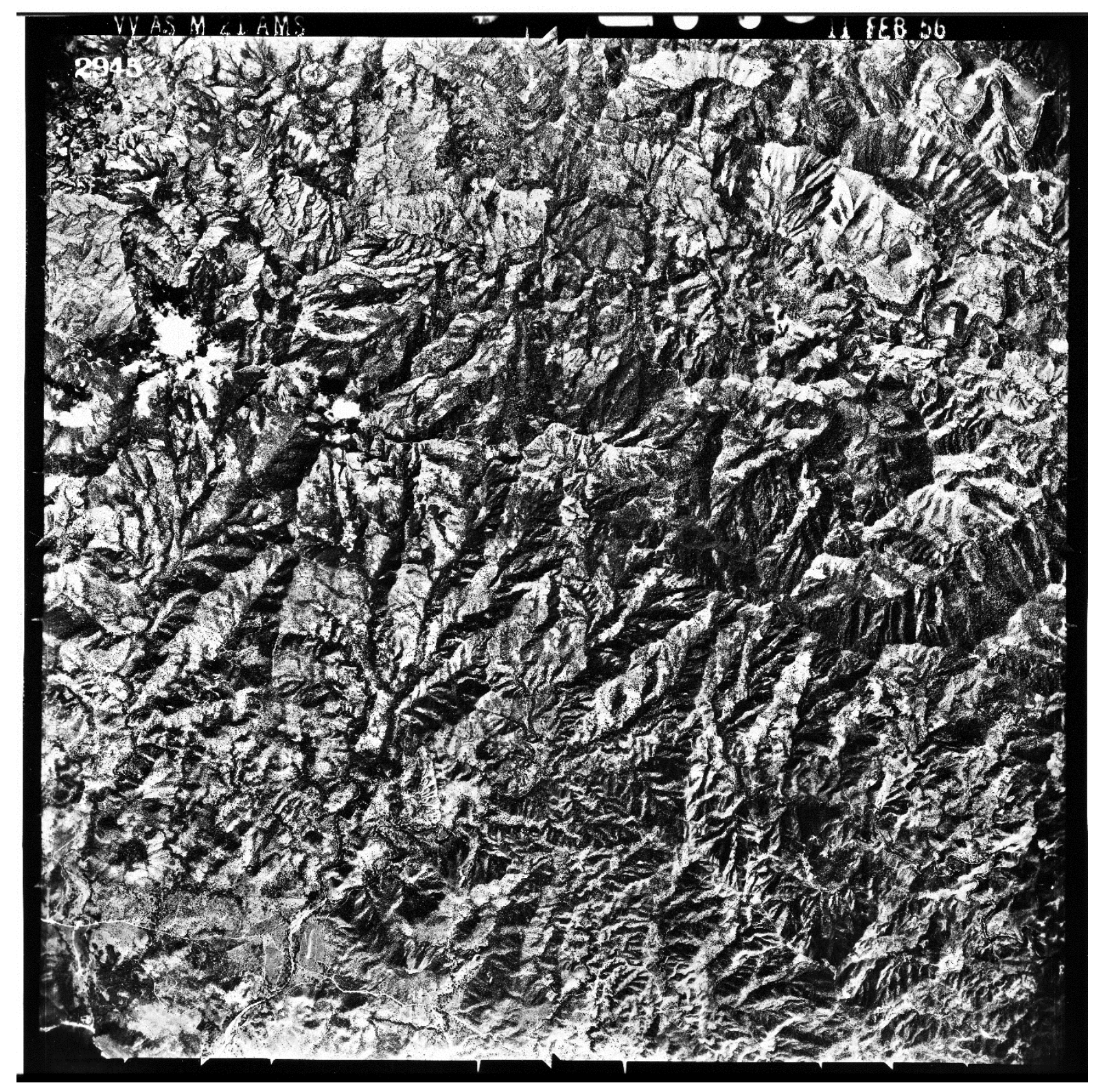

Imagem 2945 


\section{APÊNDICE C}

Parâmetros de solos residuais de rochas ígneas.

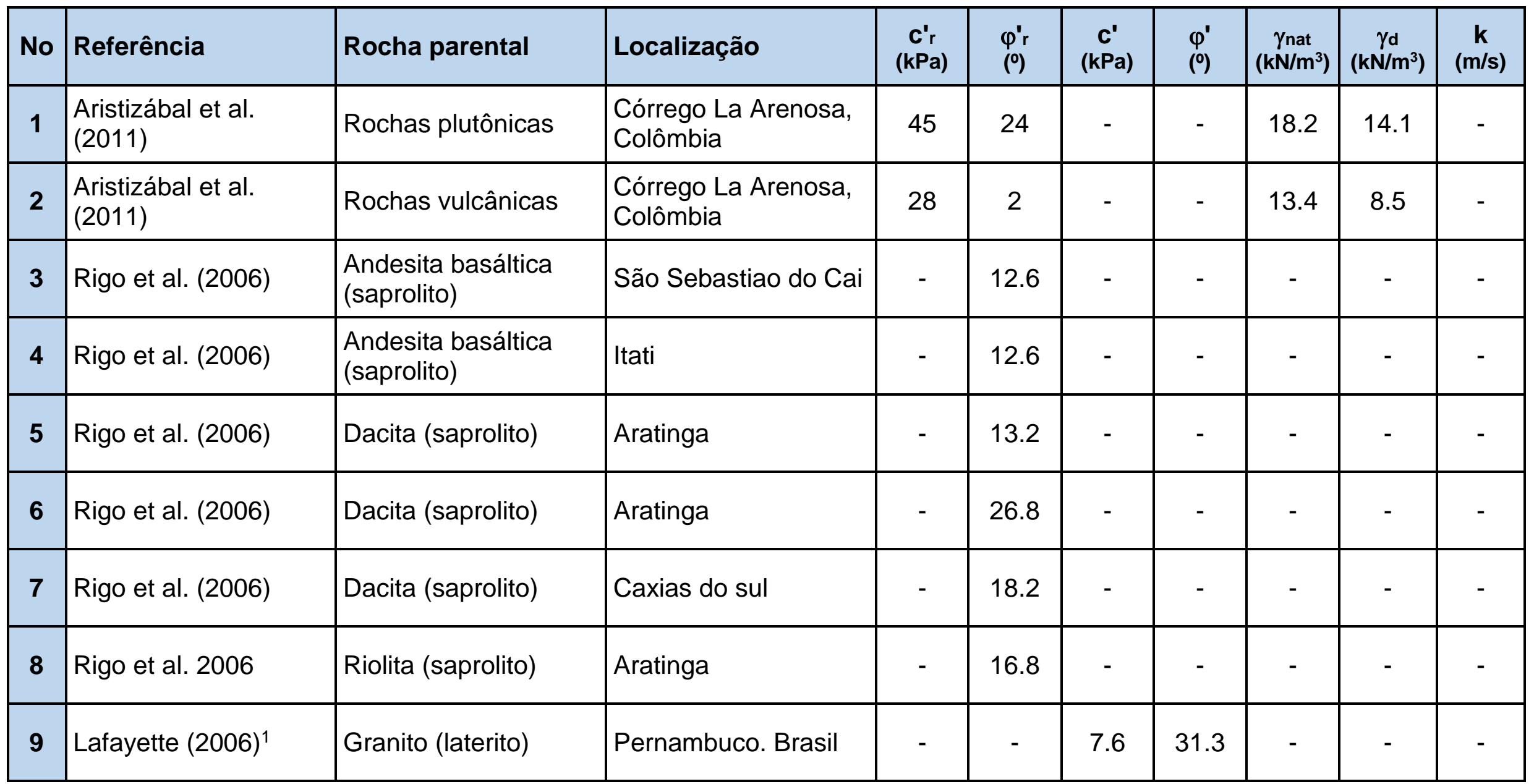




\begin{tabular}{|c|c|c|c|c|c|c|c|c|c|c|}
\hline No & Referência & Rocha parental & Localização & $\begin{array}{c}C^{\prime} r \\
(\mathrm{kPa})\end{array}$ & $\begin{array}{l}\varphi^{\prime} r \\
\text { (o) }\end{array}$ & $\begin{array}{c}\mathbf{c}^{\prime} \\
(\mathrm{kPa})\end{array}$ & $\begin{array}{l}\varphi^{\prime} \\
(\stackrel{)}{)}\end{array}$ & $\begin{array}{c}\gamma_{\mathrm{nat}} \\
\left(\mathrm{kN} / \mathrm{m}^{3}\right)\end{array}$ & $\begin{array}{c}\gamma_{d} \\
\left(\mathbf{k N} / \mathbf{m}^{3}\right)\end{array}$ & $\underset{(\mathrm{m} / \mathrm{s})}{\mathbf{k}}$ \\
\hline 10 & Silva $(2007)^{1}$ & Granito (laterito) & Pernambuco. Brasil & - & - & 9.7 & 26.3 & - & - & - \\
\hline 11 & $\begin{array}{l}\text { (Viana da Fonseca } \\
(1996)^{1}\end{array}$ & Granito (saprolito) & Porto. Portugal & - & - & 10.5 & 37.5 & - & - & - \\
\hline 13 & Bastos (1999) & Granito & Porto Alegre & - & - & 20.5 & 35 & - & - & - \\
\hline 14 & Bastos (1999) & Granito & Porto Alegre & - & - & 20.7 & 36 & - & - & - \\
\hline 15 & Bregoli et al. (2015) & $\begin{array}{l}\text { Granito, granodiorita, } \\
\text { piçarra (cascalho), } \\
\text { diorita }\end{array}$ & Portugal & - & - & - & - & - & - & $\underset{4}{0.5 \times 10}$ \\
\hline 16 & Pursza (1983) ${ }^{2}$ & Granito (laterito) & Venezuela & - & & 20 & 21.5 & - & - & - \\
\hline 17 & Boyce $(1985)^{3}$ & $\begin{array}{l}\text { Silte vermelho, } \\
\text { dolerita }\end{array}$ & Harare, Zimbabwe & 7 & 29.7 & - & - & - & - & - \\
\hline 18 & Boyce $(1985)^{3}$ & $\begin{array}{l}\text { Silte vermelho- } \\
\text { marrom, dolerite }\end{array}$ & Troutbeck, Zimbabwe & 4 & 38.3 & - & - & - & - & - \\
\hline 19 & Boyce $(1985)^{3}$ & Dolerita com mica & Troutbeck, Zimbabwe & 4 & 13.3 & - & - & - & - & - \\
\hline 20 & Boyce $(1985)^{3}$ & Argila preta, basalto & lowveld, Zimbabwe & 4 & 9.5 & - & - & - & - & - \\
\hline
\end{tabular}




\begin{tabular}{|c|c|c|c|c|c|c|c|c|c|c|}
\hline No & Referência & Rocha parental & Localização & $\begin{array}{l}C^{\prime} r \\
(\mathrm{kPa})\end{array}$ & $\begin{array}{l}\varphi^{\prime} r \\
\left(\frac{0}{)}\right)\end{array}$ & $\begin{array}{c}\mathbf{C}^{\prime} \\
(\mathrm{kPa})\end{array}$ & $\begin{array}{l}\varphi^{\prime} \\
(\stackrel{9}{\circ})\end{array}$ & $\begin{array}{c}\gamma_{\text {nat }} \\
\left(\mathbf{k N} / \mathbf{m}^{3}\right)\end{array}$ & $\begin{array}{c}\gamma d \\
\left(k N / m^{3}\right)\end{array}$ & $\underset{(m / s)}{k}$ \\
\hline 21 & $\begin{array}{l}\text { Bucher \& Kyulule } \\
(1980)^{3}\end{array}$ & Solo vermelho & Tukuyu, Tanzania & - & 35.6 & - & - & - & - & - \\
\hline 22 & $\begin{array}{l}\text { Bucher \& Kyulule } \\
(1980)^{3}\end{array}$ & Cinzas vulcânicas & Ruagarents, Tanzania & - & 34 & - & - & - & - & - \\
\hline 24 & Wesley (1992) ${ }^{3}$ & $\begin{array}{l}\text { Argila marrom } \\
\text { amarelada, haliosita }\end{array}$ & $\begin{array}{l}\text { Tjipanadjang dam, } \\
\text { Java }\end{array}$ & - & 35 & - & - & - & - & - \\
\hline 25 & Wesley $(1992)^{3}$ & $\begin{array}{l}\text { Argila marrom } \\
\text { avermelhada }\end{array}$ & $\begin{array}{l}\text { Jakarta-Bogor Rd. } \\
\text { Java }\end{array}$ & - & 24.5 & - & - & - & - & - \\
\hline 26 & Wesley $(1992)^{3}$ & $\begin{array}{l}\text { Argila marrom } \\
\text { amarelada, allophane }\end{array}$ & $\begin{array}{l}\text { Tjipanadjang dam, } \\
\text { Java }\end{array}$ & - & 39 & - & - & - & - & - \\
\hline 28 & Wesley (1992) ${ }^{3}$ & $\begin{array}{l}\text { Silte argiloso } \\
\text { castanho claro }\end{array}$ & $\begin{array}{l}\text { Omata, Nova } \\
\text { Zelândia }\end{array}$ & - & 24.5 & - & - & - & - & - \\
\hline 29 & Wesley $(1992)^{3}$ & $\begin{array}{l}\text { Silte argiloso } \\
\text { castanho claro }\end{array}$ & $\begin{array}{l}\text { New Plymouth, Nova } \\
\text { Zelândia }\end{array}$ & - & 31 & - & - & - & - & - \\
\hline 30 & Wesley $(1992)^{3}$ & $\begin{array}{l}\text { Silte argiloso } \\
\text { castanho claro }\end{array}$ & $\begin{array}{l}\text { New Plymouth, Nova } \\
\text { Zelândia }\end{array}$ & - & 18.1 & - & - & - & - & - \\
\hline 31 & Wesley $(1992)^{3}$ & $\begin{array}{l}\text { Silte argiloso } \\
\text { castanho claro }\end{array}$ & $\begin{array}{l}\text { Morrinsville, Nova } \\
\text { Zelândia }\end{array}$ & - & 28 & - & - & - & - & - \\
\hline
\end{tabular}




\begin{tabular}{|c|c|c|c|c|c|c|c|c|c|c|}
\hline No & Referência & Rocha parental & Localização & $\begin{array}{l}\mathbf{C}^{\prime} \mathbf{r} \\
(\mathrm{KPa})\end{array}$ & 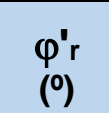 & $\begin{array}{l}\mathbf{C}^{\prime} \\
(\mathrm{kPa})\end{array}$ & $\begin{array}{l}\varphi^{\prime} \\
(\stackrel{9}{)})\end{array}$ & $\begin{array}{c}\gamma \text { nat } \\
\left(\mathrm{kN} / \mathrm{m}^{3}\right)\end{array}$ & $\begin{array}{c}\gamma_{\mathrm{d}} \\
\left(\mathrm{kN} / \mathrm{m}^{3}\right)\end{array}$ & $\begin{array}{c}\mathbf{k} \\
(\mathrm{m} / \mathrm{s})\end{array}$ \\
\hline 32 & Wesley (1992) ${ }^{3}$ & $\begin{array}{l}\text { Silte argiloso } \\
\text { castanho claro }\end{array}$ & $\begin{array}{l}\text { Morrinsville, Nova } \\
\text { Zelândia }\end{array}$ & - & 34 & - & - & - & - & - \\
\hline 33 & Wesley (1992) ${ }^{3}$ & $\begin{array}{l}\text { Silte argiloso } \\
\text { castanho claro }\end{array}$ & $\begin{array}{l}\text { Mangamahoe Dam, } \\
\text { Nova Zelândia }\end{array}$ & - & 35 & - & - & - & - & - \\
\hline 34 & Wesley $(1992)^{3}$ & $\begin{array}{l}\text { Silte argiloso } \\
\text { castanho claro }\end{array}$ & $\begin{array}{l}\text { Minden, Tauranga, } \\
\text { Nova Zelândia }\end{array}$ & - & 26 & - & - & - & - & - \\
\hline 35 & Wesley (1992) ${ }^{3}$ & $\begin{array}{l}\text { Argila siltosa laranja } \\
\text { marrom }\end{array}$ & $\begin{array}{l}\text { Ruahihi, Tauranga, } \\
\text { Nova Zelândia }\end{array}$ & - & 35 & - & - & - & - & - \\
\hline 36 & Wesley $(1992)^{3}$ & Argila siltosa laranja & $\begin{array}{l}\text { Ruahihi, Tauranga, } \\
\text { Nova Zelândia }\end{array}$ & - & 37 & - & - & - & - & - \\
\hline 37 & Wesley (1992) ${ }^{3}$ & Argila siltosa marrom & Darajat, Indonesia & - & 35 & - & - & - & - & - \\
\hline 38 & Wesley (1992) ${ }^{3}$ & Argila siltosa marrom & Darajat, Indonesia & - & 31 & - & - & - & - & - \\
\hline 39 & Wesley (1992) ${ }^{3}$ & Argila siltosa marrom & Darajat, Indonesia & - & 37 & - & - & - & -- & - \\
\hline 40 & Wesley $(1992)^{3}$ & $\begin{array}{l}\text { Argila siltosa marrom- } \\
\text { amarelada }\end{array}$ & Kamojang, Indonesia & - & 36 & - & - & - & - & - \\
\hline 41 & Tanaka (1976) ${ }^{3}$ & $\begin{array}{l}\text { Basalto denso } \\
\text { vermelho-marrom }\end{array}$ & São Simão, Goiás & - & 30 & - & - & - & - & -- \\
\hline 42 & Tanaka $(1976)^{3}$ & Basalto vermelho & São Simão, Goiás & - & 22.7 & - & - & - & - & - \\
\hline
\end{tabular}




\begin{tabular}{|c|c|c|c|c|c|c|c|c|c|c|}
\hline No & Referência & Rocha parental & Localização & $\begin{array}{l}\mathbf{C}^{\prime} \mathbf{r} \\
(\mathrm{kPa})\end{array}$ & $\begin{array}{l}\varphi_{(0)}^{\prime} r \\
(\because)\end{array}$ & $\begin{array}{c}\mathbf{c}^{\prime} \\
(\mathrm{kPa})\end{array}$ & $\begin{array}{l}\varphi^{\prime} \\
(\stackrel{9}{)})\end{array}$ & $\begin{array}{c}\gamma_{\text {nat }} \\
\left(\mathbf{k N} / \mathbf{m}^{3}\right)\end{array}$ & $\begin{array}{c}\gamma \mathrm{d} \\
\left(\mathrm{kN} / \mathrm{m}^{3}\right)\end{array}$ & $\begin{array}{c}\mathbf{k} \\
(\mathrm{m} / \mathrm{s})\end{array}$ \\
\hline 43 & Kanji (1974) ${ }^{3}$ & Basalto & $\begin{array}{l}\text { Ilha Solteira, São } \\
\text { Paulo }\end{array}$ & - & 10 & - & - & - & - & - \\
\hline 44 & $\begin{array}{l}\text { Sousa Pinto et al. } \\
(1994)^{3}\end{array}$ & Basalto & São Paulo & - & 19 & - & - & - & - & - \\
\hline 45 & $\begin{array}{l}\text { Sousa Pinto et al. } \\
(1994)^{3}\end{array}$ & Basalto & São Paulo & - & 10.5 & - & - & - & - & - \\
\hline 46 & $\begin{array}{l}\text { Sousa Pinto et al. } \\
(1994)^{3}\end{array}$ & Basalto & São Paulo & - & 9 & - & - & - & - & - \\
\hline 47 & Rigo et al. (2006) & $\begin{array}{l}\text { Basalto olivinico } \\
\text { (saprolito) }\end{array}$ & Teutonia & - & $\begin{array}{c}10.7-- \\
6.2\end{array}$ & - & -- & - & -- & - \\
\hline 48 & Rigo et al. (2006) & Basalto amigdaloide & Itati & - & 10.8 & - & - & - & - & - \\
\hline 49 & Rigo et al. (2006) & Basalto & Itati & - & 8.8 & - & -- & -- & - & - \\
\hline 50 & Rigo et al. (2006) & $\begin{array}{l}\text { Basalto amigdaloide } \\
\text { (saprolito) }\end{array}$ & Itati & - & 10.7 & - & - & - & - & - \\
\hline 51 & Rigo et al. (2006) & $\begin{array}{l}\text { Basalto amigdaloide } \\
\text { (saprolito) }\end{array}$ & Itati & - & 7.8 & -- & - & - & - & - \\
\hline 52 & Rigo et al. (2006) & $\begin{array}{l}\text { Basalto amigdaloide } \\
\text { (saprolito) }\end{array}$ & Itati & - & 15.6 & - & - & - & - & - \\
\hline 53 & Rigo et al. (2006) & Basalto (saprolito) & Itati & - & 9.5 & - & - & - & - & - \\
\hline
\end{tabular}




\begin{tabular}{|c|c|c|c|c|c|c|c|c|c|c|}
\hline No & Referência & Rocha parental & Localização & $\underset{(\mathrm{kPa})}{\mathbf{C}^{\prime} \mathrm{r}}$ & 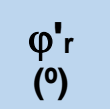 & $\begin{array}{c}\mathrm{C}^{\prime} \\
(\mathrm{kPa})\end{array}$ & $\begin{array}{l}\varphi^{\prime} \\
(\stackrel{9}{\circ})\end{array}$ & $\begin{array}{c}\gamma_{\text {nat }} \\
\left(\mathbf{k N} / \mathbf{m}^{3}\right)\end{array}$ & $\begin{array}{c}\gamma_{\mathrm{d}} \\
\left(\mathrm{kN} / \mathrm{m}^{3}\right)\end{array}$ & $\begin{array}{c}\mathbf{k} \\
(\mathrm{m} / \mathrm{s})\end{array}$ \\
\hline 54 & Rigo et al. (2006) & Basalto (saprolito) & Itati & - & 11.2 & - & -- & -- & - & - \\
\hline 55 & Rigo et al. (2006) & Basalto (saprolito) & Canela & - & 8.6 & - & - & - & - & - \\
\hline 57 & $\begin{array}{l}\text { Nakamura et al. } \\
(2010)\end{array}$ & Tufo vulcânico & Osaka, Japão & - & 8.2 & - & - & - & - & - \\
\hline 58 & $\begin{array}{l}\text { Nakamura et al. } \\
\text { (2010) }\end{array}$ & Tufo vulcânico & Nagasaki, Japão & - & 6 & - & - & & & - \\
\hline
\end{tabular}

1- Viana da Fonseca (2009). Caracterização de solos residuais em projecto geotécnico assistido por ensaios.

2- Asoudeh, A. \& Oh, E. (2014). Strength parameter selection in stability analysis residual soil nailed walls.

3- Rigo et al. (2006). The residual shear strength of tropical soils. 
Parâmetros de solos residuais de rochas sedimentares.

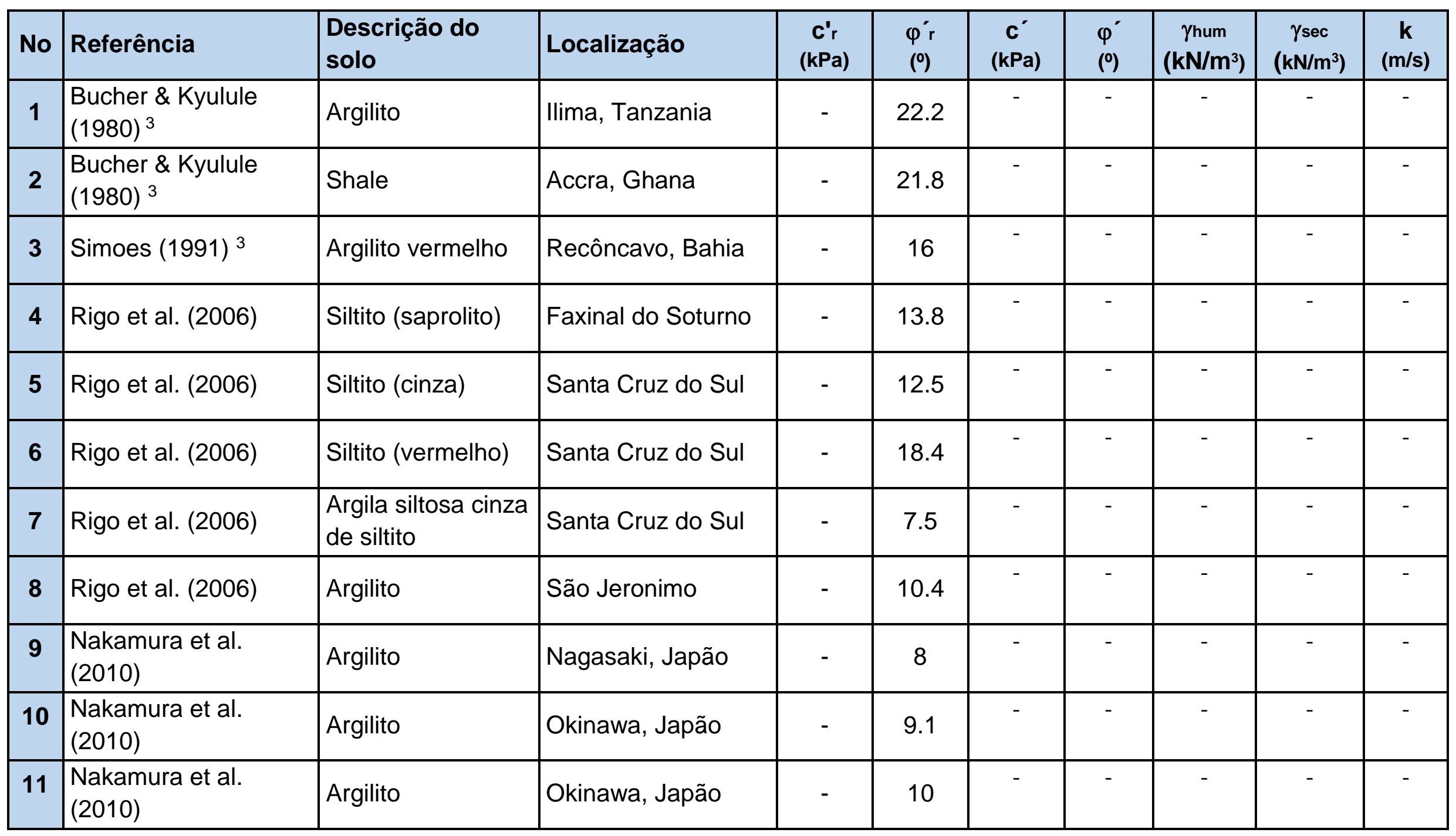




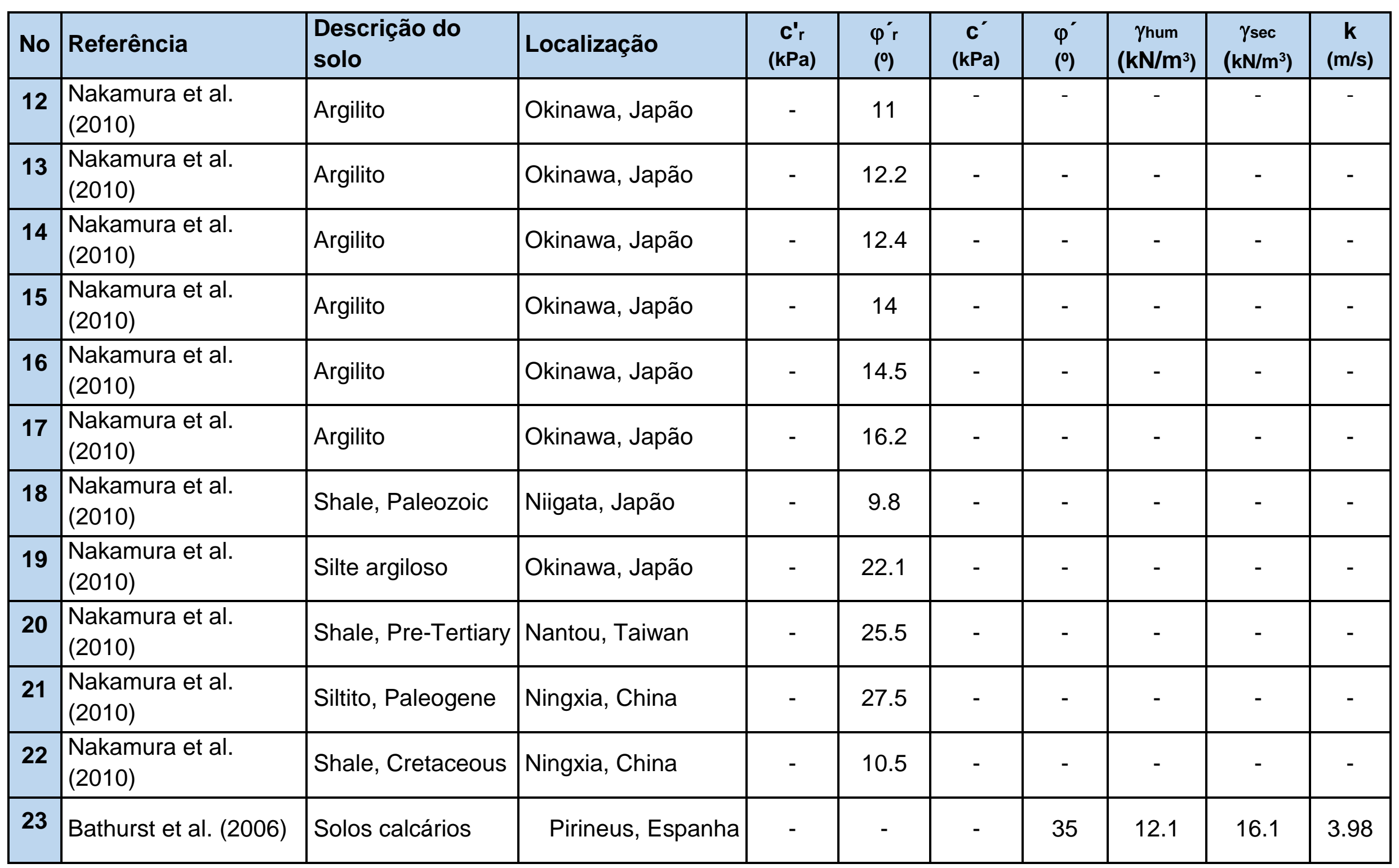




\begin{tabular}{|c|c|c|c|c|c|c|c|c|c|c|}
\hline No & Referência & $\begin{array}{l}\text { Descrição do } \\
\text { solo }\end{array}$ & Localização & $\begin{array}{c}C^{\prime} r \\
(\mathrm{kPa})\end{array}$ & $\begin{array}{l}\varphi^{\prime} r \\
(\stackrel{o}{)})\end{array}$ & $\begin{array}{c}C^{\prime} \\
(\mathrm{kPa})\end{array}$ & $\begin{array}{l}\varphi^{\prime} \\
(\stackrel{9}{)})\end{array}$ & $\begin{array}{c}\begin{array}{c}\text { Yhum } \\
\left(\mathrm{kN} / \mathrm{m}^{3}\right)\end{array} \\
\end{array}$ & $\begin{array}{c}\gamma_{\mathbf{s e c}} \\
\left(\mathrm{kN} / \mathrm{m}^{3}\right)\end{array}$ & $\begin{array}{c}k \\
(m / s) \\
\end{array}$ \\
\hline 24 & Bathurst et al. (2006) & Solos calcários & Pirineus, Espanha & - & - & - & 38 & 14.5 & 18 & 0.21 \\
\hline 25 & Bathurst et al. (2006) & Solos calcários & Pirineus, Espanha & - & - & - & 34 & 14 & 17.3 & 0.65 \\
\hline 26 & Bathurst et al. (2006) & Solos calcários & Pirineus, Espanha & - & - & - & 32 & 15.2 & 17.4 & 1.64 \\
\hline 27 & Bathurst et al. (2006) & Solos calcários & Pirineus Espanha & - & - & - & 33 & 14.1 & 17.2 & 0.4 \\
\hline 28 & Bathurst et al. (2006) & Solos calcários & Pirineus Espanha & - & - & - & 29 & 13.4 & 16.3 & 0.52 \\
\hline 29 & Bathurst et al. (2006) & Solos calcários & Pirineus Espanha & - & - & - & 28 & 14.6 & 16.8 & 0.37 \\
\hline 32 & Bregoli et al. (2015) & Solos calcários & Pirineus, Espanha & - & - & - & - & - & - & 4.32 \\
\hline 22 & Vithana et al. (2012) & Argila tufâcea & & 4.5 & 7.4 & 14.5 & 12.2 & - & - & - \\
\hline 23 & Vithana et al. (2012) & Argilito & & 5.2 & 7.7 & 16.2 & 14.3 & - & - & - \\
\hline 24 & Vithana et al. (2012) & Siltito & & 5.2 & 24.7 & 15.8 & 31.5 & - & - & - \\
\hline
\end{tabular}




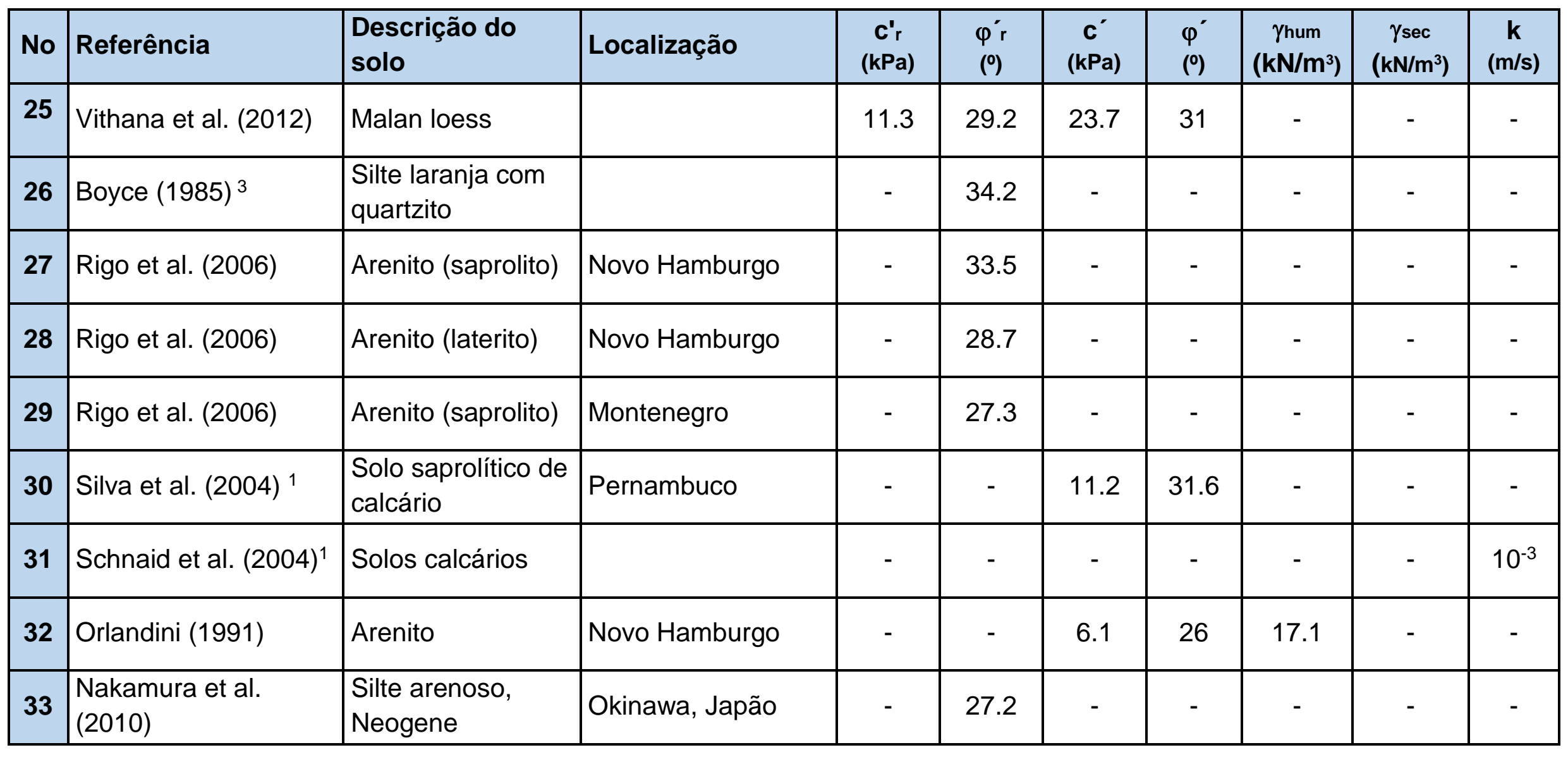

1- Viana da Fonseca (2009). Caracterização de solos residuais em projecto geotécnico assistido por ensaios.

2- Asoudeh, A. \& Oh, E. (2014). Strength parameter selection in stability analysis residual soil nailed walls.

3- Rigo et al. (2006). The residual shear strength of tropical soils. 
Parâmetros de solos residuais aluviais.

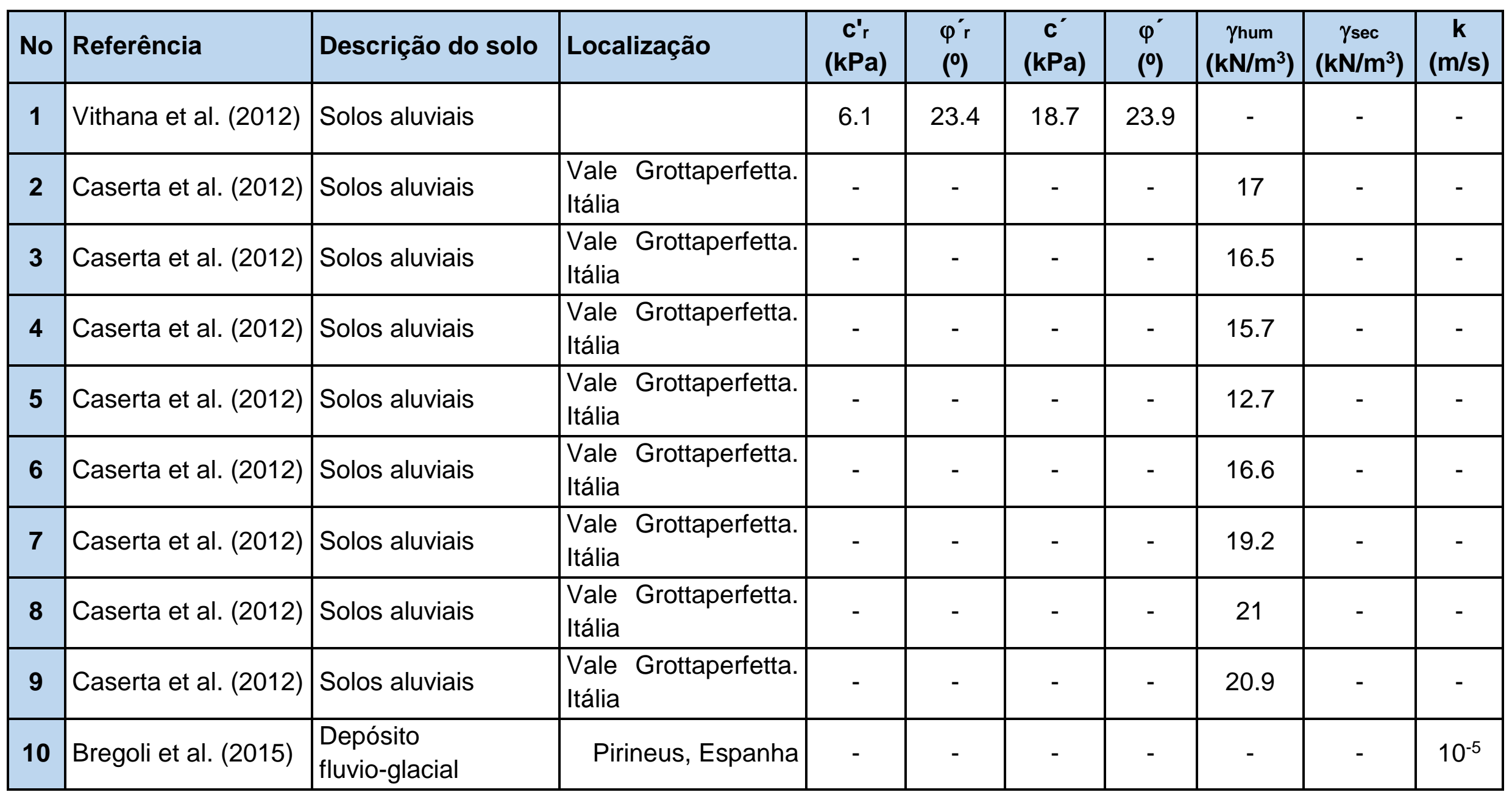

